\title{
To condition or not - is that the question? : an analysis of the effectiveness of ex-ante and ex-post conditionality in social cash transfer programs
}

Citation for published version (APA):

Schüring, E. (2012). To condition or not - is that the question? : an analysis of the effectiveness of ex-ante and ex-post conditionality in social cash transfer programs. [Doctoral Thesis, Maastricht University]. Boekenplan. https://doi.org/10.26481/dis.20120705es

Document status and date:

Published: 01/01/2012

DOI:

10.26481/dis.20120705es

Document Version:

Publisher's PDF, also known as Version of record

Please check the document version of this publication:

- A submitted manuscript is the version of the article upon submission and before peer-review. There can be important differences between the submitted version and the official published version of record.

People interested in the research are advised to contact the author for the final version of the publication, or visit the DOI to the publisher's website.

- The final author version and the galley proof are versions of the publication after peer review.

- The final published version features the final layout of the paper including the volume, issue and page numbers.

Link to publication

\footnotetext{
General rights rights.

- You may freely distribute the URL identifying the publication in the public portal. please follow below link for the End User Agreement:

www.umlib.nl/taverne-license

Take down policy

If you believe that this document breaches copyright please contact us at:

repository@maastrichtuniversity.nl

providing details and we will investigate your claim.
}

Copyright and moral rights for the publications made accessible in the public portal are retained by the authors and/or other copyright owners and it is a condition of accessing publications that users recognise and abide by the legal requirements associated with these

- Users may download and print one copy of any publication from the public portal for the purpose of private study or research.

- You may not further distribute the material or use it for any profit-making activity or commercial gain

If the publication is distributed under the terms of Article 25fa of the Dutch Copyright Act, indicated by the "Taverne" license above, 


\title{
To condition or not - is that the question?
}

\author{
An analysis of the effectiveness of ex-ante and ex-post \\ conditionality in social cash transfer programs
}

\author{
DISSERTATION
}

To obtain the degree of Doctor at the Maastricht University, on the authority of the Rector Magnificus, Prof. Dr. G.P.M.F. Mols, in accordance with the decision of the Board of Deans, to be defended in public on Thursday 5 July 2012, at 16:00 hours

By Esther Schüring 
Supervisors:

Assessment Committee:
Prof. Dr. Thomas Dohmen

Dr. Franziska Gassmann

Prof. Dr. Joan Muysken (chairman)

Prof. Dr. Armando Barrientos

Prof. Dr. Chris de Neubourg

Dr. Stephen Devereux

ISBN 9789086662647

Published by Boekenplan, Maastricht

The picture on the cover, taken by the author, depicts a scene from the allocation and conditionality experiment which was conducted in 2009 in Monze district in Zambia. 


\section{Acknowledgements}

Looking back at the $\mathrm{PhD}$ years, there are many people who deserve a big thank you for their guidance, support, encouragement and love. You made this time special, helped me greatly with multi-tasking and you deserve credit for the final product!

First of all, I was blessed in working with two supervisors, Franziska Gassmann and Thomas Dohmen, who provided a perfect balance between letting me realize my own ideas and granting me the necessary freedom whilst giving me the necessary support at the right time. I want to thank you for your commitment to this $\mathrm{PhD}$ project despite me often being thousands of kilometers away, for your valuable advice and your efforts to help me finish the dissertation before my next 'project' was due. Thanks Thomas for all your insights and critical feedback concerning the experiments in Zambia; you had already proved a great source of inspiration during the course you taught in the $\mathrm{PhD}$ program. Thanks Franziska for your critical eye and the great suggestions on the social protection front. I particularly enjoyed our feedback session in Mauritius, gazing out at the ocean and sipping fruit juices. Equally memorable are the trainings we conducted in West-Africa including the swimming sessions, joint cravings for good deserts and learning the African hip-shaking at the end.

My field work in Zambia would not have been possible within the given timeframe without the support of many diligent, hard-working and committed people. Special thanks go to Rose Mutupo and her team in the Department of Social Welfare in Lusaka, to Manzunzo Zulu and his team in the Department of Social Welfare in Monze and to Emily Ngandu at the Faculty of Humanities at the University of Zambia for their great help in facilitating research activities. After working for 3 years as an adviser in your Ministry, it was a real pleasure to have you as my advisers this time and to benefit from your knowledge and networks. The field work greatly benefited from the support of Gelson Tembo at the Department of Agricultural Economics of the University of Zambia whose contributions and suggestions in the field proved highly valuable. A big thank you also goes to Twaambo for her excellent research assistance throughout the entire project. I will certainly remember the creative dinners, the exhausting field work, sorting plastic cups and questionnaires by candlelight in the middle of the night and all the good conversations we had.

There are of course more people who contributed to the success of the field work. I want to express my sincere gratitude to the field team in Monze and the team in Lusaka for their hard work and dedication. You all worked long days and did an excellent job in conducting the experiments and surveys. And what could a researcher do without all the interview partners and respondents who volunteer to give their time and all the enriching information? I cannot thank you enough and hope that this research will live up to the promise of making a small contribution to policy changes that have a positive impact on your life. 
The field work was extensive and would have exceeded my research budget. I therefore sincerely thank the German Kiel institute for the World Economy (www.pegnet.ifwkiel.de), the Ministry of Community Development, Mother and Child Health (former MCDSS) in Zambia, the UNICEF office in Zambia and the DfID funded Regional Hunger and Vulnerability Programme (www.wahenga.net) for their financial contributions to this dissertation. Thank you for allowing me to experiment with a new methodology and to use a mixed method approach, which definitely shaped the character of this dissertation.

The dissertation also greatly benefitted from thought-provoking questions and comments from Cécile Cherrier, Nicholas Freeland, Jessica Hagen Zanker, Gabriele Köhler, Julie Lawson-McDowall, Keetie Roelen and Michael Samson. Particular thanks to Keetie for your 24/7 advice service, for the many helpful exchanges and just for being one of my "Himmelschwestern." Particular thanks also to my dear friend Julie who volunteered to do a final proof-read despite a really busy schedule managing work and family (now I know what it means!). Marte, many thanks for adding an artistic touch to the cover.

I am also really grateful to have met so many interesting and fun people at Maastricht. Despite my move to Munich, we managed to stay in touch and it was always a great pleasure to come back to the School. Thanks to Flo and Melissa for offering me a home away from home. You made my stays in Maastricht very special. Thanks to Floor for the nice coffee \& lunch breaks and all the wonderful baby advice. Thanks, Julie, Cheng and Margaret for all the special moments, for cracking jokes and jointly fighting our way through courses and research. Aziz, thanks for accompanying me throughout my $\mathrm{PhD}$, sharing worries but also many special moments such as the arrival of our daughters. Thanks to Sachin for all the stimulating conversations and the encouragement. Thanks Sepideh for coming into my life at a later stage during the $\mathrm{PhD}$ program. Thanks Mahmut for being my Maastricht connection in Munich. Thanks to Judith, the Oxanas, Metka and Maha for many interesting conversations. Thanks to Alan, Nevena, Kristine and Mulyadi for being great office-mates. Thanks to Nyasha and Dorcas for timing your research in a way that we could all be in Zambia at the same time. Thanks to Mindel for always finding a creative solution. Thanks to my cohort in general for a great time and to the school and its staff for all the support.

Last but not least möchte ich mich ganz herzlich bei meiner Familie bedanken. Antonia, Du warst die beste Motivation, die Dissertation zeitnah einzureichen. Ich kann Dir gar nicht sagen wie glücklich ich bin, dass Du in unser Leben getreten bist und wie erleichtert, dass mein anderes „Baby“, die Diss, doch noch fertig geworden ist. Mein lieber Andreas, ich danke dir für deine Unterstützung, deine Liebe und dein Verständnis für die ein oder andere lange Nacht hinter dem Computer. Ohne Dich hätte ich so manche Hürde (ich sage nur Dateneingabe in Sambia) nicht so gut gemeistert und ohne Dich wäre mein Leben sicherlich nur halb so schön. Ich bin froh, dass es Dich gibt. Meine lieben Eltern und Tobi, ohne Euch stände ich nicht dort, wo ich heute 
stehe. Ihr habt mir immer Türen und Tore geöffnet, ihr wart mein Anker, auch in stürmischen Zeiten, und habt sicherlich einen großen Anteil daran, dass ich heute meine Dissertation in den Händen halte. Ich danke Euch für Eure Anteilnahme, Unterstützung und den Glauben an mich; ich hätte mir keine bessere Familie wünschen können. 


\section{Table of contents}

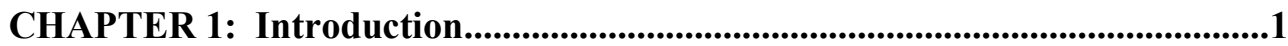

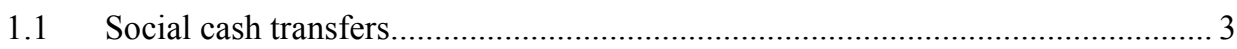

1.2 Why focus on conditionality? ................................................................. 4

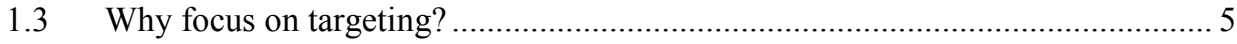

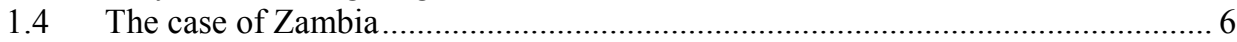

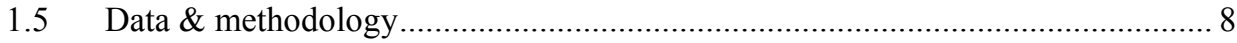

1.6 Outline \& main findings ............................................................................ 10

CHAPTER 2: Conditions, conditionality, conditionalities, responsibilities finding common ground ................................................................13

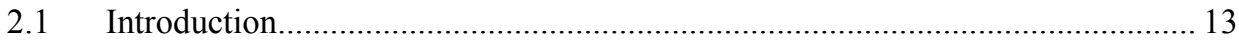

2.2 The concept of conditionality ..................................................................... 14

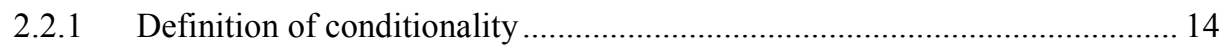

2.2.2 Dimensions of conditionality ............................................................... 15

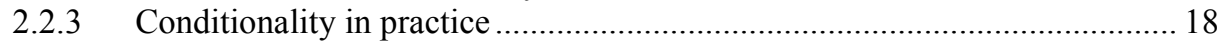

2.3 Rationale behind conditionality ................................................................. 19

2.3.1 Economic superiority of unconditional cash transfers ................................ 20

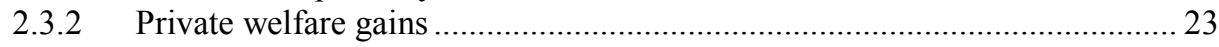

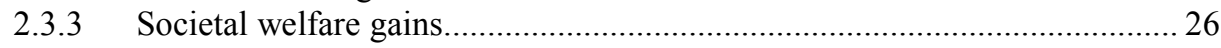

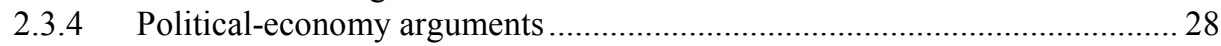

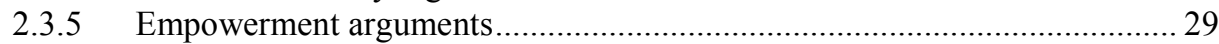

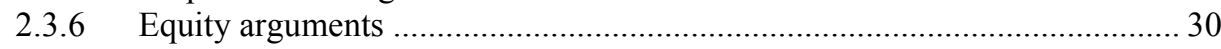

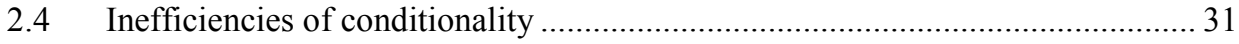

2.4.1 Behavioral side effects ........................................................................ 32

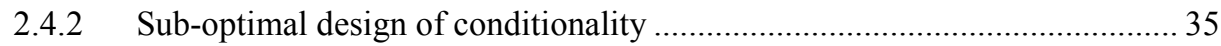

2.4.3 Implementation inefficiencies ……………………..................................... 42

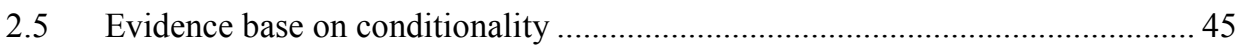

2.5.1 Optimizing behavior - does conditionality lead to more education and

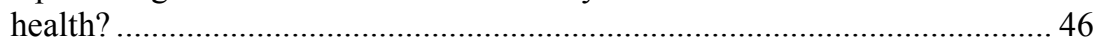

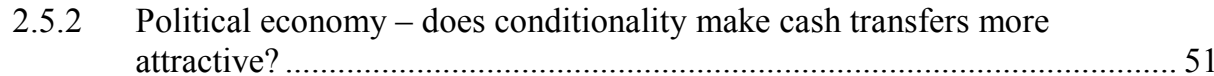

2.5.3 Empowerment - does conditionality (dis) empower? .....................................52

2.5.4 Equity - does conditionality increase targeting efficiency? ........................... 53

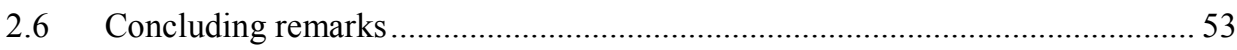

CHAPTER 3: Conditionality preferences with respect to government assistance - experimental evidence from Zambia........................57

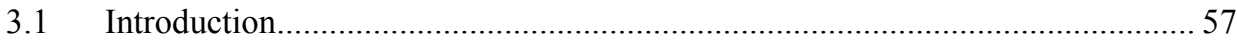

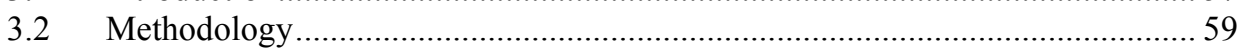

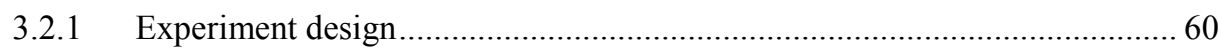

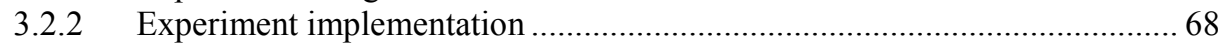




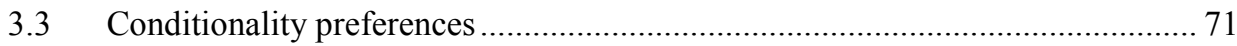

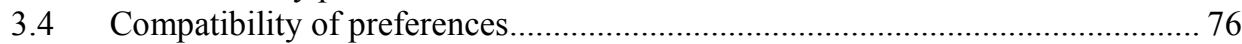

3.4.1 Preferences of (potential) beneficiaries ………………………………..... 76

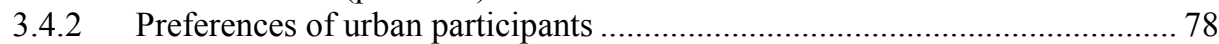

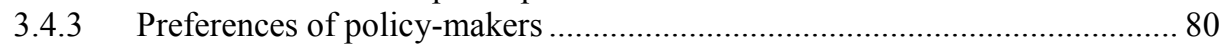

3.4.4 Preferences of decentralized structures ……………………………….... 81

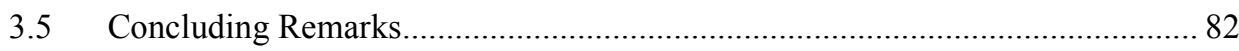

CHAPTER 4: Conditionality re-assessed - a focus on inefficiencies.................85

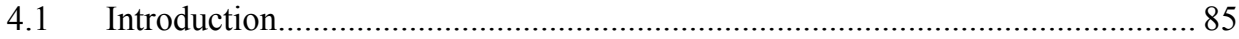

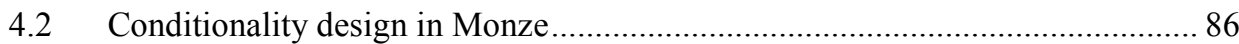

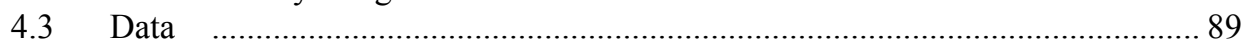

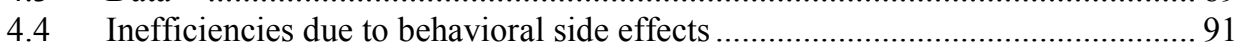

4.5 Inefficiencies due to a sub-optimal design of conditionality ............................... 94

4.5.1 Promotion of existing behavior …………………................................... 94

4.5.2 Promotion of suboptimal behavior ............................................................. 95

4.5.3 Conditionality as a sub-optimal measure ………….................................... 97

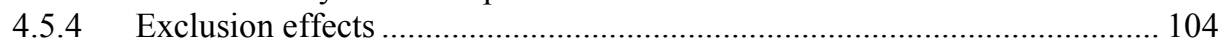

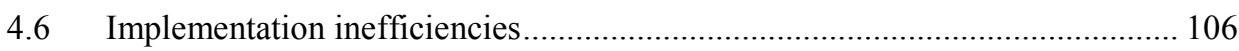

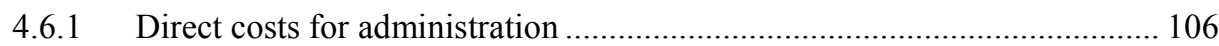

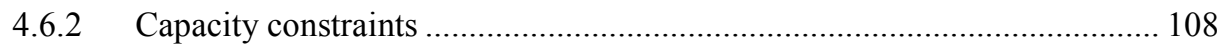

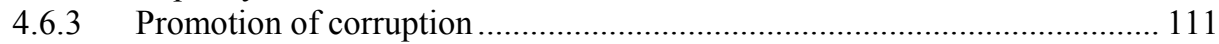

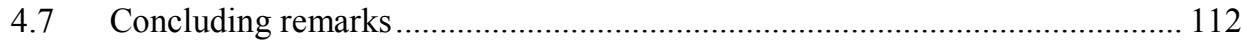

CHAPTER 5: Community-based targeting - which motives are at play? ....113

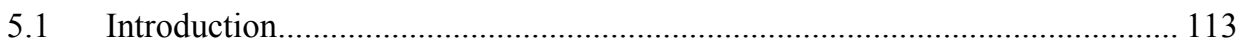

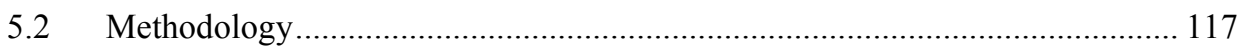

5.2.1 Description of the community experiments …………………………........ 117

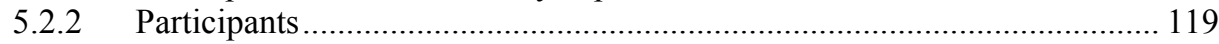

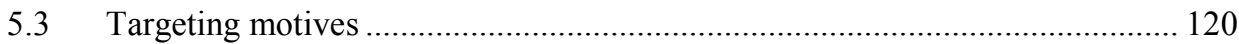

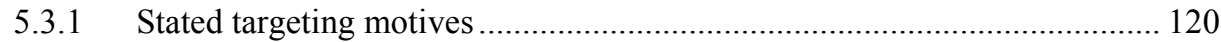

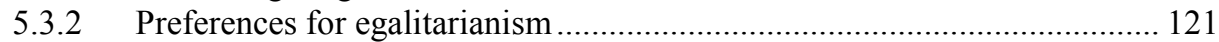

5.3.3 Preferences for inter-personal distributions.............................................. 124

5.3.4 Preferences for selfishness ................................................................ 127

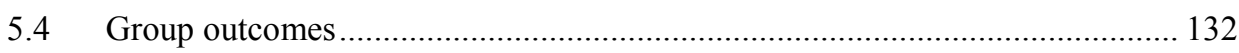

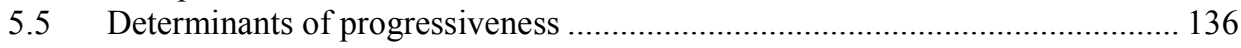

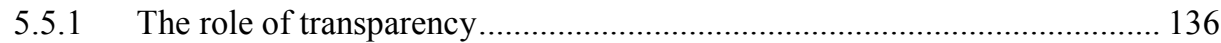

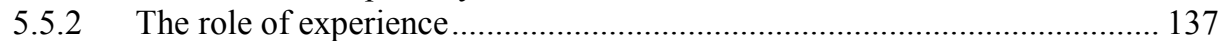

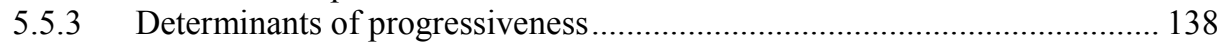

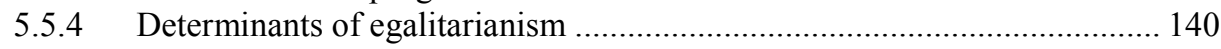

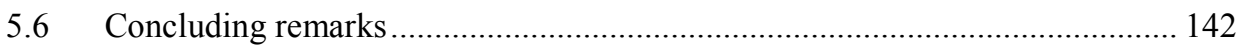


CHAPTER 6: Whom to target - an obvious choice?

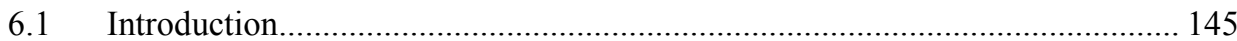

6.2 Revisiting the arguments for universal transfers............................................ 146

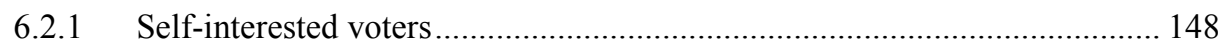

6.2.2 A coalition of the poor and middle class is politically decisive ................... 149

6.2.3 Budget endogeneity................................................................................ 149

6.3 Looking beyond the model assumptions....................................................... 150

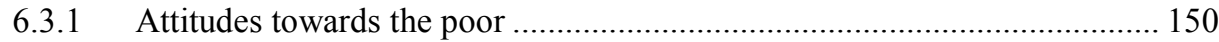

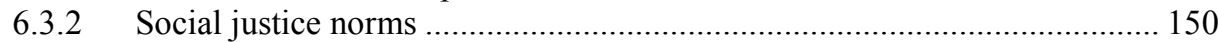

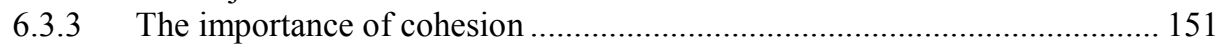

6.3.4 Procedural justice \& effectiveness ......................................................... 151

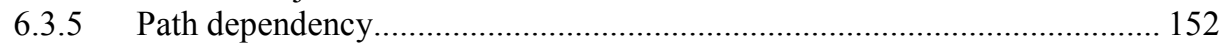

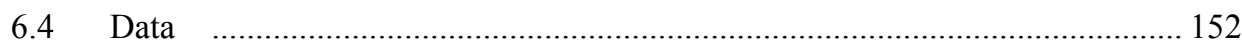

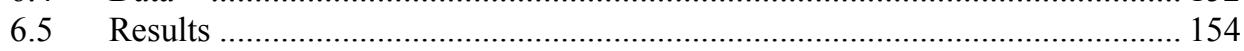

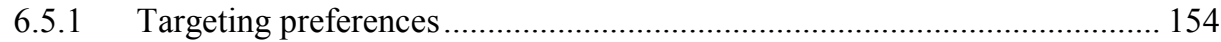

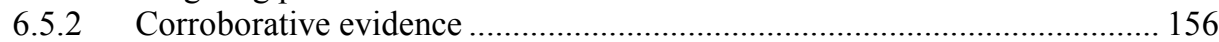

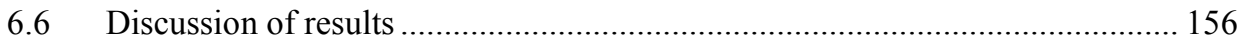

6.6.1 Revisiting the assumptions of the political economy model ........................ 157

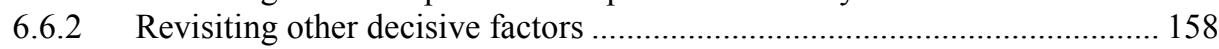

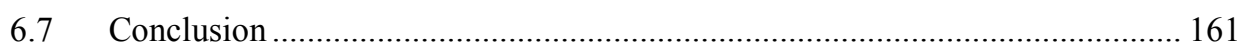

CHAPTER 7: Social protection in Zambia - whose politics? ............................163

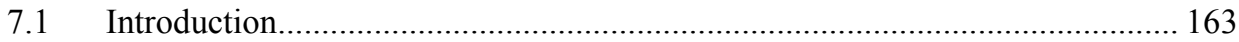

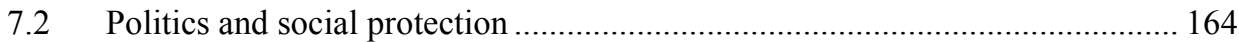

7.3 The politics behind social protection in Zambia ……………......................... 165

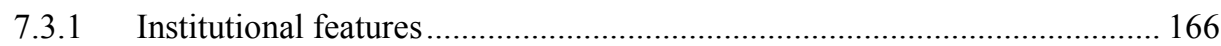

7.3.2 Discourse \& thinking on poverty ................................................................. 170

7.3.3 Knowledge base - getting the right message out to the right people?......... 173

7.3.4 Drivers of change - going the right way? ……………………………....... 175

7.3.5 Design \& implementation - the devil is in the detail? ................................ 179

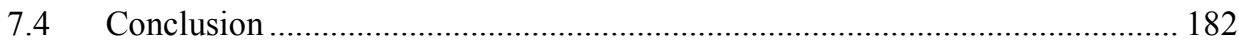

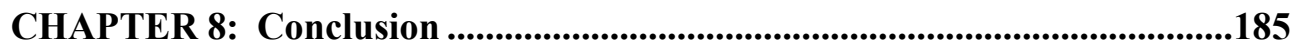

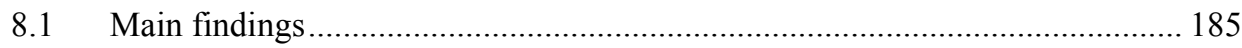

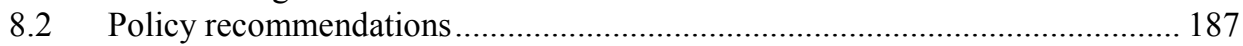

Bibliography _....................................................................................................190

Annex 1: Overview of conditional cash transfer programs reviewed ...209

Annex 2: Overview of studies conducted on the impact of conditionality....................................................................................215

Annex 3: Pre-survey form for community members interested in participating in the experiment ........................................................221 
Annex 4: Instructions for the introduction of the experiment .222

Annex 5: Instructions and questionnaire for Round 1 of the experiment

Annex 6: Instructions and questionnaire for Round 2 of the experiment ........................................................................................227

Annex 7: Conditionality monitoring cards ...........................................234

Annex 8: Questionnaire for beneficiary survey............................................238

Annex 9: Questionnaires for the attitudinal survey ...................................247

Annex 10: Interview outline for semi-structured interviews.....................254

Annex 11: Motivation for using OLS ........................................................258

Samenvatting ….........................................................................................................259

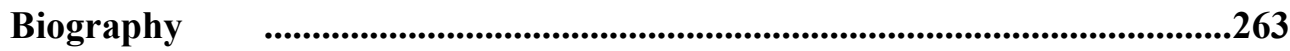

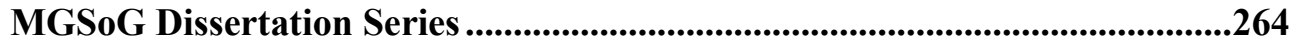




\section{Table of tables}

Table 2.1: Implications of behavioral side-effects .................................................. 32

Table 2.2: Implications of a sub-optimal conditionality design ............................... 35

Table 2.3: Implications of implementation inefficiencies ........................................ 43

Table 3.1: Selection of communities participating in the community experiments . 61

Table 3.2: Set-up of the experiment (experiment locations, experiment treatment

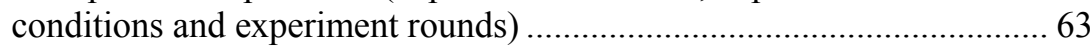

Table 3.3: Characteristics of experiment participants according to their externally assessed poverty level

Table 3.4: Logistic regression on the determinants of individual conditionality choices.

Table 3.5: Logistic regression on determinants for conditioning transfers among the urban public

Table 3.6: Percentage of individual and group transfers being conditioned, by community status

Table 4.1: Information letter on conditionality for beneficiary households 88

Table 4.2: Changes in social interaction, assessed by (un)conditioned beneficiaries

Table 4.3: Percentage of respondents investing (part of) ZMK 1 million in different areas 96

Table 4.4: Percentage of respondents saving (part of) ZMK 1 million for different areas

Table 4.5: Reasons for leaving the education system, by highest level of education obtained

Table 4.6: Reasons for non-compliance with education conditions, stated by teachers 100

Table 4.7: Time preferences of beneficiaries and rural population ......................... 101

Table 4.8: Self-assessed risk attitude of beneficiaries and rural population........... 102

Table 4.9: Priority measures by the urban population and students in the area of education and health.

Table 4.10: Percentage of beneficiary households complying with education conditions as reported by teachers 104

Table 4.11: Percentage of beneficiary households (not) complying with health conditions as reported by pay point managers 105 
Table 4.12: Estimated annual costs (in ZMK) of the SCT experiment on conditionality.....

Table 4.13: Percentage of returned monitoring cards that did not provide any information on the following conditions:

Table 5.1: Hypotheses tested in this chapter

Table 5.2: Cross-tabulation of participants' externally and self-assessed poverty status.

Table 5.3: $\quad$ Stated targeting motives of givers (more than one motive could be stated)

Table 5.4: Percentage of individuals opting for a uniform distribution, by community status and treatment condition

Table 5.5: Additional number of tokens that the recipient received if $\mathrm{s} / \mathrm{he}$ had a relationship with the giver as opposed to no relationship

Table 5.6: $\quad$ OLS regression on distribution motives of individuals in TC2 2............ 126

Table 5.7: OLS regression on distribution motives of individuals in TC1............ 129

Table 5.8: Logistic regression on determinants for self-allocation ....................... 131

Table 5.9: Percentage of individuals and groups opting for a uniform distribution, by community status and treatment condition....

Table 5.10: OLS regression on distribution motives of groups

Table 5.11: Depth and incidence of progressiveness of group distributions, by treatment condition.

Table 5.12: Depth and incidence of progressiveness of group distributions, by community status

Table 5.13: Logistic regression on determinants of progressiveness of individual distributions, by treatment condition

Table 5.14: Logistic regression on determinants of egalitarianism of individual distributions for TC2

Table 6.1: Respondents' opinions on whether the following stakeholders have some form of responsibility to take care of the poor

Table 7.1: Respondents' opinions about the importance and feasibility of labor... 171

Table 7.2: Respondents' opinions about the causes of poverty.

Table 7.3: Respondents' prioritization of economic growth, redistribution or both as a policy-maker

Table 7.4: Respondents' preference for unconditional, conditional or no cash transfers as a policy-maker. 


\section{Table of figures}

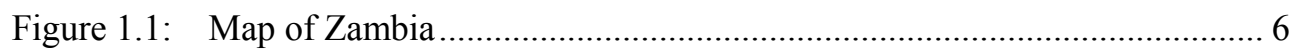

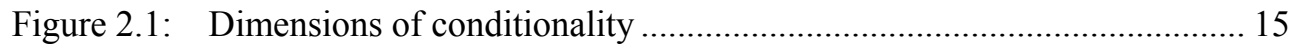

Figure 2.2: Welfare effects of a conditional vs. an unconditional cash transfer scheme 21

Figure 2.3: Welfare effects of conditionality in case of an insufficient transfer........ 23

Figure 2.4: Inefficiency of conditionality when promoting existing behavior .......... 36

Figure 2.5: Comparison of educational outcomes of different interventions............. 39

Figure 2.6: Effect of the transfer amount on beneficiaries' acceptance of the transfer

Figure 2.7: Theoretical and decision-making framework for conditionality ............. 55

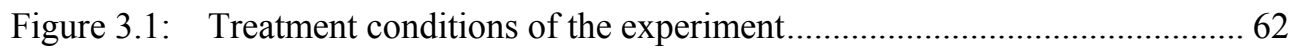

Figure 3.2: Experiment tools: conditionality cards, a token and answer scale .......... 66

Figure 4.1: Reason for non-enrolment in school provided by local interview partners in Monze 99

Figure 4.2: Percentage of beneficiaries who believed in being subject to the following conditions (the first 5 conditions were the official conditions that conditioned beneficiaries had to comply with) 109

Figure 5.1: Fraction of tokens allocated to oneself by individuals in TC1 128

Figure 5.2: Satisfaction of individuals with group outcomes and the decision-making process, ranging from 1 (completely disagree) to 7 (completely agree) 135

Figure 6.1: Priority target group selected by urban, student and rural respondents. 155

Figure 6.2: Priority target group selected by respondents, by self-assessed income 155

Figure 6.3: Respondents' opinions on whether the poor take responsible decisions or whether they are irresponsible and should be told what to do 158

Figure 6.4: Respondents' preferences for income (in)equality and perception on the merits of working hard 159

Figure 6.5: Respondents' opinions on whether the government or individual should take more responsibility 160

Figure 7.1: Framework for links between politics and social protection. 164 


\section{Acronyms}

ACC

CBT

CCT

CSO

CWAC

DP

DSWO

FGD

LCMS

MCDSS

MDGs

MOH

OLS

PWAS

SAG

SCT

TC

TPI

TWG

UCT

ZDHS
Area Coordinating Committee

Community-based targeting

Conditional Cash Transfer

Central Statistical Office

Community Welfare Assistance Committee

Development Partner

District Social Welfare Office

Focus Group Discussions

Living Conditions Monitoring Survey

Ministry of Community Development and Social Services / now: Minister of Community Development, Mother and Child Health ${ }^{1}$

Millennium Development Goals

Ministry of Health

Ordinary Least Squares

Public Welfare Assistance Scheme

Sector Advisory Group

Social Cash Transfers

Treatment Condition

Targeting Performance Indicator

Technical Working Group

Unconditional Cash transfer

Zambia Demographic Health Survey

\footnotetext{
${ }^{1}$ The name of the Ministry was changed to Minister of Community Development, Mother and Child Health after the last elections in September 2011.
} 


\section{CHAPTER 1: Introduction}

One person in five still lives in a situation of extreme poverty, surviving on the equivalent of less than one dollar a day. This is a sad reality in light of the fact that the cost of eradicating poverty represents a mere $1 \%$ of global income. ${ }^{2}$ It raises the question as to why poverty reduction still remains such a big challenge and why development policy seems to have achieved so little. Looking at financial and technical support over the last decades, should it not be feasible for developing countries to eradicate extreme poverty and reach the Millennium Development Goals (MDGs)? We still have a very limited understanding as to why this mission has not been accomplished. We do know, however, that identifying the poor, finding the right form of assistance and ensuring that the support reaches its final destination and is put to the best use is not as easy as it sounds.

Against these challenges of finding the right mechanisms for poverty reduction, it does not seem surprising that the instrument of social cash transfers (SCT) - regular, taxfunded and direct transfers of cash to poor or vulnerable individuals or households has gained enormous popularity over the last decade. While in the 1990s, cash transfers were largely a Latin American phenomenon, there is today hardly any country left in the South which has not at least piloted a cash transfer program, translating into 0.75 1 billion transfer recipients. SCT can be targeted to those in greatest need, transfers offer ample flexibility in reacting to different household constraints, are relatively cheap and transparent when it comes to delivery and, if large enough, may enable households to satisfy present consumption needs and make investments into longerterm development at the same time. ${ }^{3}$

Needless to say, by themselves SCT are not a guarantee of success. How cash should be targeted, delivered and combined with incentives has been subject to many debates. In some areas, factors of success can be easily identified and agreed upon. Everybody would concur that payments of transfers through the private banking sector will be, in the longer term, the way forward; most would also agree that the transfer amount has to do justice to the objectives of the cash transfer program. Other areas are more contested; in particular the topics of behavioral conditions as well as targeting. ${ }^{4}$ Practitioners and academia alike have controversially debated whether targeting the poor (ex-ante conditionality) and conditioning the support (ex-post conditionality) is a desirable option from an economic, political as well as social point of view in lowincome countries.

\footnotetext{
${ }^{2}$ http://www.teamstoendpoverty.org/wq_pages/en/visages/chiffres.php.

${ }^{3}$ For further information about the instrument of SCT, see e.g. Samson, van Niekerk et al. (2006), Grosh, Ninno et al. (2008), Fiszbein and Schady (2009), Hanlon, Barrientos et al. (2010) and Arnold (2011).

${ }^{4}$ See for instance the debates about conditionality and targeting on Wahenga, a knowledge platform for social protection practitioners and researchers: www.wahenga.net.
} 
While some authors have drawn strong conclusions that "[...] programmes that rely on targeting and conditionalities are invariably arbitrary, inequitable and inefficient" (Standing 2007: 1) or that conditionality is "economically superfluous, physically pernicious, morally atrocious and politically abominable," (Freeland 2007: 1) this dissertation argues that the question of whether to condition or not cannot be answered in one sentence. Preventing the debate on ex-post conditionality (hereafter referred to as conditionality) and ex-ante conditionality (hereafter referred to as targeting) from being predominantly shaped by ideological convictions, this dissertation therefore aims to systematically unpack the factors that policy-makers have to consider when deciding whether to target SCT and condition the support. The main research question it addresses is: "Under what conditions do conditionality and targeting enhance the effectiveness of social cash transfers in a low-income country setting?"

Important sub-questions in this regard are:

$>$ In what ways does conditionality influence the effectiveness of social cash transfers and to what extent are those transmission mechanisms supported by evidence? (Chapter 2)

$>$ What are the conditionality preferences of those most concerned and in what way are they compatible with preferences of decision-makers at different levels? (Chapter 3)

$>$ Which inefficiencies do we encounter in a low-income country context with respect to conditionality? (Chapter 4)

$>$ Which motives drive community-based-targeting and what are the determinants of progressiveness? (Chapter 5)

$>$ In what way do the political economy models of targeting, postulating universalism, apply in a low-income country context? (Chapter 6)

$>$ Which other factors, next to conditionality and targeting, determine the political sustainability of a social cash transfer program? (Chapter 7)

This dissertation critically discusses these questions for SCT programs in a low-income country context where evidence is even scarcer. The analysis and subsequent policy recommendations are based on empirical data from Zambia. In order to get a better grip of the underlying mechanisms, the dissertation is based on a novel methodology in the area of cash transfers. Inspired by behavioral economics, field experiments were carried out in rural Zambia, which were specifically designed to elicit conditionality and targeting preferences and test for other factors that influence targeting and conditionality outcomes. Complemented by an attitudinal survey, a survey with beneficiaries as well as administrative and qualitative data, this data-mix allows for a rich and comprehensive analysis of different factors that have a bearing on whether conditionality and targeting are optimal choices. 


\subsection{Social cash transfers}

SCT primarily serve as a tool to smooth consumption when individuals face particular lifecycle risks such as childhood, disability, maternity, old age, etc. and to ensure that poor individuals or households have access to a socially accepted minimum of goods and services. Following the IDS framework of social protection (Devereux and Sabates-Wheeler 2004), SCT can be protective, preventive and even promotive in nature. Transfers can protect households from moving below a certain threshold that society considers an essential minimum. They can prevent households from falling into poverty in the future if they assist them to build up a sustainable livelihood basis that shields them from future shocks. Cash transfers can also be promotive in terms of allowing individuals / households to strengthen their productive capacity, accumulate an asset basis, invest in small businesses and stimulate local market mechanisms.

Many countries have found seasonal or long term SCT an attractive instrument to replace structural food aid or other types of emergency assistance delivered to fight chronic poverty rather than in response to acute emergencies. SCT also appeared to be an appropriate response to the ambitious Millennium Development Goals due to their in-built flexibility in terms of reacting to the different challenges households face at the same time. The greater concern of ensuring that aid reaches the poor directly and in a cost-effective manner similarly made SCT appear an interesting policy alternative. SCT also fitted with the increased attention paid to budget aid over the last few years as they - even when conditioned - are not as restrictive as other types of transfers that are provided in-kind or given in terms of fee reductions / waivers for certain social services.

SCT programs are among the best evaluated programs, in particular, the flagship programs in Latin America such as Progresa (now: Oportunidades) in Mexico. We now have a much better understanding of what kind of impacts they can possibly generate (Fiszbein and Schady 2009; Arnold, Conway et al. 2011), even if impact from lowincome countries is still mostly based on pilots while studies on the long-term human capital effects are only starting. The research gap on the impact of SCT has substantially narrowed over the past few years. Evaluators have however only recently begun to unpack the black box of cash transfers, assessing more closely which parameters prove most decisive in maximizing program outcomes (Aber and Rawlings 2011; Gentilini and Omamo 2011; Gómez 2011; World Bank 2011). The second generation of conditional cash transfer (CCT) evaluations, as the World Bank called its recent workshop in October $2011^{5}$, is currently pursuing this mission. This dissertation

\footnotetext{
${ }^{5}$ For further information, visit: http://web.worldbank.org/WBSITE/EXTERNAL/TOPICS/EXTSOCIALPROTECTION/0,,contentM DK:23035938 menuPK:2643917 pagePK:64020865 piPK:51164185 theSitePK:282637 isCURL: Y,00.html.
} 
forms part of this second generation of evaluations and is therefore a timely contribution to the recent research and policy debate on SCT.

\subsection{Why focus on conditionality?}

Conditionality ties the receipt of social transfers to beneficiaries' compliance with predefined conditions that intend to optimize beneficiaries' behavior, generally in the area of education and health. While the cash transfer reduces households' financial barriers in accessing services, conditionality is expected to tackle behavioral barriers to the use of social services. The debate on whether and how to condition social assistance has received increasing attention in the last few years in developing as well as developed countries (Aber and Rawlings 2011). Compared to a decade earlier when the impact of conditionality was mainly assessed through simulations, the evidence base has not only grown but also become more robust with the new generation of experiments that has isolated the impacts of conditionality.

Nevertheless, even in the more recent studies, conditionality is still mentioned as one programmatic area that would benefit from a more rigorous and holistic analysis (Gómez 2011). The literature up until now has predominantly shed light on the household dimension and evaluated whether conditionality has led to any behavioral changes and improved human capital outcomes (Hoddinott and Skoufias 2004; Gitter and Barham 2008; Schady and Araujo 2008; Handa, Peterman et al. 2009; Ribas, Soares et al. 2010; Baird, McIntosh et al. 2011; de Brauw and Hoddinott 2011). The behavioral side-effects of conditionality have been largely ignored. In additional, few studies have given adequate consideration as to how the effectiveness of conditionality varies with differences in design features, the capacity of the administration, political preferences as well as systemic factors. Following the spirit of the second generation of evaluations, determinants of success still need to be unbundled (Aber and Rawlings 2011) and greater linkages have to be drawn to existing research in behavioral economics and psychology in order to do justice to the complexities of behavioral change (Schady 2011).

A better understanding will not only help to explain why conditionality has proven effective in some country contexts while we see little impact and also negative implications in other countries. It will also allow policy-makers to use the instrument of conditionality more selectively - when chances of success are realistic - and effectively, optimizing the design of conditionality for a particular country context. Further research is of enormous practical value given the great potential of conditionality of promoting long-term development beyond the initial boost in consumption on the one hand and the serious negative consequences of badly designed and implemented conditionality on the other hand. Conditionality risks discontinuing support or denying support to households, translating into foregone poverty reduction 
effects, complications in the administration and potentially negative political consequences.

\subsection{Why focus on targeting?}

Contrary to conditionality, there is more conceptual clarity on targeting, e.g. the criteria and mechanism on the basis of which applicants are selected into a particular program. The different characteristics of targeting mechanisms, their advantages, costs as well as the appropriate context have been explored in greater detail. The evidence base on the performance of different targeting mechanisms has also grown over the past decade (Coady, Grosh et al. 2004; Slater and Farrington 2009; Handa, Huang et al. 2010). Policy-makers therefore have a better decision-making matrix on how to select targeting criteria as well as mechanisms.

Similar to conditionality, evaluations of targeting have focused less on the factors of success at each step of the targeting process, ranging from the choice of criteria, the degree of decentralization and standardization to the information, application, selection and grievance process. Choices of targeting criteria and methods still partly rely on a number of assumptions that have been not rigorously tested and where we have a limited understanding as to how they work. The dissertation therefore concentrates on two dimensions where evidence is still scare: the functionality of decentralized targeting and the political economy aspects behind the selection of targeting criteria.

Community-based targeting (CBT) has often been considered an attractive combination for low-income countries as it allows a program to tap into the informational advantages where information is difficult to verify, fosters accountability where formal decision-making structures are very remote and ensures cost-effectiveness for programs that often deliver small benefits. In the framework of SCT programs, policymakers and technical advisers have however raised doubts as to whether CBT would be a feasible option for a program at large scale which requires frequent re-targeting. In order to make the best choices in the interests of beneficiaries, the administration and politicians alike, policy-makers need to know under what conditions the potential advantages of a decentralized targeting mechanism materialize.

Academics have rightfully bemoaned the ignorance regarding the important role that political economy considerations play in the debate on targeting. While the political economy of targeting has been modeled by a number of authors, there is still very little evidence that substantiates the assumptions made by those models, in particular in the context of low-income countries. As policy-makers have an interest in choosing a targeting regime that results in greater political popularity as well as benefits for the poorest in society, they need to know under what conditions it is worth choosing a universal approach. 


\subsection{The case of Zambia}

With a large research gap for low-income countries and the need for effective SCT programming even greater, this dissertation focuses on conditionality and targeting in a low-income country context, using Zambia as a case study.

Zambia is a land-locked country in Southern Africa with a population of about 13 million inhabitants (CSO 2011b). It is has suffered a great deal from the ramifications of the HIV pandemic; the relatively low life expectancy of 49 years (UNDP 2011) is just one indication of this. With about two thirds of its population living in poverty in 2006 according to the international poverty line of $1.25 \mathrm{US}^{6}$ a day as well as the multi-dimensional poverty index in 2011 (Alkire, Roche et al. 2011), Zambia is still classified as one of the poorest countries in Africa. ${ }^{7}$ Zambia ranks 195 out of 225 countries with respect to GDP per capita (Central Intelligence Agency 2011) and 164 out of 187 countries regarding the Human Development Index (UNDP 2011).

Figure 1.1: Map of Zambia

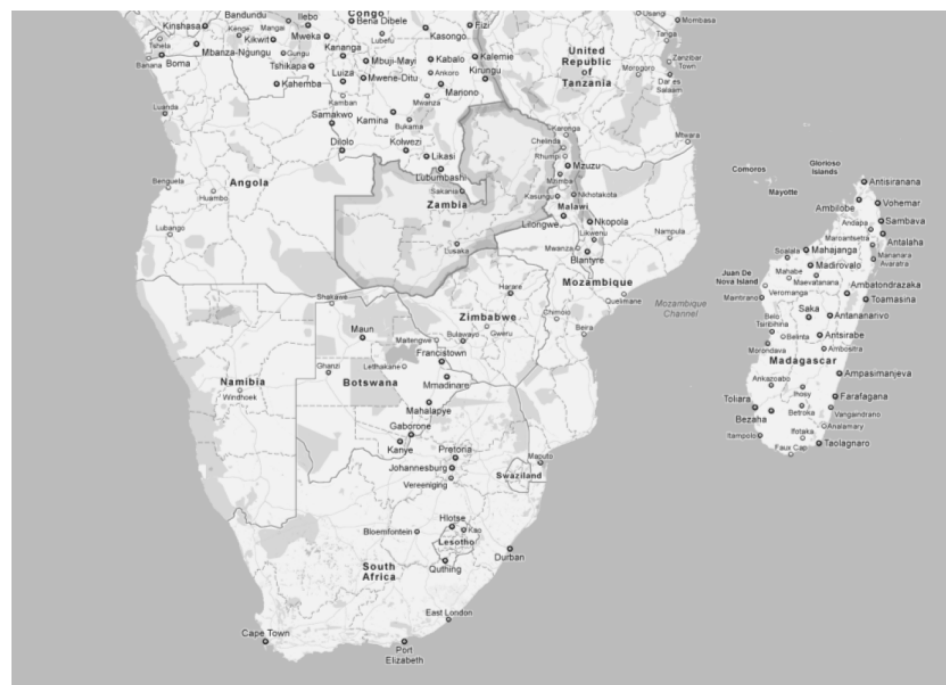

Source: Google Maps

Zambia was one of the first low-income countries in Africa in 2003 to pilot a SCT approach. The SCT scheme built on the existing Public Welfare Assistance Scheme (PWAS), administered by the Ministry of Community Development and Social

\footnotetext{
${ }^{6}$ The 1 US\$ a day international poverty line was calibrated in 2008 by the World Bank at 1.25 US\$ at 2005 purchasing power parity.

${ }^{7}$ This is not changed by the fact that Zambia was re-classified as lower-middle income country in 2011. 
Services $(\mathrm{MCDSS})^{8}$, whose structures at community and district level are present throughout the country. While maintaining the institutional set-up and adopting the decentralized approach to targeting, management and monitoring, MCDSS changed the modality from in-kind support to cash whilst also testing modifications to the targeting, monitoring, training and management procedures. Next to improving the welfare of the beneficiary households, the objective of the SCT pilot was predominantly to learn whether a SCT approach would be feasible, effective and affordable.

As the SCT scheme meant to capture households affected by HIV and AIDS, it started by targeting households with a high dependency ratio - considered incapacitated - who suffered from extreme poverty. Nationally, it was estimated that $10 \%$ of all households fell into this category, which inspired the choice of $10 \%$ as a threshold in the targeting process. Beneficiaries were identified through a multi-stage process, with criteria being pre-defined at national level, community committees selecting beneficiaries, headmen verifying the accuracy of information, the community approving the ranking and the PWAS committee at district level verifying the choices made. Beneficiary households with children received a monthly transfer of ZMK $50,000^{9}$ while households without children received ZMK 10,000 less. Transfers were paid on a bimonthly basis at fixed pay points at village level which were administered by public servants such as school teachers and health workers.

Even if SCT have gradually been extended to eight districts in Zambia, the program still operates on a relatively small scale and still counts as a pilot. The pilot has actively been used for learning purposes, principally to test the use of cash and the impact at household level and also a range of different alternative program parameters such as targeting, conditionality, payment mechanism, performance incentives, MIS etc. ${ }^{10}$ These continuous revisions have demanded a great deal of flexibility, in particular on the side of the administration, but they have greatly improved the program whilst allowing the design to be tailored to the changing circumstances in the country. While still considered a pilot, SCT feature in Zambia's social protection strategy which was drafted in 2005 and which has then been recast in chapters of the 5th and 6th national development plan in 2006 and 2011 respectively.

Zambia proves to be a particularly interesting case study for this dissertation for different reasons. It is first of all a country where conditionality and targeting have been tested at small scale in the framework of a SCT pilot. This means that the country has been exposed to the concepts of conditionality and targeting but no decision has yet been taken which systems to adopt for a national program. The fact that systems have

\footnotetext{
${ }^{8}$ The name of the Ministry was changed to Ministry of Community Development, Mother and Child Health after the last elections in September 2011.

${ }^{9}$ According to the average exchange rate for the first quarter of 2012, ZMK 50,000 amount to $7.2 €$ and 9.5 US\$.

${ }^{10}$ For more information about these studies, visit the accompanying toolbox of the study Cashing in How cash transfers shore up Zambian households affected by HIV (Schüring 2009).
} 
only been tested at small scale ensures variability in program parameters that we can exploit in our empirical analysis. It also makes the research more policy-relevant. Targeting is continuously in discussion and evolving. While the first pilot districts for the SCT scheme started with identifying the poor and incapacitated households through CBT, the later districts have been testing alternative categorical targeting approaches for the elderly and children. As early as 2007 a targeting study was commissioned to look into alternative targeting methods and assess their potential against the functionality of the existing mechanisms (Watkins 2008a). In 2010, the Ministry, with support from UNICEF, decided to contract out further work on targeting, trying to centralize and standardize the decentralized targeting mechanism.

In 2007, the technical working group on social assistance, which is spearheaded by the Department of Social Welfare within the MCDSS, decided to run an experiment on conditionality that - like the experiments in Kenya, Malawi, Morocco and Burkina Faso - would allow the Ministry to estimate the differential impact of conditionality. One of the pilot districts in southern Province, Monze district, was therefore randomly divided into unconditional treatment communities, conditional treatment communities and control communities. The first baseline study was carried out in 2007 (Tembo and Freeland 2008b) with a follow-up study planned for 2009. Due to implementation irregularities concerning the payments but also the management of conditionality (see section 4.6.2 for further information), the follow-up study was only carried out in 2011 and used to estimate the impact of SCT in general and not to separate out the impact resulting from cash and from conditionality.

\subsection{Data \& methodology}

Unpacking the black box does not only call for more research but also a careful deliberation of which methodology would be most appropriate. As the dissertation is not only multi-disciplinary in nature but also aims at substantiating some of the linkages between conditionality / targeting and the effectiveness of SCT programs through robust empirical evidence, it draws on different data sources and methodologies that help address specific questions and triangulate findings.

Every chapter presents in detail the data and methodology that has predominantly been used to answer the particular research question. The analysis in chapter 3 and 5 is mainly based on experimental data, whereas the analysis in chapter 6 and 7 predominantly uses data from the attitudinal surveys with the urban and rural public as well as students. In chapter 4 , the beneficiary survey, administrative data and secondary data sources feature most prominently.

The allocation and conditionality experiment in chapters 3 and 5 is methodologically speaking the centerpiece of the dissertation. Inspired by experiments in behavioral 
economics, the allocation and conditionality experiment was specifically designed by the author to elicit people's preferences around conditionality and targeting in a more rigorous way. ${ }^{11}$ The experiment is unique in the sense that it is tailored to the Zambian context as well as to the research question at hand and therefore conducted for the first time. The experiment not only allows us to elicit participants' preferences but also to test the influence of different treatment conditions and to observe the decision-making process more closely. It is therefore an interesting tool to open up the black-box behind targeting and conditionality.

The experiment contrasts with the impact evaluations of SCT up to date which have been carried out in Latin America but also increasingly in African countries. (Fiszbein and Schady 2009; 3ie 2010). Evaluations of actually implemented policies are often costly and do not always give us sufficient information about the mediators between a policy and policy outcomes (Ludwig, Kling et al. 2011), a phenomenon in which we are particularly interested. The allocation and conditionality experiment might therefore also inform future policy evaluations about the factors that should be studied in greater detail.

The attitudinal surveys in chapter 6 and 7 are not new as such but also prove innovative in some aspects. The surveys are inspired by the format of the world values survey ${ }^{12}$ and Graham's (2002) analysis which has applied some of the questions on poverty and policy perceptions in the context of social protection and SCT. The innovation of the attitudinal surveys that we administered in Zambia is that they use existing as well as additional questions for the purpose of gauging the political potential of conditionality in the Zambian context. They furthermore add to the relatively scarce evidence base on attitudes towards poverty and government assistance in Sub-Saharan Africa (Barrientos and Neff 2011).

The beneficiary survey shares some commonalities with the attitudinal survey but also includes a range of different questions which helped us evaluate the implementation of the conditionality experiment. In addition, they created a direct feedback loop for those most concerned by conditionality and allowed us to triangulate the data from the conditionality monitoring cards and the information obtained through stakeholder interviews.

All research instruments were designed by the author herself. She conducted the research activities in Zambia in collaboration with a team of enumerators and with the

\footnotetext{
${ }^{11}$ This experiment, conducted by the author in 2009 , is different from the experiment that was run by the Government of Zambia in collaboration with other development partners as described in section 1.4. The experiment by the Government of Zambia will be referred to as SCT experiment on conditionality to allow for easier distinction between the two experiments.

${ }^{12}$ For further information, see http://www.worldvaluessurvey.org.
} 
research assistance of colleagues from the University of Zambia. ${ }^{13}$ All enumerators and research assistants underwent a training that was conceptualized and carried out by the author.

\subsection{Outline \& main findings}

The dissertation is divided into two main sections: the first one deals with the topic of (ex-post) conditionality and encompasses chapters $2-4$. The second section is dedicated to targeting (ex-ante conditionality) and comprises chapters 5 and 6. Chapter 7 puts the topic of conditionality and targeting into the broader context and demonstrates that they should not be considered in isolation when contemplating how to increase the political sustainability of SCT programs. Chapter 8 concludes, providing a synthesis of the main findings as well as policy recommendations.

Section 1 on ex-post conditionality begins in chapter 2 with a conceptual chapter in light of the fact that the question of whether to condition a SCT program or not has been controversially debated in the development scene, often without a clear concept of what conditionality constitutes, what it can realistically achieve and where the limitations are. The aim of this chapter is to generate a common understanding regarding the concept of and theory behind conditionality, to highlight the different factors that prove essential in determining whether conditionality makes a SCT program more cost-effective and to bring together existing evidence. While building on many important contributions made by other authors, the value added of chapter 2 is that it clearly differentiates between different dimensions of conditionality, brings together a theoretical economic perspective with insights from psychology and political science, comprehensively and systematically disentangles all factors that determine the impact conditionality can have on the effectiveness of SCT programs and cites evidence beyond conditionality's influence on household behavior. The chapter is supposed to equip policy-makers with a decision-making framework for deciding on whether to opt for conditionality or not and it is supposed to highlight areas where further research is required.

The empirical chapters 3 and 4 are inspired by the research gaps elaborated in chapter 2. While preferences for conditionality have been frequently modeled by economists and political scientists, they have not been rigorously tested empirically. Chapter 3 therefore scrutinizes local preferences for conditionality and discusses the extent to which they are compatible with conditionality preferences of decision-makers at different levels. Using experimental evidence from rural Zambia, this chapter elicits preferences for conditionality of those most affected by a policy decision for making

\footnotetext{
${ }^{13}$ The research activities were funded through a research grant from the Poverty Reduction, Equity, and Growth Network, financial support from MCDSS and UNICEF as well as from the DfID-funded Regional Hunger and Safety Net Project.
} 
transfers conditional. The study also examines how individual preferences translate into policy-making at decentralized level and how they compare to conditionality preferences of beneficiaries of the SCT scheme, the urban population of Lusaka and policy-makers across different Ministries and at different levels. We find that conditionality meets the interests of policy-makers, the general public and beneficiaries alike, exerting the necessary control for transfer givers and the guidance for transfer recipients. The experiment, however, also demonstrates that conditionality preferences are neither homogeneous nor static and are likely to change with more exposure to SCT and conditionality, better information about recipients and greater levels of trust and certainty about beneficiaries' behavior.

Chapter 4 highlights the different inefficiencies of conditionality that are likely to occur in a low-income country setting, which have a negative impact on the effectiveness of a SCT program. Recent research has focused on enlarging the evidence base of behavioral effects of conditionality. While this quest for more robust evidence is laudable, it has often left aside the cost-side of conditionality and therefore only presented half the truth. Drawing on data from a beneficiary survey, administrative data and other sources, this chapter shows that enforced conditionality would have generated significant inefficiencies in the Zambian context. Despite the fact that there seemed to be some scope for conditionality to positively influence household behavior, it would have come at the risk of excluding beneficiaries from the scheme and of generating significant direct or indirect administrative cost. The findings therefore call into question whether conditionality is the best choice for a country like Zambia where behavioral fine-tuning might not be regarded as a priority measure, where the transfer amount is very limited and where the overall budget and administrative capacity are constrained.

Moving to section 2 and the thematic area of targeting, chapter 5 tests a number of critical assumptions behind CBT, helping us acquire a better understanding of the progressiveness of this mechanism and under which conditions it operates best. While the engagement of local structures in decision-making has generally been considered beneficial, how much engagement and what degree of influence there should be over targeting decisions are fiercely debated. Using evidence from an economic experiment in rural Zambia, we shed more light on the relative importance of different targeting motives in CBT, the compatibility of individual and group targeting decisions as well as on the determinants of progressiveness. The findings of the study support the evidence of previous studies that CBT is at least mildly progressive. While egalitarian tendencies can be observed among individuals and groups, they vary greatly with the degree of peer pressure and prior exposure to targeting. Poverty is one of the main targeting motives and carries more weight than favoritism to family members or favoritism to important people in one's social network. Although constrained through the group decision-making process, community members behave selfishly if they have the option of favoring themselves. Selfishness is not positively correlated with being better-off or having a status position in society, making us question whether elite 
capture is not an over-emphasized problem of CBT. Community members are not consistent in their targeting choices, although this does not lead to dissatisfaction with the decisions made as a group. CBT appears to have more potential in communities with greater cohesion, less distrust and where people know each other better. The engagement of people with an important social position in the community and the involvement of an expert committee rather than the entire community have a positive influence on the progressiveness of outcomes.

There has been an ongoing debate among researchers, policy-makers and development partners in low-income countries on whether and to what degree non-contributory social transfers should be targeted to the poor or paid out universally to every citizen or to all citizens in a particular category. Chapter 6 critically discusses the assumptions behind the political economy arguments of targeting and tests whether a universal mechanism is bound to politically excel in a low-income country context. A number of authors have argued that going universal is a win-win situation, both for the poor, the middle class as well as those who are in power. We would therefore expect broadbased support to rally behind a universal scheme, in particular in countries where poverty is wide-spread and targeting also proves administratively challenging. On the basis of attitudinal surveys with the urban, rural and student population in Zambia, we actually detect more support for targeting the poor than the political economy models would predict. These findings are corroborated by experimental evidence from rural Zambia. We discuss the assumptions of the political economy models in the light of these findings and consider potentially decisive parameters that the models currently do not incorporate.

Chapter 7 illustrates that conditionality and targeting are both just pieces of a bigger puzzle and can only partly explain as to why SCT gain popularity or stagnate. Attempts have been made to explain why social protection systems seem least likely to become established where they are most needed, in countries hard hit by the HIV and AIDS epidemic, confronted with a growing OVC population, overwhelming rural poverty and high levels of inequality. Often however, these attempts have not captured the rather complex politics in the countries in question. Analyses have turned the Minister of Finance into the sole representative of political will, have equated low budgetary allocations with the politically unattractive program design and ignored the long, erratic histories of social protection in the Western world. The appropriate roles for donors and civil societies in such political economies remain equally unclear. On the basis of other drivers of change studies, this study takes a closer look at the political dynamics behind social protection in Zambia. It examines whether the observed or deduced stagnation in social protection is due to stakeholders in Zambia rejecting policy recommendations, the inappropriate nature of the recommendations, or a premature assessment of the progress made. 


\section{CHAPTER 2: Conditions, conditionality, conditionalities, responsibilities - finding common ground ${ }^{14}$}

\subsection{Introduction}

The question of whether to condition a SCT program or not has been controversially debated in the development scene. Those who favor conditionality assume that it is above all the conditionality rather than the cash itself that produces mid- to long term improvements in human capital outcomes such as education and health. They also view conditionality as a powerful tool to make SCT programs politically more attractive and to empower beneficiaries (de Janvry and Sadoulet 2006b; Fiszbein and Schady 2009). Opponents of conditionality usually refer to the meager robust evidence that is available to substantiate the impact of conditionality, are concerned about the feasibility of conditioning in low-income countries, the paternalistic nature of conditionality and its potential to exclude qualifying beneficiaries from the program (Freeland 2007; Kidd and Calder 2011).

Very often, discussions on conditionality have an ideological underpinning and the decision whether to condition or not is not based on a comprehensive analysis of the different factors that determine whether conditionality is indeed an appropriate instrument in social transfer programming. In light of the growing endeavors for evidence-based policy making, this is regrettable. People however do not only differ in their views on conditionality but also in their concept of conditionality which often complicates discussions. In order to have a meaningful and critical discussion about the evidence base on conditionality, it is important to keep the various forms that conditionality can take in mind. Failing to base discussions on the same concept of conditionality or using existing evidence selectively are not conducive to finding common ground.

This chapter therefore starts off by conceptualizing conditionality and highlighting different dimensions along which conditionality differs (Section 2.2). Taking a theoretical perspective, we then systematically disentangle the factors that determine to what extent conditionality affects the effectiveness of SCT programs in a positive (Section 2.3) as well as a negative way (Section 2.4). The chapter continues by presenting existing evidence on the impact of conditionality (Section 2.5) and concludes by summarizing the main points and pointing to further research gaps (Section 2.6).

\footnotetext{
${ }^{14}$ An earlier version of this chapter is published as MGSoG working paper 2010WP014 in English as well as French, available from http://www.merit.unu.edu/publications/mgsog_wppdf/2010/wp2010014.pdf.
} 


\subsection{The concept of conditionality}

Having a common understanding of conditionality is important when engaging in discussions about its necessity and value added. Surprisingly, conditionality evokes fairly different connotations among policy-makers, government staff and academics. Some associate eligibility criteria with conditionality; others refer to programs that explicitly solicit certain behavior; others in turn only regard programs that strictly enforce conditionality as conditional. There is consequently no agreement as to whether programs with soft conditionality - conditions that are not enforced - public work programs or bursaries qualify as CCT programs. This leads to discussions on conditionality in which programs of a completely different nature - e.g. programs that make exemptions for beneficiaries and are lenient vs. programs that demand a specific outcome such as a grade point average in school - are compared. So what is conditionality and along which dimensions does it differ?

\subsubsection{Definition of conditionality}

The term conditionality is mostly known in the foreign aid context where bilateral and multilateral donors as well as development banks make the receipt of grants and credits conditional on the country's performance in areas that are deemed critical by the financers, such as macro-economic stability. In the context of social welfare, the term conditionality refers to a similar idea but it applies to households or individuals who receive government transfers, conditional on some form of behavioral compliance. This means that in order to continue receiving support, eligible households have to meet specific conditions that are spelled out by the program. While the cash is supposed to reduce the financial barrier faced by households in improving their living standard and making use of existing social services, conditionality is supposed to tackle behavioral barriers that prevent households from improving their situation and escaping from poverty.

The term conditionality is not used unanimously across the world. In reaction to the negative connotation of conditionality during the structural adjustment phase, some governments or development agencies have replaced the word conditionality by coresponsibilities or commitments emphasizing the active rather than passive role that the beneficiaries have to play and the dual responsibility on the side of the beneficiary as well as government. The term conditionalities has also appeared in a number of articles and manuals, which has stimulated a debate on whether this word exists or is just an unnecessary creation. ${ }^{15}$

\footnotetext{
${ }^{15}$ For a discussion about the semantics of conditionalities, see http://www.wahenga.net/node/1756. 


\subsubsection{Dimensions of conditionality}

Figure 2.1: Dimensions of conditionality

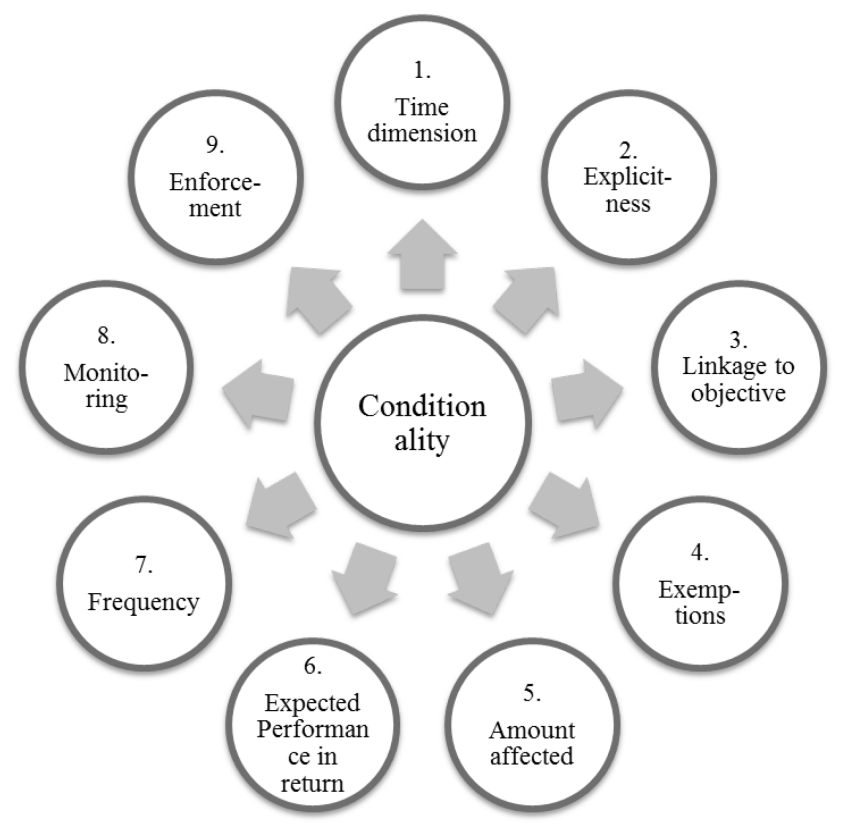

Conditions vary considerably in the way they are designed and implemented. Nine broad dimensions can be identified, along which conditionality differs (Figure 2.1): the time when conditions are placed, how explicitly they are mentioned, to what extent they respond to the primary objective of the program, whether there are any exemptions from the conditions, whether they are tied to the entire welfare payment or to a supplementary transfer, whether conditions are output or outcome driven, how often beneficiaries have to comply with them, and to what degree they are monitored and finally enforced. All these different characteristics have an impact on the administrative feasibility of conditionality, on the way conditionality may lead to unbearable costs for some beneficiaries and force them to drop out and on the potential positive changes that conditionality can produce at household and political level. These implications will be discussed in more detail in the sections to follow.

\section{Time dimension}

Conditionality can range from ex-ante conditionality, determining whether households are eligible for the program, to ex-post conditionality, deciding on a household's or individual's continuation in a particular program. Ex-ante conditionality, defining the types of households that will be accepted into the program, is common practice in cash transfer programs with the exception of truly universal programs such as the Basic 
Income Grant in Namibia. Ex-post conditionality, on the contrary, is not an essential design element of every cash transfer program.

\section{Explicitness}

Conditionality can be directly built into the program and explicitly spelled out to beneficiaries in form of a letter or a contract that they need to sign or it can be indirect in nature. Indirect means that conditionality influences household behavior through the choice of implementation modalities instead of an officially communicated obligation. For instance, the program implementer can decide against using the banking system to stimulate consumption or s/he can opt for vouchers to control spending (Schubert and Slater 2006).

\section{Linkage to main objective}

Programs can have an exclusive focus on the conditioned area or they can pursue broader objectives with the conditioned area just being one of them. When the transfer is conditioned on school enrolment in the case of bursaries or on a professionally assisted delivery in the case of a maternity grant for pregnant mothers, conditionality is tied to the main objective. As per the nature of the program, the transfer is only paid when households engage in these activities. This differs from conditionality in programs whose principal objective is to increase consumption levels of households and which intend to guide but not completely pre-determine households' expenditure patterns. In this case, conditionality applies to selected areas that are supposed to be reinforced.

\section{Exemptions}

Conditionality can apply to all beneficiary households or just a sub-group, with other beneficiaries being exempt. Beneficiary households can be exempt because they do not have any household members such as children of school-going age, children under five, pregnant women, etc. whose behavior can be conditioned. The need for such exemptions is interlinked with the objective of the cash transfer program. If the main objective is to alleviate critical poverty and all poor households regardless of their composition are targeted, exemptions are necessary. If the transfer has exclusive education and health objectives and only households with members that can be conditioned are included, exemptions might not be required. Further exemptions can be made for households that cannot comply with the conditionality for reasons beyond their control, such as the unavailability of services within walking distance or the irregularity of services offered due to teacher or health staff shortages, etc. 


\section{Amount affected}

Closely related to the objective of the program, cash transfers can be completely or only partly conditional. If conditionality is tied to specific education or health grants, non-compliance usually leads to the cancellation of the entire transfer. If the conditionality is attached to a more general consumption transfer that, among other objectives, pursues health and education outcomes, non-compliance does not have to affect the entire transfer amount but might only reduce the part which covers education and health related expenses. While conditionality might be perceived as a stick in case non-compliance leads to the cancellation of a more general consumption transfer, it has more the character of a carrot if only the supplementary health or education subtransfer is affected.

\section{Expected performance in return}

Conditionality can be output-related, requiring the beneficiary to make use of certain services such as going to the under-five clinic or attending school on a regular basis, or it can be outcome-related, expecting the beneficiary to show a positive outcome such as good test results in school, no repetition of a particular grade or continuous growth for children under five. We can also differentiate between simple (direct accomplishment) and complex (sustained) behavior requirements, using the terms by Kane, Johnson et al. (2004).

\section{Frequency}

Conditionality can be a one-off requirement such as the immunization of an infant or the acquisition of a birth certificate, or it can be regular in nature such as requiring a regular attendance rate or regular growth monitoring visits throughout the household's participation in the program (Lund, Noble et al. 2008).

\section{Monitoring}

A conditioned transfer necessitates compliance-monitoring; the intensity of monitoring, however, varies across programs. Given the administrative challenges involved in monitoring, some programs have opted to either waive monitoring activities or restrict themselves to irregular spot-checks while other programs require regular and documented monitoring.

\section{Enforcement}

Conditionality can be punitive, developmental or soft in nature. As the word already entails, punitive conditionality punishes non-complying households by withdrawing at least part of the cash transfer. Developmental conditionality entails that a case-worker follows up on the reasons for non-compliance and tries to work out an individualized 
solution with the household before the transfer is definitely stopped. Soft conditionality means that conditions are not enforced but officially remain a responsibility of the beneficiary household. The focus in programs with soft conditionality is thus more on monitoring and sensitization, rather than rewarding good and punishing bad behavior.

\subsubsection{Conditionality in practice}

For the remainder of this and the following two chapters, we mainly restrict the discussion of conditionality to programs with explicit, ex-post conditionality, attached to programs with an overall welfare focus. While most CCT programs are conditioned in the area of education and health, they still differ substantially in the different dimensions discussed above. The information on altogether 39 active or recently active CCT programs around the world compiled by the World Bank in 2009 (Fiszbein and Schady 2009) and 2010 (Garcia and Moore 2010) gives us a first impression of this variety (see Annex 1 for an overview). Most programs reviewed are concerned with the overall well-being and survival of a particular household / individual (objective). Twenty two percent of all programs are pure education or health grants and therefore have an exclusive focus on the conditioned area.

The majority of programs officially do not have a provision for exemptions. Given the low degree of monitoring and enforcement, in particular in African countries, indirect exemptions are however granted. There are also programs such as the community CCT program in Tanzania and the OVC program in Kenya that only make conditionality mandatory for those who have access to schools or health centers. In Jamaica, children with disabilities are exempt. Indonesia started in locations where supply-side constraints did not present a barrier.

In terms of the amount affected, the non-compliance with conditionality affects the entire transfer in about $40 \%$ of all CCT programs. In about $21 \%$ of all programs, the transfer is divided into education and health sub-transfers and non-compliance with one of the conditions only concerns the respective part of the transfer. The lowest number of programs ( $13 \%$ of all programs) places conditionality on supplementary education and health grants, next to a basic food / welfare grant that the household is guaranteed in any case.

In about $67 \%$ of all programs the conditionality is output-related, meaning that conditions only require beneficiaries to use health and education services but the use of these services does not have to lead to a particular outcome (expected performance in return). Most programs with outcome-related conditionality are specific education or health transfers which predominantly intend to reward good performance such as the bursary program in Cambodia or the HIV and AIDS program in Tanzania. 
The majority of programs have regular conditionality, with only a few programs asking for additional one-off conditions such as the receipt of a birth certificate or the participation in a particular training session (frequency). The regularity of conditionality, however, varies. There are for instance programs asking for $75 \%$ of regular school attendance such as the one in Bangladesh vs. programs that require $90 \%$ such as the program in Burkina Faso. Some programs demand monthly health checkups for children under 1 while others demand quarterly check-ups. Not only the percentage but also the reference unit differs across programs with programs demanding $80 \%$ of regular school attendance per month vs. programs that allow for $80 \%$ of regular school attendance over the year.

The regularity as well as the number of conditions affect the regularity of monitoring activities, which again range from intensive monitoring in countries such as Chile, Brazil, Mexico and Turkey to random checks in Argentina, Bangladesh and Tanzania, to no monitoring at all in countries like Ecuador and Ghana.

Programs differ significantly when it comes to enforcement mechanisms. Countries like Brazil, Chile and El Salvador have officially adopted a developmental approach, involving an extensive exchange between the defaulting household and a social worker before the transfer is stopped. There are also a number of other countries where transfers are more rapidly reduced or cut such as Mexico or Jamaica. Most programs with soft conditionality have been soft in nature due to capacity constraints, which rendered proper monitoring and enforcement of conditionality virtually impossible.

\subsection{Rationale behind conditionality}

From a welfare perspective, standard micro-economic theory teaches us that unconditional cash transfers (UCTs) are superior to CCTs as the former allow the beneficiary to maximize his/her utility by choosing a bundle of different goods and services that meets his/her preferences. Nevertheless, households sometimes face constraints in realizing optimal investment levels in education and health, in which case more paternalistic policy making such as conditioning cash transfers might be warranted. While economists view such paternalism with some skepticism (see for instance Glaeser 2005), they usually tend to accept it in cases where children are deprived of education and health services or when poor decision-making has disastrous effects on society (Stiglitz 2000; Thaler and Sunstein 2003).

There are principally five arguments for why conditionality could enhance the effectiveness of SCT programs: welfare gains for the household and society, political economy effects, empowerment and equity gains (Das, Do et al. 2005; de Janvry and Sadoulet 2006b; Bastagli 2008; Fiszbein and Schady 2009; Barrientos 2011). First of all, the government might be concerned that households do not reach their private 
optimum in terms of making the right investment decisions for education and health (private welfare gains). This can occur due to misinformation, non-altruism of parents towards their children or myopia. Even if households reach their private optimum, the government might wish to intervene if the households' optimum differs from society's optimum (societal welfare gains). Conditionality can moreover be the trigger that makes voters and politicians accept an otherwise unpopular social welfare intervention (political economy). It is also argued to empower beneficiary households as well as individual household members by, for instance, increasing the bargaining power of women (empowerment). Last but not least, conditionality can lead to more equity by improving the targeting performance of a social welfare program, working as a disincentive for those who are non-qualifying (equity).

Fields other than economics have also explored the role of incentives. The use of conditional incentives to influence behavior is also a common treatment form in behavioral therapy in psychology. Contingency management, a treatment used for substance use disorders such as drug abuse or obesity is based on the three main principles of 1) frequent monitoring of target behavior, 2) provision of incentives when target behavior occurs and 3) removal of incentive when it does not occur (Petry, Petrakis et al. 2001). While psychology has a long-standing tradition of incentivizing behavior, going back to earlier token economy approaches, little effort has been undertaken to use their experiences for research on CCT programs (Medlin and de Walque 2008). This chapter will make an attempt to draw more heavily on experiences and insights from psychology to complement the rationale and evidence taken from economics.

\subsubsection{Economic superiority of unconditional cash transfers}

In order to see which type of transfer is more effective, clarifying the objective of the program is crucial. As discussed previously, CCT programs can set different priorities when it comes to objectives, which range from a primary focus on increasing consumption levels of the poor or vulnerable (short-term poverty reduction) to one on human capital accumulation (long-term poverty reduction). If the focus is predominantly on improving schooling and health outcomes which necessitates behavioral change, a CCT targeted at those who under-invest in education and health, can be more effective. If however the main focus is on increasing the welfare of the poor with a secondary objective of strengthening human capital to avoid long-term poverty, the stakes look different.

If we are mainly interested in the welfare of households ${ }^{16}$, UCTs would be the optimal choice in a situation where agents behave rationally, markets function and the

\footnotetext{
${ }^{16}$ It should be noted though that not all SCT programs pursue welfarist objectives. They often prioritize the achievement of defined consumption levels without considering the utility of 20
} 
government takes decisions in the best interest of its citizens. UCTs allow agents to maximize their utility by letting them choose the bundle of goods and services that they prefer. The combination of goods and services might coincide with the choices made by the social planner if preferences are alike but any form of standardizing the goods and services that each citizen is required to use risks lowering some of the agents' welfare.

Figure 2.2: Welfare effects of a conditional vs. an unconditional cash transfer scheme

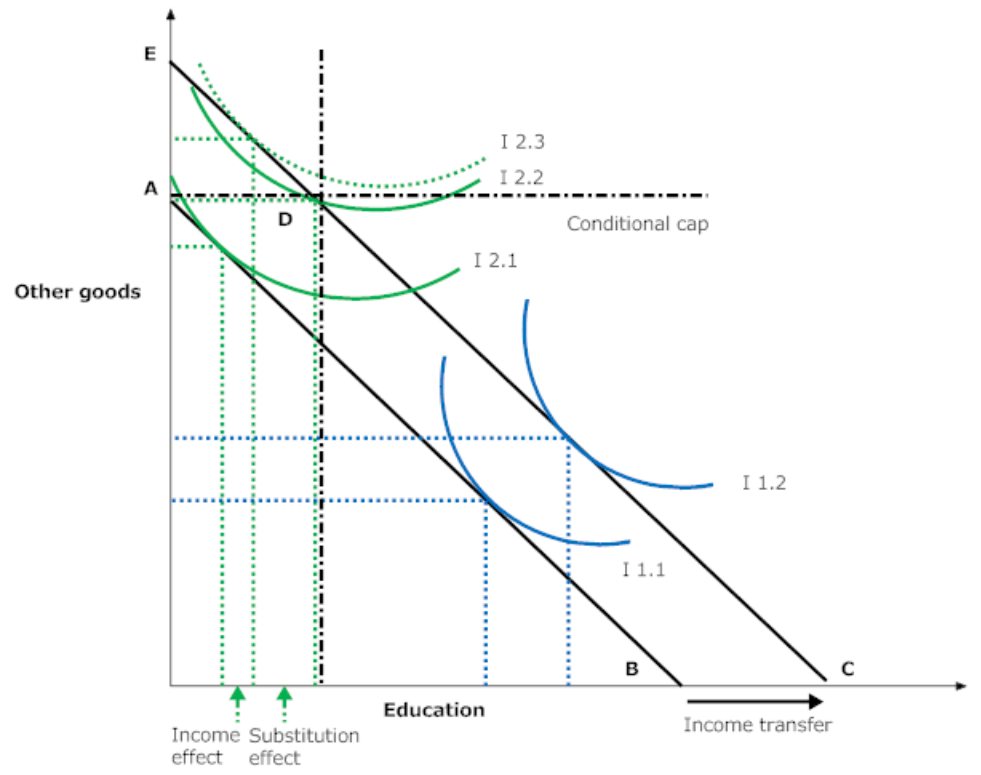

Taking a look at figure 2.2 we see the impact of a conditional vs. an unconditional cash transfer on two different households marked by the colors blue and green according to a simple standard economics framework. Both households can choose a bundle of education and other goods that is within their budget constraint, which is demarcated by the points A and B. Important to note here is that for the conditioned good, be it education and health, we do not regard dichotomous choices - e.g. whether a child is enrolled in school or whether a vaccination book is available - but areas where small changes are possible (school attendance, percentage of completion of all vaccinations etc.). The unconditional income transfer moves the budget line from $\mathrm{AB}$ to $\mathrm{CE}$ whereas the CCT moves the line AB to CDA, capping the consumption of "other goods" at A. The cash transfer in this scenario is expected to cover all school-related expenses and is

households. However, even for those programs, the welfarist perspective allows us to understand the positive and negative side-effects of conditionality. 
supposed to allow the household to meet the condition even if none of the prior income is invested in education.

While household blue would be indifferent between an unconditional or conditional cash transfer as the conditionality does not change the level of the indifference curve it can reach (I 1.2), household green would prefer a UCT. A CCT would restrict the household to indifference curve I 2.2 and the respective bundle of education and other goods at the corner point while a UCT would allow the household to reach a higher indifference curve (I 2.3). A CCT would consequently lower the welfare of household green. At the same time, household green is the household that is the main target group of a CCT program as this household in absence of the unconditional transfer would decide to take the CCT and substitute some of the income it would have normally invested in other goods (see decision under I 2.3) for education.

Lowering the welfare of household green only makes sense if we believe there are market inefficiencies leading household green to make sub-optimal decisions from a private point of view, meaning that household green bases its decision on the wrong indifference curve that does not reflect its true preferences. This can occur due to information constraints or incomplete altruism within the household for instance. It is furthermore justified if household green makes sub-optimal decisions from a social point of view by not factoring in the positive externalities that education and health generate, leading to a sub-optimal social welfare outcome for society. A CCT might also be the optimal choice if a government provides the income transfer only in case the condition is attached for political reasons. In this scenario both individual green and blue would support conditionality if this is the only way that an income transfer was to take place.

The graph in figure 2.3 presents a slightly modified scenario, where the transfer does not cover all education related expenses, leading therefore to different trade-offs for some households. Household blue is still indifferent between a conditional and an unconditional cash transfer and household green still would have made a different decision and moved to a higher indifference curve (I 2.2) if the transfer had been unconditional. As opposed to household green, household red would refuse to participate in the program as it would have to substitute too much of its income away from other goods for the good education in order to meet the conditions. Who participates in the program is therefore largely determined by the cut-off point and the size of the transfer. If the transfer is for instance doubled or the education requirement halved, household red would also decide to participate in the program. For any household in the bottom left quarter as demarcated by the conditional cap lines, the transfer would lead to a behavioral change. 


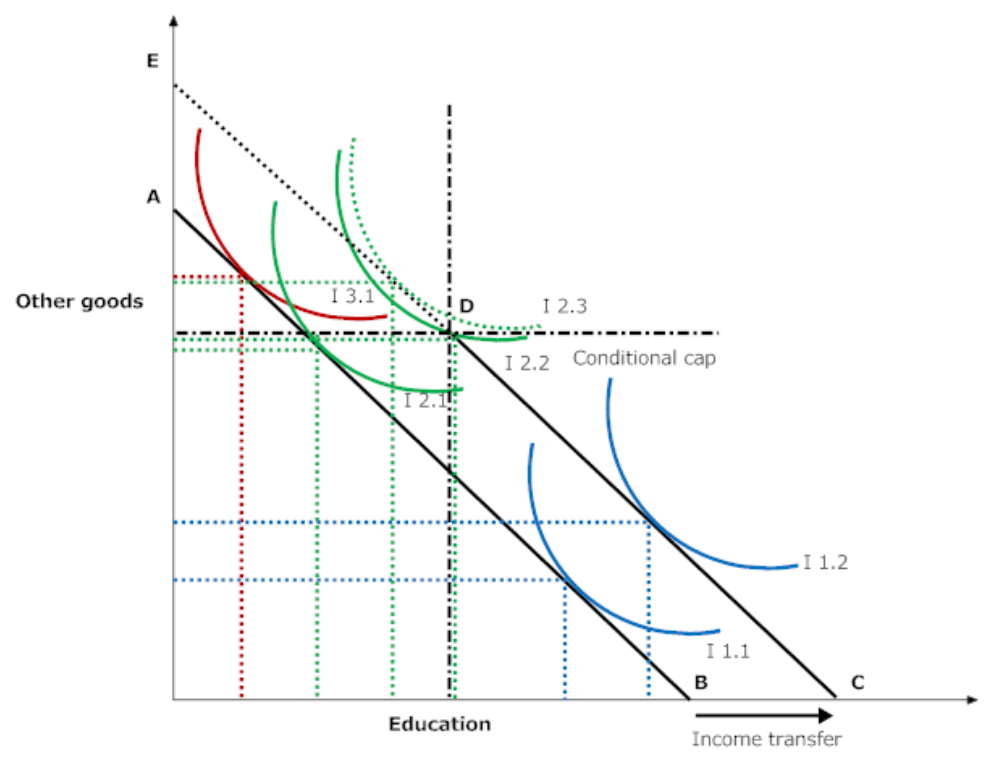

In conclusion, from a welfarist perspective and when all households behave rationally, markets are fully functional and the government is benevolent, UCTs are at least as efficient as CCTs and might be even superior for certain households such as household green and red in our example.

\subsubsection{Private welfare gains}

One way that conditionality can improve effectiveness is when households do not reach their private optimum in terms of their education and health investments. Households might not reach their private optimum because they only have access to imperfect information on the benefits of education and health, because parents do not behave completely altruistically towards their children and/or because parents are myopic and therefore under-invest in education and health.

\subsubsection{Imperfect information}

Households, in particular those where parents have not been exposed to education themselves, are often misinformed about the present and future value of education for their children and therefore invest sub-optimally. They might not realize that education is a prerequisite for achieving productivity gains in the local market or they might not be adequately informed about the returns to education in communities outside. Lack of education is even more problematic when it comes to optimally combining the 
components of multi-sectoral programs that simultaneously address education, health and nutrition (de Janvry and Sadoulet 2006b).

Conditionality in this case has a signaling effect by informing households about the minimum level of education required. They come particularly into play when other approaches such as public information campaigns have not been successful in reducing simple information asymmetries (de Brauw and Hoddinott 2011). While Fiszbein and Schady (2009) argue that information campaigns might often be more cost-effective at reducing some of these information asymmetries, they also warn that wrong beliefs are self-reinforcing and that only people who would like to be informed will take advantage of such campaigns. This is especially the case when misconceptions about the preconditions for good learning or about the actual returns of education are handed down from generation to generation.

Studies by Jensen (2010) for the Dominican Republic, by Attanasio and Kaufmann (2009) for Mexico and by Nguyen (2008) for Madagascar demonstrate that expected returns to education are often substantially lower than realized returns, in particular for those children who originate from households with lower education levels. This might be due to the fact that parents have less confidence in their children's ability to absorb the knowledge taught at school. Even if they believe in their children's potential, they are often skeptical as to whether schooling outcomes per se rather than social capital translate into higher future earnings.

\subsubsection{Incomplete altruism}

Parents do not always fulfill their role of acting as an agent on behalf of their children's preferences even if they have access to all information. Some parents discount for instance the future at a higher rate or estimate a lower return rate than their children, which results in lower education and health outcomes. Empirical studies by Kochar (cited in: Das, Do et al. 2005) show that the rate of return to children's education differs significantly between parents and children and that education decisions follow the parents' rate of return. The gender differences in education and health decisions, mostly disadvantaging girls, are another example of a dysfunctional principal-agent relationship between children and parents. Parents might also decide against a better education of their children, for instance, because less education limits children's mobility and thereby serves as a guarantee to have children stay in the vicinity.

Parents themselves are not always unitary agents either. The conflict of interest and the subsequent bargaining process in the household might also be between the household head on one side and his spouse and children on the other side. This is due to the fact that the spouse, whose preferences tend to be more aligned with her children's 
preferences ${ }^{17}$, usually has a lower bargaining position in the household in most developing countries with patriarchal relations. The children, as well as the woman whose utility increases with greater welfare for the children, would therefore stand to benefit from conditionality. The value added of the conditionality when compared to just appointing the woman as the transfer recipient is that the conditionality usually affects a greater share of the income than just the transfer from government itself (Martinelli and Parker 2003).

\subsubsection{Myopia}

Even if parents have access to perfect information and behave altruistically towards their children, they make sub-optimal choices if they have a present bias. There are several reasons that explain present bias such as dynamic inconsistency of preferences, anticipation utility, habit-formation, visceral influences, projection bias and other considerations (see Frederick, Loewenstein et al. 2002 for a comprehensive overview). In our scenario where households decide against human capital investments with potentially larger pay-offs in the end, the dynamic inconsistency of preferences and visceral influences appear to be plausible reasons for myopia.

The dynamic inconsistency of preferences, hyperbolic discounting, refers to the phenomenon that sacrifices are promised when they are distant but reversed once the moment has come. This inconsistency is supported by a large body of collective evidence (Frederick, Loewenstein et al. 2002). To what extent people are prone to selfcontrol problems depends on their degree of sophistication as O'Donoghue, Rabin et al. argue (2003). Sophisticated people might not be completely immune to phenomena such as over-consumption or procrastination but they search for and respond to commitment devices, whereas more naïve people would only do that if they were either better educated or if they received incentives for using commitment devices. However, education or sensitization of naïve people should not rely too much on a demand approach as the same naïve people might also experience procrastination in information gathering.

Others have explained this impatience by attributing it to visceral influences such as hunger and other sudden cravings which present transient fluctuations in tastes. These visceral influences let certain activities appear more attractive even though people would often prefer not to succumb to those forces. In addition, people, even if they have experienced them once, tend to ignore the influence of visceral forces in the future (Loewenstein, Camerer et al. 2004).

\footnotetext{
${ }^{17}$ See evidence on the higher likelihood of women to invest in children, provided by Haddad, Hoddinott et al. (1997), Kakwani, Soares et al. (2005), Barrientos and de Jong (2006). Ezemenari, Chaudhury et al. (2002) also provide a recount of the positive evidence but also caution the reader to automatically assume that the woman will always be objective in her judgments.
} 
Myopia is problematic as households over-consume in the present - even compared to their own preferences - and their welfare is consequently lowered. Commitment devices and incentives for people to use them are proposed by several authors (Laibson 1998; Frederick, Loewenstein et al. 2002; O'Donoghue, Rabin et al. 2003) as measures of self-control. In this light, conditionality can be seen as a device to limit households' ability to trade off future for present consumption (de Brauw and Hoddinott 2011) and the cash is the incentive to use this commitment device. The same authors that propose commitment devices as a solution, however also caution their use. Laibson (1998) points to the fact that commitment devices can take away flexibility in reacting to household shocks and O'Donoghue, Rabin et al. (2003) critically remarks that prior to devising any policies for self-control problems, the magnitude of harm needs to be assessed.

The role of credit markets should not be ignored when discussing people's time preferences. When credit markets are perfect, we expect people's discount rate to affect consumption but not any investment decisions in human capital. When credit markets are imperfect, which is a likely scenario in low-income countries, parents who are restricted in their choice set might not be able to make optimal investment decisions because decisions on consumption and investment are no longer separately taken. If parents consequently do not have any other means for consumption smoothing, they might prefer greater consumption today through the earnings on child labor and the saving on school-related expenses rather than foregoing more consumption for better education and health for their children.

\subsubsection{Societal welfare gains}

Even if households reach their private optimum, this might not be optimal from a societal point of view. There could be a discrepancy between the private and social optimum because of direct positive externalities of education and preventive health care measures and/or high future social costs of under-investment in education and health. The household might not adequately factor them in when making education and health choices, because of a lack of information, a high degree of impatience and/or risk aversion on the side of the household for instance.

Das, Do et al. (2005) distinguish between two types of externalities that households often do not reflect on when making education and health decisions: physical externalities and learning externalities. Physical externalities are spill-over effects from a positive experience in one household or community to the neighboring household or community. Learning externalities refer to the benefits from initial experimentation with a new approach for other potential participants, which creates a classical free-rider scenario. 
While some empirical studies cast doubt on the importance of positive externalities, at least for Western economies (Acemoglu and Angrist 1999; Heckman 2000; Bils, Klenow et al. 2004), studies from low and middle-income countries mostly confirm their existence. In the area of health, Miguel and Kremer (2004) show that untreated students equally benefited from a deworming program in Kenya, and Handa (2000) confirms positive health externalities concerning healthcare behavior for ineligible households in Mexico. With respect to education, Kremer, Miguel et al. (2009) provide evidence on positive externalities resulting from a bursary program in Kenya for girls that had a positive effect on low-scoring girls as well as on boys. Lalive and Cattaneo (2009) show proof of a social interaction effect on schooling that is almost as great as the direct effect of the Progresa cash transfer. Positive schooling externalities in secondary schooling are equally found by Bobonis and Finan (2009). By contrast, Teixeira, Soares et al. (2011) do not detect any externalities regarding health and education outcomes.

Janvry and Sadoulet (2006b) highlight the high future costs that can result from underinvestments in education and preventive health measures such as increased crime and insecurity levels, lost labor and entrepreneurial contributions to overall economic growth, lack of informed participation to democratic practices, and continued underestimation by future parents of the value of education. The pioneering work of Heckman (2000) has also demonstrated the negative long-lasting implications of under-investment in early childhood for the development of the child and for society itself such as lower productivity and earning capacity, greater criminal potential and poor parenting practices.

In addition, it is important to realize that impatience and risk aversion restrain investments in education and health. Impatient individuals tend to be reluctant to incur investment costs today that would only be offset by returns accruing in the future; risk adverse individuals tend to shy away from investments in education and health, which are risky as returns are uncertain. ${ }^{18}$ Impatient and risk averse individuals, who make privately optimal education and health decisions, thus arrive at levels of investments in education and health that are low from a societal point of view.

Green, Myerson et al. show that impatience is more pronounced for lower-income individuals (1996) and Dohmen, Falk et al. (2010) find greater impatience among people with lower cognitive ability. Lower-income and lower cognitive ability are likely to be attributes of social assistance recipients, meaning that impatience is particularly magnified. Potential beneficiaries, coming from low-income households, have also often been characterized as extremely risk-adverse. Economists such as

\footnotetext{
${ }^{18}$ Schooling in lower grades has often been characterized as a risky investment decision for parents due to the direct and indirect costs attached, the uncertain ability of children and uncertain return rate in the labor market at the end (Belzil, C. and M. Leonardi 2007). The risk of human capital investments is furthermore increased by the fact that human capital risks are noninsurable and nondiversifiable (Shaw, K.L. 1996).
} 
Lipton (1968) up to economists behind the World Development Report (2001) have emphasized the correlation between poverty and risk aversion and limited risk coping mechanisms. This is consistent with the expected utility theory that postulates a decrease in absolute risk aversion as wealth increases. The causal chain from poverty to risk aversion to sub-optimal human decisions is however only partly confirmed by evidence. $^{19}$

\subsubsection{Political-economy arguments}

An analysis of the political institutions, actors and incentives in the decision-making process can help explain why actual policies diverge from economically optimal policies. Governments do not always represent the interests of their constituents in the decision-making process and decisions are often a result of bargaining processes, lobbying and rent-seeking, rather than just the majority position.

Even if Künnemann and Leonhard (2008) argue that cash transfers are a human right, which comes with the obligation for the state to act upon and therefore requires no further legitimacy in form of conditionality, it should not be overlooked that the way a program is designed and implemented influences its political sustainability (Hickey 2006). Conditionality is expected to buy political support for welfare programs, which tend to be politically unpopular. The unpopularity is often explained by the fact that these programs transfer resources to a narrowly targeted group of people who are too distant in terms of characteristics from the middle class and who are (partly) held responsible by society for their poverty status which is seen as resulting from bad income management or lack of motivation.

Conditionality can react to the unpopularity of a welfare program in different ways. The impact of conditionality on the unpopularity resulting from narrow targeting is ambivalent. On the one hand conditionality is meant to benefit children and women in society, increasing political acceptability but on the other hand, conditionality risks adding to the unpopularity of targeting by working as a screening mechanism that excludes the better-off. Conditionality can however transform the image of cash transfers going to undeserving individuals. As Hickey puts it: "CCT have an intuitive appeal to elites as they help make better citizens of the poor." (2006: 4) According to Lindert and Vincensini (2009), this appeal applies to the political right as well as to the political left with the Right appreciating conditionality as a contractual arrangement with clear obligations attached and the Left viewing conditionality as a re-statement of basic rights.

\footnotetext{
${ }^{19}$ For evidence on the link between wealth and risk aversion, see Binswanger (1980), Wik, Kebede et al. (2004), Yesuf (2004), Mosley and Verschoor (2005), Tanaka, Camerer et al. (2010). For evidence on the relationship between risk and human capital decisions, see Belzil and Leonardi (2007) for education and Hammitt and Haninger (2010) for health. 
By adding requirements to the transfer, the conditionality introduces an element of control preventing households from consuming demerit goods or engaging in socially undesirable activities. It also introduces an element of reciprocity, asking the individual to actively graduate out of poverty, to reduce the risk of falling into poverty again and to prevent the coming generation being equally dependent on social welfare. In this way conditionality can be seen as a guarantee that society shares the burden fairly across generations. All of these attributes of conditionality are likely to resonate well with different types of taxpayers, ranging from the paternalistic taxpayer who likes to control, the prudent taxpayer who prefers to take precautions up to the selfish taxpayer who likes to limit any possible negative effects for him/herself (Barrientos 2011).

In addition, conditionality might also enhance the effectiveness of a program, which tends to increase political acceptance levels. It can also have important signaling effects in terms of the performance of government, which is important given that "politicians and policy makers are often evaluated by performance indicators" as de Brauw and Hoddinott state (2011: 359). Conditionality assists policy-makers in demonstrating success such as positive enrolment statistics and frequent use of preventive health services long before the actual impact evaluation has been carried out. This might be particularly crucial in countries which are donor dependent and where donors demand observable measures of performance within a short period of time as they are equally accountable to taxpayers in their respective countries (Das, Do et al. 2005).

Following the argumentation by Coate and Morris (1995) we can furthermore assume that politicians would favor CCTs over pure cash transfers if they are interested in corrupt practices benefitting their constituencies or special interest groups. Having conditionality that turns the transfer more into a project would result less in a reputational penalty for politicians than direct transfers.

In as much as conditionality can make the outcome more predictable and serve as a guarantee to the middle class or the donors of a country that they are getting value for money, conditions can also have negative political consequences if they foster corrupt practices, if conditions are not fulfilled by beneficiaries or if conditionality renders a program too complex, expensive and less efficient. Britto (2004) points out that noncompliance on the part of beneficiaries for instance leads to a withdrawal of political support by the middle class. This sentiment was also reiterated in interviews with Zambian stakeholders (Schüring 2010a).

\subsubsection{Empowerment arguments}

By turning the welfare payment into a contractual agreement between the state and the beneficiaries to which both parties make a contribution, conditionality can reduce the stigma that is usually attached to social assistance programs and thereby increase the 
potential take-up rate of SCT (de Brauw and Hoddinott 2011). As Fiszbein and Schady (2009: 10) state, "when conditions are seen as co-responsibilities, they appear to treat the recipient more as an adult capable of agency to resolve his or her own problems".

This might be the reason why several authors such as de la Brière and Rawlings (2006), Cohen and Franco (2006) or de Janvry and Sadoulet (2006b) have characterized CCT programs as less paternalistic than unconditional programs and have emphasized the contract character of conditionality with a provision of penalties in case obligations are not fulfilled. Conditionality might also be regarded as empowering because it permits the beneficiary household to realize outcomes that it desires but fails to attain due to informational asymmetry or present bias. This can give beneficiaries control over their decisions and increase their feeling of autonomy (for evidence in psychology, see: Corrigan 1997).

A number of authors are skeptical of these empowerment effects (Schubert and Slater 2006; Freeland 2007; Standing 2007) and consider conditionality to be paternalistic as it is based on the assumption that the government cares more about the welfare of the next generation than parents themselves. Veit-Wilson (2009) criticizes that conditions are often set for people but not together with people, which is even more critical in regimes that people themselves cannot shape and influence. It might also be questionable whether a system of co-responsibilities where only one party to the contract can be penalized is really empowering. Co-responsibility would normally mean that parents could also take the service providers to task if services are not adequately provided. This is however rarely the case in SCT programs in low-income countries.

Another dimension of empowerment is the strengthening of women's position in society as well as in the household. Conditionality is said to increase the bargaining position of the woman in the household, institutionalizing her preferences (Martinelli and Parker 2003). In addition, the courses on different topics women are asked to attend as part of conditionality (at least in a number of Latin-American countries) are meant to strengthen women's self-confidence, broaden their perspective and encourage them to speak out and move freely. According to Adato and Hoddinott (2007) conditionality can furthermore legitimize social change such as equal access for girls and boys to education and health services. Authors such as Molyneux (2006) and Bradshaw (2008) are more critical of these gender effects, pointing to the fact that conditionality reinforces traditional gender roles and responsibilities without changing the status and decision-making power of the woman.

\subsubsection{Equity arguments}

Information asymmetries between the government and the population lead to adverse selection problems for social assistance programs. Individuals have an incentive to 
provide wrong information about themselves and their household in order to qualify for the program. This incentive is even greater in low-income countries where information provided by potential beneficiaries is often very difficult and costly to verify due to lack of infrastructure, lack of administrative capacity, lack of functional registration systems or of reliable external sources for verification.

Conditionality can improve the targeting efficiency of a SCT program by decreasing the attractiveness of the transfer to those households that are ineligible and would either be unwilling to bear additional costs or shy away from public appearances to get conditionality cards verified and stamped. In this way, households voluntarily reveal information about their characteristics with no additional expensive verification required. Such a screening mechanism can be particularly useful for countries where means tests are logistically or politically unfeasible (Das, Do et al. 2005). Equally highlighting the merits of self-selection, Blackorby and Donaldson (1988) show in their model that in the case of imperfect information for the government, an in-kind transfer, which is implicitly conditioned, is superior to a cash transfer. De Janvry and Sadoulet (2006b) highlight another way as to how conditionality can increase equity; they argue that conditionality contributes to a higher program take-up rate among eligible beneficiaries due to the positive empowerment effects they experience.

The challenge is to design conditionality in a way that it screens out ineligible households but not eligible households for whom the compliance costs can also be prohibitively high. Further information on screening-out effects of qualifying households is provided in section 2.4.2.4 and 2.4.2.5.

\subsection{Inefficiencies of conditionality}

While the arguments in section 2.3 demonstrate that conditionality can make a SCT program more effective and politically acceptable, there are a number of factors that can actually offset these gains and even lead to an efficiency loss. If conditional programs have indeed a tendency to be self-sustaining even if proven inefficient (Bougheas, Dasgupta et al. 2007), there is an even greater need to carefully study the potential inefficiencies before launching conditionality. The inclusion of conditionality can produce different types of inefficiencies. Conditionality can for instance provoke negative behavioral side effects such as undesirable behavior in unconditioned areas or demotivation. Conditionality can also be sub-optimally designed and/or its implementation can produce significant costs and be challenging to handle for the administration. It is crucial to realize that not all inefficiencies carry the same weight: while some design inefficiencies can be avoided through a careful design that is tailored to the country context and some implementation inefficiencies might be transitory in nature, others such as negative behavioral side effects are more difficult to tackle as they intrinsically relate to the nature of conditionality. 
Most theoretical discussions mention drawbacks of conditionality (Das, Do et al. 2005; de Janvry and Sadoulet 2005; Bastagli 2008; Fiszbein and Schady 2009; Barrientos 2011) but not all of them do this in the most systematic way, disentangling the different factors that produce inefficiencies. Behavioral side effects are the ones which are least discussed by any of the authors with the exception of unintended behavioral consequences illustrated by Bastagli (2008) and Das, Do et al. (2005). Implementation challenges are mentioned by different authors (de Janvry and Sadoulet 2005; Bastagli 2008) but not always sufficiently problematized in the context of low-income countries.

\subsubsection{Behavioral side effects}

Table 2.1: Implications of behavioral side-effects

\begin{tabular}{|l|c|l|}
\hline \multicolumn{2}{|l|}{ Behavioral side effects affect: } \\
\hline \hline $\begin{array}{l}\text { Private \& societal welfare } \\
\text { gains }\end{array}$ & - & $\begin{array}{l}\text { Negatively affected if behavior in unconditioned areas } \\
\text { cancels out the positive behavioral change in conditioned } \\
\text { areas, leading to overall undesirable household behavior } \\
\text { - }\end{array}$ \\
\hline Political economy & - & $\begin{array}{l}\text { Negatively affected if behavioral side effects lead to a higher } \\
\text { drop-out rate among beneficiary households and to a reversal } \\
\text { of impact due to undesirable behavior in unconditioned areas }\end{array}$ \\
\hline Empowerment & - $\begin{array}{l}\text { Negative motivation effects might increase the distrust vis-à- } \\
\text { vis government and lead to disempowerment }\end{array}$ \\
\hline Equity & - $\begin{array}{l}\text { Could be worsened if negative motivation effects lead to } \\
\text { higher drop-out among beneficiaries }\end{array}$ \\
\hline
\end{tabular}

Conditionality can lead to unintended consequences in terms of distorting decisions in unconditioned areas or in terms of having negative motivational effects and reversing the desired behavioral change in the long run. This means that if one does not only care about target behavior in conditioned areas but also about household behavior in general, these negative behavioral effects might undo any positive behavioral gains. The negative motivation effects might, at least in the long run, affect household behavior and reverse any gains in private welfare and could also lead to disempowerment. See table 2.1 for a more detailed overview of how behavioral side effects reduce the effectiveness of conditionality.

\subsubsection{Negative behavioral effects in unconditioned areas}

The compliance with conditionality might motivate or oblige households to alter consumption choices in unconditioned areas, which could in the end lead to an overall sub-optimal outcome. If there is for instance an education condition in the program and households substitute a greater variety and quantity of food for all household 
members for the required amount of education, then this behavioral change might not be welfare-enhancing for the entire household.

Davis, Handa et al. (2002) raise concerns that Procampo, a program conditioned in the area of agriculture, led to an overinvestment in agriculture, shifting expenditure away from non-agricultural investments. This might be an example where conditionality can channel resources away from higher return activities in other economic fields. The fact that Procampo has even led to a decrease in school expenditure, possibly because more labor was required for the additional agricultural investments, is equally a sign of how conditionality might produce negative side-effects in unconditioned areas.

In Malawi, the conditionality in the Zomba experiment (see 2.5.1.4 for further information about the experiment) equally dampened the effects in unconditioned areas. Only the UCT had a significant impact on reducing early marriages and childbearing among girl beneficiaries by $44 \%$ and $27 \%$ respectively (Baird, McIntosh et al. 2011). This effect is mostly noticed among the school-dropouts who continued receiving financial support as beneficiaries of a UCT and therefore maintained some financial independence. While girls receiving UCTs in Malawi were 38\% less likely to suffer from mental health problems, the probability was more than halved (down to 17\%) for girls receiving CCTs (Baird, de Hoop et al. 2011).

\subsubsection{Negative motivation effects on (re)-engagement}

Whereas standard economic theory highlights the positive impact of incentives on individuals' efforts, latest theories and evidence from psychology and experimental economics provide more controversial results (Kremer, Miguel et al. 2009). Insights from these disciplines show that conditionality can actually have a negative impact on the engagement or the re-engagement of those who are intrinsically motivated to carry out the activities that are conditioned. The conditionality might be perceived as a controlling device or as lack of trust; people might lose their intrinsic motivation and discontinue the activity when the external reward is terminated. Furthermore, this negative effect on intrinsic motivation can spill over to other areas or even influence fellow citizens.

In psychology, different theories point to the potential of extrinsic motivators to exert a negative impact on intrinsic motivation. Cognitive evaluation theory mentions two oppositional forces that influence intrinsic motivation (Deci, Koestner et al. 1999): extrinsic rewards can be negatively perceived as controllers of behavior or positively as an indicator of competence. Attributional approaches share the concerns expressed by the cognitive evaluation theory: they suggest a negative impact through an overjustification effect where an external reward makes people attribute the activities undertaken to the external reward rather than their own motivation. Behavorists in psychology have highlighted negative as well as positive forces that affect intrinsic motivation: negative forces such as the feeling of helplessness when rewards are 
general in nature and not tied to specific outcomes and positive forces such as learned industriousness when rewards depend on the quality of performance.

A meta-study by Deci, Koestner et al. of over 100 experiments depicts a rather clear and consistent pattern of negative motivation impacts across different psychological experiments conducted. Only verbal rewards had a positive impact on motivation and unexpected or non-contingent rewards were neutral. This negative effect on the individual's motivation can have substantial consequences as Frey (2008) demonstrates: quality of performance is substituted by quantity; negative actions that are sanctioned are repeated as the bad conscience is paid off through the sanction and indirect damaging effects are transferred onto other fields and people. These conclusions are however not uncontested. Another meta-study by Cameron, Banko et al. (2001), using a different methodology, does not find pervasive negative effects on intrinsic motivation and shows that intrinsic motivation was maintained or strengthened when participants had to meet a specific criterion or were enticed to outperform fellow participants. Evidence from the contingency management literature shows that incentivizing behavior can be successful in treating drug abuse or obesity problems but that people resume old behavior patterns once the incentive is removed (Medlin and de Walque 2008).

Evidence from experimental economics has supported the findings of negative motivational effects from psychology. Benabou and Tirole (2003), developing an economic model to explain the effects of extrinsic rewards on intrinsic motivation, demonstrate that even if incentives increase performance in the short term, they can have a demotivating effect once they are removed. These findings are also endorsed by the studies on long-term effects of economic incentives to promote preventive health behavior that Kane, Johnson et al. (2004) reviewed. They all show that behavior had eventually returned to original levels. Fehr and Gächter (2001) find evidence that material incentives crowd out fairness-driven voluntary cooperation and lead to an efficiency loss of the contract and lower effort levels of the agents. Falk and Kosfeld (2006) illustrate that agents' intrinsic motivation is negatively impacted by control devices that are perceived as a signal of distrust.

There is some evidence of conditionality leading to emotional stress for beneficiaries, which can have demotivating effects. As alluded to in 2.4.1.1, psychological distress mounted with every additional dollar of conditional cash transferred in the Malawi experiment, showing that girls might have felt uncomfortable handling the pressure of having their entire family depend on their actions (Baird, de Hoop et al. 2011). The condition on adequate weight gain in Nicaragua, even at the time when it had already been officially discontinued, also added more stress to beneficiaries' lives (Adato and Roopnaraine 2004). Unfortunately, there is very limited evidence from CCT programs on the extent to which the desired behavior change lasts beyond participation in the program. This is due to the fact that CCT programs are still a fairly recent phenomenon 
and that they often stop when the conditioned behavior is no longer required, i.e. when children have completed school or all antenatal checks have been carried out.

\subsubsection{Sub-optimal design of conditionality}

The design of conditionality might be sub-optimal and reduce the effectiveness of a SCT program. Conditionality is inefficient if it promotes already existing behavior, leads to sub-optimal behavior or if constraints in accessing good and services are not predominantly behavior-related and alternative approaches would be more costeffective. Conditionality is equally inefficient if it asks for too much in exchange for the money and excludes qualifying beneficiaries.

Table 2.2: Implications of a sub-optimal conditionality design

\begin{tabular}{|c|c|}
\hline \multicolumn{2}{|c|}{ A sub-optimal design affects: } \\
\hline $\begin{array}{l}\text { Private \& societal welfare } \\
\text { gains }\end{array}$ & $\begin{array}{l}\text { - Limited and possibly no effect if behavior is not the } \\
\text { actual problem and if eligible beneficiaries are screened } \\
\text { out } \\
\text { - Inefficient if behavior is already optimal or if a more } \\
\text { cost-effective instrument could be chosen } \\
\text { - Negative effect if sub-optimal behavior is promoted }\end{array}$ \\
\hline Political economy & $\begin{array}{l}\text { - Negatively affected if there is a high drop-out rate or if } \\
\text { inefficient instruments are chosen for either an } \\
\text { improvement in education / health or a behavioral } \\
\text { change }\end{array}$ \\
\hline Empowerment & $\begin{array}{l}\text { - Negatively affected if either sub-optimal behavior is } \\
\text { promoted or if beneficiaries are excluded due to sub- } \\
\text { optimal programming }\end{array}$ \\
\hline Equity & $\begin{array}{l}\text { - Negatively affected if qualifying beneficiaries are } \\
\text { excluded due to an insufficient transfer amount or other } \\
\text { constraints that they cannot influence }\end{array}$ \\
\hline
\end{tabular}

The promotion of existing or sub-optimal behavior through conditionality means that gains in private and societal welfare cannot be realized. In the case of the promotion of sub-optimal behavior, beneficiaries might actually decide to leave the program, which negatively affects equity. If behavior is not the actual problem behind the sub-optimal use of health and education services, then conditionality will not have any impact on the private and societal welfare. Not having considered alternative, more cost-effective instruments influences predominantly the private and societal welfare as more or the same level of effectiveness could have been achieved with less or the same. The exclusion effects through inadequate conditions or an inadequate amount also have a negative bearing on equity and subsequently on empowerment as well as the political 
economy behind. See table 2.2 for a more detailed overview of the different effects of a sub-optimal design of conditionality.

\subsubsection{Promotion of existing behavior}

CCTs are inefficient if they are paid to households / individuals who already display the required behavior (Das, Do et al. 2005; de Janvry and Sadoulet 2006b). In the case of conditionality in education, this would mean that transfers are paid to households who already send their children to school on a regular basis and where no behavioral change is required. In Mexico for instance, conditionality for primary school would not be a cost-effective choice as close to $97 \%$ of all children are enrolled (de Janvry and Sadoulet 2005). Even when encouraging the transition to secondary school, de Janvry and Sadoulet demonstrate that effective transfers, going to those who only enroll when offered a transfer, amount to $12 \% ; 64 \%$ of the transfer volume would go to children who would progress to secondary school even without the transfer.

\section{Figure 2.4: Inefficiency of conditionality when promoting existing behavior}

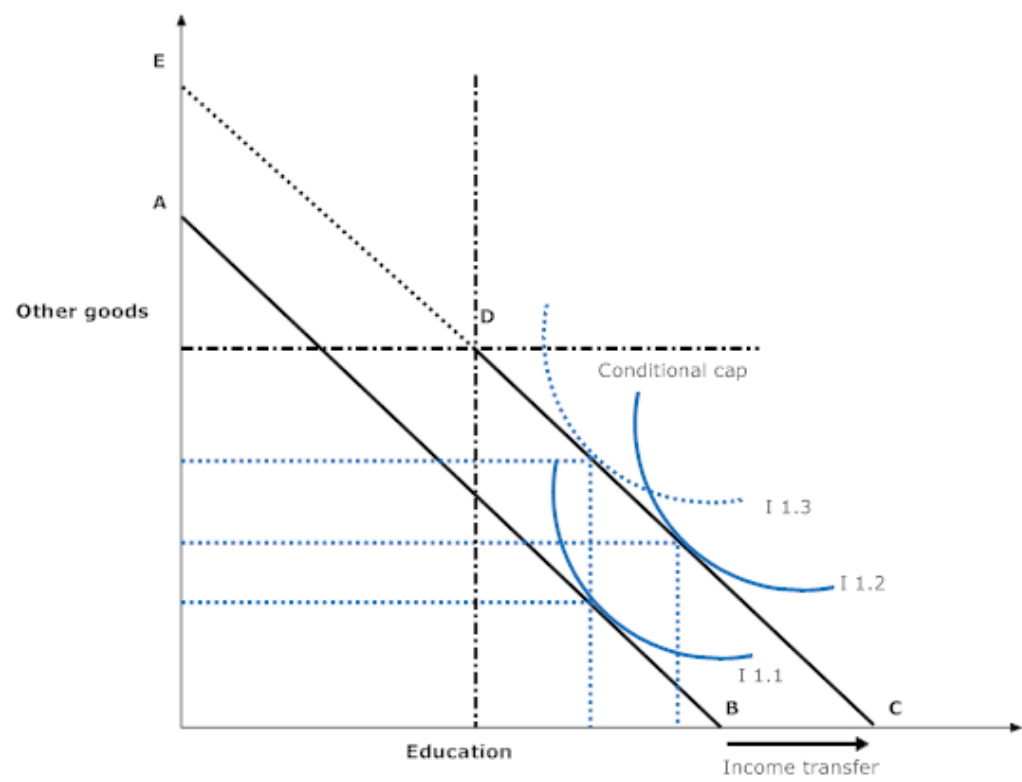

The graph in figure 2.4 presents household blue who already invests more in education than is required and who would not necessarily need the transfer. The transfer increases the welfare of the household as the household shifts to a higher indifference curve from for instance I 1.1 to I 1.2 but if the objective of the transfer is to increase education levels in the country, the transfer might not deliver the desired outcome. Household blue might move to I 1.2 after the income transfer in which case the transfer still fulfills its purpose but household blue might also opt to keep the level of education 
investments constant and to invest the additional income in other goods and services as depicted by I 1.3. This is possible as money is fungible. In this way money would be spent inefficiently as the objective of increasing education levels would not be attained. Education choices might even be adjusted downwards to the required level of the conditionality if households interpret the conditional cap as the desirable investment level.

This can be avoided by either changing the conditionality if the primary objective of the program is to increase the welfare of this particular group in society or by adjusting the target group if the objective of the program is to improve educational outcomes. ${ }^{20}$

\subsubsection{Promotion of sub-optimal behavior}

Conditionality can distort households' consumption and potentially investment choices and thereby lower the welfare of households. Martinelli and Parker (2003) problematize that conditionality could lead to an over-accumulation of human capital and point out that the effectiveness of conditionality greatly depends on whether conditions are placed on activities that actually lead to an increase in human capital. This might not always be the case in areas or countries where a CCT program operates. If for instance the quality of growth checks for children under five is low while (in)direct costs for parents are high or if beneficiary girls face discrimination and abuse at school, it might be a sensible decision for households to not access these health and education services or to utilize them less frequently. The case of Nicaragua, where a conditionality on adequate weight gain for children under five resulted in some households overfeeding their children right before the check-up (Adato and Roopnaraine 2004), exemplifies how conditionality can promote sub-optimal behavior.

Conditionality can also lead to an under-accumulation of human capital (Kidd and Calder 2011). Policy-makers usually express leniency in fixing conditions. Whereas the optimal attendance rate would be $100 \%$, they might lower the required attendance rate to $85 \%$ to not risk punishing households for events that are out of their control. In this way, conditionality could also lower the benchmark for health and education choices and encourage those households who make optimal choices from both their own as well as the societal perspective to reduce their participation rate.

The market outcome might consequently be optimal from a household perspective and only be misperceived by the social planner as sub-optimal. For conditionality to reduce and not produce sub-optimal behavior, there needs to be assurance that the social

\footnotetext{
${ }^{20}$ De Janvry and Sadoulet (2005) compare different targeting and calibration schedules to optimize SCT and conclude that variable transfers targeted predominantly to those with a low probability of attending school results in an efficiency gain of $43.6 \%$ over a universal uniform conditional transfer program. Even for what they call an implementable program with more simplified criteria, the efficiency gain still lies at $29.4 \%$.
} 
planner is better informed about the private costs and benefits of conditionality than the household itself.

\subsubsection{Suboptimal measure}

Conditionality can only address constraints that are related to the behavior of households and do very little in terms of households' supply side and financial constraints. Evidence on the relative cost-effectiveness of demand- and supply-side interventions is often scarce. Kane, Johnson et al. (2004) point out in their review of economic incentives that only 7 out of 47 studies provided cost-effectiveness calculations and that in 5 out of 7 studies, similar interventions without the incentive proved more cost-effective.

When analyzing the heterogeneity of impact on school enrolment in Progresa, de Janvry and Sadoulet (2005) conclude that a demand-side intervention only has limited impact on those children who live further away from school and that a supply-side intervention such as school transportation or the building of additional schools would be more effective. Assessing reasons for uptake failure, they furthermore propose complementary interventions on the supply-side as well as increased assistance for children originating from uneducated households. In Nicaragua, Honduras and Colombia - countries that are poorer than Mexico - demand-side strengthening has not resulted in bringing those $10-15 \%$ of children back to school who are at present not enrolled in school, mainly due to lack of access to school (Handa and Davis, 2006).

With respect to Africa, Handa and Davis (2006), using data from Mozambique, compare demand-side with supply-side interventions and come to the conclusion that the former would be the least cost-effective choice. Schubert and Slater (2006) conclude that, in the case of Zambia, the quantitative and qualitative supply side constraints lie at the heart of the problem rather than the unwillingness of children and their families to invest in education. Lund, Noble et al. (2008) also highlight the predominance of supply-side constraints in South Africa - such as resources, facilities, management and teaching/health practices - in preventing children from accumulating human capital and escaping from poverty in the long term.

The Abdul Latif Jameel Poverty Action Lab (2010) compared the cost-effectiveness of different education measures across countries and demonstrated that among demandside interventions, the provision of information on returns of education in Madagascar and the deworming initiative in Kenya were the most successful interventions (figure 2.5). On the basis of their educational outcomes alone, CCTs do not come out as a particularly cost-effective option. Even if it is debatable as to whether these programs across countries are really comparable due to different country contexts, constraints in education as well as potential differences in how programs are run, the illustration points to the importance of cost-effectiveness analysis before costly interventions are implemented at great scale. 


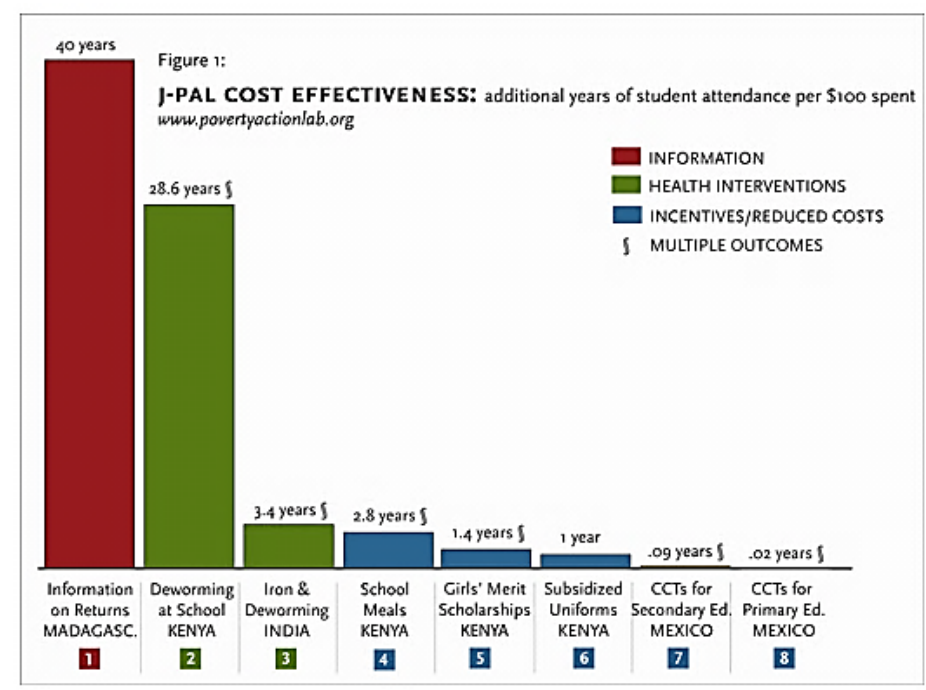

Extra Years of Education per $\$ 100$ Spent

Source: Abdul Latif Jameel Poverty Action Lab

Consequently, before using conditionality, the primary barriers to education and health have to be carefully analyzed. In most countries where a cash transfer program was introduced, no prior analysis was conducted on whether problems were mostly demand- or supply-side related (Handa and Davis 2006). This criticism is echoed by Kane, Johnson et al. (2004) who show that out of 47 studies on economic incentives only three studies provided a justification for the incentive chosen and the majority employed a condition on services that had not proven adequately cost-effective themselves.

In addition, if the supply side is the main barrier, the negative effects of imposing conditionality should also be considered. If conditionality works, then it stimulates more demand than a mere income transfer and might therefore negatively impact on the capacity of schools and health centers to absorb more people and still offer quality services. This not only disadvantages beneficiaries but also all the other households who come without additional incentives.

Even if prior analysis has shown that behavior of households presents a great barrier to using social services such as education and health, conditionality is not always the most cost-effective tool to affect behavioral change. It is important to first analyze the forces that are at work behind the behavior in order to effect change (Kane, Johnson et al. 2004). Information campaigns that offer parents an opportunity to understand the value of using social services or more intensive social-counseling that allow parents to express their concerns and problems can be more effective and come at a lower cost 
than conditionality. These alternative approaches might also propel a real behavior and attitude change that can be sustained even when the transfer comes to an end while the behavior change induced through conditionality might not last longer than the transfer itself.

In Ecuador, the mere signaling effect of conditionality, without actual enforcement, proved sufficient to change the behavior of beneficiaries (Schady and Araujo 2008). Barrientos and de Jong (2004) equally suggest that once beneficiaries have internalized the information about entitlements and responsibilities, non-compliance is rare even if conditionality is not rigorously enforced. ${ }^{21}$ These findings are not confirmed by Teixeira, Soares et al. (2011) who exploit the fact that not all households in Paraguay were visited by a social worker and / or were aware of conditionality to determine which factors were most decisive in causing the behavioral change. They find that differences in social worker visits and conditionality awareness did not lead to differences in education and health behavior.

\subsubsection{Exclusion effects due to the inadequacy of the amount}

The monetary transfer has to allow the beneficiary to comply with conditionality, e.g. that it caters for any additional expenses that the household incurs in meeting the conditions such as fees, transport costs or opportunity costs. Coady, Perez, and VeraLlamas (2005), using data from Progresa, calculate that recipients' private costs in a conditional program are twice as high as the private costs of recipients in an unconditional program.

An insufficient transfer amount is problematic. Take for instance household green in Figure 2.6 who receives a $\mathrm{CCT}$ that moves his budget line from $\mathrm{AB}$ to $\mathrm{CDH}$ so that the household can invest the required amount in education as demarcated by point $\mathrm{D}$. If the compliance costs moves the budget line back to FGH because of higher costs incurred and income forgone, household green will no longer be in a position to comply with conditionality. Meeting the condition would mean for household green that it would have to substitute away some of the other goods, which the household would decline to do. Household green would therefore either refuse to participate in the program from the onset or would be screened out in case the conditions are rigorously enforced. This means for the government that a chance to optimize the education investments of this household and to increase its welfare would be forgone. If this change in education and welfare can only be achieved at a relatively high cost through the instrument of conditionality, we might also inquire as to whether conditionality is indeed costeffective, as discussed in 2.4.2.3.

\footnotetext{
${ }^{21}$ Such flypaper / labeling effects do not conform to economic thinking that presupposes that individuals treat their income from different sources as fully fungible but have been confirmed through experimental evidence.

40
} 


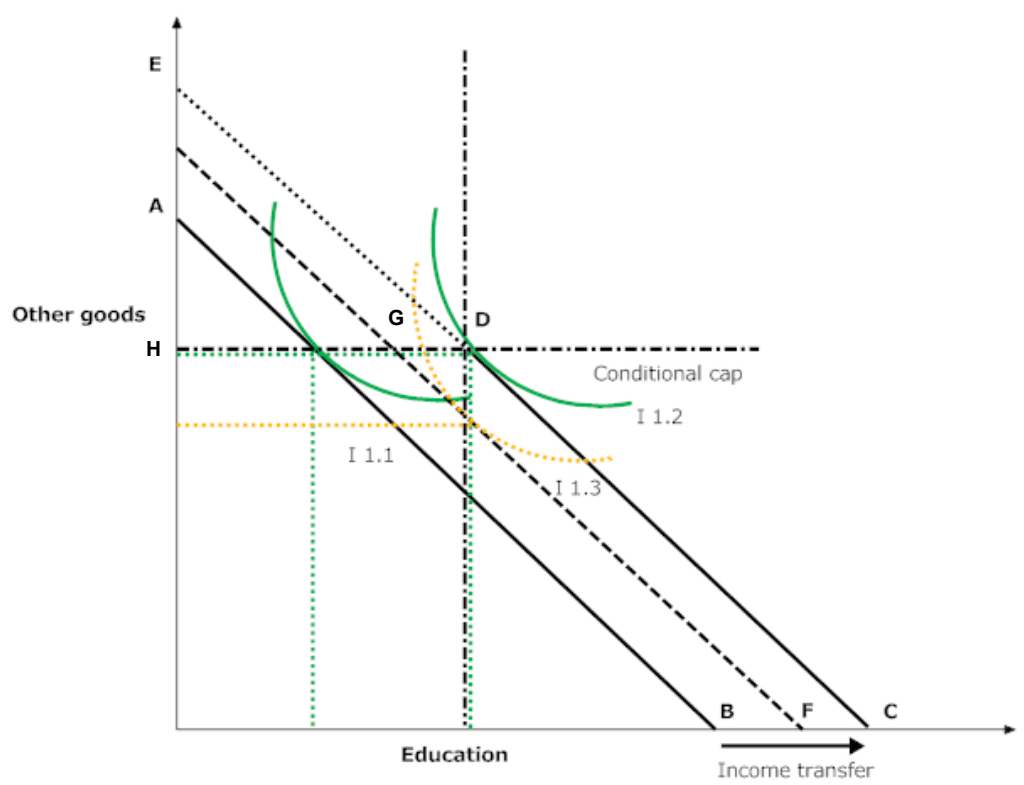

Next to being adequate, the transfer also has to be paid on a regular basis as irregularities in the payment process might force households to reduce the utilization of conditional services and lead to non-compliance and expulsion.

\subsubsection{Exclusion effects due to factors beyond beneficiaries' control}

There are other factors that prevent beneficiary households from accessing the conditioned services such as unavailability, irregularity or low quality of respective health and education services (Barrientos and de Jong 2006). Poverty, culture, social exclusion, discrimination and other historical processes might also hamper households' access to social services (Adato and Hoddinott 2007). Beneficiary households in Nicaragua complained about being punished for errors by teachers in registering information as well as for their children's sickness (Adato and Roopnaraine 2004). These factors are beyond beneficiaries' control and not easily overcome through an incentive system. Besides, outcome-related requirements such as the completion of a particular grade or the attainment of a particular grade point average might exacerbate the exclusion of qualifying, low-performing households as performance does not only depend on motivation and financial means, but also on ability, the learning environment and other factors.

As discussed in 2.4.2.4, excluding qualifying households comes at a cost because potential poverty reduction effects are not realized. Some programs tried to avoid this 
problem by introducing exemptions for certain households. The downside of exemptions is that they lead to higher administrative costs and might also incentivize other households to present their non-compliance as inability. One has to therefore carefully weigh the advantages and potential costs of exemptions. Another form of exemption is not to offer a CCT program in regions where health and education services are not available. This artificially solves the problems concerning the inability to comply with conditionality, but still leads to poverty reduction effects being foregone.

Teachers in Colombia and Argentina practiced exemptions by promoting children into the next year despite poor academic performance and ensured by doing so that poor households were not denied the transfer (Heinrich 2007). Even though this form of exemptions prevents poverty reduction effects being foregone, it might set a precedent for corrupt practices and prove counterproductive for constructively solving children's learning deficits.

\subsubsection{Implementation inefficiencies}

The implementation of a CCT program that involves different social ministries can present a unique opportunity to better institutionalize inter-ministerial coordination (Barrientos 2011). The greater need for information and data exchange should in principle lead to a better harmonization of social services. By promoting better collaboration and joint problem solving, conditionality can help improve service delivery, motivating countries like El Salvador to further invest in measures to strengthen the supply side or countries like Jamaica to implement joint targeting solutions (for country examples see: Fiszbein and Schady 2009). Better coordination might also prevent inter-ministerial rivalries and subsequent budget cuts in social spending (Samson, van Niekerk et al. 2006).

Despite these promising side-effects for the administration of conditionality, there are a number of inefficiencies related to the implementation of conditionality. The monitoring of compliance with conditionality and the subsequent enforcement do not only produce higher (in) direct costs but also additional capacity challenges for the administration and potentially higher corruption in-country. Implementation inefficiencies might negatively affect the private and societal welfare gains if the administration devotes less time to other critical services that beneficiaries and their community members use. Beneficiaries might also feel less compelled to change their behavior if the administration does not regularly monitor conditionality compliance due to capacity constraints. Implementation inefficiencies can negatively impact the political economy if the overall service quality is lowered, if administrative costs skyrocket and if corruption levels rise. See table 2.3 for a more detailed overview of the different effects of implementation inefficiencies. 
Table 2.3: Implications of implementation inefficiencies

\begin{tabular}{|l|ll|}
\hline \multicolumn{2}{|l|}{ Implementation inefficiencies affect: } \\
\hline \hline $\begin{array}{l}\text { Private \& societal welfare } \\
\text { gains }\end{array}$ & $\bullet \begin{array}{l}\text { Negatively affected if overall quality of services } \\
\text { provided by the Ministry in charge decreases } \\
\text { - }\end{array}$ & $\begin{array}{l}\text { Negatively affected if Ministry in charge does not have } \\
\text { the capacity to monitor behavioral compliance and } \\
\text { beneficiaries resort to old behavior patterns }\end{array}$ \\
\hline Political economy & $\bullet \begin{array}{l}\text { Negatively affected if service quality decreases, } \\
\text { administrative costs skyrocket and corruption is } \\
\text { fostered }\end{array}$ \\
\hline Empowerment & $\bullet$ & $\begin{array}{l}\text { Potentially affected if capacity constraints translate into } \\
\text { inappropriate treatment of beneficiaries }\end{array}$ \\
\hline Equity & $\bullet$ & $\begin{array}{l}\text { Only negatively affected if capacity constraints hinder } \\
\text { beneficiaries from complying with conditionality }\end{array}$ \\
\hline
\end{tabular}

\subsubsection{High direct / indirect costs for the administration}

Conditionality can increase administrative costs and also raise the opportunity costs of the intervention as the extra time invested in managing and monitoring conditionality cannot be availed to the provision of other social services. In order to determine the cost-effectiveness of the intervention and see whether additional costs are warranted by the greater gains through conditionality, it is important to have a precise idea of the direct and indirect costs attached to conditionality.

Very few studies have been conducted to calculate those costs and use these results to analyze whether conditionality is indeed a cost-effective instrument. Given the otherwise rigorous impact evaluations and studies done around CCT programs, this finding is surprising. Fiszbein and Schady (2009) partly attribute this to the fact that some of the costs are borne by the service providers directly. Coady, Grosh et al. (2004) cite the unavailability of detailed administrative data as the principal reason.

Coady, Perez et al. (2005) estimate that after deducting the actual transfers, the conditionality component was the third largest cost item of Progresa (18\%), following targeting and the delivery of benefits over the period from 1997 to 2000. Most of the time of program staff was allocated to the certification of responsibilities, out of all activities. Caldés, Coady et al. (2006) extend the cost analysis to two more countries, Nicaragua (RPS) and Honduras (PRAF) and show that all three countries spend considerable resources on conditionality, ranging from 16 to $27 \%$ of program costs if transfer costs and fixed costs such as an external evaluation and program design are excluded. These costs could even be higher if conditionality was properly administered, which was not the case in Nicaragua and Honduras at the time when the calculations were made (Caldes, Coady et al. 2006). 
Further ballpark figures are provided by Grosh, del Ninno et al. (2008) who suggest that the costs for conditionality amount to $1-3 \%$ of total program resources, assuming that monitoring compliance takes about the same share of administrative costs as payments and targeting.

\subsubsection{Capacity constraints}

Conditionality cannot only be a strain on the budget but also on the capacities of an administration due to the additional layer of complexity they add to the program (Tabor 2002). They involve several stages in the implementation process from informing beneficiaries, training the administration, ensuring regular monitoring of compliance to enforcing decisions, which means either counseling beneficiaries, reducing transfers or taking beneficiaries off the program. In order to ensure professional management, information needs to flow on a regular basis and has to be well-managed. Management information systems that interlink data from different social ministries are, however, still in their infancy in most low income countries despite significant improvements over the past couple of years.

Such management complexity can result in a chaotic implementation process, demotivation of staff, potentially the non-provision of other key services and eventually even in the failure of the program. Beneficiaries might also decide against any behavioral changes if they notice that the administration does not have sufficient capacity to monitor their behavior. While the case of Ecuador has shown that even unenforced conditionality can have an impact, at least in the short run, programs which are conditional on paper and unconditional in practice also come with certain risks. They might not only waste valuable resources and therefore minimize potential poverty effects but also lead to a loss of credibility of the Ministry or agency in charge (Regalia 2006).

These negative implications are of particular concern to low income countries where Ministries of Social Affairs are typically understaffed and do not always have personnel with the necessary qualifications. Bastagli stresses how difficult it is to obtain statistics of non-compliance and enforcement in saying "where information exists, it confirms the irregularity with which monitoring and responses to conditionality compliance are implemented" (Bastagli 2008).

Even countries like Brazil faced - at least initially - huge implementation challenges (Fiszbein and Schady 2009). In 2004, only 33\% of all education providers reported on conditionality compliance and two years later, when education saw an increase to $93 \%$, health reporting still lagged behind with $55 \%$. Despite the fact that conditionality monitoring and enforcement has improved in Indonesia over the last year, at least for the education sector, the spot check report from 2010 highlights challenges ranging from the delivery and completion of monitoring forms to data entry and management (Center for Health Research University of Indonesia 2010). 
The situation proves even more challenging for low-income countries. In Zambia, the Social Ministries failed jointly in monitoring conditionality with problems of miscommunication, under-reporting and incorrect and incomplete reporting (see section 4.6.2). This experience is partly shared with Kenya where the administration of monitoring forms and communication with beneficiaries was also problematic (Ward, Hurrell et al. 2010) and where in particular the health facilities faced capacity constraints and were hindered by inadequate resources and training (Kimetrica 2010).

What kind of impact the service provider has on the effective management of conditionality and the subsequent drop-out rate is shown by Alvarez, Devoto et al. (2008) with Progresa data. According to their analysis, which does not control for health and community variables, there is a 15 percentage point difference in drop-out rates of beneficiaries between two different health providers. If schools and health centers are already over-crowded and no additional support is offered, an additional demand-stimulus might overtax the system and inconvenience those who already invest optimally in these services. This might in return negatively affect popular support for the program (Samson, van Niekerk et al. 2006).

\subsubsection{Promotion of corruption}

Staff who certify conditionality are in a particular position of power vis-à-vis beneficiaries and might also take advantage of their position. They could for instance ask for money in exchange for favorable reporting or they could force beneficiaries not to complain about the services being delivered. This would block change on the demand and supply side as well as better outcomes in education and health. Corruptive practices also include service providers twisting the rules in favor of certain clients as was the case in Colombia and Argentina (Heinrich 2007) as well as Nicaragua (Moore 2009) and Kenya (Ward, Hurrell et al. 2010). Granting exemptions can be a benevolent act on the side of the service provider but this discretionary power - when granted - can easily be used for bending the rules to the disadvantage of clients. A greater incidence of corruption can also endanger the image of the program and might lead to an early termination, in particular in countries with high corruption incidences and official intentions to fight it.

\subsection{Evidence base on conditionality}

After having explored the rationale and the potential benefits and inefficiencies of conditionality, we now turn to the evidence base and the actual impact that conditions had on increasing the effectiveness of SCT programs (Annex 2 offers an overview of the existing evidence base). 


\subsubsection{Optimizing behavior - does conditionality lead to more education and health?}

Different attempts have been made to gauge the differential impact of conditionality on household behavior, ranging from simulations and other non-experimental methods to quasi-experiments and randomized experiments.

\subsubsection{Simulations}

Bourguignon, Ferreira et al. (2002) simulate schooling decisions as well as poverty impacts of the Brazilian cash transfer program Bolsa Familia. They estimate that a CCT could increase school enrolment by 3.7 percentage points for all beneficiaries, with an even more pronounced effect of 5.2 percentage points for a sub-sample of the poor benefitting from Bolsa Familia. They attribute this change exclusively to the conditionality and conclude that a mere income transfer without the conditionality would lead to no differences in schooling decisions. The findings by Todd and Wolpin (2006) based on the Mexican program Progresa, are less radical: a UCT would still have an impact on households' schooling decisions but it would be around $20 \%$ of the order of magnitude of a CCT program. Conditionality is however not a superior choice in all circumstances. When simulating and costing out a range of policy alternatives, ${ }^{22}$ they conclude that a UCT is more cost-effective than a conditional transfer for the completion of grade 9 .

Kakwani, Soares et al. (2005) simulate the impact of a UCT on school attendance for 12 African countries and only find very modest results. With a transfer financed by $0.5 \%$ of GDP of the respective country, a cash transfer would lead to a difference in school attendance ranging from $0.03 \%$ (Malawi) to $0.26 \%$ (Cote d'Ivoire) with universal targeting and $0.04 \%$ (Malawi) to $0.42 \%$ (Cote d'Ivoire) with povertytargeting. Unfortunately, their simulation model does not include any information on the impact of supply-side factors on schooling decisions as data were unavailable. Consequently, their conclusion that the introduction of conditionality would be an important mechanism in raising attendance has to be treated with caution.

\subsubsection{Other non-experimental methods}

Using a theoretical approach, de Janvry and Sadoulet (2005) demonstrate that if the increase in schooling is the main objective, CCTs are more effective than unconditional transfers. They (2006c) also refer to a review of studies by Behrman and Knowles (1999), which demonstrates a relatively low income elasticity of education among the poor, to emphasize the role of conditionality as a price-distorting instrument. There is nowadays plenty of evidence that shows that households also respond positively to an

\footnotetext{
${ }^{22}$ They range from doubling the transfer amount to restricting the bonus to certain grades, making school attendance compulsory, prohibiting child labor and rewarding the completion of grade 9 . 46
} 
income effect in education, health and nutrition (see for instance: Devereux 2001; Case 2004; de Carvalho Filho 2008; EPRI 2008; Miller, Tsoka et al. 2008a). Even Behrman and Knowles illustrate, using the example of Vietnam, that different specifications of the model substantially increase the association between income and schooling (1999).

Even if the existence of an income effect is uncontestable, the question remains how large the additional substitution effect is. De Janvry and Sadoulet (2005) estimate the magnitude of the effect of the conditionality for Mexico by comparing the impact of the CCT and the impact of household total expenditure on schooling. They arrive at the conclusion that the conditionality multiplies the effect by 16 times. They (2006b) also calculate that UCTs such as the South Africa old age pension system would have to be six times larger in size to produce the same impact as Progresa. As the country context, the supply side characteristics, demand constraints and program objectives are not necessarily comparable across the two countries, the introduction of conditionality might not have a comparable effect.

Davis, Handa et al. (2002) compare the effects of two different conditional programs in Mexico, Progresa and Procampo to draw conclusions on the importance of conditionality for consumption decisions as well as outcomes. They find that despite different conditions - Progresa in the area of education and health and Procampo in the area of agricultural land use - both programs have a similar effect on total consumption but differ in terms of household spending on non-food items and investment outcomes concerning human capital as well as agriculture. ${ }^{23}$ This leads them to conclude that conditionality seems to have a medium- to long-term investment effect, while affecting less households' short-term welfare.

Heinrich (2007) shows that the Argentinean scholarship program Beca improved students' attendance as well as school performance and ascribed this impact in part to the conditionality that only allowed households to continue into year 2 and 3 of the program if students had regular school attendance and good school performance. She bases her assessment of the impact of conditionality on the greater effort levels of those who continued into year 2 and 3 . Whether this motivation was however induced by the conditionality remains questionable as there is no counterfactual.

Gitter and Barham (2008), including log household consumption as a control for the income effect into their regression equation, show that when it comes to school enrolment in Nicaragua's Red de Protección Social program, income effects are approximately in the order of $25-33 \%$ of non-income effects. Non-income effects on food and milk expenditure are statistically significant and substantial; only the income effect is, however, statistically significant with respect to school expenditure. These

\footnotetext{
${ }^{23}$ Progresa recipients have higher school expenditure levels and shares, while Procampo leads to a decline in school expenditure but an increase in adult clothes, personal health and hygiene. In terms of outcomes, conditionality seems to have magnified effects: Progresa produces better school and health outcomes while Procampo leads to greater agricultural investment.
} 
effects might be biased due to problems of endogeneity resulting from measurement errors and the fact that income and expenditure choices might be jointly determined by the household.

Several authors have attempted to control for these biases through different statistical methods and arrive at different conclusions to de Janvry and Sadoulet (2005) and Gitter and Barham (2008). Hoddinott and Skoufias (2004), using Progresa data, mainly ascribe the observed calorie intake to the income effect. When instrumenting per capita consumption and using a model that controls for household fixed effects, the nonincome effect on caloric availability only remains statistically significant for fruits and vegetables, with the income effect outdoing the substitution effect. The authors also detect, however, spill-over effects to non-beneficiaries, showing the presence of a nonincome effect.

Handa, Peterman et al. (2009), equally using Progesa data, account for measurement errors using an instrumental variable for the actual transfer amount and they control for the endogeneity of household income using a household fixed effects model. They estimate that conditionality does not lead to a substitution effect on spending, neither for total expenditure nor for specific education expenditure. The absence of a substitution effect shows that better outcomes in schooling are for instance not due to higher expenditure on education but due to the replacement of foregone wages through child labor.

In contrast to Hoddinott and Skoufias ${ }^{24}$ (2004), Gitter and Barham (2008) and Handa, Peterman et al. (2009), Ribas, Soares et al. (2010) use a semi-parametric approach, not assuming linearity of income, to decompose treatment effects into income and behavioral effects. Using data from Paraguay, they find that the income effect has a positive impact on consumption and savings of beneficiaries while the substitution effect cancels out the impact on consumption, reinforces the savings effect and is the only one to have an impact on the overall consumption composition. Building on the methodology suggested by Ribas, Soares et al. and adding a heterogeneity analysis with respect to the behavioral effects of the CCT program in Paraguay, Teixeira, Soares et al. (2011) mainly find that the substitution rather than the income effect explains family's increased demand for health care and education.

Rubalca, Teruel et al. (2004) would have appreciated the analysis by Teixeira, Soares et al. Not only do Rubalca, Teruel et al. (2004) demonstrate in their analysis of Progresa data that the assumption of non-linearity might be an important one but they also show that one needs to be careful in ascribing all behavioral effects to the conditionality. They illustrate that budget allocations among single-headed households remain the same, while households headed by a couple spend a greater share of

\footnotetext{
${ }^{24}$ Hoddinott and Skoufias (2004) also run non-parametric regressions; conclude however that the non-linear relationship between consumption and calories appears at levels which are above the levels of households who are eligible for the Progresa-transfer.

48
} 
Progresa income on child clothing, higher quality nutrient intake and investments in small livestock. They therefore conclude that the behavioral effect might foremost result from the fact that the transfer is allocated to women and the subsequent change in decision-making power and preferences.

\subsubsection{Quasi-experiments}

De Brauw and Hoddinott (2011), using administrative data from PROGRESA and constructing a quasi-experiment on the basis that not all beneficiaries received conditionality monitoring forms, show that the impact of conditionality largely depends on the grade of the student. There is no measurable impact of conditionality at primary level and the greatest impact is in the range of $17-20 \%$ at the transition from primary to secondary education. Despite the robustness checks carried out and attempts to control for unobservables in as much as possible, the authors suggest shedding more light on the impact of unobservables, preferably through a controlled randomized experiment.

Schady and Araujo (2008) make use of the fact that some households in the unconditional SCT program in Ecuador believed in being subject to education conditionality in order to estimate the impact of conditionality on educational outcomes. The probability of being enrolled differs among households who believe themselves to be subject to conditionality and households who are unaware of conditionality when compared to a control group that receives no cash transfers. The probability of being enrolled for conditional households is between 7.3 and 13 percentage points higher than for the control group, while the probability for households who are unaware of conditionality ranges from 1.4 to 2.1 percentage points and is furthermore statistically insignificant. The authors controlled for observable differences between the two groups but results might still be biased by unobservable characteristics.

\subsubsection{Randomized experiments}

Several randomized experiments were started in Africa to single out the effect of conditionality. The only two experiments with published results are from Malawi and Burkina Faso. ${ }^{25}$ The experiment in Zomba, Malawi, was carried out with 2,286 13-22 year old unmarried school-girls (Baird, McIntosh et al. 2011). For the girls in the treatment arm with CCTs, the transfer was conditioned on regular school attendance. When using self-reported enrolment data, no statistically significant impact of the conditionality on school enrolment is detectable and UCTs even outperform CCTs with respect to reducing school drop-out rates. Different findings emerge, however, when different monitoring data, confirmed by teachers, for school enrolment and attendance

\footnotetext{
${ }^{25}$ The experiment in Kenya as well as Zambia could not contribute to the evidence base on conditionality as both countries experienced difficulties in implementing the conditionality experiment, which would have biased the results (see section 4.6.2 for Zambia and Ward, Hurrell et al. (2010) for Kenya).
} 
is considered instead: the effect on school drop-outs of unconditional cash only represents about half the effect size of conditional cash; attendance as well as test results only improved in the CCT treatment arm. The study therefore testifies to the presence of an income effect but argues that conditionality is not only the more effective but also cost-effective choice when we are interested in promoting educational outcomes.

The randomized experiment in Burkina Faso by CNLS and World Bank started in 2008 and involved 2775 households in 75 villages. It tested one health condition for children under age 6 , who were obliged to visit the health center quarterly, and one education condition for children aged 7-15 years, who were supposed to be enrolled in school and have a $90 \%$ attendance rate each quarter (Akresh, De Walque et al. 2012). Whereas families with conditionality have 0.43 more visits to the health clinic for children under 6, no effect is discernible for families receiving UCT (Akresh, De Walque et al. 2012). The impact occurs for children older than two years. Further results, discussed at the latest World Bank workshop on the second generation of CCT evaluation, ${ }^{26}$ show that conditionality also mattered with respect to the enrolment of younger children.

Another pilot was launched in Morocco in 2007, initially reaching 53,288 households and 93,536 children in grade 3-6. The pilot had a UCT treatment arm as well as a CCT treatment arm with various degrees of monitoring, ranging from monitoring on the basis of school records, school records with threats of audits by inspectors and biometric machines. ${ }^{27}$ The conditionality was in the area of school attendance. The conditionality in Morocco did not have any impact with the researchers speculating at the World Bank workshop that this might be due to the fact that households did not share a common understanding of conditionality.

Even though not framed in the context of SCT programs for vulnerable / poor households, experiments on educational incentives also provide some valuable lessons about the potential of financial stimuli to change behavior. The effects, in developing and developed countries, can be considered small to modest at best and encourage further research on the mechanisms of how children respond to financial incentives (Fryer 2011). A better understanding of underlying constraints faced by children in responding to incentives such as a lack of knowledge as to how to comply with conditionality, self-control problems, or restrictive external and uncontrollable factors etc. would equally prove insightful for CCT programs.

\footnotetext{
${ }^{26}$ For further information and initial findings about the experiments, visit: http://web.worldbank.org/WBSITE/EXTERNAL/TOPICS/EXTSOCIALPROTECTION/0,,contentM DK:23017575 menuPK:2643917 pagePK:64020865 piPK:51164185 theSitePK:282637 isCURL: Y isCURL:Y isCURL:Y isCURL:Y isCURL:Y,00.html.

${ }^{27}$ For more information about the pilot in Morocco, see: http://web.worldbank.org/WBSITE/EXTERNAL/COUNTRIES/MENAEXT/0,,contentMDK:227057 63 pagePK:146736 piPK:226340 theSitePK:256299,00.html. 


\subsubsection{Bottom-line?}

The preceding review of evidence has demonstrated that it is difficult to draw a definite conclusion on the extent to which conditionality optimizes household behavior. On the basis of the presented evidence, we can conclude that conditionality for the most part seems to have an effect on households' health and education decisions, while its effect on household consumption is not always discernible. The magnitude of the effect on health and education and how it compares to the income effect remains inconclusive, in particular for low-income countries where evidence is even scarcer. It seems however incontestable that, in particular for programs in low-income countries, an income effect can be detected, which calls for an adaptation of some of the earlier simulation models. More research that disaggregates the non-income effect, following the study by Teixeira, Soares et al. (2011), would be helpful in identifying the elements of conditionality that produce positive as well as adverse effects.

\subsubsection{Political economy - does conditionality make cash transfers more attractive?}

Up till now there is no study that has looked closely into public attitudes on conditionality in low-income countries. A study by Taylor-Gooby (2001) on the direction and origin of political attitudes towards welfare confirms the rising popularity of activation / conditionality across various welfare states in the Western world. This inclination towards conditionality has different motives: it is based on the principle of citizens' duty towards society in the social democrat countries, on the principle of cost containment and responsibilization in Anglo-Saxon models or on the inter-linkages between work and welfare in Christian democrat countries.

Lindert and Vincensini's media analysis (2009) provides some interesting insights into the perception of the role and experience with conditionality in Brazil. Conditionality appeared as a theme in about a quarter of all articles screened. An increasing number of those articles (from 35\% from 2001-03 to close to 50\% from 2004-06) mentioned the importance of the existence of conditionality with politicians being the strongest believers in its importance in 2004-2006. Conditionality was seen to guarantee impact and avoid assistentialism. Better monitoring of conditionality was also suggested as one of the strategies to overcome criticism of dependency and assistentialism.

De Janvry, Finan et al. (2009), using data from Brazil, show however that better monitoring of conditionality can also have a negative impact on the political economy as it reduced mayors' chances of re-election. They also find that avoidance of inclusion errors can increase chances of re-election by $26 \%$, which would support the introduction of conditionality as a disincentive device. Findings from Zambia demonstrate that while conditionality increases the political attractiveness of a program among voters and politicians, this effect can be at least partly offset by the potentially 
very negative consequences of conditionality in form of a high exclusion rate of beneficiaries (see section 4.5.4).

Sources such as the world values surveys and attitude surveys carried out by Graham (2002) can help to draw preliminary conclusions about public attitudes on government assistance and the expectations that the public has of welfare recipients. Yet nobody has used this data to analyze the extent to which conditionality would resonate with the political culture in different countries.

\subsubsection{Empowerment - does conditionality (dis) empower?}

With respect to empowerment, there is very little but anecdotal evidence on whether beneficiaries feel that conditionality has transformed the welfare transfer into a contractual arrangement and empowered them. In Zambia, the overwhelming majority of beneficiaries perceived conditionality as empowering and as a vehicle to better negotiate household expenses with their spouses (see chapter 3 and 4). According to qualitative interviews, this positive connotation of conditionality is largely due to the fact that conditions provide clear information and guidelines for beneficiaries in areas where information is often not readily available, in particular for the illiterate.

There is more evidence on the impact of CCTs on the bargaining position as well as the role of the woman in the household but again, very little on the differential impact of conditionality on gender effects. Adato, de la Brière et al. (2002) find that the impact of the monthly meetings on health-related issues and other topics for women in Mexico made a contribution to increasing women's confidence, awareness and knowledge. Molyneux (2006) on the contrary shows for Mexico that conditionality can equally reinforce traditional gender roles and responsibilities if the woman is the one who has to ensure that conditions are met. This can have the exact opposite effect of disempowering women by confining them to their female duties. Bradshaw (2008) finds similar evidence in Nicaragua where the conditionality implicitly serves as a hint to women that they need to learn how to be better mothers. She equally suggests that courses which women are required to attend on good parenting might also have a disempowering effect on those mothers who are not participating, portraying them as bad parents.

Most authors furthermore caution that conditionality disproportionally affects the costs that women have to bear. Time constraints and transaction costs with respect to accessing the transfer are often higher for women than for men (Ezemenari, Chaudhury et al. 2002). In addition, time away from the household that the mother has to spend on complying with the official conditions can easily translate into more work for girls at home (Luttrell and Moser 2004). 


\subsubsection{Equity - does conditionality increase targeting efficiency?}

The impact of conditionality on targeting efficiency is also under-researched. Alvarez et al. (2008) find evidence using administrative data from Progresa that conditionality increased the targeting efficiency of the program by serving as a screening mechanism throughout the course of the program. Those that dropped out of the program were more likely to be male, more educated, non-indigenous, single and employed. Drop-out households were smaller in size and had a lower dependency rate. In Zambia, conditionality is unlikely to function as a screening-device as the better-off seemed to be more willing to bear additional costs associated with conditionality than the poorer population (Schüring 2010a).

Regarding exclusion errors, Alvarez, Devoto et al. (2008) arrive at the conclusion that conditionality in the Mexican case did not systematically screen out the extremely poor but did lead to a higher probability of drop-out in the case of the indigenous populations and in the case of the extremely poor in low-marginality communities. Castelán (2010) observes that extremely poor households as well as households close to the poverty line have a lower probability of participating in Oportunidades which he ascribes among other factors to the (in)direct costs of compliance. Rigorously enforced conditionality in Zambia could exclude a significant number of beneficiaries (see section 4.5.4). Whether conditionality increases the attractiveness of a program for potential beneficiaries through the empowerment effects and thereby leads to a higher program uptake and better targeting outcome, has not been studied at all.

\subsection{Concluding remarks}

The aim of this chapter was to generate a common understanding about the concept of and the theory behind conditionality, to highlight the different factors that prove essential in determining whether conditionality makes a SCT program more costeffective and to bring together existing evidence. While building on many important contributions made by other authors, the value added of this chapter is to clearly differentiate between different dimensions of conditionality, to bring together a theoretical economic perspective with insights from psychology, to comprehensively and systematically disentangle all factors that determine the impact conditionality can have on the effectiveness of SCT programs and to cite evidence beyond the influence of conditionality on household behavior.

For policy-makers, this chapter aims to provide an orientation on how to decide whether conditionality is an appropriate instrument in their SCT program. Figure 2.7 provides a summary of the main arguments made in this chapter and enables policymakers to consider all relevant factors when assessing the effectiveness of conditionality, thinking through the implications of conditionality for the beneficiary 
households, society, the administration as well as politics. When deciding on conditionality, it is important that policy-maker critically look at the nature of the problems that they want to address and the potential of conditionality to solve them. In addition, policymakers have to assess whether conditionality is the most cost-effective instrument, considering the different inefficiencies that conditionality introduces and costing out the implementation of conditionality in terms of direct and indirect costs, administrative as well as private and social costs.

For researchers, the review of the evidence has demonstrated that for some areas such as the impact on beneficiary behavior and the relative magnitude of income vs. nonincome effects, evidence remains inconclusive. In particular, for analyses of the same country program that draw different conclusions, it would be interesting to explain in more detail the differences and highlight any changes to the assumptions made and factors considered. There is also need to gain a better understanding of the long-term impact that conditionality has on household behavior and to deconstruct the different channels through which conditionality can influence household behavior, ranging from better information to actual punishment of non-complying households. The evidence base for areas such as the political economy, empowerment and equity arguments for conditionality is rather small and would benefit from further research. The cost side of conditionality has also received little attention with few studies looking at the actual costs at administrative and private level and little documentation of how conditionality can be tailored to a low capacity administration. In addition, policy-makers would also benefit from more holistic assessments of conditionality, not only singling out certain aspects such as the potential of conditionality to affect household behavior, but a comprehensive analysis of all the different factors that determine whether conditionality turns into a cost-effective choice. 
Figure 2.7: Theoretical and decision-making framework for conditionality

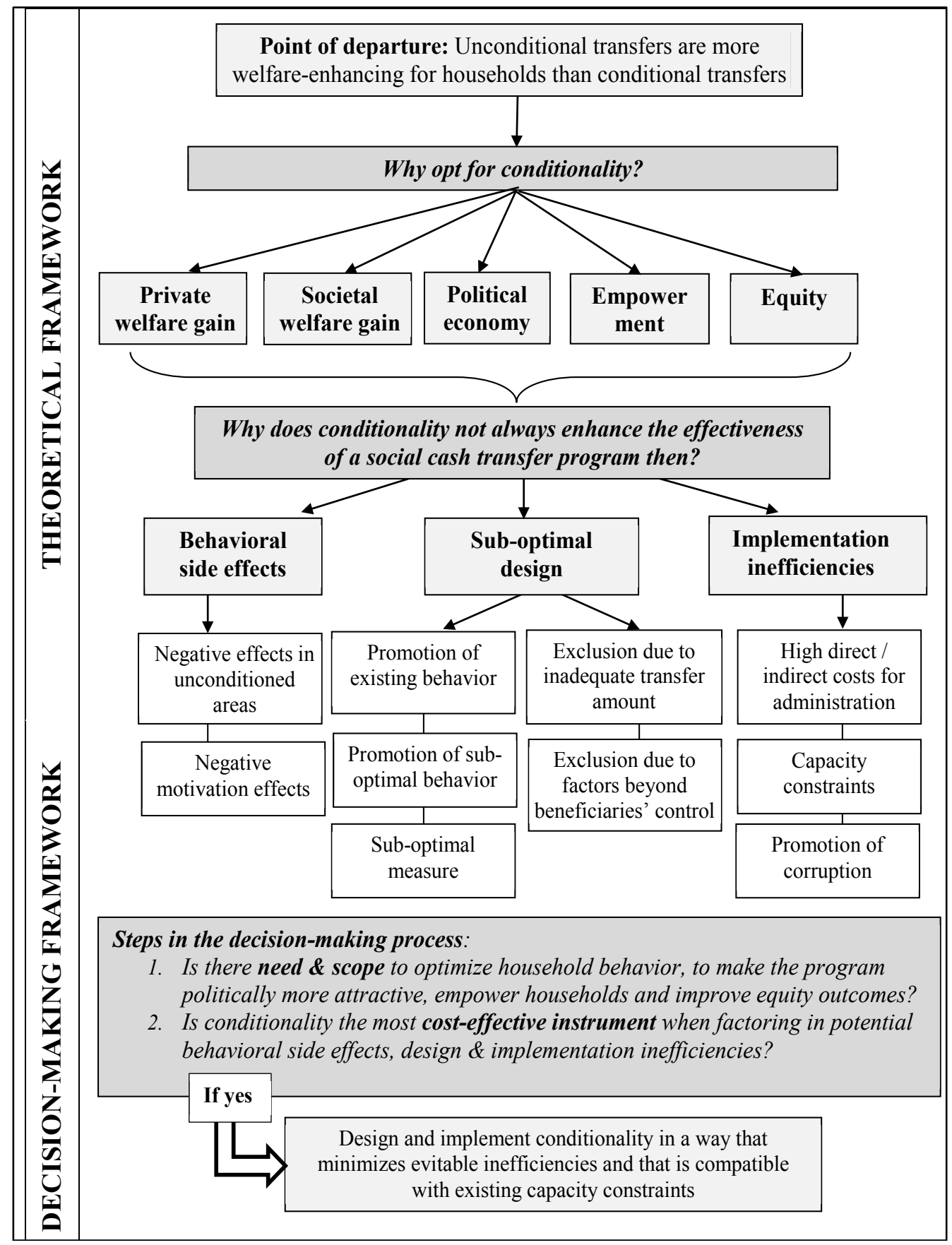




\section{CHAPTER 3: Conditionality preferences with respect to government assistance - experimental evidence from Zambia $^{28}$}

\subsection{Introduction}

Policy makers struggle with whether or not to opt for conditionality in a SCT program. There are different economic arguments that guide their choices. While all of these arguments make implicit assumptions regarding households' utility, there is little but anecdotal evidence about preferences for conditionality on the side of those to whom they are applied. We therefore do not know whether the models depart from the right assumptions and whether policy-making at national as well as decentralized level correctly factor in households' (dis-) utility and the resulting political consequences.

In order to enlarge the body of evidence, this chapter studies preferences for conditioning transfers in a low-income context more intensively. Through an incentivized experiment in rural Zambia, we elicit conditionality preferences of community members of different backgrounds. The preferences for conditionality of rural community members are of particular interest: on the one hand they could be affected as potential beneficiaries by the choices they make and on the other hand they are expected to be more sensitive to the need, consequences and costs of particular conditions on fellow community members.

In this way, the experiments allow us to test whether and to what extent a rural population derives utility from conditionality and to reconsider the different arguments that are advanced in favor and against conditionality. More than half of all experiments were carried out in communities that have been incorporated into the SCT program in Zambia, which lets us test whether greater exposure and experience with cash transfers and beneficiaries' use of it, changes conditionality decisions in any way.

According to classical consumer theory, households would opt against the use of conditionality as conditionality risks lowering the welfare of those individuals who prefer consuming less of the conditioned good and services (for a more extensive discussion see section 2.3). Following paternalist arguments, conditionality might help households achieve greater utility levels when they are at present taking sub-optimal decisions from a personal point of view (Das, Do et al. 2005; de Janvry and Sadoulet 2006b; Bastagli 2008; Fiszbein and Schady 2009). This can for instance happen if

\footnotetext{
${ }^{28}$ An earlier version of this chapter is available as UNU-Merit working paper \#2011-046, UNU-Merit / MGSoG, available from http://www.merit.unu.edu/publications/wppdf/2011/wp2011-046.pdf.
} 
households have access to imperfect information, if individuals with greater authority within the household do not behave completely altruistically vis-à-vis other household members (age and gender hierarchies) or if household members are myopic in their choices. Conditionality could therefore orient individuals' choices towards an optimum for the recipient, ensuring that the shape of households' utility curve reflects households' true rather than misguided preferences. Households or particular individual household members such as women might also be in favor of conditionality if they view it as a contractual arrangement that empowers them in their decisionmaking (Martinelli and Parker 2003; Cohen and Franco 2006; de la Brière and Rawlings 2006; de Janvry and Sadoulet 2006b).

Households indirectly concerned by conditionality as fellow citizens would opt for conditionality if there are positive externality effects that could be realized with the help of conditionality. As voters, they might also find conditionality politically more acceptable (Das, Do et al. 2005; de Janvry and Sadoulet 2006b; Bastagli 2008; Fiszbein and Schady 2009); it is not clear whether this results from a preference for controlling behavior, ensuring that beneficiaries pursue the optimal path or from a concern that unconditional behavior might affect their own well-being in any negative way (Barrientos 2011). For policy-makers, conditionality can have an important signaling effect in terms of demonstrating success long before the actual impact evaluation has been carried out.

There are however several inefficiencies that need to be highlighted, which reduce the utility of conditionality for households or particular household members and thereby also affect the political utility for decision-makers. Some authors have stressed the patronizing and disempowering nature of conditionality (Schubert and Slater 2006; Freeland 2007; Standing 2007; Veit-Wilson 2009). Beneficiaries might feel demotivated by the extra nudge from government and perceive conditionality as a lack of trust, with the consequence of not (re) engaging in the desired behavior (Fehr and Gächter 2001; Falk and Kosfeld 2006; Sliwka 2007; Frey 2008; Kremer, Miguel et al. 2009).

Critics furthermore highlight the possibility that conditionality might reinforce traditional gender roles and responsibilities (Molyneux 2006; Bradshaw 2008), that it could lead to higher costs for the beneficiary (Coady, Perez et al. 2005) and that eventually recipients risk being screened out where they cannot comply with the conditions. These arguments suggest that conditionality might not be the preferred choice of beneficiaries under certain circumstances, in particular when other factors prevent beneficiary households from accessing the conditioned services such as unavailability, irregularity or low quality of respective health and education services (Barrientos and de Jong 2006; Handa and Davis 2006).

These contradicting arguments of whether households or individual members are motivated, empowered and in the end better off with conditionality highlight the need 
for more evidence. Exploring whether and under what conditions participants in the experiment condition the transfer, the chapter starts by introducing the methodology (section 3.2). It then discusses participants' conditionality preferences as well as different factors that influence their conditionality choices (section 3.3). Section 3.4 tests the compatibility of participants' preferences with preferences of actual and potential beneficiaries, with preferences of urban respondents, preferences of policy makers as well as preferences of decentralized decision-making structures. Section 3.5 concludes with an assessment of the political potential of conditionality.

\subsection{Methodology}

Experiments can be carried out for various reasons: for testing hypotheses derived from formal theoretical models, investigating phenomena which have not been explained by any of the existing theories and providing advice and support to policy making (Kagel and Alvin E. Roth eds 1995). There are different types of experiments, ranging from tightly controlled conventional lab experiments, artefactual field experiments, framed field experiments to natural field experiments where participants are not even aware that they are participating in an experiment (Harrison and List 2004). ${ }^{29}$

Economic experiments are not a novelty in developing countries anymore; even field experiments have become more common practice and have allowed for interesting comparisons between developed and developing countries. They are a suitable tool to open up the black-box of preferences and decision-making processes with respect to conditionality as well as CBT, two areas of great importance in SCT policy-making. The targeting and conditionality experiment, conducted in rural Zambia, contributes to the existing body of knowledge but also adds new elements to behavioral experiments $^{30}$.

Experiments were not only conducted at two levels - the individual and group level but they were carried out in groups with a heterogeneous poverty composition, with different treatment conditions - distributions within or between groups - and in

\footnotetext{
${ }^{29}$ Differentiations are based on six factors: the nature of the subject pool, of experiment participants' information level, of the commodity, of tasks or rules applied, of stakes and the environment. ${ }^{30}$ According to Harrison and List's classification, the experiment in Zambia would fall under artefactual or framed field experiments as the subject pool was nonstandard, the rules of the experiment were externally imposed and it is debatable to what extent the experiment was framed according to the field context. Community members were asked to carry out a task which has been common practice in a number of communities for government programs. Community members had the opportunity to use their knowledge of such distributions as well as their knowledge about other community members participating in the experiment. In the treatment communities for the SCT scheme, community members were also familiar with the commodity of "cash." At the same time, not all community members were performing a task that they were familiar with and the task also did not follow all the standards that communities were used to such as being elected as a representative and familiarized with targeting rules and regulations.
} 
different localities - with and without exposure to SCTs. The experiment is furthermore complemented by different survey rounds that allow us to get more information about participants' characteristics, their attitudes and justifications for targeting and conditionality decisions. The experiment was carefully contextualized to mimic the local situation in Zambia; the mechanisms tested in this experiment are, however, relevant for other countries as well.

\subsubsection{Experiment design}

\subsubsection{Choice of communities and experiment participants}

Community experiments were conducted in 25 different communities in Zambia's Southern district of Monze, with a pre-test carried out in one additional community. Monze district was an ideal study location for a research project on conditionality as it was the only district in Zambia that conducted a randomized experiment to test the differential impact of soft conditionality. Due to the randomized experiment, communities were divided into communities receiving unconditional cash, communities receiving conditional cash and communities not being incorporated into the scheme and serving as a control group. This design allowed us to test whether decision-making patterns were different between communities that were trained on standardized targeting procedures for the SCT scheme and communities that had not had any additional exposure. It was also supposed to let us assess whether the conditionality status of the community had any influence on conditionality decisions.

To determine the required sample size of participants and communities, other studies that examined allocation and conditionality behavior in rural areas in Zambia were consulted. While no study on conditionality choices could be identified, even for comparable countries, estimates by Watkins (2008b) on the different outcomes of enhanced (guided) vs. basic (non-guided) community based targeting were used for predicting the difference in effect size between SCT and non-SCT communities in Zambia. Watkins calculated the correct prediction of the poor to be close to $67 \%$ with enhanced and $46 \%$ with basic community based targeting. ${ }^{31}$ After conducting a power analysis and factoring in possible implementation problems, a sample size of 160 experiment participants from the two treatment groups each (conditional and unconditional communities and therefore "guided") and 180 from the control group (no cash transfers yet and therefore "non-guided") was chosen.

The 25 communities - 8 locations with UCTs, 8 locations with CCTs, and 9 control locations - comprising 20 participants each, were randomly selected through stratified cluster sampling from the list of treatment and control communities in Monze district.

\footnotetext{
${ }^{31}$ Even if do not calculate the prediction rate of the poor with the help of the experiments, we are interested in the percentage of benefits going to the poor vs. the non-poor. 60
} 
For logistical purposes only locations that could be reached within 1.5 hours by car, were considered, which disqualified 23 out of the 106 Communities in Monze district. Due to the fact that one community which was listed as unconditional turned out to be a control community, we ended up with 7 unconditional locations, 8 conditional locations and 10 control locations (see table 3.1$)^{32}$

Table 3.1: Selection of communities participating in the community experiments

\begin{tabular}{|c|c|c|c|c|c|}
\hline$\#$ & Area & Community & Status & $\begin{array}{l}\text { Treatment } \\
\text { condition }\end{array}$ & Distance $^{33}$ \\
\hline 1 & Chikuni & Chipembele & Control & TC 2 & Mid distance \\
\hline 2 & Monze Central & Freedom & Control & TC 1 & Very close \\
\hline 3 & Monze Central & Freedom 2 & Control & $\mathrm{TC} 2^{34}$ & Very close \\
\hline 4 & Monze Central & Miyoba & Control & TC 1 & Close \\
\hline 5 & Monze Central & Kayuni & Control & TC 2 & Close \\
\hline 6 & Namateba & Chona & Control & TC 2 & Mid distance \\
\hline 7 & Nteme & Kanundwa & Control & TC 2 & Mid distance \\
\hline 8 & Sichiyanda & Rusangu & Control & TC 1 & Mid distance \\
\hline 9 & Sichiyanda & Hanamaila & Control & TC 1 & Far \\
\hline 10 & Bweengwa & Malundu & Control & TC 1 & Mid distance \\
\hline 11 & Chikuni & Singonya & Unconditional & TC 2 & Mid distance \\
\hline 12 & Kaloba & Ciyumu & Unconditional & TC 2 & Far \\
\hline 13 & Keemba & Banakaila & Unconditional & TC 1 & Far \\
\hline 14 & Keemba & Kambaza & Unconditional & TC 1 & Far \\
\hline 15 & Keemba & Loncinvar & Unconditional & TC 2 & Far \\
\hline 16 & Nteme & Nteme & Unconditional & TC 1 & Very close \\
\hline 17 & St. Marys & St. Marys & Unconditional & TC 2 & Close \\
\hline 18 & Kazungula & Kabanga & בConditional & TC 1 & Mid distance \\
\hline 19 & Keemba & Gonhwe & Conditional & TC 2 & Far \\
\hline 20 & Monze Central & Manungu 2 & Conditional & TC 1 & Very close \\
\hline 21 & Nteme & Sigubbu & Conditional & TC 2 & Close \\
\hline 22 & Nteme & Hamwimbu & Conditional & TC 1 & Mid distance \\
\hline 23 & Sichiyanda & Simwendengwe & Conditional & TC 2 & Mid distance \\
\hline 24 & Sichiyanda & Mwala & Conditional & TC 1 & Far \\
\hline 25 & St. Marys & Gaali & Conditional & TC 2 & Mid distance \\
\hline
\end{tabular}

\footnotetext{
${ }^{32}$ Given that the implementation of the randomized experiment failed with respect to having a distinguishable unconditional and conditional treatment arm (see section 4.6.2), the new composition of (un)conditional and treatment communities is not likely to affect our results in any way.

${ }^{33}$ Very close: up to 15 minutes, close: $15-30$ minutes, mid distance: 30 minutes -1 hour, far: 1-1 1/2 hours.

${ }^{34}$ Due to a mistake on the side of enumerators, individuals had TC1 and the group had TC2.
} 
In every community, two groups of 10 members each participated in the experiment. The experiments were designed to mimic the existing SCT scheme and its CBT mechanism in Zambia. Community Welfare Assistance Committees (CWAC) that select the beneficiaries for the SCT scheme and for other in-kind transfers in Zambia, typically comprise 10 members.

Experiment participants were randomly selected from a pool of volunteers. ${ }^{35}$ In each community, the sampling frame of potential participants was developed during a presurvey community meeting during which basic demographic and socio-economic information of each community member present was recorded in a pre-survey form (see Annex 3). The information so collected then helped to assign each member to one of the three wealth categories - very poor, poor and better-off. The assessment of all potential experiment participants was made by the same person of the research team in collaboration with members of the local CWAC.

An effort was made to ensure that there was representation from each of these strata for the experiments in order to ensure variability and test the hypotheses around povertytargeting. Specifically, 3, 4, and 3 community members were randomly selected from the very poor, poor and better-off categories, respectively. Also, in each category one additional person was selected as an experiment participant in case one of the other members of the same wealth category did not show up for the interview.

\subsubsection{Treatment conditions}

Figure 3.1: Treatment conditions of the experiment

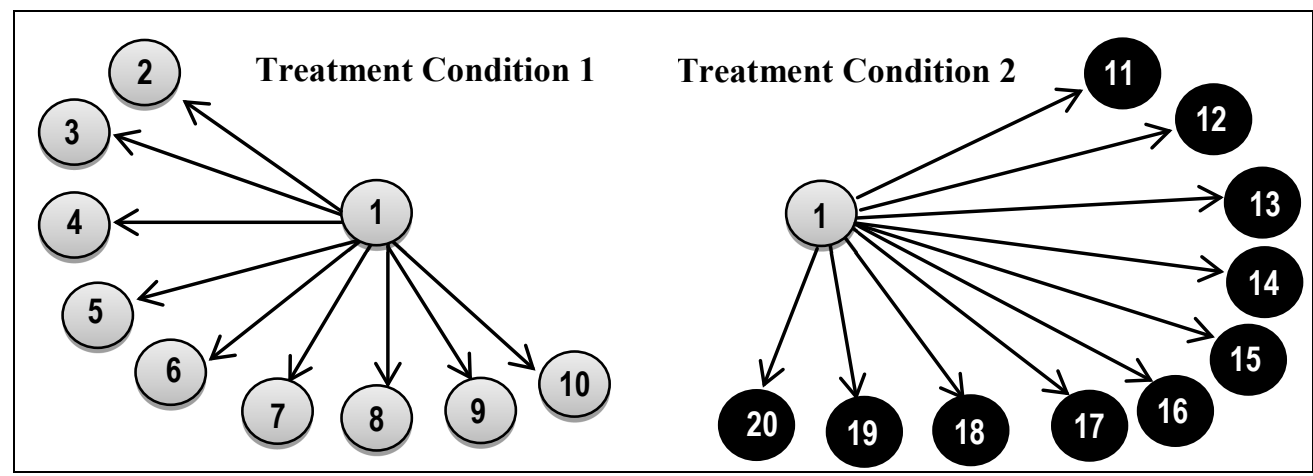

There were two different treatment conditions in the experiment, which were randomly allocated to different communities. Every individual could only participate in one of the two treatment conditions. For treatment condition 1 (TC1), group members made decisions for members of their own group including themselves whereas for treatment

\footnotetext{
${ }^{35}$ About 54 people volunteered in each community.
} 
condition 2 (TC2), group members made decisions for members of the second group in the community that participated in the experiment (see figure 3.1).

The two treatment conditions were included in order to see whether the direct contact with potential beneficiaries during the decision-making process lead to different decisions and whether people decided differently when they knew that they themselves could not benefit. Once more, this is to mimic a scenario that is currently common practice in Zambia. At the individual level, the SCT program specifies that committee members themselves cannot be registered as beneficiaries and therefore only decide on the inclusion of other community members. At the group level, the two experiment treatment conditions represent two variations in CBT that have been critically discussed in Zambia. The SCT scheme stipulates that an elected committee makes targeting choices for the community (TC2) with involvement of the community at the approval stage while other programs opt for letting the entire community select beneficiaries directly (TC1).

\subsubsection{Description of the different rounds of the experiment}

Table 3.2: Set-up of the experiment (experiment locations, experiment treatment conditions and experiment rounds)

\begin{tabular}{|c|c|c|c|}
\hline \multicolumn{2}{|c|}{ SCT communities } & \multicolumn{2}{|c|}{ Non-SCT Communities } \\
\hline $\begin{array}{l}\text { Treatment condition } 1 \\
\text { - intra-group }\end{array}$ & $\begin{array}{c}\text { Treatment condition } 2 \\
\text { - inter-group }\end{array}$ & $\begin{array}{c}\text { Treatment condition } 1 \\
\text { - intra-group }\end{array}$ & $\begin{array}{c}\text { Treatment condition } 2 \\
\text { - inter-group }\end{array}$ \\
\hline & \multirow{6}{*}{\multicolumn{3}{|c|}{$\begin{array}{ll}\text { 1. } & \text { Pre-survey } \\
\text { 2. Instructions \& Introduction of participants } \\
\text { 3. Individual allocation round } \\
\text { 4. Survey I } \\
\text { 5. Group allocation round } \\
\text { 6. Survey II }\end{array}$}} \\
\hline & & & \\
\hline & & & \\
\hline & & & \\
\hline & & & \\
\hline & & & \\
\hline
\end{tabular}

Each experiment started with an instruction phase (see table 3.2 for the overall set-up of the experiment) during which all the rules and procedures of the experiment were clearly communicated to the experiment participants in local language (see Annex 4 for the instructions to the moderator). Each participant introduced him/herself, mentioning name, household size, number of children from $0-5$, number of children of schoolgoing age as well as main occupation. This information was important in ensuring that experiment participants who did not know a particular person very well got an impression of his/her socio-economic situation. Groups in TC1, each had their own instruction phase and introduction round, whereas for groups in TC2, the round of introduction was done jointly for both groups.

For each of these treatment conditions, two different rounds were played. In the first round of the experiment, every experiment participant received 20 tokens, each worth ZMK 50,000 ( US\$ 9.5), amounting to a total budget of ZMK 1,000,000 ( US\$ 190). 
ZMK 50,000 represents the value of the maximum monthly transfer in Zambia's SCT program. While there were no specific allocation rules that experiment participants were asked to follow, participants were told that the overall objective of this experiment was to alleviate poverty in the community. For each and every group member of his/her own group (TC1) or the other group (TC2), the experiment playing individual had to decide 1) whether to give any tokens, 2) how many to give, 3) whether to make the transfer conditional, and 4) which condition to choose out of an education, growth monitoring, vaccination, training and community work condition.

After all individuals had made their allocation and conditionality decisions in private without any other group member observing them, they were interviewed about their motives (see questionnaire in Annex 5). For each group member, they had to state why they made or decided against a transfer, why they opted for or against conditionality as well as why they chose a particular condition. Participants also had to state how they would personally feel if someone placed a condition on them and whether or not they would still accept a transfer if it was conditioned. This allowed us to compare participants' stated and revealed preferences for targeting and conditionality.

In the second round of the experiment ${ }^{36}$, all group members had to play the distribution experiment together, deciding on how to allocate a total of ZMK 10,000,000 to either their own group members (TC1) or members of the other group in the community (TC2). The enumerators observed the decision-making process from a distance and the moderator equally observed and only assisted with counting or with time-keeping when the group took longer than half an hour.

After the group decision-making process, each group member was again interviewed individually about his/her satisfaction with the group outcome for targeting and the group outcome for conditionality (see questionnaire in Annex 6). This served to understand more about the group dynamics behind the group allocation of tokens. Additional questions were asked about each participant's preferences for education and health, his/her risk and time preferences, attitudes about trust, reciprocity, sources of poverty, government assistance etc. This enabled us to test the extent to which targeting choices were determined by socio-economic characteristics and attitudes of the giver as well as the receiver, whether stated and revealed preferences overlapped and whether group processes created tensions and disagreement. The survey ended by asking experiment participants to characterize their relationships with the members of their own group for TC1 and with members of the other group for TC2.

\footnotetext{
${ }^{36}$ Originally three different rounds of the experiment were planned with one additional round where the group decided on an allocation of tokens for hypothetical households. This would have allowed us to compare a distribution of tokens that factored out human relationships with one that did not. As the pre-test already took close to 6 hours for one group to finish 2 rounds of the experiment, the hypothetical experiment was dropped and a shorter version of the hypothetical round was included in the questionnaire instead. Participants were asked to rank three different households according to who they would support first as a social welfare officer.

64
} 


\subsubsection{Monetary reward}

In order to incentivize choices, there was a real monetary gain for participants. Each token-receiving individual was awarded $1 \%$ of the value of the tokens received minus the conditionality costs. The initial endowment of 20 tokens during the individual round is worth $(20 \times 50,000 \mathrm{ZMK}) / 100=\mathrm{ZMK} 10,000$. Assuming equal sharing and no conditions, each individual could have earned 20,000 ZMK during the experiment (ZMK 10,000 during the individual and ZMK 10,000 during the group round). This covers the schooling costs for one child for one semester, buys two chickens or about $20 \mathrm{~kg}$ of maize. It is a little less than half of the average transfer that a beneficiary of the SCT scheme receives in a month and about $1 / 10$ of monthly per capita income in rural areas (CSO 2008). We can thus assume that this transfer amount is attractive enough to make people reveal their true preferences. ${ }^{37}$

In order to ensure that experiment participants understood that there are costs attached to complying with conditionality, every condition had a separate cost, which was deducted from the real monetary gain, using a conversion factor of 1:100. The costs referred to direct costs such as accessing the services that were conditioned but did not include any indirect costs such as foregone income. For the education condition, ZMK 20,000 was deducted per child aged 5 years and above from the final amount (total number of tokens) that the individual had received through the experiment. ZMK 20,000 is roughly the price that households have to pay for unofficial school fees. For the training condition, a flat rate of ZMK 20,000 was deducted as a training fee. For the vaccination condition as well as the growth monitoring condition, ZMK 10,000 was taken for every child below 5 years in order to cater for transport costs to the nearest health post. For the community work condition, no money was deducted but it was reiterated to participants that community work would demand time and energy. For people who were already engaged in conditioned activities and therefore in practice did not incur any additional costs for compliance, the costs for the conditionality had a symbolic character. The costs symbolized that the household could not freely decide over a certain portion of the household budget. If different participants placed the same conditionality on the same recipient, the costs were only deducted once.

\subsubsection{Addressing challenges}

For a successful implementation of field experiments, Cardenas and Carpenter (2008) stress in particular the issues of numeracy, credibility of the protocol and the experimenter, sampling and recruitment, clear communication of rules, strategy responses, desirability of cash and cross talk, which we addressed in the following way:

\footnotetext{
${ }^{37}$ It is definitely more than Cardena's and Carpenter's (2008) suggestion of paying one to two days wage for a half day session.
} 


\section{Literacy \& numeracy}

We always tried to match up older participants with older enumerators who had more experience in field work and in explaining the different tasks and questions asked. Where possible, we used pictures to illustrate the procedures and possible answers (see figure 3.2). Instead of a name tag, every experiment participant received a number tag during the round of introduction as even illiterate people were able to recognize numbers. For TC2, one group received red name tags and the other group received black name tags so that it was easier for participants to differentiate between groups.

Figure 3.2: Experiment tools: conditionality cards, a token and answer scale
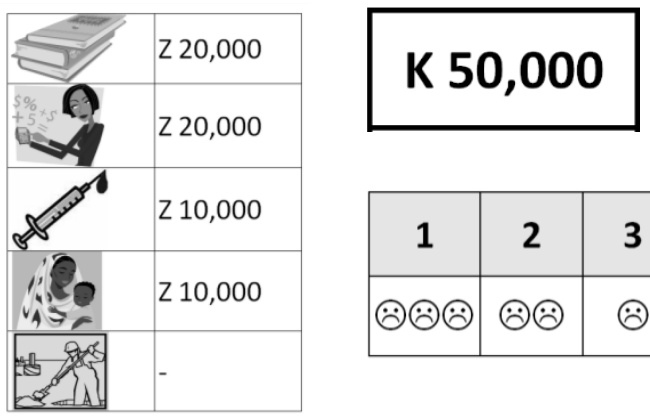

\begin{tabular}{|c|c|c|c|c|c|c|}
\hline 1 & 2 & 3 & 4 & 5 & 6 & 7 \\
\hline 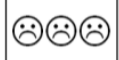 & 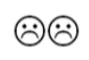 & : & :) & (;) & (:); & (:)(:); \\
\hline
\end{tabular}

Every experiment participant received 20 tokens in paper form, which $\mathrm{s} / \mathrm{he}$ then had to distribute across 10 different plastic cups, which represented the 10 token-receiving individuals. Each cup had a number for the respective experiment participant on it and the enumerator also mentioned the name of each experiment participant to make sure that experiment participants did not confuse numbers and participants. Names were mentioned once more when the enumerator counted the number of tokens in each plastic cup in order to give the experiment participant the choice to make any further corrections. For subsequent questions on satisfaction or agreement with statements, we showed experiment participants a scale with smileys, where they could just point to a smiley that reflected their mood.

\section{Credibility}

The experiments were carefully introduced in the respective communities. Prior to entering the community for experiments, each community received a letter of introduction and was visited by one member of the team who informed the community about the research activities in more detail. The research project was introduced as a joint project by the University of Maastricht and University of Zambia and all interviewers were recruited from Monze district due to their familiarity with the language and the context. Even if the experiments were an unfamiliar activity, the institutions and people carrying out the experiment were not seen as completely foreign. Given that pay-outs directly followed the experiment, there was less 
uncertainty or concern of experiment participants that they would not receive their share.

\section{Sampling \& recruitment}

Due to the fact that the selection was at least partially randomized, the experiment does not face the same degree of selection bias as other experiments that explicitly invite and take all participants responding to their advertisement. With around two thirds of Zambia's population in poverty (see section 1.4), the poverty composition of the group approximates the poverty shares in the national population. Regarding the representativeness of groups for the average composition of a CWAC, we need to be more cautious. Even though CWACs usually comprise members of different socioeconomic background, members from the very poor category might be overrepresented in the experiment. CWAC members are not allowed to benefit from the welfare programs themselves, which tends to discourage those who are very poor from volunteering as CWAC members. Our pool of volunteers is, however, likely to share the motivation and engagement of those serving on community committees as they volunteered to come to the meeting and participate in an experiment, even though no promises about financial remuneration were made at this point.

The selection of experiment participants was based on their externally assessed poverty status. It is therefore important that the judgment of the poverty status is consistent across communities. In order to guarantee consistency, the same person on the research team with extensive participatory research skills managed the pre-survey in communities. He relied on assistance from members of the CWAC from the respective community in filling in the pre-surveys but was asked to ensure quality control of the data and consistency in assessments.

\section{Clear communication of rules}

The rules of the experiment were explained twice to the experiment participants, one time to the entire group by a person who had particular experience in participatory research and subsequently, a second time by the enumerator. During the initial round of explanation, experiment participants were asked to repeat some of the rules and also make some simple calculations together. To make it easier, cards with graphic illustrations for the tokens as well as for the different conditions were shown throughout the instruction round. As at any stage during the experiment, participants were guided and could ask further questions to the enumerator, we can safely assume that the basic rules of the experiment were understood.

\section{Desirability of cash}

Based on the fact that the SCT program has operated in the district without any market constraints and that there were no recent shocks that could have led to a malfunctioning 
of markets, we opted for cash as an incentive. All experiment participants appeared to be satisfied with this choice.

\section{Cross talk}

Cross talk was of a particular concern for us when playing the experiment with TC2. We tried to physically separate waiting places for the groups after they had a joint round of introduction to avoid any secret agreements. Group 2 usually started the individual round of the experiment when Group 1 was playing the group round so that there was little possibility for interaction. Within one group, we also limited the time for cross talk by having 5 enumerators that played the experiment with 2 individuals each. Usually all individuals started the experiment at the same time, avoiding a situation where those who finished earlier could have influenced the late starters. Individuals were then interviewed about their experiment choices one after the other. Individuals were seated in a way that nobody could see the decisions they made. This gave individuals space and freedom to decide and also made sure that one allocation pattern did not influence someone else's decisions.

\subsubsection{Experiment implementation}

Overall, the implementation of the experiment went satisfactorily, in particular when we consider that the preparation and implementation of field experiments was new territory for the enumerators as well for the communities. Enumerators went through a one week training including a dry-run of the experiment, exercises in their community and a more extensive field test in the community of Manungu. They had to pass an exam at the end of the training and continued to be coached during the initial days of the experiment by two Zambian colleagues from the University of Zambia who accompanied them during the interviews and corrected any misunderstandings.

\subsubsection{Sampling}

When looking at differences in household characteristics according to the externally assessed poverty status (see table 3.3), poverty assessments appear reasonable. We predominantly find beneficiary households of the SCT scheme among the very poor and the poor, with a few belonging to the group of better-off. The better-off have the greatest share of active households and correspondingly, the lowest number of experiment participants who are too ill or disabled to carry out any work. They also have paid labor as one of the main sources of income next to own produce, have the most spacious accommodation, the best quality housing, the greatest number of livestock and land and more meals per day than the very poor and poor. 
Table 3.3: Characteristics of experiment participants according to their externally assessed poverty level

\begin{tabular}{|c|c|c|c|}
\hline & $\begin{array}{l}\text { Very } \\
\text { poor }\end{array}$ & Poor & $\begin{array}{l}\text { Better- } \\
\text { off }\end{array}$ \\
\hline \multicolumn{4}{|l|}{ Total number } \\
\hline & 150 & 201 & 149 \\
\hline$\%$ beneficiaries & $16 \%$ & $12 \% * * *$ & $1 \% * * *$ \\
\hline$\%$ CWAC members & $6 \%$ & $9 \%$ & $14 \% * *$ \\
\hline
\end{tabular}

\begin{tabular}{|l|l|l|l|}
\hline \hline Gender & \multicolumn{3}{l|}{} \\
\hline \hline Female & $68 \% * *$ & $56 \%$ & $52 \% * * *$ \\
\hline Male & $32 \%$ & $44 \%$ & $48 \%$ \\
\hline
\end{tabular}

\begin{tabular}{|l|l|l|l|}
\hline \hline Average age & \multicolumn{3}{l|}{} \\
\hline \hline & $58^{* * *}$ & $50^{* *}$ & $46^{* * *}$ \\
\hline
\end{tabular}

\begin{tabular}{|l|l|l|l|}
\hline \hline \multicolumn{4}{|l|}{ Level of activism } \\
\hline \hline Very active $(\mathrm{DR}=0)$ & $11 \%$ & $8 \%$ & $11 \%$ \\
\hline Active $(0<\mathrm{DR}<3)$ & $35 \%$ & $43 \%$ & $47 \% * * *$ \\
\hline Inactive $(3<=\mathrm{DR}<5)$ & $21 \%$ & $19 \%$ & $18 \%$ \\
\hline Very inactive $(\mathrm{DR}>=5)$ & $33 \%$ & $30 \%$ & $24 \% *$ \\
\hline
\end{tabular}

\begin{tabular}{|c|c|c|c|}
\hline \multicolumn{4}{|c|}{ Average number of meals } \\
\hline & 2.35 & $2.38 * * *$ & $2.72 * * *$ \\
\hline \multicolumn{4}{|c|}{ Average number of hectare cultivated } \\
\hline & $1 * * *$ & $1.3 * * *$ & $1.77 * * *$ \\
\hline \multicolumn{4}{|c|}{ Average number of rooms of the main house } \\
\hline & $1.75 *$ & $2.00 * * *$ & $2.53 * * *$ \\
\hline \multicolumn{4}{|c|}{ State of housing } \\
\hline Good & $5 \%$ & $7 \% * *$ & $13 \% * *$ \\
\hline Average & $32 \% * * *$ & $54 \%$ & $59 \% * * *$ \\
\hline Bad & $62 \% * * *$ & $39 \% * *$ & $28 \% * * *$ \\
\hline
\end{tabular}

\begin{tabular}{|l|l|l|l|}
\hline \hline \multicolumn{4}{|l|}{ Livestock holdings } \\
\hline \hline Cattle & $0.49^{*}$ & $.87 * * *$ & $2.62 * * *$ \\
\hline Goats & $.63 * * *$ & $1.33 * * *$ & $2.79 * * *$ \\
\hline Chickens & $2.79 * * *$ & $4.86^{* *}$ & $6.66^{* * *}$ \\
\hline
\end{tabular}

\begin{tabular}{|c|c|c|c|}
\hline & $\begin{array}{l}\text { Very } \\
\text { poor }\end{array}$ & Poor & $\begin{array}{l}\text { Better- } \\
\text { off }\end{array}$ \\
\hline \multicolumn{4}{|l|}{ Main occupation } \\
\hline Farmer/herder & $63 \%$ & $69 \%$ & $71 \%$ \\
\hline Unpaid family worker & $1 \%$ & $3 \%$ & $1 \%$ \\
\hline Mining & $1 \% *$ & $0 \%$ & $1 \%$ \\
\hline Trader & $6 \% *$ & $2 \%$ & $3 \%$ \\
\hline Self-employed & $0 \% * * *$ & $5 \%$ & $2 \% *$ \\
\hline Government & $0 \%$ & $1 \% * * *$ & $9 \% * * *$ \\
\hline Other wage employment & $1 \%$ & $1 \%$ & $3 \%$ \\
\hline Piecework & $12 \%$ & $12 \%$ & $8 \%$ \\
\hline Retired & $0 \%$ & $0 \%$ & $1 \%$ \\
\hline Too ill/disabled to work & $15 \% * * *$ & $7 \% * * *$ & $1 \% * * *$ \\
\hline Other & $1 \%$ & $1 \%$ & $1 \%$ \\
\hline
\end{tabular}

\begin{tabular}{|l|l|l|l|}
\hline \multicolumn{4}{|l|}{ Main source of income } \\
\hline \hline Community Assistance & $26 \% * * *$ & $12 \% * * *$ & $2 \% * * *$ \\
\hline Government Assistance & $3 \%$ & $3 \%$ & $2 \%$ \\
\hline Pension & $1 \%$ & $0 \%$ & $1 \%$ \\
\hline Own Business & $7 \%$ & $8 \%$ & $5 \%$ \\
\hline Own Produce & $57 \% * *$ & $68 \%$ & $70 \% * *$ \\
\hline Rental income & $1 \%$ & $1 \%$ & $2 \%$ \\
\hline Paid labor & $7 \%$ & $10 \% * * *$ & $21 \% * * *$ \\
\hline Other & $1 \%$ & $0 \%$ & $0 \%$ \\
\hline
\end{tabular}

\begin{tabular}{|l|l|l|l|}
\hline \hline \multicolumn{5}{|l|}{ Status } & $5 \%$ & $6 \%$ & $9 \%$ \\
\hline \hline Headman & $1 \%$ & $1 \%$ & $2 \%$ \\
\hline Chairperson & $0 \%$ & $0 \%$ & $1 \%$ \\
\hline Treasurer & $0 \% * *$ & $3 \%$ & $5 \% * * *$ \\
\hline Secretary & $5 \%$ & $9 \%$ & $13 \% * * *$ \\
\hline Committee member & $1 \%$ & $0 \% * * *$ & $6 \% * * *$ \\
\hline Teacher & $1 \%$ & $1 \%$ & $1 \%$ \\
\hline CHW/TBA & $0 \%$ & $0 \%$ & $0 \%$ \\
\hline Councilor & $0 \%$ & $0 \% *$ & $1 \%$ \\
\hline Court & & & \\
\hline
\end{tabular}

$* 10 \%$ significance level $* * 5 \%$ significance level $* * * 1 \%$ significance level; statistical differences across participants of different poverty backgrounds are reported as follows: for the difference between the very poor and poor, the significance level is indicated in the column of the very poor; between the poor and the better-off in the column of the poor and between the very poor and better-off in the column of the better-off

\section{Source: Pre-survey}


When compared to the poor, the very poor are on average 8 years older and have a greater share of women. They have smaller land and livestock holdings, worse housing conditions and more people who are too ill or disabled to work and who rely on community assistance.

Sixty percent of groups playing the experiments had the desired group composition of 3 very poor, 4 poor and 3 better-off participants. In 14\% of all experiments, there was one or two more very poor as envisaged; in $18 \%$ of all experiments, there was an additional poor person and in $8 \%$ of all experiments we saw an additional better-off person playing. These differences to the original design can be explained by the fact that in a few cases the poverty status was reconsidered after the randomization ${ }^{38}$ and that in a number of groups, participants on the stand-by list were called upon who did not always share the same poverty status.

\subsubsection{Experiment rounds \& survey}

Overall, the implementation of the different experimental rounds and the administration of the surveys went smoothly. The implementation of the experiment only deviated from the design in a few initial cases. Enumerators in community Freedom B used TC1 of the experiment for the first round and TC2 for the second round. ${ }^{39}$ In Sigubbu, two enumerators made a mistake when recording the relationship status of the participants they interviewed. In order to avoid introducing any bias, we excluded this data from the analysis.

Experiment participants confirmed that they felt comfortable with the selection into the experiment and the experiment process. Altogether, experiment participants enjoyed the experiments and a number of them stated that they had learned something from the experiments and surveys. The experiment proved a welcome variation to the surveys that they had experienced until then. Experiment participants were also enthusiastic about the randomized selection process into the experiments as they felt that this was a fair and objective method.

\subsubsection{Data entry}

In order to ensure a quality data entry process in CSPro, questionnaires were doubleentered and quality checks were carried out by several people. Quality checks consisted of consistency checks and random comparisons of the questionnaires with the data entered. Unfortunately, questionnaires of the first round for Freedom A and 5 questionnaires of the first round for Kambaza, detailing the experiment results for each experiment participant, were lost during the data entry process in Zambia. ${ }^{40}$ Only the

\footnotetext{
${ }^{38}$ Whenever there were any doubts that the poverty classification in the pre-survey did not match with participants' appearance, the poverty-status was double-checked with local CWAC members.

${ }^{39}$ Some enumerators repeated this mistake in Kayuni, which was however corrected afterwards.

${ }^{40}$ As this happened randomly, it should not bias our results.
} 
final allocation of tokens and conditions to each participant could be reconstructed using the excel sheet which was used to calculate the pay-outs. The second round data for these individuals was equally excluded from the analysis to ensure that individual and group outcomes were comparable.

\subsection{Conditionality preferences ${ }^{41}$}

In the experiment, participants had to decide for each recipient whether they wanted to condition the transfer and if so, what kind of conditionality they preferred. About $68 \%$ of all transfers were conditioned despite the fact that a condition in the experiment translated into a transfer reduction for the respective recipient. This shows that individuals largely preferred conditionality in a SCT program and were willing to accept the costs. Conditionality decisions did not vary greatly by the relationship that giver and receiver had: about two thirds of all transfers, whether to family members, friends, to oneself or to people to whom the giver had no relationship, were conditioned. The only group that received substantially fewer conditional transfers (about $42 \%$ of them) were people with a prominent position in the community.

The official reason mentioned for more than half of all positive conditionality decisions was "to guide the beneficiary" (56\%), followed by "to avoid abuse" (39\%) and "avoid laziness" $(16 \%) .{ }^{42}$ Reasons for not conditioning were primarily that it was considered unnecessary for $68 \%$ of all unconditional transfers - in particular for recipients to whom the giver had a relationship and recipients who were better-off - , too costly for the recipient (19\% of all UCT) and too much work ( $6 \%$ of all UCT). Infrastructure and quality service considerations as well as the fear of no self-determination for recipients and stigmatization were mentioned for about $3 \%$ of all unconditional transfers and therefore did not figure as prominently as the literature suggests.

The majority - about three-quarter of those who opted for conditionality - decided to place one condition out of the five conditionality options. Seventeen percent placed two conditions. The negligibly small percentage of people voting for all five conditions $(0.2 \%)$ is probably due to the fact that five conditions were judged too much for the transfer amount given. So we see that people were sensitive to the additional burden that conditionality might bring. Taking the perspective of the recipient, we observe that the majority of participants ended up receiving more than one condition. Aggregating conditions that individuals received from other participants, we see that individuals received on average 3.3 conditions of different types.

\footnotetext{
${ }^{41}$ Targeting preferences and decisions are discussed separately in chapter 5. Targeting motives are however also discussed as one of the determinants for conditionality choices in this chapter.

${ }^{42}$ Givers were allowed to state multiple motives.
} 
Education was the preferred conditionality. Most transfers (60\%) were conditional on education, followed by conditions in health $(22 \%$ for growth monitoring and $18 \%$ for vaccinations) and then public works (17\%). The training condition was least used $(11 \%)$. This shows that education must have been greatly valued by experiment participants, in particular as it also had the greatest financial implications for the respective recipient. It does not mean, however, that most households were not in compliance with the education conditionality. The choice of the conditionality was mainly motivated (in $82 \%$ of all conditionality choices) by the fact that givers wanted to guide the beneficiary through the conditionality, signaling the importance and value of education. Only $12 \%$ imposed a conditionality arguing that the recipient was not engaging in the activity prescribed.

In order to have a better understanding of the determinants of conditionality choices and their relative weight, we assess the impact of different factors that are proposed in the literature in a regression framework. The most intuitive appeal of conditionality is the possibility to control behavior and in this way solve the principal-agent problem. We therefore expect individuals with low levels of trust to condition more. We would also expect that fewer conditions are placed on the unproductive and very poor, due to the consideration that conditionality presents a cost to beneficiaries. It is furthermore probable that the poor and possibly also women as givers are more sensitive to the costs of conditionality. They are the ones most affected by it, either by risking exclusion from the program or having to bear the (in)direct costs of compliance. Also individuals regarding social transfers as an entitlement by government might be more reluctant to use conditionality.

We estimate the following logit model, running different regressions for the full sample (model 1) and for the sub-sample in TC1 (model 2):

$$
\operatorname{Prob}\left(\mathrm{Y}_{\mathrm{ij}}=1\right)=\alpha+\beta \mathbf{D}_{\mathrm{i}}+\gamma \mathrm{c}_{\mathrm{i}}+\delta \mathbf{T}_{\mathrm{i}}+\varepsilon \mathbf{A}_{\mathrm{i}}+\zeta \mathbf{X}_{\mathrm{i}}+\eta \mathbf{X}_{\mathrm{j}}+\theta \mathbf{E}_{\mathrm{i}}+\mathrm{u}_{\mathrm{ii}}
$$

where

Prob $\left(Y_{i j}=1\right)=$ probability that giver $i$ conditions the transfer for recipient $\mathrm{j}$

$\mathbf{D}_{\mathrm{i}}=$ vector of different distribution behaviors of giver i

$\mathrm{c}_{\mathrm{i}}=$ conditionality perception of giver $\mathrm{i}$

$\mathbf{T}_{\mathrm{i}}=$ vector of trust variables of giver $\mathrm{i}$

$\mathbf{A}_{\mathrm{i}}=$ vector of attitude variables of giver i regarding the responsibility for the poor ${ }^{43}$

$\mathbf{X}_{\mathrm{i}}=$ vector of background characteristics of giver i

$\mathbf{X}_{\mathrm{j}}=$ vector of background characteristics of recipient $\mathrm{j}$,

$\mathbf{E}_{\mathrm{i}}=$ vector of experiment conditions for giver i

\footnotetext{
${ }^{43}$ Givers were not asked to rank stakeholders with respect to their responsibility for the poor but to determine for each stakeholder separately to what degree $\mathrm{s} / \mathrm{he}$ is responsible. There is no strong correlation between these responsibility variables, meaning that they do not cause any problems of multi-collinearity in the regression analysis.
} 
$\alpha=$ constant

$\beta, \delta, \varepsilon, \zeta, \eta, \theta=$ vectors of coefficients to be estimated

$\gamma=$ coefficient to be estimated

$\mathrm{u}_{\mathrm{ii}}=$ error term

The higher the number of tokens allocated to a particular recipient, the greater the probability that the giver decided to condition the transfer (see table 3.4). This might reflect that givers are more concerned with guiding recipients' behavior and preventing abuse when the monetary stakes are higher. Whereas progressive givers ${ }^{44}$ were less inclined to condition cash transfers, egalitarian givers felt a greater need to condition. Progressive givers might have more faith in recipients' capacity to spend the money according to their priority needs while egalitarian givers might be giver types who are more risk-averse and shy away from making mistakes in their allocation and conditionality decisions. $^{45}$

If we focus on the sub-sample of individuals in TC 1, which was allowed to behave selfishly and allocate tokens to themselves, progressive or egalitarian distribution patterns no longer have a statistically significant effect on conditionality decisions. Selfish givers, those who allocated a greater number of tokens to themselves than they would have been entitled to according to their poverty status, ${ }^{46}$ had a lower probability of conditioning. This is not necessarily related to their intention of not conditioning themselves as evidenced by section 3.4 .1 but could be due to the fact that the amounts they allocated to others were smaller and they saw less need for conditionality or did not want to decrease the amount even further.

Givers who had characterized conditionality as disempowering, also conditioned fewer transfers, meaning that stated and revealed preferences coincided. This is by far the strongest effect on individuals' conditionality decisions and an insightful finding, in particular for later comparisons of experiment outcomes to survey evidence.

Trust comes out as an important factor in conditionality decisions, confirming the theory that conditionality is a tool to control uncertain behavior. Distrust vis-à-vis the community leads to a higher probability of conditioning the transfer. Assuming that trust levels are higher among people who know each other, we included a proximity variable in the regression. Transfers going to those who the giver knows (very) well are less conditioned. ${ }^{47}$ Givers who are convinced of a certain level of fairness in the community and do not expect to be exploited are also less likely to condition the transfer. This could also be an indication that they trust the intensions of other community members.

\footnotetext{
${ }^{44}$ Givers were considered progressive when the very poor received more than they would have received through an equal distribution.

${ }^{45}$ For more information about egalitarian allocation preferences, see section 5.3.2.

${ }^{46}$ See section 5.3.4 for a more detailed discussion of selfishness in allocation decisions.

${ }^{47}$ It is however difficult to say for sure whether unconditional transfers to those one knows are a result of higher trust or reluctance to impose costs on receivers one is close with.
} 
Table 3.4: Logistic regression on the determinants of individual conditionality choices

Dependent variable: Indicator variable that equals 1 if transfer was conditioned

\begin{tabular}{|c|c|c|c|c|c|c|}
\hline \multirow{3}{*}{$\begin{array}{l}\text { Explanatory variables } \\
\text { Number of tokens allocated }\end{array}$} & \multicolumn{3}{|c|}{ Model 1} & \multicolumn{3}{|c|}{ Model 2} \\
\hline & \multicolumn{6}{|c|}{ Coefficients } \\
\hline & 0.08 & $* *$ & $(0.04)$ & 0.07 & * & $(0.04)$ \\
\hline $\begin{array}{l}\text { Progressive giver with the very poor receiving more than through } \\
\text { equal distribution }(0=\text { No, } 1=\text { Yes })\end{array}$ & -0.32 & $*$ & $(0.17)$ & -0.31 & & $(0.24)$ \\
\hline $\begin{array}{l}\text { Egalitarian giver, allocating the same number of tokens to every } \\
\text { group member }(0=\mathrm{No}, 1=\text { Yes })\end{array}$ & 0.35 & $*$ & $(0.20)$ & 0.00 & & $(0.33)$ \\
\hline $\begin{array}{l}\text { Giver agrees with helping people who cannot do anything in } \\
\text { return }(0=\text { No, } 1=\text { Yes })\end{array}$ & 0.13 & & $(0.28)$ & 0.56 & & $(0.51)$ \\
\hline $\begin{array}{l}\text { Selfish giver, allocating more to oneself than one would have } \\
\text { been entitled to }(0=\text { No, } 1=\text { Yes })\end{array}$ & & & & -0.50 & ** & $(0.24)$ \\
\hline Giver thinks that conditionality disempowers $(0=\mathrm{No}, 1=\mathrm{Yes})$ & -2.89 & $* * *$ & $(0.39)$ & -3.59 & $* * *$ & $(0.42)$ \\
\hline $\begin{array}{l}\text { Giver agrees that the community cannot be trusted } \\
(0=\text { No, } 1=\text { Yes })\end{array}$ & 0.63 & $* *$ & $(0.27)$ & 0.54 & & $(0.41)$ \\
\hline $\begin{array}{l}\text { Degree to which the giver knows the recipient } \\
(0=\text { not really }-->4=\text { =ery well })\end{array}$ & -0.12 & $* *$ & $(0.05)$ & -0.23 & $* * *$ & $(0.08)$ \\
\hline $\begin{array}{l}\text { Giver thinks that overall people try to be fair rather than to } \\
\text { exploit others }(0=\text { No, } 1=\text { Yes })\end{array}$ & -0.42 & $* * *$ & $(0.16)$ & -0.44 & ** & $(0.21)$ \\
\hline $\begin{array}{l}\text { Giver agrees that the government is responsible for the poor } \\
(0=\text { No, } 1=\text { Yes })\end{array}$ & -0.98 & $* * *$ & $(0.37)$ & -0.80 & & $(0.57)$ \\
\hline $\begin{array}{l}\text { Giver completely agrees that the community is responsible for } \\
\text { the poor }(0=\text { No, } 1=\text { Yes })\end{array}$ & 0.33 & * & $(0.18)$ & 0.77 & $* *$ & $(0.33)$ \\
\hline Gender giver $($ male $=0$, female $=1)$ & -0.19 & & $(0.17)$ & -0.32 & & $(0.24)$ \\
\hline Giver poverty assessment: very poor $(0=\mathrm{No}, 1=\mathrm{Yes})$ & 0.08 & & $(0.21)$ & -0.11 & & $(0.28)$ \\
\hline Giver poverty assessment: poor $(0=\mathrm{No}, 1=\mathrm{Yes})$ & 0.16 & & $(0.19)$ & 0.34 & & $(0.27)$ \\
\hline Age giver & 0.01 & & $(0.01)$ & 0.01 & & $(0.01)$ \\
\hline $\begin{array}{l}\text { Giver has an important position in the community } \\
(0=\mathrm{No}, 1=\text { Yes })\end{array}$ & 0.22 & & $(0.20)$ & 0.17 & & $(0.31)$ \\
\hline Gender recipient $(0=$ male, $1=$ female $)$ & -0.09 & & $(0.09)$ & -0.15 & & $(0.14)$ \\
\hline Recipient poverty assessment: very poor $(0=\mathrm{No}, 1=\mathrm{Yes})$ & 0.16 & & $(0.09)$ & 0.13 & & $(0.14)$ \\
\hline Recipient poverty assessment: poor $(0=\mathrm{No}, 1=\mathrm{Yes})$ & 0.18 & $* *$ & $(0.07)$ & 0.37 & $* * *$ & $(0.12)$ \\
\hline Age recipient & 0.00 & & $(0.00)$ & 0.00 & & $(0.00)$ \\
\hline $\begin{array}{l}\text { Recipient has an important position in the community }(0=\mathrm{No} \text {, } \\
1=\text { Yes })\end{array}$ & -0.20 & $* *$ & $(0.10)$ & -0.18 & & $(0.15)$ \\
\hline Number of $0-5$ in recipient household & 0.05 & & $(0.03)$ & 0.12 & ** & $(0.05)$ \\
\hline Recipient is too old $/$ sick to work $(0=\mathrm{No}, 1=\mathrm{Yes})$ & -0.13 & & $(0.17)$ & 0.17 & & $(0.23)$ \\
\hline $\mathrm{SCT}$ community $(0=$ non-SCT, $1=\mathrm{SCT})$ & -0.37 & $* *$ & $(0.17)$ & -1.50 & $* * *$ & $(0.25)$ \\
\hline Treatment condition $(0=\mathrm{TC} 1,1=\mathrm{TC} 2)$ & 0.24 & & $(0.16)$ & & & \\
\hline Constant & 1.95 & $* * *$ & $(0.65)$ & 2.30 & $* *$ & $(1.06)$ \\
\hline Pseudo R2 & 0.13 & & & 0.22 & & \\
\hline $\mathrm{N}$ & 3918 & & & 1878 & & \\
\hline
\end{tabular}


Logistic regression. In parentheses, robust standard errors, adjusted for clustering on givers. $* 10 \%$ significance level $* * 5 \%$ significance level $* * * 1 \%$ significance level. Model $1=$ full sample, Model 2 = restricted sample to groups in TC1. Reference group for Model $1=$ male, non-(very) poor givers in non-SCT communities in TC1 with no important position in the community who allocate tokens regressively, who do not agree with helping people who cannot do anything in return, who think that conditionality empowers, who do not agree that the community cannot be trusted, who do not know the recipient, who think that overall people try to exploit others, who do not agree that the government is responsible for the poor and who do not completely agree that the community is responsible for the poor, who give to non-(very) poor recipients who do not have an important position in the community and are not too old/sick to work. Reference group for Model $2=$ male, non-(very) poor givers in non-SCT communities with no important position in the community who allocate tokens regressively but not selfishly, who do not agree with helping people who cannot do anything in return, who think that conditionality empowers, who do not agree that the community cannot be trusted, who do not know the recipient, who think that overall people try to exploit others, who do not agree that the government is responsible for the poor and who do not completely agree that the community is responsible for the poor, who give to non-(very) poor recipients who do not have an important position in the community and are not too old/sick to work.

\section{Source: Experiment - pre-survey, Experiment - individual allocation round, Experiment - survey I, Experiment - survey II}

Those who thought that the government should be responsible for taking care of the poor were less inclined to condition cash transfers. This could mean that they viewed support from the government as an entitlement, given without any conditions attached. The opposite can be said for givers who felt strongly that the community had a responsibility for the poor. One possible reason is that the idea of a mutual agreement and responsibility on both sides is more strongly anchored at the community level, with the community not serving as the same category of provider as government.

Giver characteristics played a less important role, which refutes our initial assumption that poorer and possibly female givers were more sensitive to the costs of conditionality. The only scenario where gender proves statistically significant is if we run a regression for the sub-set of individuals in SCT-communities in TC1.

Background characteristics of the recipients, on the contrary, mattered more for conditionality decisions. There is little support for our initial hypothesis that recipients least able to comply with conditionality would be less conditioned. Poorer recipients had a higher probability of being conditioned. This counter-intuitive finding is easier to comprehend once we take a closer look at the positive connotation that participants had of conditionality (see section 3.4.1). Community members with an important position were less conditioned, possibly because they were deemed to require less guidance on the appropriate use of cash transfers. The same argument can also explain why individuals from communities with prior SCT experience saw less need for conditioning. Those who had experience with recipients putting cash transfers to good use in the past were more reassured and probably concluded that recipients would require less guidance. 


\subsection{Compatibility of preferences}

We now want to contrast the individual preferences distilled through the experiment with the perspectives of different stakeholders. We first compare the experiment outcomes with preferences of (potential) beneficiaries, whom we expect to be more sensitive to the costs of conditionality and to have better insight into the need for optimizing their choices. We then relate experiment outcomes of rural Zambia to conditionality preferences of the urban population whom we expect to be more politically active and decisive. The opinions of (future) decision-makers are scrutinized afterwards, letting us assess in what way they are in line with rural and urban preferences. Last, we look at the group outcomes of the experiment and analyze to what extent decentralized decision-making reflects individual preferences as well as national political priorities.

\subsubsection{Preferences of (potential) beneficiaries}

Altogether 216 beneficiaries from 17 different communities in Monze district were interviewed. ${ }^{48}$ We differentiated between beneficiaries who actually thought they were subject to conditionality in the SCT program and those who answered the question about conditionality hypothetically. ${ }^{49}$ Close to all beneficiaries $(97 \%)$ who believed in being subject to conditionality self-assessed that the conditionality had empowered them. Not a single beneficiary perceived the conditionality as disempowering.

This empowerment effect is also noted for those beneficiaries who did not believe themselves to be subject to conditionality. The majority (92\%) considered conditionality as empowering, while $8 \%$ stated that they perceived conditionality as disempowering. Experiment participants who were not benefiting from the SCT scheme were also asked about their perceptions of conditionality. When asked hypothetically, rural participants answered in a similar way as beneficiaries, stating for the most part $(88 \%)$ that they would perceive conditionality as empowering. About $10 \%$ characterized it as disempowering. The outcome neither differs statistically across poverty groups nor across gender. This positive association with conditionality confirms earlier statements by rural participants who when arguing why they had not conditioned transfers, did not mention "being patronized" as one of their main concerns.

\footnotetext{
${ }^{48}$ The choice of communities was determined by the random selection of locations for the community experiments. At least 6 beneficiaries were interviewed in each community. See section 4.3 for more details on the beneficiary survey and Annex 7 for the questionnaire.

${ }^{49}$ This differentiation is made as the experiment in Monze, which intended to test the difference between unconditional and conditional cash transfers and originally differentiated between conditional and unconditional communities, was not implemented as planned. 
The perceived empowerment effect by (potential) beneficiaries is in line with the experimental evidence on conditionality. As several authors have, however, highlighted the negative implications of conditionality for beneficiaries, we carried out different robustness checks to ascertain that this empowerment effect was real. First of all, enumerators made sure that respondents referred to the conditionality and not the transfer itself when answering the question on empowerment. ${ }^{50}$

Secondly, we also tried to get more information as to why respondents characterized conditionality as empowering. According to interviews with local stakeholders and beneficiaries themselves, beneficiaries appreciated the guidance of the conditionality in making choices. For them, greater flexibility did not necessarily translate into greater utility but greater insecurity as to what would be the best decision to make. Having no official rules, beneficiaries were worried about breaching informal rules and being arbitrarily excluded from the program over time. Beneficiaries also appreciated conditionality as a negotiation tool in household decision-making processes.

Thirdly, the experiment and TC1 in particular had a built-in robustness check. The experiment in general allowed us to contrast stated and revealed preferences (see section 3.3), which we discovered to coincide. ${ }^{51}$ With TC1, givers had the chance to condition themselves; if the positive connotation of conditionality was merely presented to please the enumerator and eventually the policy-maker, we would expect participants to mainly decide against conditionality for tokens allocated to themselves. Seventy percent of participants in TC1 conditioned tokens going to themselves. This either means that conditionality is indeed perceived as positive guidance, that conditionality is used as a commitment device or that givers felt guilty about giving tokens to themselves and therefore committed to do something in exchange.

If guilt was the main driver, we would expect a higher proportion of very generous self-allocations to be conditioned. We observe, however, that more generous transfers of 5-20 tokens are less often conditioned (50\% on average) than self-transfers of 1-4 tokens $(77 \%$ on average). Self-conditioning is stronger among individuals from nonSCT communities with $85 \%$ of self-transfers being conditioned, compared to $61 \%$ from SCT communities. The difference is statistically significant at the $1 \%$ level. This could also mean that guidance was deemed more important in communities that had not experienced the rules as well as the effects of a SCT scheme, demonstrating once more the signaling effect of conditionality in cases of uncertainty. It therefore appears plausible that participants either viewed conditionality as a positive reinforcement or regarded it as a useful tool for self-commitment.

\footnotetext{
${ }^{50}$ Whether psychologically it is possible for people to neatly separate the two is difficult to say. We can however conclude that conditionality - at the very least - did not evoke any negative feeling.

${ }^{51}$ The fact that $85 \%$ of those who considered conditionality as disempowering did not condition themselves shows once more that people's stated and revealed attitudes are compatible and not purely coincidental.
} 


\subsubsection{Preferences of urban participants}

The majority of 435 urban participants in a survey about people's attitudes towards poverty, government assistance and conditionality ${ }^{52}$ opted for conditionality in SCT programs; $71 \%$ of those who decided in favor of a social transfer program conditioned the transfer. Among those who indicated that they had voted in the last election, a majority of $70 \%$ preferred CCTs, demonstrating its political potential if politicians were to turn cash transfers into an election issue. We can thus conclude that urban preferences are coherent with rural preferences. Regardless of the methodology used (experiment vs. survey) and the area sampled (rural vs. urban), we see similar conditionality preferences.

In order to explore the impact of different explanatory factors for conditionality preferences such as background characteristics and values of respondents, the following logit model could be estimated:

$$
\operatorname{Prob}\left(\mathrm{Y}_{\mathrm{i}}=1\right)=\alpha+\beta \mathbf{X}_{\mathrm{i}}+\gamma \mathbf{A}_{\mathrm{i}}+\mathrm{u}_{\mathrm{i}}
$$

where

$\operatorname{Prob}\left(Y_{i}=1\right)=$ probability of respondent $i$ to condition the transfer,

$\mathbf{X}_{\mathrm{i}}=$ vector of background characteristics of respondent i

$\mathbf{A}_{\mathrm{i}}=$ vector of attitudes towards poverty of respondent $\mathrm{i}$

$\alpha=$ constant

$\beta, \gamma=$ vectors of coefficients to be estimated

$\mathrm{u}_{\mathrm{i}}=$ error term

As we do not have randomized data, the following analysis is done on an exploratory basis and would have to be substantiated using a probability sample. Anyone characterizing him/herself as very poor ${ }^{53}$ and who had not completed any type of education was less likely to condition the transfer (see table 3.5). Here we find some evidence that giver characteristics could matter and that poorer respondents might either be more sensitive to the cost and time implications of conditionality or might consider the decision more carefully because they could be affected by it themselves. Those with a higher education could have greater expectations of what recipients should do with the money, displaying a more paternalistic attitude.

\footnotetext{
${ }^{52}$ For more details about the attitudinal survey, see section 6.4 and Annex 9.

${ }^{53}$ Respondents were asked to classify themselves as very poor, poor, middle, upper middle, rich, upper rich. Out of those opting for a social cash transfer program, 13 respondents classified themselves as very poor, 34 as poor, 149 as middle-income, 32 as upper-middle, 13 as rich and 2 as very rich. For the analysis, the upper middle, rich and upper rich categories were collapsed. 78
} 
Table 3.5: Logistic regression on determinants for conditioning transfers among the urban public

Dependent variable: Indicator variable that equals 1 if respondent preferred to condition the SCT

\begin{tabular}{|l|lc|}
\hline Explanatory variables & \multicolumn{2}{|c|}{ Coefficients } \\
\hline \hline Respondent is very poor $(0=\mathrm{No}, 1=\mathrm{Yes})$ & $-1.67 * *$ & $(0.78)$ \\
Respondent is poor $(0=\mathrm{No}, 1=\mathrm{Yes})$ & -0.32 & $(0.60)$ \\
Respondent is in the middle-income bracket $(0=\mathrm{No}, 1=\mathrm{Yes})$ & -0.54 & $(0.46)$ \\
Respondent has not completed any education $(0=\mathrm{No}, 1=\mathrm{Yes})$ & $-1.98 * * *$ & $(0.70)$ \\
Respondent has completed primary education $(0=\mathrm{No}, 1=\mathrm{Yes})$ & 0.46 & $(0.76)$ \\
Respondent has completed lower secondary $(0=\mathrm{No}, 1=\mathrm{Yes})$ & $-0.82 *$ & $(0.45)$ \\
Respondent has completed upper secondary $(0=\mathrm{No}, 1=\mathrm{Yes})$ & -0.18 & $(0.39)$ \\
Respondent agrees that incomes should be made more equal $(0=\mathrm{No}$, & $-0.58 *$ & $(0.35)$ \\
$1=Y e s)$ & -0.42 & $(0.44)$ \\
Respondent thinks that poverty is due to a lack of initiative of the & $-0.77 *$ & $(0.40)$ \\
poor $(0=\mathrm{No}, 1=\mathrm{Y} e s)$ & $2.04 * * *$ & $(0.46)$ \\
Respondent prefers targeting children $(0=\mathrm{No}, 1=\mathrm{Yes})$ & 0.10 & \\
Constant & 219 & \\
\hline \hline Pseudo $\mathrm{R}^{2}$ & $\mathrm{~N}$ & \\
\hline
\end{tabular}

Logistic regression. In parentheses, standard errors. * $10 \%$ significance level $* * 5 \%$ significance level *** $1 \%$ significance level. ${ }^{54}$ Reference group = rich respondents who have completed tertiary education, who do not agree that incomes should be made more equal, who do not think that poverty is due to a lack of initiative of the poor and who do not prefer to target children.

\section{Source: Attitudinal survey with the urban population}

Respondents who thought that incomes should be made more equal in society and whose priority target group would be children, were less inclined to condition. This could be related to the fact that those who stress the need for more equality and less competition view a public transfer as an unconditional right and children as deserving unconditional support. We can hypothesize that richer, better educated and more liberal voters would support conditionality and that the choice of the target group plays a role in conditionality decisions. This hypothesis would have to be tested using a representative sample.

\footnotetext{
${ }^{54}$ Significance levels are reported under the assumption that any selection bias is minimized by controlling for observable differences.
} 


\subsubsection{Preferences of policy-makers}

Altogether $68 \%$ of 44 interviewed civil servants at central, provincial and district level as well as Members of Parliament, opted for conditionality, with preferences strongest among civil servants across different Ministries at district and provincial level $(80 \%$ in favor of conditionality). While there seemed to be a general inclination towards conditionality, the rationale for this view varied across stakeholder groups. The need to guide as well as the encouragement to take initiative appeared to be more prevalent among staff members at different levels of MCDSS and other ministries, while the urge to demonstrate impact mattered most for Members of Parliament. Preferences of the rural and urban population are consequently in line with those of policymakers.

The only group of respondents with no majority favoring conditionality is the MCDSS, which is in charge of social protection and poverty alleviation programs $(50 \%$ in favor of conditionality). MCDSS staff opposed to conditionality were concerned that conditionality could drive up costs, overtax government capacity and weaken people's confidence in government's ability to deliver. There was also concern that conditionality would not be compatible with the MCDSS mandate of rendering unconditional assistance to those who qualified for support. MCDSS staff members in favor of conditionality saw the need for further guidance of beneficiaries and to avoid nurturing households' belief that government was in charge of everything and citizens did not have to take any responsibility.

Not only within MCDSS were opinions more nuanced than the averages might suggest. The majority of interview partners did not view conditionality as an either or question but looked more carefully at the conditions under which conditionality would be appropriate such as the transfer amount, the percentage of the transfer being conditioned, the target group and objective of the program, the management capacity of the country and the nature of conditionality. The concern for the target group is a factor we also encountered in the urban attitudinal survey.

In order to get a better idea about the attitudes of the next generation of decisionmakers, we also conducted the attitudinal survey with 396 university students. ${ }^{55}$ About $86 \%$ of students were in favor of conditioning transfers, with a higher probability of conditioning the transfers among female and richer students. ${ }^{56}$ Motives behind conditionality choices are similar for students and policy-makers. We can thus conclude that conditionality not only mirrors decision-makers' preferences but would also help politicians who prefer conditionality to get more political support from rural and urban voters.

\footnotetext{
${ }^{55}$ For more details about the attitudinal survey, see section 6.4 and Annex 9.

${ }^{56}$ Preferences of students as future policy-makers might change when they get more information about the target group and are faced with the (political) trade-offs of conditionality choices. It is, however, unlikely for the trend of preferences to be completely reversed. 80
} 


\subsubsection{Preferences of decentralized structures}

Individual preferences were still largely reflected by the group decisions in the experiment, even if fewer transfers were conditioned: $57 \%$ of all group transfers had a condition attached. Individual preferences and group outcomes diverge the most in SCT communities, where individuals' preference for conditioning is about 13 percentage points higher than group outcomes (see table 3.6).

Table 3.6: Percentage of individual and group transfers being conditioned, by community status

\begin{tabular}{|l|r|r|r|r|}
\cline { 2 - 5 } \multicolumn{1}{c|}{} & \multicolumn{2}{c|}{ Individuals } & \multicolumn{2}{c|}{ Groups } \\
\cline { 2 - 5 } \multicolumn{1}{c|}{} & Percentage & No of obs. & Percentage & No of obs. \\
\hline \hline Community status & $67 \%$ & 2639 & $54 \%$ & 281 \\
\hline \hline SCT community & $69 \%$ & 1510 & $62 \%$ & 160 \\
\hline Non-SCT community & \multicolumn{3}{|c|}{} \\
\hline
\end{tabular}

Source: Experiment - individual allocation round, Experiment - group allocation round

Why do individual preferences and group outcomes diverge? It could be due to the fact that participants were more reluctant to officially place conditionality on a fellow group member, that a person who did not believe in conditionality dominated the process, that no conditionality was the most common denominator or that the group process led to better information about the characteristics and behavior of recipients and generated greater trust. We cannot see any evidence for people being ashamed to publicly place a condition on fellow group members. Otherwise we would have expected to generally see fewer conditions for TC1 where participants had to make decisions for members of their own group. This is not the case as the greatest number of transfers is conditioned in non-SCT communities in TC1 $(76 \%)$. We equally cannot say that fewer conditions are a result of someone dominating the process. Eighty-three percent of all participants did not feel that the process was dominated by someone within the group and those who sensed the pressure by another group member were equally split across groups with no, few and many conditions.

It is therefore likely that the group process either generated more quality information, lowering the need to condition or that there was more heterogeneity of opinions, turning no conditionality into the default position in case there was no initial group consensus. More exposure to SCT coupled with better information, more trust and / or a greater variety of opinions in the group process probably reduced the likelihood of transfers being conditioned in SCT communities. The fact that more than $90 \%$ of all members felt (very) comfortable with the group outcome and, hence, with the smaller number of conditions shows, however, that individual preferences were still compatible with group outcomes. It also raises the question whether more exposure and information could also change the mind-set of policymakers. 
Similar to the individual experiment choices, the majority of conditioned transfers by the group only had 1 condition (76\%), followed by transfers that had 2 conditions (20\%). Group decisions also prioritized education as a condition. However, in contrast to individual choices, vaccinations were ranked lower by 9 percentage points and community work a lot higher by 18 percentage points. The increasing importance of community work could be explained by the fact that the group might have looked beyond the personal benefits of an individual and recognized advantages for the community.

\subsection{Concluding Remarks}

The unique feature of this chapter is that it provides evidence on conditionality preferences, which have been frequently modeled but not yet rigorously tested by economists and political scientists. Despite the inefficiencies conditionality introduces, conditionality has not only great appeal among policy-makers and richer voters but also among beneficiaries and the broader public, as demonstrated by the results of the allocation and conditionality experiment in rural communities. Two thirds of participants conditioned transfers in the experiment, even though their decision to condition the transfer had financial implications for the recipient. This shows a certain predilection for paternalistic policy-making.

The choice for conditionality was mainly driven by givers' distribution behavior, perceived trust levels, givers' associations with conditionality, their attitude regarding who should carry responsibility for the poor, recipients' poverty status as well as givers' prior experience with a SCT program. Progressive givers and those who viewed support as a responsibility of the government saw less need for conditionality; this contrasts with egalitarian givers and individuals who ascribed the community an important role in catering for the poor. Distrust and a greater desire to control individuals' behavior led to more conditioned transfers. Participants mainly equated conditionality with more information, guidance and security, which explains why poorer transfer recipients were more conditioned while those community members with a prominent position were less likely to be conditioned. More experience with $\mathrm{SCT}$, more information about recipients and transparency around all processes of a SCT program seem to obviate the need for conditioning to some extent.

Revealed preferences of rural respondents through the experiment matched the stated preferences by beneficiaries, urban respondents as well as policy-makers. The majority of beneficiaries and rural respondents to an attitudinal survey experienced conditionality in reality or hypothetically as empowering. They appreciated the signaling effect of conditionality, orienting beneficiaries' behavior and letting them know that they were in conformity with what was expected of them. This shows that (potential) beneficiaries would not derive greater utility from a completely unrestricted 
choice set of goods and services. The majority of urban respondents and the voters among them also favored conditionality. We can thus conclude that conditionality meets the interests of policy-makers, the general public and beneficiaries alike, exerting the necessary control for transfer givers and the guidance for transfer recipients.

Groups in the experiment conditioned on average fewer transfers, in particular those in SCT communities. Decentralized decision-making is therefore likely to produce slightly different outcomes than central decision-making. It is reasonable to assume that prior experience coupled with better information at the group level and greater trust might have led to fewer conditioned transfers. Relatively high satisfaction levels with the group outcome testify that individuals were still content with group choices and that group outcomes were compatible with their individual preferences.

Even if the political potential of conditionality should not be underrated, the experiment has also demonstrated that conditionality preferences are neither homogeneous nor static. If conditionality was more rigorously enforced and/or lead to greater costs on the side of beneficiaries than mimicked in the experiment or experienced in Zambia's SCT scheme, the predominantly positive associations of conditionality might change. This was for instance evidenced in the case of Brazil where actual enforcement produced different reactions than the initial announcement of conditionality (de Janvry, Finan et al. 2009). Time, experience and future consultations with those predominantly concerned will therefore be indicative of whether conditionality remains an individual preference as well as a political priority. 


\section{CHAPTER 4: Conditionality re-assessed - a focus on inefficiencies}

\subsection{Introduction}

The effectiveness of conditionality has been debated in many academic and practitioner circles and while more evidence has increasingly become available on the behavioral effects of conditionality, less attention has been paid to potential inefficiencies that conditionality introduces. As those inefficiencies can greatly reduce the effectiveness of conditionality and of the cash transfer program itself, they deserve being studied more carefully, prior to the introduction of conditionality as well as throughout the implementation process. Concerning inefficiencies, authors have mainly pointed to the negative motivational effects of imposing conditionality and have also cast their doubts as to whether the administration has the capacity to manage conditionality. There is however very little evidence that has substantiated some of the claims and which systematically and holistically analyses different sources of inefficiencies in a particular country context.

Inefficiencies can have different origins, which have been discussed in detail in chapter 2. The inclusion of conditionality can produce negative behavioral effects which at least partly undo the impact of conditionality. Conditionality can furthermore produce inefficiencies which are related to the way conditionality has been designed as well as the way it is being implemented. Regarding behavioral side effects, conditionality might motivate the household to alter consumption choices in other vital areas (for some examples, see: Baird, McIntosh et al. 2011), which could in the end lead to an overall sub-optimal welfare outcome for the household. In addition, households might perceive the introduction of conditionality as a sign of distrust and react demotivated or they might be demotivated once the conditionality is removed and revise any previous behavioral changes.

A sub-optimal design of conditionality introduces inefficiencies that either produce higher costs or reduce the effectiveness of conditionality. This happens when conditionality is used as a universal tool in SCT programming, without giving due considerations to the country context and without analyzing the need, the relative importance and the scope for improvement of conditionality in relation to the costs. CCTs are inefficient if they are paid to households or individuals who already display the required behavior (Das, Do et al. 2005; de Janvry and Sadoulet 2006a) or if they lead to sub-optimal behavior. Conditionality is also inefficient if constraints in social services are not predominantly behavior-related (Handa and Davis 2006; Schubert and Slater 2006; Lund, Noble et al. 2008) or if alternative, more cost-effective measures are available to respond to behavioral constraints such as better information campaigns or more intensive counseling. 
Conditionality can also lead to the exclusion of households that qualify for the program but that are unable to fulfill the conditionality due to factors beyond their control such as unavailability, irregularity or low quality of respective health and education services (Barrientos and de Jong 2006), socio-cultural factors (Adato and Hoddinott 2007) or the inadequacy of the amount to cover all related costs. Moreover, if there are serious problems on the supply side, conditionality might actually have a negative impact on the capacity of schools to absorb students and offer quality education.

With respect to implementation inefficiencies, conditionality can increase the direct as well as indirect costs of the administration as the extra time invested in managing and monitoring conditionality cannot be availed to the provision of other social services. Conditionality cannot only be a strain on the budget but also on the capacities of an administration due to the additional layer of complexity they add to the program (Tabor 2002; Bastagli 2008). Such a complexity can result in a chaotic implementation process, loss of credibility of the Ministry or agency in charge, demotivation of staff, non-provision of other key services, and eventually even failure of the program. Staff who certify conditionality are in a particular position of power vis-à-vis beneficiaries and might also abuse this, introducing greater corruptive practices.

In order to shed more light on the different inefficiencies that conditionality introduces in the context of a low-income country, we study the case of Zambia which has experimented with soft conditionality in one of its districts called Monze. Communities in Monze were randomly selected to either participate in the unconditional treatment arm of the experiment, the conditional treatment or to serve as a control group. In section 4.2 we introduce the conditionality design in Zambia, while section 4.3 briefly outlines the data and methodology used to assess the different inefficiencies in the Zambian context. Based on survey evidence, administrative data and secondary data such as the Living Conditions Monitoring Survey (LCMS) 2006 (CSO 2008), we analyze whether and to what extent conditionality has produced any unfavorable behavioral side effects (section 4.4), any inefficiencies through a sub-optimal design (section 4.5) and / or any implementation inefficiencies due to high costs and a weak administration (section 4.6). Section 4.7 concludes.

\subsection{Conditionality design in Monze}

The choice of conditionality in Zambia's pilot district Monze has been inspired by the experience of other countries - mostly in Latin America - that had put in place conditional SCT programs with health and education requirements. ${ }^{57}$ The final choice of conditions was not based on an in-depth prior analysis of education and health statistics. The areas of education and health were rather suggested by an evaluation expert team that was interested in studying the value added of conditionality. The

\footnotetext{
${ }^{57}$ For further information about the design of the social cash transfer pilot, consult section 1.4. 86
} 
precise requirements in the area of education and health were then established in a participatory process with the Department of Health and Education in the pilot district of Monze.

Concerning the area of education, the MCDSS decided to use enrollment in primary school as well as a regular attendance of $80 \%$ per term as conditions. ${ }^{58}$ Enrolment was restricted to primary education because of the additional costs and supply-side constraints related to secondary education in rural areas. With respect to health, the MCDSS chose to focus on preventive health care services for children. The availability of an under-five card ${ }^{59}$ was one of the health conditions, whereas the other two health conditions related to the actual use of the under-five card, asking beneficiary households to complete all the required vaccinations and to go for growth monitoring at least once per quarter. The details of the conditionality are outlined in the letter that every beneficiary received (see table 4.1).

The conditionality only applied to households who either had a child of school-going age or a child under five; households without children received the cash unconditionally. The conditionality was soft in nature, meaning that non-compliance with the conditionality would not lead to an automatic transfer reduction or expulsion from the program. The beneficiary letter demonstrates however that it was not communicated to households that their inaction would not have any consequences.

MCDSS as the Ministry spearheading the SCT scheme was responsible for the implementation of conditionality, with the schools as well as the pay point managers who normally deliver the cash transfer to the beneficiaries - monitoring and reporting on beneficiaries' compliance in regular intervals. For each and every child of schoolgoing age from beneficiary households ${ }^{60}$, a monitoring card was printed on the basis of the information obtained from the original household application form for the SCT program (see Annex 7). Teachers had to enter whether and in which grade the child was enrolled, calculate the attendance rate per term and give a reason for an attendance rate below $80 \%$. They were asked to state whether the child dropped out of school and

\footnotetext{
${ }^{58}$ The minimum attendance requirement was fixed at $80 \%$ in order not to be too restrictive. The calculation per term instead of per month was meant to give households whose income base is mostly dependent on agriculture more flexibility as absenteeism during time of planting and harvest is disproportionately high in rural areas in Zambia.

${ }^{59}$ The Ministry of Health, assuming coverage rate close to $100 \%$, did not anticipate the availability of an under-five card documenting vaccinations and growth monitoring, as a priority action for the district. This assumption was however proven wrong by the Monze baseline survey, which demonstrated that only $78 \%$ of all (potential) beneficiary households were in possession of such a card in Monze (Tembo and Freeland 2008b).

${ }^{60}$ The card was printed for all children participating in the experiment, also those coming from unconditional communities in order to allow for comparisons across unconditional and conditional treatment arms. This was possible because the education card was exclusively administered by the schools and not by households, which could have potentially affected the behavior of households in even unconditional communities.
} 
if so provide a reason and enter whether the child completed the school year. Teachers were also given space to make any further comments on the child's situation or performance.

Table 4.1: Information letter on conditionality for beneficiary households

\section{Excerpt from the information letter to beneficiary:}

In exchange for the money, you are, however, asked to carry out certain activities in the area of education as well as health.

With respect to education, you have to ensure that:

1) all children in the household of school-going age are enrolled in primary school. ${ }^{61}$

Children up to the age of 10 years, who have not been enrolled in school before, will be asked to start school.

Children who dropped out of school, will also be asked to return to school, depending on their age and the grade they completed last:

For grade 2, children who are 11 years and younger are required to go back. For grade 3, children who are 12 years and younger are required to go back. For grade 4, children who are 13 years and younger are required to go back. For grade 5, children who are 14 years and younger are required to go back. For grade 6, children who are 15 years and younger are required to go back. For grade 7 , children who are 16 years and younger are required to go back.

2) all children in the household of school-going age complete primary school and

3) all children in the household of school-going age, enrolled in primary or secondary school, attend at least $80 \%$ each term.

With respect to health, you are required to

1) have an under 5 card for all children under 5 ,

2) to complete all vaccinations for children under 5 and

3) to take the under 5 to the under 5 clinic for growth monitoring at least once every quarter.

Source: Information letter for beneficiaries, MCDSS, 2007

For children under five years of age from beneficiary households in conditional communities, a health monitoring card was printed and distributed to the pay point manager. The pay point manager had to check the availability of the U5-card, the status of the vaccination and the regularity of growth monitoring visits and s/he had to enter

\footnotetext{
${ }^{61}$ Primary school in Zambia is from grade 1-7, junior secondary from grade 8-9 and upper secondary from grade 10-12. The Ministry of Education now broadly distinguishes between basic education covering grades 1-9 and high school comprising grades 10-12.

88
} 
this information twice a year on the monitoring card. Households were therefore asked to take the U5 cards to the pay point twice a year. ${ }^{62}$

The education cards were supposed to be returned after the third term of the school year while health cards were returned to the District Social Welfare Office (DSWO) every 6 months. Whenever cards were returned to the DSWO, officers had to verify their completeness and correctness. If cards were not properly filled in or incomplete, the office had to send them back to the field with new instructions, using the pay point manager as a messenger. DSWO staff also had to enter the information from the monitoring cards into the management information system. After data entry, the data were supposed to be analyzed to retrieve information on beneficiaries' compliance with conditionality as well as the difference in education decisions between conditional and unconditional households.

The DSWO was tasked to supervise the monitoring of conditionality. The district office, supported by the Provincial Social Welfare Office, was supposed to control during field visits whether the monitoring cards had actually arrived at the schools, whether Community Welfare Assistance Committees (CWACs) ${ }^{63}$, schools, pay point manager as well as beneficiaries had understood the concept of conditionality and whether everybody had been properly informed about his/her respective duties. The office was also supposed to check whether beneficiaries had received a copy of the information letter and whether schools and pay point managers were comfortable handling the monitoring cards. Next to these spot-checks, CWACs and Area Coordinating Committees (ACC), which are the next level above CWACs in the Public Welfare Assistance Scheme (PWAS), had the opportunity to report any problems with conditionality through the internal monitoring system; pay point managers were anyway in regular contact with the office due to the bimonthly cash distribution.

\subsection{Data}

The multiple sources of inefficiencies also call for different data sources and methodologies. While the survey with beneficiary households in 16 randomly selected communities in Monze district is the main data source ${ }^{64}$, it is complemented by secondary data, administrative data, qualitative data and an attitudinal survey with respondents from rural as well as urban Zambia. A total of 216 beneficiaries participated in the beneficiary survey, out of which 40 also participated in the

\footnotetext{
${ }^{62}$ Due to the obvious character of this monitoring activity and the potential of monitoring activities to alter household behavior if they are aware, the health monitoring cards were only issued for children of beneficiary households from conditional communities.

${ }^{63}$ Lowest structure at community level of Zambia's welfare administration, the Public Welfare Assistance Scheme.

${ }^{64}$ See Annex 8 for the questionnaire.
} 
attitudinal survey for rural respondents, which was attached to an economic experiment. Ten beneficiaries only participated in the rural survey, which however had some common questions with the beneficiary survey. The average age among the beneficiaries interviewed was 64.5 and $72 \%$ of beneficiaries were women.

Beneficiaries' participation in the survey was solicited during a community meeting. Those beneficiaries who could not attend the community meeting, were later on informed by the CWAC members about the upcoming survey. As beneficiaries were not randomly selected but self-selected themselves for the interview, there is a chance that beneficiaries attending the interviews were particularly motivated, fitter to travel or came from communities with a more active CWAC. Beneficiaries were interviewed about their awareness of conditionality, their experience or their thoughts on conditionality as well as about their preferences regarding health, education, time and risks, the decision-making process in the household, their interaction with the program officials and the community and their satisfaction with their situation.

Regarding the administrative data, the research project entered all the monitoring cards that were collected by the Department of Social Welfare from the schools and the pay point managers to get an idea about the compliance rate but also the administrative feasibility of the monitoring system.

The rural and urban attitudinal surveys are described in further detail in Annex 9 . Altogether 500 rural participants responded to the survey (450 in addition to the 50 beneficiaries) as well as 435 urban respondents in Lusaka plus 396 students from the University of Zambia (UNZA). The quantitative data were complemented with qualitative data, gathered through 76 semi-structured interviews with different stakeholders at national, provincial, district and community levels. Interviews were carried out with school teachers, pay point managers and CWAC members at community level, with district, provincial and national representatives of MCDSS, Ministry of Education and Ministry of Health, with national representatives from other Ministries, with political representatives as well as with NGOs and development partners (DPs). ${ }^{65}$

The assessment of behavioral side effects - first source of inefficiencies - mainly draws on data collected through the beneficiary and rural survey, informing us about any potential demotivation effects of conditionality. An assessment of any adverse behavioral effects in unconditioned areas would require an impact evaluation allowing us to estimate the differential impact of conditionality. Even though this impact evaluation was originally planned for Monze district, it was never carried out because of the implementation difficulties mentioned in section 4.6. We can therefore only discuss any potential demotivation effects.

\footnotetext{
${ }^{65}$ See Annex 10 for the interview outline for qualitative interviews. 90
} 
The analysis of inefficiencies due to a sub-optimal design of conditionality - second source of inefficiencies - uses the beneficiary and rural survey to see whether conditions are in line with beneficiaries' preferences or whether they lead to potentially inefficient behavior. These surveys also serve as a source for estimating any exclusion effects of conditionality. The secondary data (Monze baseline study of 2008, Living Conditions Monitoring Survey of 2006, Zambia Demographic Health Survey of 2007) on education and health statistics allows us to gauge whether conditionality would be an appropriate tool to ease households' constraints in accessing education and health services. We also use data from the attitudinal survey among the urban population and university students to get further insights about what they would consider priority measures in the area of health and education. ${ }^{66}$

Implementation inefficiencies - third source of inefficiencies - are assessed on the basis of administrative data as well as interviews with implementing stakeholders. Administrative data mainly encompasses the data recorded on the conditionality monitoring cards as well as financial data for the calculation of the costs associated with conditionality management.

\subsection{Inefficiencies due to behavioral side effects}

As already mentioned, the data does not allow us to draw any conclusions as to whether conditionality led to negative household behavior in unconditioned areas. With the help of the beneficiary survey and the survey among the rural population, we gathered some evidence on the motivational effects of conditionality. Beneficiaries and the rural sample were interviewed about their perception of conditionality and asked whether they perceived conditionality as patronizing or empowering. We differentiated between beneficiaries who actually thought they were subject to conditionality in the SCT program and those who answered the question about conditionality hypothetically. It was also assessed whether conditionality had any effect on households' interaction with program staff or on the dynamics in household bargaining processes. This also helps us to assess whether conditionality proved (dis)empowering and in this way (de)motivating for beneficiaries.

Beneficiaries, who believed they were subject to conditionality, mostly (84\%) regarded the conditions as fair. Beliefs did not vary across different age groups or gender. Out of those who believed they were unfair, the main reason for unfairness that beneficiaries cited was an insufficient transfer amount. This result has to be treated with caution as the response rate for this question was very low. Beneficiaries, who did not believe to have any obligations in exchange for the cash transfer, were equally optimistic about

\footnotetext{
${ }^{66}$ Question was taken out of the rural questionnaire after the pre-test in an effort to reduce the number of questions and keep the attention span of rural participants.
} 
the feasibility of the conditionality. They felt either comfortable or very comfortable ${ }^{67}$ with all of the conditions that households were asked to comply with in the Monze experiment. They also stated that for the most part those conditions were either feasible or very feasible. ${ }^{68}$ This optimism about the feasibility of conditionality might result from the fact that respondents under-estimated the costs and efforts that were really required. The general positive feeling about conditionality matches however the perception of conditioned beneficiaries as well as the perception of the (very) poor rural population in Monze who also felt very comfortable with an education, growth monitoring and vaccination condition. ${ }^{69}$

As already mentioned in chapter 3, close to all beneficiaries (97\%) who believed in being subject to conditionality self-assessed that the conditionality had empowered them, meaning that it had enabled them to make choices, access opportunities and have control of their life. Not a single beneficiary perceived the conditionality as disempowering. This empowerment effect is also noted for those beneficiaries who did not believe to be subject to conditionality. The majority $(91 \%)$ considered conditionality as empowering, while $9 \%$ stated that they perceived conditionality as disempowering. Rural participants who were not benefiting from the SCT scheme were also asked about their perceptions of being conditioned. When asked hypothetically, rural participants answered in a similar way than beneficiaries, stating for the most part $(89 \%)$ that conditionality would be empowering. About $9 \%$ characterized it as disempowering. ${ }^{70}$ The outcome neither differs statistically across poverty groups nor across gender. ${ }^{71}$

Beneficiaries' social interactions as well as their interaction with program staff, claiming their rights and launching complaints in case the other party does not fulfill its obligations, also give us an indication of whether conditionality proved activating or demotivating. In general, all beneficiaries - whether conditioned or unconditioned stated that the SCT scheme had positively changed their confidence, status in the community as well as the participation in community activities and official

\footnotetext{
${ }^{67}$ Mean satisfaction level of 6.2 on a scale from very uncomfortable (1) to very comfortable (7).

${ }^{68}$ Mean feasibility level of 5.9 on a scale from unfeasible (1) to very feasible (7).

${ }^{69}$ Mean satisfaction level of 6.3 among the very poor and 6.6 among the poor on a scale from very uncomfortable (1) to very comfortable (7).

${ }^{70}$ The percentages marginally differ from the percentages presented for the rural participants in section 3.4.1 because the sample that is used for the analysis in this chapter is slightly larger, including observations that were dropped for chapters $3 \& 5$ due to implementation mistakes in the allocation and conditionality experiment. As we concentrate in this chapter on the attitudinal survey questions, we are less concerned by those implementation mistakes.

${ }^{71}$ As highlighted in chapter 3, according to interviews with local stakeholders and beneficiaries themselves, beneficiaries appreciated the guidance of the conditionality in making choices. For them, greater flexibility did not necessarily translate into greater utility but greater insecurity as to what would be the best decision to make. Having no official rules, beneficiaries were worried about breaching informal rules and being arbitrarily excluded from the program over time. Conditionality therefore had an important signaling effect for beneficiaries, letting them know what was expected of them in exchange for the money.
}

92 
committees. Participation in political events was less affected. In comparison with unconditioned beneficiaries, fewer conditioned beneficiaries noticed no changes and more of them remarked a greater change (table 4.2).

Table 4.2: Changes in social interaction, assessed by (un)conditioned beneficiaries

Question: Has the social cash transfer scheme changed...

\begin{tabular}{|l|r|r|r|r|r|r|r|r|}
\cline { 2 - 10 } \multicolumn{1}{c|}{} & \multicolumn{2}{c|}{ Not at all } & \multicolumn{2}{c|}{ A bit } & \multicolumn{2}{c|}{ A lot } & \multicolumn{2}{c|}{ No of Obs. } \\
\cline { 2 - 10 } \multicolumn{1}{c|}{} & UBen & CBen & UBen & CBen & UBen & CBen & UBen & CBen \\
\hline Your confidence & $3 \%$ & $3 \%$ & $29 \%$ & $17 \%$ & $69 \%$ & $80 \%$ & 35 & 167 \\
\hline Your status in the community & $3 \%$ & $2 \%$ & $51 \%$ & $42 \%$ & $46 \%$ & $56 \%$ & 35 & 168 \\
\hline Your participation in community activities & $24 \%$ & $19 \%$ & $62 \%$ & $42 \%$ & $15 \%$ & $39 \%$ & 34 & 166 \\
\hline Your participation in political events & $94 \%$ & $89 \%$ & $3 \%$ & $6 \%$ & $3 \%$ & $5 \%$ & 35 & 167 \\
\hline Your participation in official committees & $38 \%$ & $35 \%$ & $50 \%$ & $33 \%$ & $12 \%$ & $32 \%$ & 34 & 167 \\
\hline
\end{tabular}

\begin{tabular}{|l|r|r|r|r|}
\cline { 2 - 5 } \multicolumn{1}{c|}{} & \multicolumn{2}{c|}{$\begin{array}{c}\text { In a positive } \\
\text { way? }\end{array}$} & \multicolumn{2}{c|}{ No of Obs. } \\
\cline { 2 - 5 } \multicolumn{1}{c|}{} & \multicolumn{1}{c|}{ UBen } & \multicolumn{1}{c|}{ CBen } & UBen & CBen \\
\hline Your confidence & $100 \%$ & $100 \%$ & 34 & 162 \\
\hline Your status in the community & $97 \%$ & $99 \%$ & 34 & 163 \\
\hline $\begin{array}{l}\text { Your participation in community } \\
\text { activities }\end{array}$ & $100 \%$ & $100 \%$ & 26 & 133 \\
\hline Your participation in political events & $100 \%$ & $89 \%$ & 2 & 18 \\
\hline Your participation in official committees & $100 \%$ & $98 \%$ & 21 & 110 \\
\hline
\end{tabular}

Source: Beneficiary survey

In terms of complaint frequency, conditioned and unconditioned beneficiaries do not differ much: $9 \%$ of unconditioned and $10 \%$ of conditioned beneficiaries launched at least one complaint to one of the stakeholders since the inception of the scheme. Conditioned beneficiaries however launched on average twice as many complaints to stakeholders and also to people other than the CWAC and ACC: they interacted with the DSWO, schools, health centers, pay point managers and other stakeholders. Due to the relatively small number of complainants, it is however difficult to draw any robust conclusions regarding the motivational effects of conditionality. About $18 \%$ of conditioned beneficiaries self-reported that they contacted at least one of the stakeholders of the scheme more often due to conditionality. While this interaction is positive when it comes to discussing education, health and development related matters, it can also possibly turn into a burden if it is more about administrative matters such as signing statements, helping the school to fill in the monitoring cards and outlining to the CWAC on which items the money has been spent. Unfortunately, no information is available about the reasons for more contact. 


\subsection{Inefficiencies due to a sub-optimal design of conditionality}

\subsubsection{Promotion of existing behavior}

If not well designed, conditionality can promote behavior that households already display and in this way introduce unnecessary complexities.

\subsubsection{Take-up of education services}

The Monze baseline study that was carried out with (potential) beneficiaries of the scheme notes that $76.3 \%$ of children aged between 5 and 17 years were enrolled in school at the time of the survey (Tembo and Freeland 2008b). With respect to attendance rates, $84.2 \%$ of all pupils attended all classes in the week prior to the survey. This relatively high attendance rate might however not be representative for attendance throughout the school year as the reference week for most respondents was the last week of the $2^{\text {nd }}$ term where most pupils attend school to be prepared for the exams.

At a national scale, the net attendance rate for primary school was overall $76 \%$ in 2006 and the one for secondary school just $37 \%$ with the gross attendance rate for primary school being $100 \%$ and for secondary 55\% (CSO 2008). When disaggregated by income, we can see that households who are non-poor have a greater tendency of sending their children to school at the right age when compared with the extremely poor. The difference in attendance by socio-economic status further worsens for secondary school where more than twice as many children from non-poor households attend vis-à-vis the poor. The gross attendance rate shows the same divergence for secondary school but gross enrolment rates in primary school are very similar across the extremely poor and the non-poor.

These findings are confirmed by the Zambia Demographic Health Survey (ZDHS) from 2007 (CSO, MOH et al. 2009), which shows a net enrolment rate for primary school of $80 \%$ and for secondary school of $36.8 \%$ and a gross enrolment rate of $104 \%$ for primary and $52.4 \%$ for secondary school. Once more we can see a divergence between the poorest and the richest quintile of close to 14 percentage points with respect to the net enrolment rate and a divergence of 12 percentage points for the gross enrolment rate (CSO, MOH et al. 2009). The ZDHS 2007 (CSO, MOH et al. 2009) and LCMS 2006 (CSO 2008) both illustrate that still a relatively high proportion of the 2024 year old group never completed primary school: according to the ZDHS 2007 (CSO, MOH et al. 2009), close to $30 \%$ of men and $43 \%$ of women either had no education or never completed primary school. The LCMS 2006 (CSO 2008) shows that $28 \%$ either did not enjoy any education or only completed up to grade 4 . 
Based on the information provided through these three sources of secondary data and despite the overall positive trends that the education sector has shown in Zambia over time, there still seems to be some leeway in improving education outcomes for the poorest quintile, in particular with respect to sending children to school at an appropriate age as well as encouraging them to complete primary school and transition to secondary education. ${ }^{72}$

\subsubsection{Take-up of health services}

Concerning the conditioned areas in health, the Monze baseline study finds that $78 \%$ of all children had an U5 card and 93\% rate of children received all three vaccinations (Tembo and Freeland 2008b). No data were available on regular growth monitoring but the fact that the average distance to the nearest under-five health post is $3.7 \mathrm{~km}$ with a standard deviation of $4 \mathrm{~km}$ for the (potential) beneficiaries in Monze shows that it requires time and effort to attend the clinic on a regular basis. According to the ZDHS 2007 (CSO, MOH et al. 2009), 78\% of all children were in possession of a vaccination card and only $55 \%$ of all children were fully vaccinated (within the first 12 months of their life) at the time of the survey. $67.6 \%$ of children received all necessary immunizations (CSO, $\mathrm{MOH}$ et al. 2009). Interestingly, the lowest wealth quintile had the highest percentage of vaccination cards and also came in second concerning the completion of all vaccinations. This seems to suggest that there are other reasons besides financial barriers that prevent households from completing all vaccinations.

On the basis of this secondary data on health, we can equally conclude that there is still room for further improvement with respect to children having vaccination cards and all vaccinations being completed. This however does not only apply to the lowest wealth quintile alone but across different income groups.

\subsubsection{Promotion of suboptimal behavior}

Conditionality can also promote behavior that is considered sub-optimal from the perspective of the household. We therefore use primary data to analyze education and health preferences of beneficiaries as well as their fellow community members to see whether they are aligned with the conditions of the pilot.

Almost all respondents - beneficiaries and the rural population - considered education and health checks for their (grand) children as important, with 97\% assessing it as very important ( 7 on a scale from $1=$ unimportant to $7=$ very important) for education ${ }^{73}$ and

\footnotetext{
${ }^{72}$ Reasons for non-enrolment and absenteeism are further discussed in section 4.5.3. This section mainly serves to highlight whether conditionality promotes behavior that households already display.

${ }^{73}$ Both $97 \%$ of beneficiaries and $96.4 \%$ of rural respondents thought that education was very important. Nobody considered it as unimportant.
} 
$93 \%$ for health. ${ }^{74}$ Opinions did not differ across income groups for the rural population. Only one respondent from all beneficiaries and rural respondents did not consider it important to plan ahead in education and health. When giving reasons for their choice, respondents did not only see direct advantages for their children - better opportunities to find a job and an easier and more prosperous life - but also indirect advantages for themselves, such as a better security mechanism in the future. From the responses it becomes apparent that households recognized the value of education and preventive health care mechanisms.

Table 4.3: Percentage of respondents investing (part of) ZMK 1 million in different areas

Question: If you had access to ZMK $1,000,000^{75}$, what would you do with the money?

\begin{tabular}{|c|c|c|}
\hline Invest money in: & Rural respondents & Beneficiaries \\
\hline Agriculture & $59 \%$ & $69 \%$ \\
\hline Sanitary items & $2 \%$ & $3 \%$ \\
\hline IGA & $32 \%$ & $25 \%$ \\
\hline Home & $8 \%$ & $12 \%$ \\
\hline Assets & $1 \%$ & $3 \%$ \\
\hline Education & $64 \%$ & $54 \%$ \\
\hline Food & $48 \%$ & $48 \%$ \\
\hline Health & $28 \%$ & $37 \%$ \\
\hline Clothes & $10 \%$ & $10 \%$ \\
\hline Other & $2 \%$ & $4 \%$ \\
\hline No of observations & 448 & 214 \\
\hline
\end{tabular}

Source: Beneficiary survey \& survey with rural population in Monze

As respondents might have thought that these responses were expected of them, we triangulated these findings with other primary data sources. When asked what they would do if they had ZMK 1 million at their disposal, education figured highest among the rural population - highest among the very poor - and $2^{\text {nd }}$ highest among beneficiaries (Table 4.3). ${ }^{76}$ As access to education is not only dependent on resources explicitly set aside for education but also on food and clothes, we might assume that households' investment choices in other areas equally benefitted education and also health. Health was in general lower on the priority list, supposedly because respondents

\footnotetext{
${ }^{74} 91 \%$ of beneficiaries and $94 \%$ of rural respondents thought that U5 checks were very important. Only $2 \%$ of beneficiaries did not consider it important.

${ }^{75}$ According to the average exchange rate of the first quarter of 2012, ZMK 1 million amount to roughly $144 €$ and 190 US\$.

${ }^{76}$ If we further differentiate between households who had children and those who did not among the rural respondents, households with children prioritized education and health slightly more with the differences being statistically significant. For beneficiary households, we unfortunately lack the information about whether they had any children.

96
} 
did not see health as an immediate investment choice. Investment in agriculture was considered a priority by both groups, which might come as a surprise with respect to beneficiaries, given that they were selected on the basis that they had no or little productive capacity. Preferences for agriculture might be high due to the fact that CWAC members strongly advised investment in livestock and agricultural activities. It is furthermore not a sub-optimal investment strategy given the uncertain duration of the SCT program.

Table 4.4: Percentage of respondents saving (part of) ZMK 1 million for different areas

Question: For what purpose would you keep the money?

\begin{tabular}{|c|c|c|}
\hline Keep money for: & Rural respondents & Beneficiaries \\
\hline Investment & $41 \%$ & $15 \%$ \\
\hline Health & $22 \%$ & $34 \%$ \\
\hline Education & $30 \%$ & $50 \%$ \\
\hline Contingencies & $30 \%$ & $49 \%$ \\
\hline Food & $7 \%$ & $11 \%$ \\
\hline Give to others & $2 \%$ & $1 \%$ \\
\hline Other & $1 \%$ & $3 \%$ \\
\hline No of observations & 332 & 160 \\
\hline
\end{tabular}

Source: Beneficiary survey \& survey with rural population in Monze

When we asked respondents whether they would want to save any of the money, $76 \%$ of all beneficiaries decided to keep part of the money (on average ZMK 370,000) and $78 \%$ of the rural population kept part of the money, with an average of ZMK 350,000 . Again, education is high on the priority list of what to save for, next to other contingencies (Table 4.4), followed by health for beneficiaries. ${ }^{77}$

We therefore have little evidence to prove that the proposed conditions would have forced households to adopt a behavior that would not be in line with their own preferences, even if we can see by their list of priorities that beneficiaries have more priorities than just education and health alone.

\subsubsection{Conditionality as a sub-optimal measure}

Even if the utilization of education and health services could be improved, conditionality might not be the most cost-effective tool of doing so. We therefore take a closer look at the main constraints on access to health and education and gauge the

\footnotetext{
${ }^{77}$ We do not see any statistically significant difference in investment and saving decisions across very poor, poor and better-off households among the rural respondents.
} 
scope for improvement that we expect to see with the instrument of conditionality and then conclude as to whether conditionality can be considered a priority measure.

\subsubsection{Scope for improvement}

\section{General constraints on access to education and health}

Table 4.5: Reasons for leaving the education system, by highest level of education obtained

\begin{tabular}{|c|c|c|c|c|c|c|c|c|}
\hline & \multicolumn{7}{|c|}{ Highest level of Education Attained } & \multirow[b]{2}{*}{ Zambia } \\
\hline & None & $\begin{array}{r}\text { Grade } \\
1 \text { to } 4 \\
\end{array}$ & $\begin{array}{c}\text { Grade } \\
5-7\end{array}$ & $\begin{array}{c}\text { Grade } \\
8-9 \\
\end{array}$ & $\begin{array}{c}\text { Grade } \\
10-12 \\
\end{array}$ & $\begin{array}{c}\text { Grade } 12 \text { GCE } \\
\text { (A)/College/ } \\
\text { Undergraduate }\end{array}$ & $\begin{array}{l}\text { Bachelors } \\
\text { Degree and } \\
\text { above }\end{array}$ & \\
\hline Zambia & 100 & 100 & 100 & 100 & 100 & 100 & 100 & 100 \\
\hline Working & & 1.2 & 1.1 & 2.4 & 3.3 & 8.0 & 8.8 & 2.3 \\
\hline Too Expensive & 1.8 & 1.6 & 1.2 & 1.4 & 0.7 & 2.8 & 0.1 & 1.2 \\
\hline $\begin{array}{l}\text { School too far } \\
\text { Not }\end{array}$ & 5.7 & 8.5 & 2.8 & 0.9 & 0.1 & . & 0.1 & 2.7 \\
\hline $\begin{array}{l}\text { Selected/Failed/ } \\
\text { Couldn't get a } \\
\text { place. }\end{array}$ & 9.0 & 0.9 & 20.7 & 24.3 & 2.4 & . & 0.1 & 13.1 \\
\hline Pregnancy & 20.2 & 2.1 & 6.4 & 10.7 & 4.3 & 5.3 & 0.2 & 5.8 \\
\hline $\begin{array}{l}\text { Made Girl } \\
\text { Pregnant }\end{array}$ & 2.0 & 0.4 & 0.7 & 1.3 & 0.5 & . & . & 0.7 \\
\hline $\begin{array}{l}\text { Completed } \\
\text { Studies }\end{array}$ & 6.3 & 0.4 & 0.5 & 0.5 & 67.9 & 67.8 & 88.3 & 19.1 \\
\hline Got Married & 11.0 & 4.4 & 6.0 & 5.5 & 2.0 & 1.0 & 0.6 & 4.5 \\
\hline $\begin{array}{l}\text { No Need to } \\
\text { continue School }\end{array}$ & 2.6 & 11.6 & 6.4 & 3.5 & 1.2 & . & 0.1 & 5.3 \\
\hline $\begin{array}{l}\text { School not } \\
\text { important }\end{array}$ & 2.8 & 13.0 & 5.4 & 2.4 & 0.6 & . & . & 4.8 \\
\hline $\begin{array}{l}\text { Unsafe to travel } \\
\text { to school }\end{array}$ & . & 1.5 & 0.5 & 0.2 & 0.1 & . & . & 0.5 \\
\hline Expelled & . & 0.4 & 0.5 & 0.6 & 0.5 & . & 0.2 & 0.5 \\
\hline $\begin{array}{l}\text { Lack of financial } \\
\text { Support }\end{array}$ & 30.4 & 42.7 & 42.5 & 42.9 & 15.3 & 15.2 & 0.9 & 34.7 \\
\hline $\begin{array}{l}\text { Need to Help out } \\
\text { at home }\end{array}$ & . & 5.2 & 2.4 & 0.8 & 0.4 & . & 0.3 & 2.0 \\
\hline $\begin{array}{l}\text { Illness/Injury/ } \\
\text { Disability }\end{array}$ & 6.5 & 4.2 & 2.0 & 1.3 & 0.6 & . & 0.2 & 1.9 \\
\hline Other (Specified) & 1.8 & 1.9 & 0.9 & 1.3 & 0.2 & . & 0.1 & 1.0 \\
\hline
\end{tabular}

Source: LCMS (2006 data), 2008

According to the LCMS 2006 (CSO 2008), the primary reason for leaving school at any point in the education system is the lack of financial support (Table 4.5). Conditionality's leverage over financial resources is minimal, unless it is a question of prioritization. For higher grades as well as those who never joined school, the fact that they could not get a place or failed to make it to the next highest level play an important role, besides the fact that girls who got pregnant were excluded from school. Whether conditionality can have an impact on passing grades and delaying pregnancies is contestable. The impact of conditionality on the use of health and education services is much better established than its effect on outcome indicators (Fiszbein and Schady 2009). While a longer stay in school usually delays early pregnancies, the Malawi experiment demonstrated that UCTs can be more effective in preventing early pregnancies as they also financially supported school drop-outs (Baird, McIntosh et al. 2011). For lower grades in Zambia, behavioral reasons for leaving school come into play such as "No need to continue school" and "school is not important." Here conditionality could exert pressure on households to consider education as important and push them to continue school. A further analysis of why school is not considered 
important would help to see whether forcing households to send their children to school would lead to optimal outcomes.

Figure 4.1: Reason for non-enrolment in school provided by local interview partners in Monze

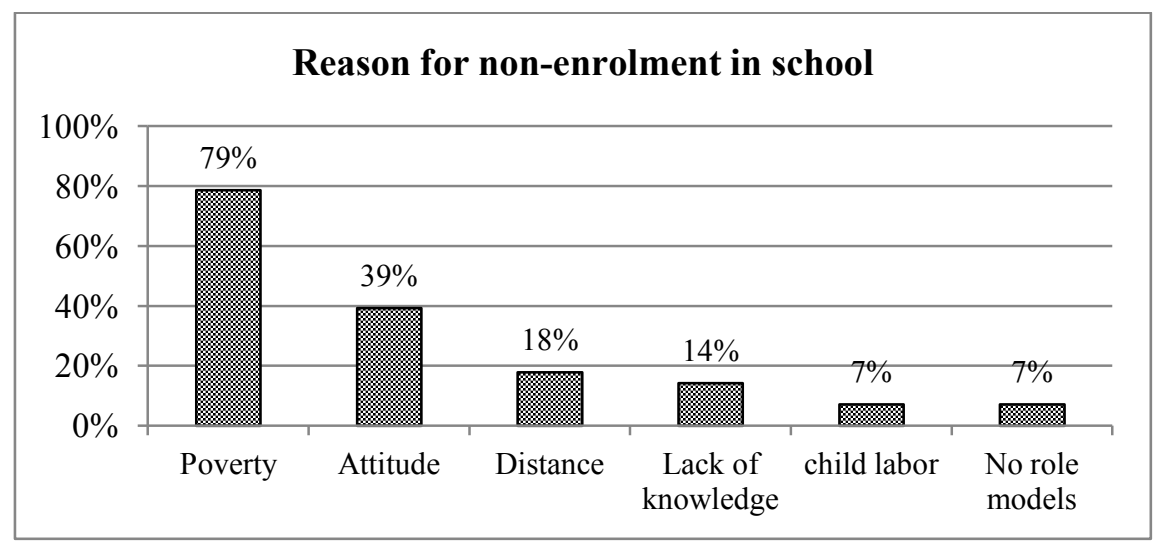

Source: Qualitative interviews $(\mathbf{n}=\mathbf{2 8})$

Unfortunately the national surveys explain very little in why someone never attended school. The data collected in the LCMS 2006 (CSO 2008) for never having been to school was not very informative with the main reasons being for all age groups "Under age" and "Was never enrolled." Primary data from interviews with stakeholders in Monze provide some further insights. Local stakeholders were interviewed on what they considered the most important reasons for households to not send their children to school. In close to $80 \%$ of all interviews in which the reasons for non-enrolment were discussed, respondents mentioned poverty as a reason (Figure 4.1). They said that parents could not afford any school related expenses and also did not want to send their children to school on an empty stomach. At times, high poverty levels and the lack of the bare minimum forced parents to prioritize who among the children would go to school and to send children off to work to find enough resources for school. Another reason mentioned was attitude: in about $40 \%$ of all interviews, respondents stated that parents did not view the education of their children as important and preferred them to help with agricultural activities or home chores.

According to the information provided by teachers on the education monitoring cards, lack of interest and the fact that the child had to assist with family chores equally mattered (see table 4.6). This contrasts with our earlier findings that parents considered the education and health of their children as a priority. One reason for this discrepancy might be that the financial situation of households forces them to make tough choices and that in the hierarchy of household needs, food and other basic necessities figure higher. 
Table 4.6: Reasons for non-compliance with education conditions, stated by teachers

Percentage of children whose absenteeism and / or drop-out was due to the following reasons:

\begin{tabular}{|l|r|r|r|r|}
\cline { 2 - 5 } \multicolumn{1}{c|}{} & \multicolumn{2}{c|}{$\mathbf{2 0 0 7}$} & \multicolumn{2}{c|}{$\mathbf{2 0 0 8}$} \\
\cline { 2 - 5 } \multicolumn{1}{c|}{} & Attendance & Drop out & Attendance & \multicolumn{1}{c|}{ Drop out } \\
\hline Financial reasons & $13 \%$ & $0 \%$ & $17 \%$ & $8 \%$ \\
\hline Sickness & $25 \%$ & $13 \%$ & $21 \%$ & $21 \%$ \\
\hline Pregnancy & $4 \%$ & $13 \%$ & $15 \%$ & $38 \%$ \\
\hline Child has to assist family & $22 \%$ & $6 \%$ & $11 \%$ & $8 \%$ \\
\hline No need/interest & $24 \%$ & $38 \%$ & $11 \%$ & $17 \%$ \\
\hline Long distance & $4 \%$ & $13 \%$ & $10 \%$ & $0 \%$ \\
\hline Other & $6 \%$ & $19 \%$ & $14 \%$ & $8 \%$ \\
\hline No of observations & 67 & 16 & 71 & 24 \\
\hline
\end{tabular}

Source: Education monitoring cards

Out of all reasons cited, conditionality can only address absenteeism related to attitude and potentially also help to reduce child labor if the transfer amount is sufficient to compensate foregone earnings. The enforcement of conditionality might, however, potentially punish students who have difficulties attending due to financial constraints, sickness or long distance.

Unfortunately there was no information from secondary data sources such as the ZDHS 2007 (CSO, MOH et al. 2009) and LCMS 2006 (CSO 2008) report as well as the statistical bulletin by the Ministry of Health 2009 on reasons for lack of access to health. There are also too few monitoring cards that mention the reasons for noncompliance with health conditionality.

\section{Behavioral constraints on access to education and health}

Even if we can hypothesize on the basis of the preceding discussion on constraints that conditionality seems to have some leverage in improving access to education, it would be helpful to have more certainty about its scope for improvement. As we do not have any survey evidence on the behavioral impact of conditionality, we can only see whether any of the reasons that push households to make sub-optimal choices from a private as well as societal perspective such as households having imperfect information about the value of education and health or households being non-altruistic towards their children, myopic or risk adverse, apply in the Zambian context.

The preferences on education and health of beneficiary households and community members have shown that the majority are aware of the value of education and health for the children but also the household and prioritizes these areas in their spending and saving patterns. This is in line with recent evidence from Malawi which shows that 
there is no sign of incomplete altruism between the girl beneficiary and her parents (Baird, McIntosh et al. 2011).

Studying time preferences of beneficiaries and rural respondents on the basis of the beneficiary and experiment survey, we can conclude that our rural population could have a tendency to be impatient and not invest the money despite relatively high interest rates. As discussed in chapter 2, this can be sub-optimal from a societal perspective. Both beneficiaries and experiment participants were asked hypothetically whether they would prefer taking ZMK 50,000 today or ZMK 70,000 in a month's time. If they decided to take the ZMK 50,000 today, the offer was increased by ZMK 10,000 in each round, up to a total amount of ZMK 110,000. Table 4.7 shows that the majority of both groups had a preference for consuming the money now rather than waiting a month's time. Even when offered more than twice the original amount, 19\% of rural respondents and 8\% of beneficiaries still decided to get the ZMK 50,000 now. Both beneficiaries and rural respondents were largely consistent in their time preferences as we get similar results when we change the choices between now and in a month's time to 6 and 7 months.

Table 4.7: Time preferences of beneficiaries and rural population

\begin{tabular}{|c|c|c|c|c|}
\hline & $\begin{array}{l}\text { Rural } \\
\text { respondents }\end{array}$ & Beneficiaries & $\begin{array}{l}\text { Rural } \\
\text { respondents }\end{array}$ & Beneficiaries \\
\hline & \multicolumn{2}{|c|}{ Today or in a month's time } & \multicolumn{2}{|c|}{6 or 7 months } \\
\hline $\begin{array}{l}\text { Decision not to delay } \\
\text { consumption irrespective of } \\
\text { higher offers made }\end{array}$ & $19 \%$ & $8 \%$ & $16 \%$ & $6 \%$ \\
\hline \multicolumn{5}{|c|}{ Decision to delay consumption for higher offer of: } \\
\hline 70,000 & $35 \%$ & $44 \%$ & $39 \%$ & $43 \%$ \\
\hline 80,000 & $21 \%$ & $16 \%$ & $15 \%$ & $24 \%$ \\
\hline 90,000 & $11 \%$ & $15 \%$ & $10 \%$ & $14 \%$ \\
\hline 100,000 & $10 \%$ & $10 \%$ & $14 \%$ & $9 \%$ \\
\hline 110,000 & $4 \%$ & $7 \%$ & $5 \%$ & $6 \%$ \\
\hline No of observations & 446 & 209 & 444 & 211 \\
\hline
\end{tabular}

Source: Survey with experiment participants in Monze / beneficiary survey

There is in general a strong preference for present consumption, which might lead parents to trade investment in schooling and higher future consumption for present consumption. Whether this is due to the fact that households are cash-constrained is debatable as time preferences did not vary greatly with income status of rural respondents. The impatience to consume now is however likely to depend on the transfer amount since we discovered in section 4.5.2 that households were definitely interested in setting money aside of the ZMK 1 million they received. Conditionality as 
a self-restraining device could therefore have a greater effect if the transfer amount is not very generous and there are many competing interests.

Looking at the self-assessed risk attitudes of beneficiary households and their fellow community members, we cannot conclude that those two groups are particularly risk averse. The percentage of people not willing to take any risk is relatively small and represents less than half of the size of the group of people who are completely riskloving (Table 4.8). The majority of beneficiaries are on the risk-loving side, while rural respondents are almost evenly spread. Although it is difficult to apply a general risk measure to all areas of life, it appears unlikely, looking at respondents' risk preferences and their conscious investment decisions in education and health, that they would shy away from investing in primary education of their children due to the risks attached.

Table 4.8: Self-assessed risk attitude of beneficiaries and rural population

\begin{tabular}{|c|c|c|}
\hline & Rural respondents & Beneficiaries \\
\hline Not prepared to take any risk & $6 \%$ & $6 \%$ \\
\hline 1 & $16 \%$ & $9 \%$ \\
\hline 2 & $7 \%$ & $9 \%$ \\
\hline 3 & $6 \%$ & $6 \%$ \\
\hline 4 & $10 \%$ & $8 \%$ \\
\hline 5 & $11 \%$ & $15 \%$ \\
\hline 6 & $5 \%$ & $12 \%$ \\
\hline 7 & $5 \%$ & $7 \%$ \\
\hline 8 & $10 \%$ & $9 \%$ \\
\hline 9 & $9 \%$ & $7 \%$ \\
\hline Fully prepared to take risks & $14 \%$ & $14 \%$ \\
\hline No of observations & 443 & 213 \\
\hline
\end{tabular}

Source: Survey with experiment participants in Monze / beneficiary survey

In conclusion, the scope for improvement due to conditionality is not likely to be immense. Conditionality could, however, play a role in motivating impatient households, who face different needs at the same time, to prioritize household spending in the conditioned areas. When differentiating between beneficiaries who claimed to be subject to an education or health conditionality and those who thought that they received either unconditional cash or cash with conditionality in a different area, we for instance detect differences in their spending preferences. In response to the question of what they would do with ZMK 1,000,000, 52\% of beneficiaries who believed in having an education condition prioritized education as opposed to $21 \%$ of beneficiaries with no education condition. In the area of health, $27 \%$ of conditioned beneficiaries in health prioritized health compared to $16 \%$ of unconditioned beneficiaries in health. While we do not know whether conditionality actually led to different behavioral 
outcomes, it might have changed beneficiaries' readiness to spend more on education and health. If household income plus the transfer are however too small, conditionality might result in exclusion rather than a change in spending patterns, as further discussed in 4.5.4.

\subsubsection{Priority measures}

Even if conditionality is likely to respond to some of the shortcomings mentioned, conditionality is probably not the most cost-effective measure to attain better education and health outcomes. The discussion about the general constraints on access to education has shown that more financial support, better access to quality education and possibly more sensitization about contraception might be more appropriate in remediating some of the constraints. This confirms the importance of cost-effectiveness studies as discussed in section 2.4.2.

Table 4.9: Priority measures by the urban population and students in the area of education and health

Question: If you were a policymaker in Zambia, would you...

\begin{tabular}{|l|r|r|}
\cline { 2 - 3 } \multicolumn{2}{c|}{} & \multicolumn{2}{l|}{ Urban sample } & Students \\
\hline \hline Raise school enrolment by & $12 \%$ & $21 \%$ \\
\hline \hline Making it a condition & $39 \%$ & $40 \%$ \\
\hline Raising more awareness & $49 \%$ & $38 \%$ \\
\hline Building schools & $0 \%$ & $1 \%$ \\
\hline No need for any intervention & 417 & 382 \\
\hline Number of observations & \multicolumn{2}{|c|}{} \\
\hline \hline Raise school attendance by & $8 \%$ & $17 \%$ \\
\hline \hline Making it a condition & $50 \%$ & $44 \%$ \\
\hline Raising more awareness & $41 \%$ & $38 \%$ \\
\hline Improving quality of schooling & $0 \%$ & $1 \%$ \\
\hline No need for any intervention & 417 & 379 \\
\hline Number of observations & & \\
\hline \hline Get more women to take their babies to health checks by & $9 \%$ & $17 \%$ \\
\hline \hline Making it a condition & $47 \%$ & $82 \%$ \\
\hline Improving availability of services & $44 \%$ & Not asked \\
\hline Raising more awareness & $0 \%$ & $1 \%$ \\
\hline No need for any intervention & 421 & 378 \\
\hline Number of observations & \multicolumn{2}{|c|}{} \\
\hline
\end{tabular}

Source: Attitudinal surveys with the urban population \& students 
The attitudinal survey among the urban population as well as university students ${ }^{78}$ equally reflects that the majority did not consider conditionality to be a priority measure. Participants were asked to choose only one out of different measures to improve enrolment, attendance and health checks for children under five. Supply side interventions such as improving the quality and availability of services as well as awareness-raising measures among households both received more than twice the number of votes as conditionality (table 4.9).

\subsubsection{Exclusion effects}

Conditionality can exclude households from the program if households do not comply with the conditions set. This is not always an intentional choice of beneficiaries, in particular when services that the transfer is conditioned on are not sufficiently available or if the transfer amount is too low to allow the household to comply with all conditions.

Forty percent of all interview partners in the communities stated that not all beneficiaries had complied with conditionality. The majority of those who defaulted did, however, change their behavior after being counseled and monitored. Only a few isolated cases were excluded from the program, which is an interesting finding in itself as CWACs were originally not given the discretion to make such exclusions.

Table 4.10: Percentage of beneficiary households complying with education conditions as reported by teachers

\begin{tabular}{|c|c|c|c|c|}
\hline & 2007 & No of obs. & 2008 & No of obs. \\
\hline Enrolment & $96 \%$ & 114 & $81 \%$ & 187 \\
\hline Attendance Term1 & $81 \%$ & 42 & $82 \%$ & 59 \\
\hline Attendance Term2 & $81 \%$ & 63 & $87 \%$ & 59 \\
\hline Attendance Term 3 & $86 \%$ & 20 & $84 \%$ & 56 \\
\hline No drop-out & $96 \%$ & 114 & $85 \%$ & 159 \\
\hline
\end{tabular}

Source: Conditionality monitoring cards

The administrative data from the education and health monitoring cards permit us to triangulate this finding. ${ }^{79}$ Looking at the education compliance rates among conditioned beneficiaries in table 4.10 , we can see that the highest default rate per

\footnotetext{
${ }^{78}$ We have no information about preferences for priority measures of the rural population.

${ }^{79}$ Even though we have to conclude that the return rate, completeness and consistency of those cards leave much to be desired as Section 4.6 illustrates.
} 
conditionality was $19 \%$ for attendance in Term 1 and Term 2 in 2007 and $19 \%$ for enrolment in $2008 .^{80}$

Calculating the total percentage of households who defaulted on at least one of the conditions, we arrive at a percentage of $19 \%$ (22 actual households) of all officially conditioned households in 2007 for whom a card was filled in and 36\% (68 actual households) in 2008. Those households would have been excluded from the scheme if conditionality had been rigorously enforced. Among the unconditioned households, $42 \%$ (42 households) would not have complied in 2007 and $46 \%$ (16 households) in 2008 .

Table 4.11: Percentage of beneficiary households (not) complying with health conditions as reported by pay point managers

\begin{tabular}{|l|r|r|r|r|r|r|r|r|}
\hline $\begin{array}{l}\text { Compliance with } \\
\text { health conditions }\end{array}$ & $\mathbf{2 0 0 7 / 0 1}$ & $\begin{array}{c}\text { No of } \\
\text { obs. }\end{array}$ & $\mathbf{2 0 0 7 / 0 2}$ & $\begin{array}{c}\text { No of } \\
\text { obs. }\end{array}$ & $\mathbf{2 0 0 8 / 0 1}$ & $\begin{array}{c}\text { No of } \\
\text { obs. }\end{array}$ & $\mathbf{2 0 0 8 / 0 2}$ & $\begin{array}{c}\text { No of } \\
\text { obs. }\end{array}$ \\
\hline \hline Availability of card & $64 \%$ & 53 & $73 \%$ & 11 & $55 \%$ & 56 & $100 \%$ & 3 \\
\hline Vaccinations & $94 \%$ & 35 & $73 \%$ & 11 & $84 \%$ & 37 & $67 \%$ & 3 \\
\hline Growth monitoring & $91 \%$ & 35 & $67 \%$ & 12 & $89 \%$ & 38 & $100 \%$ & 3 \\
\hline \hline $\begin{array}{l}\text { Non-compliance with } \\
\text { at least one condition }\end{array}$ & $36 \%$ & 53 & $31 \%$ & 13 & $50 \%$ & 58 & $20 \%$ & 5 \\
\hline
\end{tabular}

Source: Conditionality monitoring cards

The compliance rate for the health conditions varies quite a lot across the different terms (Table 4.11). Due to the small sample size for some of the periods (only a few cards were actually filled in for 2007/02 and 2008/02) and the incompleteness of cards (for many cards certain questions were left blank), the compliance rate might not necessarily be representative for the whole group. Between $20 \%$ of beneficiaries in $2008 / 02$ and $50 \%$ of beneficiaries in 2008/01 for whom cards were available would have been excluded from the scheme. This appears in line with the irregular compliance rate reported by teachers and CWAC members. The main difficulties around the U5 cards as noted by the pay point managers were that the mother had taken the card with her to a different place or that there were name mismatches and it was impossible to verify.

We can also estimate the potential exclusion rate for unconditioned beneficiaries and (potential) beneficiaries among the rural population on the basis of the beneficiary and experiment survey. Three out of 34 beneficiaries who believed not to be subject to conditionality, stated that they would decide against a transfer of ZMK 50,000 if the conditions of the Monze experiment were attached. Twelve percent of the very poor

\footnotetext{
${ }^{80}$ Compliance rate for attendance was calculated on the basis of whether a reason was cited for noncompliance and not on the attendance rate as calculated by the teacher. See section 4.6 for more information on the discrepancy between those two rates.
} 
among the rural survey participants and $12 \%$ of the poor would equally reject a ZMK 50,000 transfer with conditionality attached. The main reasons cited for deciding against the transfer among the (very) poor were that it would be too costly $(51 \%)$ and that it would produce too much work $(26 \%)$.

Surprisingly, the majority of the people (94\%) who said that they would decide against a transfer also stated that they would feel comfortable with conditionality. This appears to be inconsistent at first sight. One possible reason for this seeming inconsistency could be the insufficiency of the transfer amount of ZMK 50,000 which was mentioned when respondents had to decide on whether they would accept the transfer but was not stated in the question on the level of comfort with different conditions. In addition, respondents were asked to comply with all of the conditions when deciding on whether to accept the transfer, as opposed to just one condition at a time in the question about their comfort levels with conditionality.

Considering the non-compliance reflected by the monitoring cards, interview partners and survey participants, the limited transfer amount and the number of constraints on access to education and health that are beyond the control of households (see 4.5.3), we would expect to see relatively large exclusion errors if conditionality was rigorously enforced.

The availability of infrastructure and / or quality services seems to be less of a concern than the transfer amount as a source of exclusion according to the beneficiary and experiment survey. They were not mentioned by beneficiaries and (very) poor rural households as a reason for not accepting a conditioned transfer or for regarding conditionality as unfair. In the experiment with rural respondents on their preferences for targeting and conditioning transfers (for further details, see chapter 3 and chapter 5 ), less than $2 \%$ of those who decided against a condition, were motivated by the lack of infrastructure and quality services. This is not proof that there would have been no exclusion effects at all for this reason but it signals that exclusion effects are likely to be limited.

\subsection{Implementation inefficiencies}

\subsubsection{Direct costs for administration}

The pilot in Monze district only provided limited information about the real costs of conditionality. The budget and reconciliation form of the district did not capture conditionality as a separate activity. Certain activities such as the printing of the cards and the design of the database modules for conditionality were externally funded and monitoring activities for conditionality were also combined with other tasks such as payment for pay point managers or regular monitoring activities for the Department 
Social Welfare, which made it complicated to ascribe the costs to conditionality. The performance of the monitoring system was furthermore weak so even a more detailed breakdown of costs might not have depicted the actual investment needed for a functional system.

If we factored in all necessary expenses for an effective SCT experiment on conditionality such as an adequate training for all stakeholders involved, costs for printing and photocopying, regular monitoring visits, guidance and quality control, data entry and analysis as well as monitoring trips by the district, province and headquarters, we would arrive at an annual budget of about ZMK 113 million (see table 4.12). This presents $11.5 \%$ of the transfer costs as well as $39.5 \%$ of an administrative budget which is fixed at $15 \%$ of total costs excluding the costs for conditionality. We can already see that this budget, which at the moment does not even include any incentives for pay point managers, school teachers or CWAC members for the additional work involved, is considerably high. Conditionality therefore requires not only manpower and competencies but substantial additional resources.

Table 4.12: Estimated annual costs (in ZMK) of the SCT experiment on conditionality

\begin{tabular}{|c|c|}
\hline \multicolumn{2}{|l|}{ Assumptions about staff $\&$ activities } \\
\hline \multicolumn{2}{|l|}{ Staff $\&$ activities } \\
\hline Number of office staff & 3 \\
\hline Number of trainers from ACC & 12 \\
\hline Number of conditioned CWACs & 33 \\
\hline Number of CWACs on the social cash transfer scheme & 65 \\
\hline Number of U5 per CWAC & 10 \\
\hline Number of school-going children per CWAC & 50 \\
\hline Number of beneficiaries per CWAC & 30 \\
\hline Training duration for training of trainers (days) & 3 \\
\hline Training duration for PPM/teachers (days) & 2 \\
\hline Duration of introduction to CWAC / ACC (day) & 1 \\
\hline Monitoring days district (days) & 2 \\
\hline Monthly monitoring days province / HQ (day) & 1 \\
\hline \multicolumn{2}{|l|}{ Unit costs } \\
\hline Training fee per person per day for training of trainers & 250,000 \\
\hline Training fee per person per day for local trainings & 75,000 \\
\hline Cost per monitoring card & 2,500 \\
\hline Cost per page photocopied & 200 \\
\hline Field trip costs for district per day & 200,000 \\
\hline Share of field trip costs for province/HQ per day & 300,000 \\
\hline Monthly salary of a Social Welfare Officer & $1,939,178$ \\
\hline Monthly transfer volume for beneficiaries in treatment CWACs & $92,625,000$ \\
\hline Monthly administrative costs ( $15 \%$ of the total) & $16,345,588$ \\
\hline
\end{tabular}




\begin{tabular}{|c|c|}
\hline \multicolumn{2}{|c|}{ Estimated annual costs of the conditionality experiment } \\
\hline \multicolumn{2}{|l|}{ Training of stakeholders } \\
\hline Training of trainers / introduction for the office & $11,250,000$ \\
\hline Training of teachers & $9,750,000$ \\
\hline Training of pay point managers & $4,950,000$ \\
\hline Training of CWACs / ACCs & $57,750,000$ \\
\hline \multicolumn{2}{|l|}{ Printing \& photocopying } \\
\hline Printing of monitoring cards & $8,950,000$ \\
\hline Photocopying of consent letter & 396,000 \\
\hline \multicolumn{2}{|c|}{ Data verification, entry $\&$ analysis (one additional officer) } \\
\hline Quality checks of monitoring cards & \multirow{4}{*}{$23,270,136$} \\
\hline Data entry & \\
\hline Data analysis & \\
\hline Guidance of PPM / schools & \\
\hline \multicolumn{2}{|l|}{ Monitoring trips } \\
\hline Routine field visits for district, province \& HQ & $12,000,000$ \\
\hline Total & $128,316,136$ \\
\hline$\%$ of annual transfer volume & $11.5 \%$ \\
\hline$\%$ of administrative costs & $39.5 \%$ \\
\hline
\end{tabular}

\subsubsection{Capacity constraints}

Implementation of conditionality proved particularly challenging as is evidenced by stakeholders' limited awareness of conditionality and the dysfunctional monitoring system. About $34 \%$ of all local respondents in qualitative interviews incorrectly identified the conditionality status of their community. Out of those who correctly identified the conditionality status, only about a quarter correctly identified the health and education conditions spelled out during the training and in the Manual of Operations. Representatives of the department of Health and Education at district level were also not aware of the SCT experiment on conditionality. The lack of information and lack of ownership for the monitoring system at the top level of the departments negatively impacted on the functionality of the overall monitoring system.

Looking at the fact that local stakeholders such as CWAC members, pay point managers and school teachers had understood the choice and nature of conditionality in different ways, it is not surprising that beneficiary households did not have a common understanding of whether they were subject to conditionality or not in different locations and what kind of conditions they had to comply with. About $41 \%$ of surveyed beneficiaries in unconditional communities believed in receiving CCTs and the range of conditions that beneficiaries believed in being conditioned on exceeded and differed from the conditions mentioned in the Manual as well as in the letter to beneficiaries 108 
(see figure 4.2). This is an experience which is shared with Nicaragua where a number of new localized conditions surfaced (Adato and Roopnaraine 2004).

Figure 4.2: Percentage of beneficiaries who believed in being subject to the following conditions (the first 5 conditions were the official conditions that conditioned beneficiaries had to comply with)

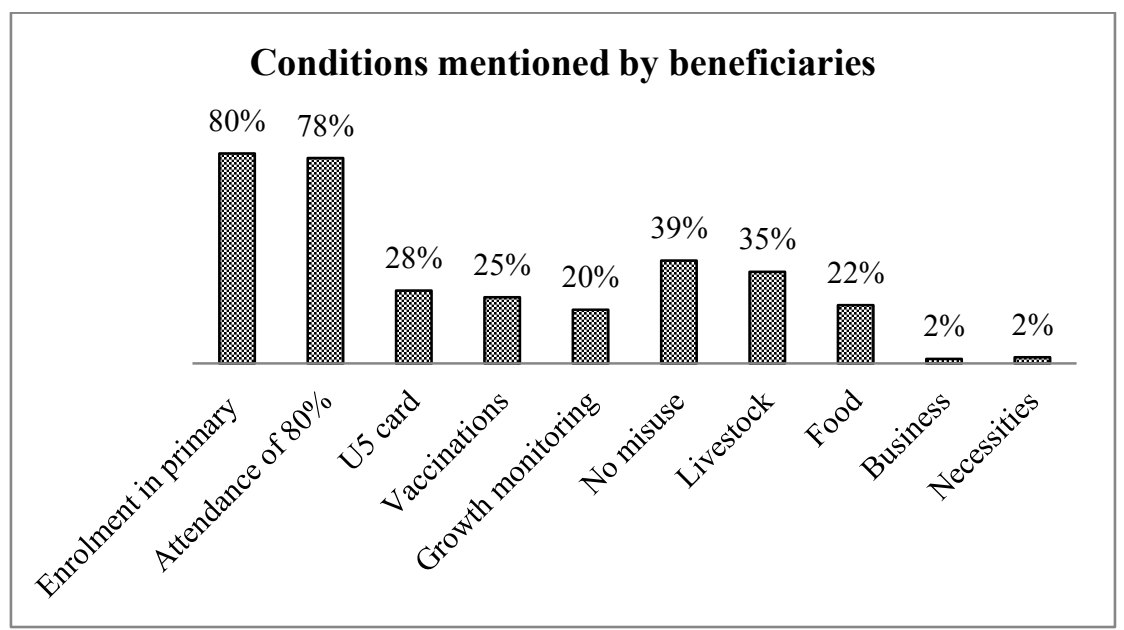

Source: Beneficiary survey

The mismatch of conditions has different reasons. Through discussions with teachers and pay point managers it became clear that some schools created their own localized conditions as it served their purpose and not necessarily due to a misunderstanding. A number of teachers mentioned that beneficiaries were obliged to pay the Parent Teacher Association with the transfer money. Other stakeholders such as CWAC members also added different conditions depending on their conviction of what was best for the beneficiaries. Most CWAC members stressed during the interview that it was of utmost importance for beneficiaries to invest in livestock, which we see reflected in beneficiaries' understanding of conditionality. The Manual also encourages CWAC members to ensure that beneficiaries do not misuse the money, which equally surfaces as one of the official conditions.

Despite the fact that the soft nature of conditionality implied no sanctions, more than $60 \%$ of all interview respondents claimed to have either implemented sanctions or to implement sanctions if a beneficiary did not comply. ${ }^{81}$ Even if most interview partners stated that sanctions would be preceded by a discussion with the beneficiary to allow for behavior changes, they did not follow the official rules stipulated in the Manual of Operations. The insufficient training and little support service might present one reason

\footnotetext{
${ }^{81}$ A little less than $20 \%$ of interview partners stated that they would go for mild sanctions, meaning that another household member would be signed up as a recipient or that there would be an intensive counseling phase.
} 
why the main parameters of the SCT experiment on conditionality were incorrectly understood by those managing it. Other reasons could be the great variance in levels of education and understanding among CWAC members and the partly conflicting information by the DSWO on the status of communities. ${ }^{82}$

Not only communication but also monitoring activities proved challenging: both the response rate to the monitoring cards as well as the quality of completed monitoring cards was rather low. Thirteen percent of all education cards were returned in 2007 and 2008 and only one third of all conditional and unconditional communities participated in the monitoring activity. Concerning health, the percentage of cards returned and the percentage of participating communities is slightly higher with $51 \%$ of all cards being returned by $42 \%$ of all communities during the first half of 2008 and $44 \%$ of cards by $40 \%$ of all communities during the second half. ${ }^{83}$

Table 4.13: Percentage of returned monitoring cards that did not provide any information on the following conditions:

\begin{tabular}{|l|r|r|}
\hline Health & $\mathbf{2 0 0 8 / 0 1}$ & $\mathbf{2 0 0 8 / 0 2}$ \\
\hline \hline Availability of card & $29 \%$ & $96 \%$ \\
\hline Completion of vaccinations & $51 \%$ & $96 \%$ \\
\hline Completion of growth monitoring & $49 \%$ & $96 \%$ \\
\hline \hline Education & $\mathbf{2 0 0 7}$ & $\mathbf{2 0 0 8}$ \\
\hline \hline Enrolment & $4 \%$ & $36 \%$ \\
\hline Grade mentioned & $13 \%$ & $47 \%$ \\
\hline Attendance rate for term 1 & $81 \%$ & $83 \%$ \\
\hline Attendance rate for term 2 & $71 \%$ & $83 \%$ \\
\hline Attendance rate for term 3 & $91 \%$ & $84 \%$ \\
\hline
\end{tabular}

Source: Conditionality monitoring cards

When we analyze the monitoring cards in more detail, we notice that information was not completely filled in for the cards that were returned (table 4.13 ). While $96 \%$ of all cards still detailed whether the child was enrolled in 2007, only one fifth of all cards mentioned the attendance rate for the different terms. The completeness of information deteriorates for 2008 with $36 \%$ of all cards not stating the enrolment status and $83 \%$ of all cards not containing further information on the attendance rate. For the health monitoring cards, the non-response rate is even higher. Cards were furthermore

\footnotetext{
${ }^{82}$ While only conditional communities received the official documentation and sensitization on conditionality as well as written reminders to stress the obligation of beneficiaries to send their children to schools and health centers, all pay point managers across conditional and unconditional communities were verbally encouraged to reiterate the importance of education and health.

${ }^{83}$ There were only 5 children under five whose households started receiving the transfer in 2007 so monitoring activities only really started in 2008 .
}

110 
inconsistently filled in, meaning for instance that cards contained information on reasons for absenteeism but lacked the actual attendance rate. These findings contrast with the perception of local stakeholders who for the most part were aware of the monitoring cards and did not see any problems in filling them in. ${ }^{84}$

The inaccuracy of the data derived from beneficiaries' application forms also proved challenging for a number of schools. Teachers complained that children's names, the name of the school as well as the grade were incorrect on the form and that it was at times impossible to trace these beneficiary children. Some cards were printed out twice and only on roughly every second monitoring form did the grade by the school correspond with the grade provided by the household. Out of the 16 communities on the SCT scheme visited, 5 communities were not part of the database and no monitoring cards had been printed. Data were neither cleaned nor analyzed by the DSWO due to problems experienced with the database software.

Another reason for the low-quality monitoring might have been the lack of incentives on the side of teachers and pay point managers to engage in monitoring activities. Teachers expected an allowance for their service, in particular in areas where this interministerial monitoring system competed with other external monitoring system of NGOs that were well-funded. Some representatives of the Ministry of Education illustrated that voluntarism, in particular among those on a government pay-roll, was difficult to find in rural communities. At times lack of internal communication and delegation also complicated the consistent completion of all monitoring cards.

The implementation inefficiencies certainly present one of the greatest challenges to make the SCT experiment on conditionality worthwhile. It is difficult to expect any behavioral responses on the side of beneficiaries if they are not adequately sensitized and if monitoring activities are neither regular nor professional in nature. The majority of beneficiaries did not notice any follow-ups ${ }^{85}$ : merely $50 \%$ of beneficiaries in conditional communities and about a quarter of beneficiaries in unconditional communities were aware of conditions being monitored.

\subsubsection{Promotion of corruption}

Conditionality can create further opportunities for cheating but local stakeholders in Monze did not seem to have made use of this opportunity. None of the beneficiaries

\footnotetext{
${ }^{84}$ Close to $80 \%$ of local respondents with whom the monitoring cards were discussed, were aware of the monitoring cards. Of those who were aware, close to $80 \%$ declared that the cards had been filled in. The majority thought the cards were manageable and relatively few among them reported any problems.

${ }^{85}$ It is furthermore difficult to recognize any consistent monitoring pattern, neither by condition nor by community: views, even within the same community, range from regular to irregular to no monitoring.
} 
claimed that any of the stakeholders involved in monitoring had ever asked them for remuneration. This was confirmed by the qualitative interviews which did not mention any instances of corruption.

\subsection{Concluding remarks}

The analysis has demonstrated the importance of not just focusing on the impact but also the potential inefficiencies that conditionality can introduce. On the positive side, we discovered that conditionality did not lead to any demotivation and was rather seen as a positive encouragement by (potential) beneficiaries. Without further information about the potentially negative effects of conditionality in unconditioned areas, we conclude that conditionality reinforced the impact of SCT on beneficiaries. For some of the critics of conditionality who view conditionality as patronizing and disempowering, this finding might come as a surprise.

On the negative side, we notice a number of design and implementation inefficiencies that call into question whether conditionality is the best choice for a country like Zambia where behavioral fine-tuning might not be regarded as a priority measure, where the transfer amount is very limited and where the overall budget and administrative capacity are constrained. Despite the fact that conditionality has some leverage to improve households' use of education and health services, it also risks excluding a number of beneficiaries as long as the transfer amount is not increased and/or the number of conditions lowered. The high administrative costs and the rather dysfunctional management and monitoring system around conditionality can be partly ascribed to the pilot stage of the SCT experiment on conditionality which had not reached maturity at the time of assessment. At the same time, it demonstrates that conditionality should only be introduced once more effective monitoring systems and inter-ministerial arrangements are in place, avoiding unnecessary (in) direct costs and confusion of stakeholders and beneficiaries as well as the eventual loss of credibility on the side of MCDSS.

It would be in the interest of policy-makers to analyze holistically the different inefficiencies before conditionality is introduced, simulating the costs and potential downsides of conditionality and ensuring that conditionality is designed in the most optimal way. A holistic analysis of the inefficiencies of conditionality should also be carried out when a CCT program is evaluated. It complements any impact analysis of conditionality, points us to specific sources of inefficiencies and in this way gives advice on the areas that could be optimized. A greater emphasis on inefficiencies would also prove beneficial for the academic world as it would allow shedding more light on the conditions that need to be in place for conditionality to prove effective. 


\section{CHAPTER 5: Community-based targeting - which motives are at play?}

\subsection{Introduction}

In low-income countries, targeting is one way of ensuring that limited fiscal resources are spent on the poor or vulnerable. Finding a targeting mechanism that is costeffective, considered fair by the communities and politically acceptable presents a challenge, and countries usually face trade-offs across these different dimensions. Most African countries have opted for a targeting mechanism that involves the community, with varying degrees to which actual decision-making power is decentralized. Mechanisms range from those that allow the community to determine and weigh targeting criteria and select beneficiaries accordingly to others that restrict the engagement of the community to a more administrative function of collecting and verifying information on potential beneficiaries. ${ }^{86}$ While it is less contested that the involvement of communities, local groups and NGOs can improve targeting outcomes (Subbarao, Bonnerjee et al. 1997), the extent to which decision-making should be decentralized is more controversial. This chapter therefore analyzes in more detail under what conditions the decentralization of targeting is an optimal choice for SCT programs in low-income countries.

Proponents of CBT argue that decentralized decision-making ensures direct accountability and empowerment of communities, making it easier for communities to understand and accept targeting choices (Conning and Kevane 2002). Communities often opt for a multi-dimensional interpretation of poverty, which might be more adequate in addressing the multiple deprivations households are suffering from. Their understanding of poverty is not exclusively linked to the income situation of a household - as opposed to a proxy-means test - and can encompass indicators that are not easily captured through existing household surveys (Coady, Grosh et al. 2004). CBT is believed to guarantee less costly access to more accurate and complete information. Community members have better knowledge of each other and are also at greater ease of obtaining information (Conning and Kevane 2002). In addition, they might sense a greater incentive or obligation to provide correct information in order to maintain their social capital (Coady, Grosh et al. 2004). In this way, CBT helps to overcome the information asymmetry that often presents a challenge in targeting.

The advantage of having better access to more reliable information can, however, only be captured by the welfare administration if communities have an incentive to make

\footnotetext{
${ }^{86}$ In addition, we also need to differentiate between pure CBT and hybrid forms where CBT is combined with other targeting methods such as geographical targeting, categorical targeting or a proxy-means test to further narrow down the target group, confirm or rectify targeting choices.
} 
use of their informational advantage (Alderman 2001). Critics of CBT argue that CBT cements existing power structures with local elites using this mechanism to their own advantage. Marginalized groups that are supposed to benefit from these interventions risk being excluded (Conning and Kevane 2002) or stigmatized. Critics are also more skeptical about the potential gains in administrative costs given that communities have weaker administrative capacity and costs are shifted from the administration to the individual community member (Coady, Grosh et al. 2004). They are also concerned that CBT might disrupt social cohesion, in particular in fairly homogeneous societies with egalitarian principles. Furthermore, they argue that the lack of standardization creates greater loopholes for corruption and misappropriation and makes it extremely difficult for central government to monitor and evaluate the targeting performance and for individual community members to claim their entitlements. ${ }^{87}$

While in 2004, at the time of the meta-review of targeting approaches by Coady, Grosh et al. (2004), there was still very little information on the effectiveness of CBT, ${ }^{88}$ the body of evidence has been growing over the past few years. Studies show that CBT for the most part has produced (at least slightly) progressive targeting outcomes (Micklewright and Marnie 2005; Watkins 2008a; Slater and Farrington 2009; Handa, Huang et al. 2010; Ridde, Haddad et al. 2010; Yusuf 2010), even though there is great variability. ${ }^{89}$ Despite this surge in quantitative as well as qualitative assessments of the performance of CBT, CBT has remained a black box in social policy with little being known about the underlying mechanisms and motives at work. We still have a limited understanding about the targeting preferences of community members and the extent to which community members are driven by egalitarian or progressive motives, by favoritism towards friends, relatives and socially important people and/or by selfishness. We also know very little as to how individuals' preferences translate into different targeting outcomes in the end and which factors at an individual and group level make CBT outcomes more progressive. A more in-depth understanding would allow us to better gauge the potential of CBT and see how the mechanism could be optimized.

It is methodologically challenging to acquire a better understanding of the mechanisms at work if we rely on evaluations of actual targeting mechanisms. While they are good at assessing the final outcome of the targeting process, they are less apt to capture individuals' original targeting motives and filter out the conditions that lead to success or more optimal results. We draw on controlled field experiments, carried out in rural

\footnotetext{
${ }^{87}$ This is even more so the case if communities factor in indicators such as status, access to and reliability of social networks etc., which are criteria that cannot easily be counterchecked through a household survey.

${ }^{88}$ Effectiveness refers here to the additional benefits the poor receive through targeting.

${ }^{89}$ In the meta-study by Coady, Grosh et al. (2004) of 122 programs and 14 with CBT, the median program with CBT gives $40 \%$ more to the poor than a uniform distribution but with considerable variation (inter-quartile range of 0.78 ). In another meta-analysis, specifically on CBT in middle and low-income countries, 10 out of 30 programs were considered progressive in targeting and 16 mildly progressive (Yusuf 2010).
}

114 
communities, to study stated and revealed targeting preferences of community members, the compatibility of individual targeting preferences with group outcomes, and determinants of progressiveness of CBT. The experiments allow us to test different variants of CBT and break down the decision-making process into controllable and measurable steps, mimicking real-life decision-making processes.

Table 5.1: Hypotheses tested in this chapter

\section{Hypotheses concerning targeting motives:}

Hypothesis 1: Community members prefer sharing the benefits equally, obviating the need for CBT.

Hypothesis 2: Community members are driven by inter-personal factors such as favoritism.

Hypothesis 3: Community members prioritize their own needs and act selfishly when allocating transfers.

\section{Hypotheses concerning the outcome of CBT:}

Hypothesis 4: CBT outcomes do not reflect majority positions.

\section{Hypotheses concerning determinants of progressiveness of CBT:}

Hypothesis 5: A more transparent CBT process leads to more progressive outcomes.

Hypothesis 6: Experienced communities achieve better targeting outcomes.

Building on the meta-studies by Coady, Grosh et al. (2004) and Yusuf (2010) and the experiment by Alatas (2010), which have sought to identify factors that influence CBT results, the experiments give us more flexibility in varying the targeting rules and enable us to take a closer look at actual targeting motives. The experiments are also different from the community mock-tests by Chininga (2005) as they incentivize participants through monetary pay-offs to reveal their true preferences rather than stating what is expected of them. They were designed in a way that would allow us to test the hypotheses laid out in table 5.1.

Concerning targeting motives, a number of studies have highlighted egalitarian tendencies across different communities (Chininga 2005; Ellis 2008; Köhler, Calì et al. 2009). We therefore question in hypothesis 1 whether egalitarianism is an actual preference of community members or whether it is mainly driven by social pressure, uncertainty or practical deliberations. Hypothesis 2 and 3 respond to the fact that there is mixed evidence with respect to the role of favoritism and elite capture in CBT, either used to favor social relations or oneself. Favoritism and political connections seem to have biased the targeting process in Ethiopia (Caeyers and Dercon 2008) and influenced results in Malawi (Miller, Tsoka et al. 2008b). Elite capture was observed in different programs in China (Park and Wang 2010), in West Africa (Platteau 2004), 
Tanzania (Pan and Christiaensen 2011) as well as Zambia (Watkins 2008a). There is however very little evidence of elite capture in the meta-study on CBT (Yusuf 2010), in the controlled experiment in Indonesia (Alatas, Banerjee et al. 2010) and in the CBT pilot in Burkina Faso (Ridde, Haddad et al. 2010)..$^{90}$

Regarding CBT outcomes, there is scarce evidence as to whether individual preferences are compatible with group choices (hypothesis 4) and in what way individual preferences are realized or constrained by targeting rules, the composition of the group and external circumstances. We should have a better understanding as to what extent poverty concepts and rankings are unanimously agreed upon or dominated by certain individuals in the group, leading to different rankings as well as satisfaction levels with targeting outcomes. The evidence up till now is inconclusive. In Honduras, different community groups arrived at different ratings of households, introducing confusion and a degree of arbitrariness (Bergeron, Morris et al. 1998). This is an experience that is shared with Malawi (Carletto 2001) as well as Nepal (Hobley and Paudyal 2008). The involvement of communities led to higher acceptance levels in Indonesia (Alatas, Banerjee et al. 2010), Ethiopia (Sharp, Brown et al. 2006) and Burkina Faso (Ridde, Yaogo et al. 2010). In other programs, the experience was less positive with committee members abusing their power for unduly excluding beneficiaries (Haenn 1999; Gugerty and Kremer 2000) and with growing tensions between non-beneficiaries and committee members (Watkins 2008a; Miller, Tsoka et al. 2008b; Slater and Farrington 2009).

The determinants of progressiveness of CBT are also contested. While transparency and accountability are both unanimously cited as factors for success in the two meta studies (Coady, Grosh et al. 2004; Yusuf 2010), the role of inequality ${ }^{91}$, quotaarrangements $^{92}$, as well as the discretion of the community in $\mathrm{CBT}^{93}$ are more

\footnotetext{
${ }^{90}$ Furthermore, the occurrence of elite capture is not necessarily related to the discretion that the community or the elite was given in the targeting process (Yusuf 2010).

${ }^{91}$ When it comes to inequality, CBT appears to have exacerbated results in Bangladesh's Food for Education program (Galasso and Ravallion 1999) and in Tanzania's input voucher pilot (Pan and Christiaensen 2011). Yamauchi (2008) on the contrary, finds the opposite effect for Indonesia's IDT Program; a result that is also confirmed by Coady, Grosh et al.'s meta-study (2004).

${ }^{92}$ Conning \& Kevane (2002) conclude that CBT works best in cases where the program is limited to a small percentage of the population so that the community-based selection committee still manages to behave altruistically towards those worse off. This is contested by Chininga (2005) who highlights the negative community dynamics of a quota as well as by several other studies (Adato and Haddad 2002; Coady, Grosh et al. 2004; Robinson 2006; Sharp, Brown et al. 2006; Pan and Christiaensen 2011) that show that insufficient resources complicate the decision-making process in the communities and lead to benefits either being spread too thinly or in a random way.

${ }^{93}$ Most policy-makers fear to give communities too much discretion in making targeting choices. Watkins (2008a) highlights for Zambia that more guidance and supervision, next to high community cohesion and lower extreme poverty rates, leads to better results. Gilligan, Hoddinott et al. (2005) hypothesize based on targeting assessments for Bangladesh, Ethiopia and Malawi that more targeting experience, also providing more guidance, improves targeting results. Yusuf (2010) in his metareview however does not find any evidence that more discretion and hence less guidance of communities in making choices translates into poorer results.
} 
controversially debated. The experiments allow us to test the role of transparency (hypothesis 5) and the role of better training and guidance of communities (hypothesis 6 ), next to giver and recipient characteristics as well as targeting rules.

We proceed to test the different hypotheses around targeting preferences, outcomes and determinants of progressiveness as follows: section 5.2 gives a brief introduction to the set-up of the experiments as well as to the characteristics of the participants in the experiment. Section 5.3 empirically tests the prevalence and relevance of the different targeting motives that the literature suggests and Section 5.4 assesses whether and how they translate into group outcomes. Section 5.5 looks more closely at factors that provoke more progressive outcomes for the (very) poor and Section 5.6 concludes.

\subsection{Methodology}

\subsubsection{Description of the community experiments ${ }^{94}$}

Community experiments were conducted in 25 different communities in Zambia, with a pre-test carried out in one additional community. The 25 communities were randomly selected through stratified cluster sampling from the list of treatment and control communities of a SCT pilot in Monze district. Communities were clustered by their SCT status to test the impact of prior targeting experience on targeting outcomes: 15 communities on the SCT pilot and 10 control locations, which had not been integrated into the SCT program, were selected. ${ }^{95}$

In each community, two groups of 10 members each participated in the experiment. Community members were randomly selected from a pool of volunteers. ${ }^{96}$ In each community, the sampling frame of potential participants was developed at a pre-survey community meeting during which basic demographic and socio-economic information of each community member present was recorded in a pre-survey form. The information so collected then helped to assign each member one of the three poverty categories: very poor, poor and better-off. Effort was made to ensure that there was representation from each of these strata in every group. Specifically, 3, 4, and 3 community members were randomly selected for each group from the very poor, poor and better-off categories, respectively.

There were two different treatment conditions in the experiment, which were randomly allocated to different communities. Every individual could only participate in one of

\footnotetext{
${ }^{94}$ A more detailed description of the experiment including instructions and questionnaires can be found in chapter 3 . In this chapter, only the main parameters of the experiment are repeated.

${ }^{95}$ For the final number of communities and participants in the experiment, see section 3.2.2 which details which observations were dropped from the analysis.

${ }^{96}$ About 54 people volunteered in each community.
} 
the two treatment conditions. For treatment condition 1 (TC1), group members made decisions for members of their own group including themselves while for treatment condition 2 (TC2), group members made decisions for members of the second group playing in the community. For each of these treatment conditions, two different rounds were played.

In the first round, participants individually distributed 20 tokens, each worth ZMK 50,000 ( US\$ 9.5), in private to either the participants of their group (TC1) or to participants of the other group (TC2) with the overall objective of alleviating poverty. For every group member, the giver had to decide 1) whether to give any tokens, 2) how many to give, 3) whether to make the transfer conditional, and 4) which condition to choose out of an education, growth monitoring, vaccination, training and community work condition. ${ }^{97}$ This and other rules of the experiment were clearly communicated to the participants prior to the commencement of the experiment. Most of the participants knew each other; in fact only 3\% claimed not to know the other person. In order to make sure that all group members had at least some basic information about the other participants, every participant was asked to introduce him- or herself before the initial instructions were given. After all individuals had made their choices concerning the distribution of tokens and conditionality, they were interviewed about their motives for doing so. ${ }^{98}$

For the second round of the experiment, all group members decided jointly on how to allocate a total of ZMK 10,000,000 to either their own group members (TC1) or the members of the other group in the community (TC2). The enumerators observed the decision-making process from a distance and the moderator only assisted with counting or time-keeping when the group took longer than half an hour. After the group decision-making process, each group member was again interviewed individually about his/her satisfaction with the group outcome, his/her preferences for education and health, his/her risk and time preferences, attitudes about trust, reciprocity, sources of poverty, government assistance etc.

The experiments were designed to mimic the existing SCT scheme and its CBT mechanism in Zambia. The CWACs that select the beneficiaries for the SCT scheme and for other in-kind transfers in Zambia typically comprise 10 members. The maximum amount that the SCT scheme gives to eligible households with children is

\footnotetext{
${ }^{97}$ A separate chapter (chapter 3) analyzes individual preferences and group choices with respect to conditionality. To the author's knowledge, there is no theory or evidence showing that targeting preferences are influenced by givers' ability to condition the support. If we were interested in testing in what way the possibility to condition the support influences targeting choices, we would have to design an experiment that asks participants to target with and without the option of conditionality.

${ }^{98}$ There is a chance that the question about their motives sharpened people's awareness for the subsequent group round. Looking at the stated motives by participants (section 5.3.1) and the fact that a great percentage of transfers going to the better-off were described as poverty transfers, we can see that participants had an interest in coming across as progressive and that this was not simply a result of the question on motives.
}

118 
ZMK 50,000 per month, the value of each token in the experiment. TC2 represents the existing targeting rule in the SCT scheme: at an individual level, committee members are not allowed to benefit from the SCT scheme and at a group level, the committee decides as an expert committee for the community rather than the entire community deciding on how benefits are allocated among themselves. TC1 has been previously discussed as an alternative.

In order to incentivize choices, there was a real monetary gain for participants. Each token-receiving individual was awarded $1 \%$ of the value of the tokens received (i.e. ZMK 500 for each ZMK 50,000 token received).

\subsubsection{Participants}

Participants in the experiment were randomly sampled according to their poverty classification. The assessment of the poverty status of all potential participants was made on the basis of the pre-survey questionnaire by the same person of the research team in collaboration with members of the local CWAC. The external assessment was not disclosed to the participants. At least $70 \%$ of the respondents were rated as poor or very poor. Participants were also asked to self-assess their poverty status. Even though general poverty classifications in the sample are similar across self- and externally assessed poverty, they can vary at an individual level as table 5.2 shows. For example, the first row of the table shows that among those who were categorized as being very poor according to the external poverty assessment, $67 \%$ also rated themselves as being very poor, while $29 \%$ rated themselves as poor and only $4 \%$ as middle income class.

Table 5.2: Cross-tabulation of participants' externally and self-assessed poverty status

\begin{tabular}{|l||r|r|r|r|r|r|r|}
\cline { 2 - 9 } \multicolumn{1}{c|}{} & \multicolumn{7}{c|}{ Self-assessed poverty } \\
\hline $\begin{array}{l}\text { Externally assessed } \\
\text { poverty }\end{array}$ & $\begin{array}{l}\text { Very } \\
\text { poor }\end{array}$ & Poor & Middle & $\begin{array}{l}\text { Upper } \\
\text { middle }\end{array}$ & Rich & Total & $\begin{array}{l}\text { No of } \\
\text { obs. }\end{array}$ \\
\hline \hline Very poor & $67 \%$ & $29 \%$ & $4 \%$ & $0 \%$ & $0 \%$ & $100 \%$ & 137 \\
\hline Poor & $12 \%$ & $65 \%$ & $20 \%$ & $2 \%$ & $1 \%$ & $100 \%$ & 174 \\
\hline Better-off & $7 \%$ & $30 \%$ & $53 \%$ & $9 \%$ & $2 \%$ & $100 \%$ & 132 \\
\hline
\end{tabular}

Source: Experiment - pre-survey

As participants were randomly selected on the basis of a pool of volunteers, we could expect that these volunteers are on average more motivated to attend to the needs of the poorest and / or that they are more selfish, mainly expecting to benefit from the experiment themselves. This is however not likely to be different from the community members who normally volunteer to engage in $\mathrm{CBT}$ and therefore unlikely to bias our results. 
Women were more likely to participate in the experiment than men (58\% vs. $42 \%)$ and with an average age of 51 years, the experiment population is a lot older than the national average (CSO 2008). The age composition is however not uncommon for community committees as the young usually face higher opportunity costs and might also not command as much respect as older people. Most participants are subsistence farmers who live on their own produce followed by a smaller percentage that declared community assistance and paid labor as their main source of income. This is in line with the findings of the LCMS 2006 (CSO 2008). Participants play a variety of different roles in the community, including traditional leaders, committee chairpersons and members, teachers, and health workers. Ten percent of all participants are CWAC members who are in charge of targeting the most vulnerable households for different in-kind as well as cash benefits by government. Ten percent of all participants are beneficiaries of the SCT scheme, corresponding with the official percentage of SCT beneficiaries in rural communities.

\subsection{Targeting motives}

People act out of different motives when giving money to other individuals. Even though the overall objective of the transfer allocation in the experiment was to alleviate poverty in the community, people were given discretion in interpreting this in their own way. This allowed them to choose and follow their own targeting motives.

\subsubsection{Stated targeting motives}

Poverty alleviation is explicitly stated by participants as one of the main motives as table 5.3 illustrates. The lack of alternative forms of support and the recipient's potential to invest the money also figure high among givers' prime motives $(24 \%$ and $22 \%$ out of all transfers were given respectively out of this motive), while relationships as well as unforeseen events matter less. This observation as such is not surprising as participants knew that the objective of the token allocation in the experiment was to reduce poverty. So participants may have responded with what they believed was a politically correct message. Conditional on motives, the average amount differed. The highest average number of tokens was given to those without any support (2.4 tokens per person on average), followed by those considered poor (2.3 tokens per person on average). The lowest average transfer was given for the motive of proximity (1.5 tokens per person on average) and the capacity of the person to invest the transfer productively (1.9 tokens per person on average). ${ }^{99}$

\footnotetext{
${ }^{99}$ Differences between the amounts given out of the support motive for those in poverty and for those without support and the amounts given out of the investment and proximity motive are statistically significant at the $1 \%$ level.
} 
Table 5.3: Stated targeting motives of givers (more than one motive could be stated)

\begin{tabular}{|l|r|r|r|}
\hline Transfer motives & $\begin{array}{l}\text { \% of } \\
\text { transfers out } \\
\text { of this } \\
\text { motive }\end{array}$ & $\begin{array}{l}\text { Average number } \\
\text { of tokens given } \\
\text { out of this } \\
\text { motive }\end{array}$ & $\begin{array}{l}\text { No of } \\
\text { obs. }\end{array}$ \\
\hline \hline Poverty: recipient is poor & $50 \%$ & 2.3 & 2078 \\
\hline No support: Recipient does not have any support & $24 \%$ & 2.4 & 998 \\
\hline $\begin{array}{l}\text { Potential to invest: Recipient has the potential to } \\
\text { invest }\end{array}$ & $22 \%$ & 1.9 & 921 \\
\hline $\begin{array}{l}\text { Unforeseen event: Recipient experienced } \\
\text { unforeseen event }\end{array}$ & $3 \%$ & 2.2 & 118 \\
\hline Proximity: Recipient is close to the giver & $3 \%$ & 1.5 & 134 \\
\hline $\begin{array}{l}\text { Other rationale (e.g. poor health, big family size, } \\
\text { age / no labor capacity) }\end{array}$ & $4 \%$ & 2.1 & 162 \\
\hline
\end{tabular}

Source: Experiment - survey I

When disaggregating the giver's motive of supporting those in poverty by the recipients' poverty status, we see that this poverty motive was more often but not exclusively used for the (very) poor. Fifty-four percent of transfers going to the very poor were given out of the poverty motive, compared to $48 \%$ of transfers to the poor and $37 \%$ of transfer to the better-off. The differences are statistically significant at the $1 \%$ level. The fact that $37 \%$ of transfers going to the better-off are still characterized as poverty transfers highlights a difference between stated and revealed targeting motives. This difference could be either due to information constraints and the givers' difficulty of realizing their targeting preferences or due to givers' dishonesty about their true targeting motive. We now analyze to what extent targeting motives are possibly driven by factors other than poverty.

\subsubsection{Preferences for egalitarianism}

Hypothesis 1: Community members prefer sharing the benefits equally, obviating the need for CBT.

Looking at the individual choices made, in particular in communities with prior exposure (table 5.4), it is difficult to conclude that community members at large have a preference for sharing benefits equally and view all community members to be in a comparable position. The fraction of those who decided against a uniform distribution is statistically significant from zero, which makes us refute hypothesis 1. Moreover,

\footnotetext{
${ }^{100}$ This refers to the total number of tokens that all givers allocated out of a particular motive divided by the total number of tokens available in the experiment.

${ }^{101}$ This refers to the average number of tokens by giver, allocated out of a particular motive.
} 
when we compare the actual distribution of tokens of 34\% going to the very poor, $39 \%$ to the poor and $27.0 \%$ to the better-off to a uniform distribution with $30 \%$ of the share going to the better-off, $40 \%$ to the poor and $30 \%$ to the very poor, we see that the two diverge in a statistically significant way. This confirms our initial conclusion of rejecting hypothesis 1 .

Table 5.4: Percentage of individuals opting for a uniform distribution, by community status and treatment condition

\begin{tabular}{|c|c|c|}
\hline & Percentage & No of obs. \\
\hline \multicolumn{3}{|l|}{ SCT communities } \\
\hline Treatment condition 1 & $23 \%$ & 136 \\
\hline Treatment condition 2 & $25 \%$ & 152 \\
\hline \multicolumn{3}{|l|}{ Non-SCT communities } \\
\hline Treatment condition 1 & $34 \%$ & 79 \\
\hline Treatment condition 2 & $41 \%$ & 80 \\
\hline
\end{tabular}

Source: Experiment - individual allocation round

About $29 \%$ of all individuals, however, adhered to an equal sharing rule, which shows that egalitarian motives in allocations were present. The inclination towards egalitarian outcomes is stronger in communities that had not been incorporated into the SCT scheme as evidenced by table 5.4. The difference between individual distributions in SCT and non-SCT communities is statistically significant at the $1 \%$ level. This could be partly ascribed to the fact that egalitarian distributions are born out of ignorance or insecurity of deviating from the default position. Greater exposure to targeting methods broadens people's targeting motives and might give them the tools and expertise for distributing transfers progressively or regressively.

There are different ways of analyzing whether those who did not opt for an egalitarian distribution, favored predominantly the poor or the non-poor in their distribution choices. ${ }^{102}$ One of the measures used by Coady, Grosh et al. (2004) in their meta-study is the following targeting performance indicator (TPI):

$$
T P I=\frac{\% \text { of total benefits allocated to the (very) poor }}{\% \text { of total benef its to the (very)poor in a neutral distribution }}
$$

The TPI analyzes what percentage of a giver's budget ( 20 tokens) is allocated to the (very) poor, comparing this with the percentage of benefits the (very) poor would have received in a neutral distribution, where everyone would have received identical benefits. A TPI $=1$ means that the distribution is neutral. A TPI of less than 1 indicates a regressive distribution and a TPI of more than 1 a progressive distribution.

${ }^{102}$ For a discussion of different methods, see Coady, Grosh et al. (2004). 
Those who were externally assessed as very poor received on average 22.3 tokens from the different group members, compared to 19.8 tokens that the poor and 18.0 tokens that the better-off received. When we analyze the minimum and maximum number of tokens allocated to people of different poverty status, we can also see differences in favor of the poorest. ${ }^{103}$ Overall, the very poor obtained $12 \%$ more through the distribution than what they would have received through a uniform distribution; the addition they received was predominantly taken from the better-off.

When we break down this average of $12 \%$ and classify each individual distribution as regressive, neutral or progressive, we note that $47 \%$ of all transfers to the very poor were neutral with $17 \%$ being regressive, $30 \%$ mildly progressive (TPI of $1-2$ ) and $5 \%$ being progressive (TPI $>2$ ). Individuals in TC1 in SCT-communities are most regressive in their choices, which could be due to the fact that individuals were allowed to behave selfishly, a phenomenon we will examine more closely in 5.3.4. In conclusion, targeting was overall pro-poor even though the extent of re-distribution from the better-off to the poor or very poor was not considerable. This result is in line with the finding of the meta-study by Yusuf (2010) that the majority of CBT programs were mildly progressive; the TPI is, however, below the median targeting incidence of 1.4 in the study by Coady, Grosh et al. (2004).

In judging the extent of progressiveness, it is important to keep in mind that an experiment with a total of 20 tokens and with $70 \%$ of participants being poor limits the pro-poorness of choices. The maximum effect of re-distribution from the better-off to the very poor would lead to a doubling of benefits for the very poor from 2 to 4 tokens on average. If we assume that participants would have been reluctant to take away all the tokens from the better-off and would have preferred the better-off to have at least one token, the additional benefits for the very poor would amount to a $50 \%$ increase from 2 to 3 tokens. We can exploit the fact that not all group compositions were homogenous (see section 3.2.2) to test whether a greater proportion of better-off recipients in the group increased the degree of progressiveness. When we compare all distributions to groups that had an additional better-off recipient to those that had the required composition or less, we notice a significant change. In groups with an additional better-off recipient, givers distributed on average 34\% more to the very poor versus $10 \%$ in groups with the required composition or fewer better-off. The difference is statistically significant at the $1 \%$ level. This demonstrates that the group composition of recipients could indeed have an influence on the progressiveness of givers' distributions.

Furthermore, we might also misinterpret individuals' preferences for progressiveness. Their assessment of the poverty status of potential recipients does not always coincide

\footnotetext{
${ }^{103}$ Among the very poor only $37 \%$ received no tokens from at least one other person, compared to $44 \%$ of the poor and $57 \%$ of the better-off. The maximum number of tokens that the very poor got from another participant was 5.1 tokens on average, compared to 3.8 tokens for the poor and 3.6 tokens for the better-off.
} 
with the external assessment. The external poverty assessment, carried out on the basis of a small questionnaire and cross-checked with community informants, might possibly be more complete than the individual assessment of each and everyone's situation. This might be the case as the external assessment combines the information from potential recipients with the knowledge of those community members who are actively engaged in the community and therefore tend to have a good oversight. For that reason, we could assume that progressive allocations would even be stronger if individuals had access to more complete information.

\subsubsection{Preferences for inter-personal distributions}

Hypothesis 2: Community members are driven by inter-personal factors such as favoritism.

Proximity to other participants figures low on the priority list of participants, even as a potentially hidden motive for transfers going to the better-off in a community. As we can expect that proximity or relationships are rarely cited as official reasons for targeting in an anti-poverty program, we now examine the preferences that participants revealed through the experiments.

Different types of relationships produce different allocation patterns as illustrated by table 5.5, which shows the additional number of tokens that recipients received when compared to a recipient with no relationship to the giver. In experiments with TC1, the highest and unparalleled allocation is to givers themselves. When we compare it with the allocation to recipients to whom the giver has no relationship 104, the difference is statistically significant. Allocations to prominent community members as well as workmates lead to a statistically significant decrease in the number of tokens given. Transfers to family members are only marginally higher than to people who are unrelated but the difference is statistically significant. In experiments with TC2, we again see lower and statistically significant contributions to prominent community members, pointing to the fact that community members do not sense any obligation to give to people in the community with a particular status. As in TC1, family members also receive a slightly higher transfer. This might be a sign of favoritism when it comes to the inner circle. When we look at the correlation between how well the giver knows the recipient and the average number of tokens given, we cannot see a clear trend.

\footnotetext{
${ }^{104}$ Half of all giver-receiver couples have no relationship. Twenty percent of relationships between giver and recipient were family relationships, followed by neighbor relations (17\%) and friendships $(6 \%)$. Around $1 \%$ of givers mentioned a relationship to one of the prominent people in the village (chief, school teacher, pastor) and church mates. Even if half of all participants had no official relationship with fellow participants, only $3 \%$ claimed that they did not really know the other person. About $52 \%$ knew the other person very well, $22 \%$ well, $14 \%$ a bit and $8 \%$ hardly.
} 
Table 5.5: Additional number of tokens that the recipient received if $s / h e$ had a relationship with the giver as opposed to no relationship

\begin{tabular}{|l|r|r|r|r|}
\hline Relationship & \multicolumn{2}{|l|}{ Treatment condition 1 } & \multicolumn{2}{l|}{ Treatment condition 2 } \\
\hline \hline $\begin{array}{l}\text { Recipient is a ... to } \\
\text { the giver }\end{array}$ & $\begin{array}{l}\text { Additional number of } \\
\text { tokens }\end{array}$ & $\begin{array}{l}\text { p-value } \\
\text { of t-test }\end{array}$ & $\begin{array}{l}\text { Additional number of } \\
\text { tokens }\end{array}$ & $\begin{array}{r}\text { p-value } \\
\text { of t-test }\end{array}$ \\
\hline \hline Self & 2.85 & 0.00 & - & - \\
\hline Family member & 0.08 & 0.10 & 0.10 & 0.04 \\
\hline Friend & 0.00 & 0.97 & -0.04 & 0.66 \\
\hline Neighbor & 0.05 & 0.31 & 0.08 & 0.14 \\
\hline Church & 0.03 & 0.91 & 0.02 & 0.88 \\
\hline Work & -0.57 & 0.07 & -0.42 & 0.17 \\
\hline Prominent & -0.75 & 0.00 & -0.58 & 0.00 \\
\hline Other & 0.52 & 0.03 & -0.03 & 0.88 \\
\hline
\end{tabular}

Source: Experiment - individual allocation round \& Experiment - survey II

Thinking about inter-personal factors, we could also hypothesize that not only relationship status and proximity but also resemblance in terms of background characteristics plays a role. Givers might identify more with recipients they are close to in terms of gender, age and poverty status. They seemingly do: recipients who are in the same poverty group, of the same gender and in the same age bracket as the giver receive 2.11 tokens on average, which is 0.25 tokens more than those who are not a match. ${ }^{105}$ The difference is statistically significant at the $1 \%$ level.

As higher transfer amounts might be driven by other factors that are correlated with the variables on relationship, we now resort to multi-variate analysis, using the following model:

(Eq. 5.2)

$$
\mathrm{Y}_{\mathrm{ij}}=\alpha+\beta \mathbf{P}_{\mathrm{j}}+\gamma \mathbf{R}_{\mathrm{ij}}+\delta \mathbf{C}_{\mathrm{ij}}+\varepsilon \mathbf{X}_{\mathrm{j}}+\mathrm{u}_{\mathrm{ij}}
$$

where

$\mathrm{Y}_{\mathrm{ij}}=$ number of tokens that individual $\mathrm{j}$ received from individual $\mathrm{i}$

$\mathbf{P}_{\mathrm{j}}=$ vector of variables describing the poverty status of recipient $\mathrm{j}$

$\mathbf{R}_{\mathrm{ij}}=$ vector of relationship variables between individuals $\mathrm{i}$ and $\mathrm{j}$

$\mathbf{C}_{\mathrm{ij}}=$ vector of different giver and recipient combinations $\mathrm{i}$

$\mathbf{X}_{\mathrm{j}}=$ vector of background characteristics of recipient $\mathrm{j}$

$\alpha=$ constant

$\beta, \gamma, \delta, \varepsilon=$ vectors of coefficients to be estimated

$\mathrm{u}_{\mathrm{ij}}=$ error term.

${ }^{105}$ Givers who were recipients at the same time, were excluded from this analysis. 
We use ordinary least squares (OLS) for this purpose. ${ }^{106}$ We run regressions separately by treatment condition as we assume that the opportunity to give tokens to oneself significantly influences targeting motives. We first begin with TC2 where participants did not have the possibility to distribute any tokens to themselves.

Table 5.6: OLS regression on distribution motives of individuals in TC2 Dependent variable: number of tokens given by individuals in TC2 in Round 1

\begin{tabular}{|c|c|c|}
\hline \multirow{2}{*}{$\begin{array}{l}\text { Explanatory variables } \\
\text { Recipient poverty assessment: very poor }(0=\mathrm{No}, 1=\mathrm{Yes})\end{array}$} & \multicolumn{2}{|c|}{ Coefficients } \\
\hline & $0.28 * * *$ & $(0.07)$ \\
\hline Recipient poverty assessment: poor $(0=\mathrm{No}, 1=\mathrm{Yes})$ & $0.16 * * *$ & $(0.05)$ \\
\hline Recipient being too old $/$ sick to work $(0=\mathrm{No}, 1=\mathrm{Yes})$ & $0.23 * *$ & $(0.10)$ \\
\hline Recipient being a family member $(0=\mathrm{No}, 1=\mathrm{Yes})$ & $0.08 *$ & $(0.04)$ \\
\hline Recipient is known $(0=$ not really $-->4=$ very well $)$ & 0.02 & $(0.02)$ \\
\hline Important position in the community of recipient $(0=\mathrm{No}, 1=\mathrm{Yes})$ & $-0.13 * * *$ & $(0.05)$ \\
\hline $\begin{array}{l}\text { Recipient shares the same characteristics with giver (poverty status, } \\
\text { gender, age bracket: } 19-30,31-40,41-50,51-60,61-70,71-80,81-100) \\
(0=\text { No, } 1=\text { Yes })\end{array}$ & $0.20 *$ & $(0.11)$ \\
\hline Very poor giver and very poor recipient $(0=\mathrm{No}, 1=\mathrm{Yes})$ & -0.07 & $(0.07)$ \\
\hline Female giver and very poor recipient $(0=\mathrm{No}, 1=\mathrm{Yes})$ & 0.06 & $(0.08)$ \\
\hline Young giver $(<45)$ and old $(>65)$ poor receiver $(0=$ No, $1=$ Yes $)$ & 0.05 & $(0.12)$ \\
\hline $\begin{array}{l}\text { Old }(>65) \text { male giver and younger }(<45) \text { female recipient } \\
(0=\text { No, } 1=\text { Yes })\end{array}$ & 0.08 & $(0.11)$ \\
\hline Age Recipient & $0.00 * *$ & $(0.00)$ \\
\hline Gender Recipient $($ male $=0$, female $=1$ ) & 0.01 & $(0.04)$ \\
\hline Number of children 0-4 in the recipient's household & $0.02 * *$ & $(0.01)$ \\
\hline Constant & $1.57 * * *$ & $(0.10)$ \\
\hline $\mathrm{R}^{2}$ & 0.05 & \\
\hline$N$ & 2295 & \\
\hline
\end{tabular}

OLS regression estimates. In parentheses, robust standard errors, adjusted for clustering on givers. * $10 \%$ significance level $* * 5 \%$ significance level $* * * 1 \%$ significance level. Reference group $=$ non(very) poor male recipients who are not too old/sick to work, are not a family member of the giver, whom the giver does not really know, who do not have an important position in the community, do not share the same characteristics with the giver, do not match any of the giver/receiver combinations and who are part of a group that does not have an additional better-off person.

Source: Experiment - pre-survey, Experiment - individual allocation round \& Experiment survey II

${ }^{106}$ This choice is motivated in Annex 11. 
While a lot of variation in the number of tokens remains unexplained, table 5.6 shows that the poverty status of the recipient and the fact that a recipient cannot work anymore and needs income support, have a statistically significant influence on the transfer allocation. We can therefore conclude that the poverty status of the recipient definitely enters into the giver's allocation equation. Next to the poverty status, givers also allocated more to recipients who were older as well as recipients who had a greater number of small children, which might signal that givers considered them to be more vulnerable.

The regression coefficient for family members is statistically significant but its effect size is comparatively small, showing that favoritism to family members did not seem to be one of the leading motives. We also do not find any evidence that participants felt compelled to give more to community members with a status position in order to maintain their social capital. Recipients with a special role in the community such as members of social committees, headmen, school teachers, health workers or pastors actually received less. Givers allocated more to participants who resembled them in terms of poverty status, gender and age group, showing support for the argument that it is easier to redistribute if one identifies with the recipient. We did not find any other giver-recipient combination that correlated with a higher or lower transfer amount.

While favoritism to family members and identification with recipients played a role in givers' allocation decisions, we do not find any compelling evidence that community members were exclusively motivated by interpersonal factors in their allocation decisions. This confirms hypothesis 2 but also shows that CBT cannot only be equated with favoritism to the inner circle.

\subsubsection{Preferences for selfishness}

Hypothesis 3: Community members prioritize their own needs and act selfishly when allocating transfers.

The first treatment condition, where individuals had the opportunity to allocate any out of the 20 tokens to themselves, enables us to test for the influence of selfishness. As demonstrated by table 5.5 earlier as well as by figure 5.1, participants in TC1 did not shy away from using the opportunity to allocate tokens to themselves. The average transfer to oneself was 4.55 tokens compared to an average transfer to other participants which did not exceed 2 tokens. There were only 4 people who did not allocate any tokens to themselves. Forty percent of givers in TC1 allocated 2 tokens to themselves - the average in a uniform distribution. A little more than half of all givers 
opted for a higher number of tokens. ${ }^{107}$ Men gave themselves about 4.2 and women allotted themselves 4.8 tokens, with the difference not being statistically significant.

Figure 5.1: Fraction of tokens allocated to oneself by individuals in TC1

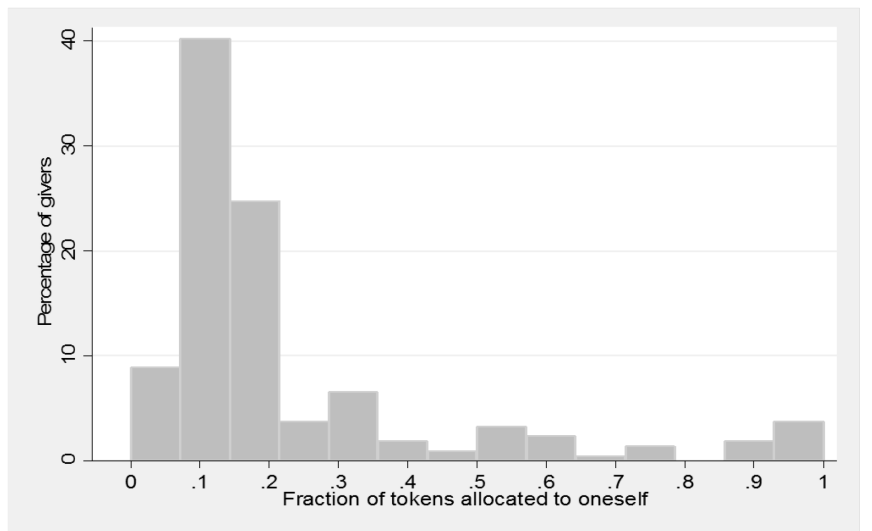

Source: Experiment - individual allocation round

If we considered any distribution as selfish where the giver did not distribute a comparable number of tokens to at least one more person in the group, about $39 \%$ of participants in TC1 would classify as selfish. The self-allocation pattern varies by poverty status. While the very poor allocated on average 6.0 tokens to themselves, the poor and the better-off allocated both 3.9 tokens respectively to themselves. The relationship between poverty status and selfishness, however, has to be put into perspective. When we factor in what someone would be entitled to according to his/her poverty status, the picture changes: ${ }^{108} 33 \%$ of the very poor would classify as selfish, $51 \%$ of the poor and $45 \%$ of the better-off.

In order to test the relative importance of the selfishness motive, we now run the same OLS regressions as in 5.3.3 on the sub-sample in TC1, controlling in addition for the possibility to give tokens to oneself.

Looking at the regression output (table 5.7) we notice that the possibility of giving tokens to oneself accounts for a relatively large part of the token allocation, in particular for the very poor. The effects are statistically significant and comparatively large. There is little evidence for a stronger inclination among the better-off to enrich

\footnotetext{
${ }^{107}$ When comparing the number of tokens allocated to oneself with the maximum number of tokens given to any participant, we can see that all of the token allocations above 6 tokens were exclusively given to oneself.

${ }^{108}$ The maximum number a very poor person would be entitled to are 20 tokens divided by the number of very poor in his/her group. A poor person in the best case scenario would receive an equal share with all the very poor and poor. A better-off person could hope for an equal share with all the group members.
} 
Table 5.7: OLS regression on distribution motives of individuals in TC1

Dependent variable: number of tokens given by individuals in TC1 in Round 1

\begin{tabular}{|c|c|c|}
\hline \multirow{2}{*}{$\begin{array}{l}\text { Explanatory variables } \\
\text { Recipient poverty assessment: very poor }(0=\mathrm{No}, 1=\mathrm{Yes})\end{array}$} & \multicolumn{2}{|c|}{ Coefficients } \\
\hline & $0.30 * * *$ & $(0.10)$ \\
\hline Recipient poverty assessment: poor $(0=\mathrm{No}, 1=\mathrm{Yes})$ & $0.12 * * *$ & $(0.04)$ \\
\hline Recipient being too old $/$ sick to work $(0=$ No, $1=$ Yes $)$ & 0.03 & $(0.20)$ \\
\hline Recipient being a family member $(0=\mathrm{No}, 1=\mathrm{Yes})$ & 0.04 & $(0.06)$ \\
\hline Recipient is known $(0=$ not really $-->4=$ very well $)$ & 0.04 & $(0.03)$ \\
\hline Important position in the community of recipient $(0=\mathrm{No}, 1=\mathrm{Yes})$ & -0.14 & $(0.09)$ \\
\hline $\begin{array}{l}\text { Recipient shares the same characteristics with giver (poverty status, } \\
\text { gender, age bracket: } 19-30,31-40,41-50,51-60,61-70,71-80,81-100) \text { and } \\
\text { giver and recipient are not the same person }{ }^{109}(0=\mathrm{No}, 1=\text { Yes })\end{array}$ & $0.26 *$ & $(0.14)$ \\
\hline Very poor giver and very poor recipient ${ }^{110}(0=\mathrm{No}, 1=\mathrm{Yes})$ & $-0.20 *$ & $(0.11)$ \\
\hline Female giver and very poor recipient $(0=\mathrm{No}, 1=\mathrm{Yes})$ & -0.13 & $(0.13)$ \\
\hline Young giver $(<45)$ and old $(>65)$ poor receiver $(0=\mathrm{No}, 1=$ Yes $)$ & -0.05 & $(0.09)$ \\
\hline Old $(>65)$ male giver and younger $(<45)$ female recipient $(0=$ No, $1=$ Yes $)$ & 0.02 & $(0.13)$ \\
\hline Self $(0=$ giver is not the recipient, $1=$ giver is the recipient $)$ & $1.93 * * *$ & $(0.52)$ \\
\hline Interaction: Self $*$ PovertyStatus $=$ very poor & $2.02 * * *$ & $(0.80)$ \\
\hline Interaction: Self $*$ PovertyStatus $=$ better-off & 0.21 & $(0.61)$ \\
\hline Interaction Self*Gender & 0.29 & $(0.61)$ \\
\hline Age Recipient & 0.00 & $(0.00)$ \\
\hline Gender Recipient $(0=$ male, $1=$ female $)$ & $0.17 * * *$ & $(0.05)$ \\
\hline Number of children $0-4$ in the recipient's household & -0.01 & $(0.03)$ \\
\hline Constant & $1.20 * * *$ & $(0.17)$ \\
\hline $\mathrm{R}^{2}$ & 0.24 & \\
\hline$N$ & 2129 & \\
\hline
\end{tabular}

OLS regression estimates. In parentheses, robust standard errors, adjusted for clustering on givers. * $10 \%$ significance level $* * 5 \%$ significance level $* * * 1 \%$ significance level. Reference group $=$ non(very) poor male recipients who are not too old/sick to work, are not a family member of the giver, whom the giver does not really know, who do not have an important position in the community, do not share the same characteristics with the giver, who do not match any of the giver/receiver combinations, are not giver and recipient at the same time and who are part of a group that does not have an additional better-off person.

Source: Experiment - pre-survey, Experiment - individual allocation round \& Experiment survey II

\footnotetext{
${ }^{109}$ For givers who are at the same time the recipient, the variable was set to 0 .

${ }^{110}$ For givers who are at the same time the recipient, the variable was set to 0.
} 
themselves if we were to assume that they had more knowledge or fewer reservations about favoring themselves. Once we control for the self-allocation effect, favoritism to family members disappears as a motive. This could be due to the fact that givers now have a possibility to directly favor themselves and do not have to use any indirect channels. Givers are, however, still more inclined to give to recipients that share similar characteristics and they can identify with.

Transfers still seem to be motivated by poverty. The very poor as well as the poor receive a greater number of tokens. The gender of the recipient also appears to matter with women receiving a higher share of tokens. Nevertheless, the effect size of the selfishness motive remains unmatched, making us conclude that participants were predominantly driven by the possibility to favor themselves rather than by other motives. Considering that volunteers were not told about the monetary pay-offs in the initial community meeting, we can assume that the selfishness motive might even be more prevalent among those community members who explicitly join community committees, expecting to benefit through this engagement. We can therefore confirm hypothesis 3 that community members indeed have a tendency of prioritizing their own needs.

We now take a closer look at the characteristics of the givers who behaved selfishly, using the following logistic model:

$$
\operatorname{Prob}\left(\mathrm{Y}_{\mathrm{i}}=1\right)=\alpha+\beta \mathbf{A}_{\mathrm{i}}+\gamma \mathbf{X}_{\mathrm{i}}+\delta \mathrm{l}_{\mathrm{i}}+\mathrm{u}_{\mathrm{i}}
$$

where

$\operatorname{Prob}\left(\mathrm{Y}_{\mathrm{i}}=1\right)=$ probability of giver $\mathrm{i}$ of being selfish ${ }^{111}$

$\beta=$ coefficients to be estimated

$\mathbf{A}_{\mathrm{i}}=$ vector of attitude variables of giver $\mathrm{i}$

$\mathbf{X}_{\mathrm{i}}=$ vector of background characteristics of the giver i

$l_{i}=$ status of the location where individual i resides

$\alpha=$ constant

$\beta, \gamma=$ vectors of coefficients to be estimated

$\delta=$ coefficient to be estimated

$\mathrm{u}_{\mathrm{i}}=$ error term.

As illustrated by table 5.8, there is a greater tendency towards selfishness in SCT communities (18 percentage point higher probability of self-allocation at the mean). This could be an effect of community members either having acquired more experience in manipulating the system or being disappointed with the targeting experience so far and therefore giving priority to oneself. Those who thought that the poor should take

\footnotetext{
${ }^{111}$ Selfishness being defined as giving more to oneself than one would have normally been entitled to according to one's poverty status (see p. 128). 
responsibility for their own situation gave less to themselves (21 percentage point lower likelihood of self-allocation). This could be due to givers strongly believing in being pro-active and therefore being less inclined to favor themselves. People with an important position in the community, who often engage in community work, did not view the experiment as an opportunity to claim compensation for otherwise unpaid community services as the effect is neither statistically significant nor positive.

Table 5.8: Logistic regression on determinants for self-allocation

\section{Dependent variable: Indicator variable that equals 1 if giver is selfish}

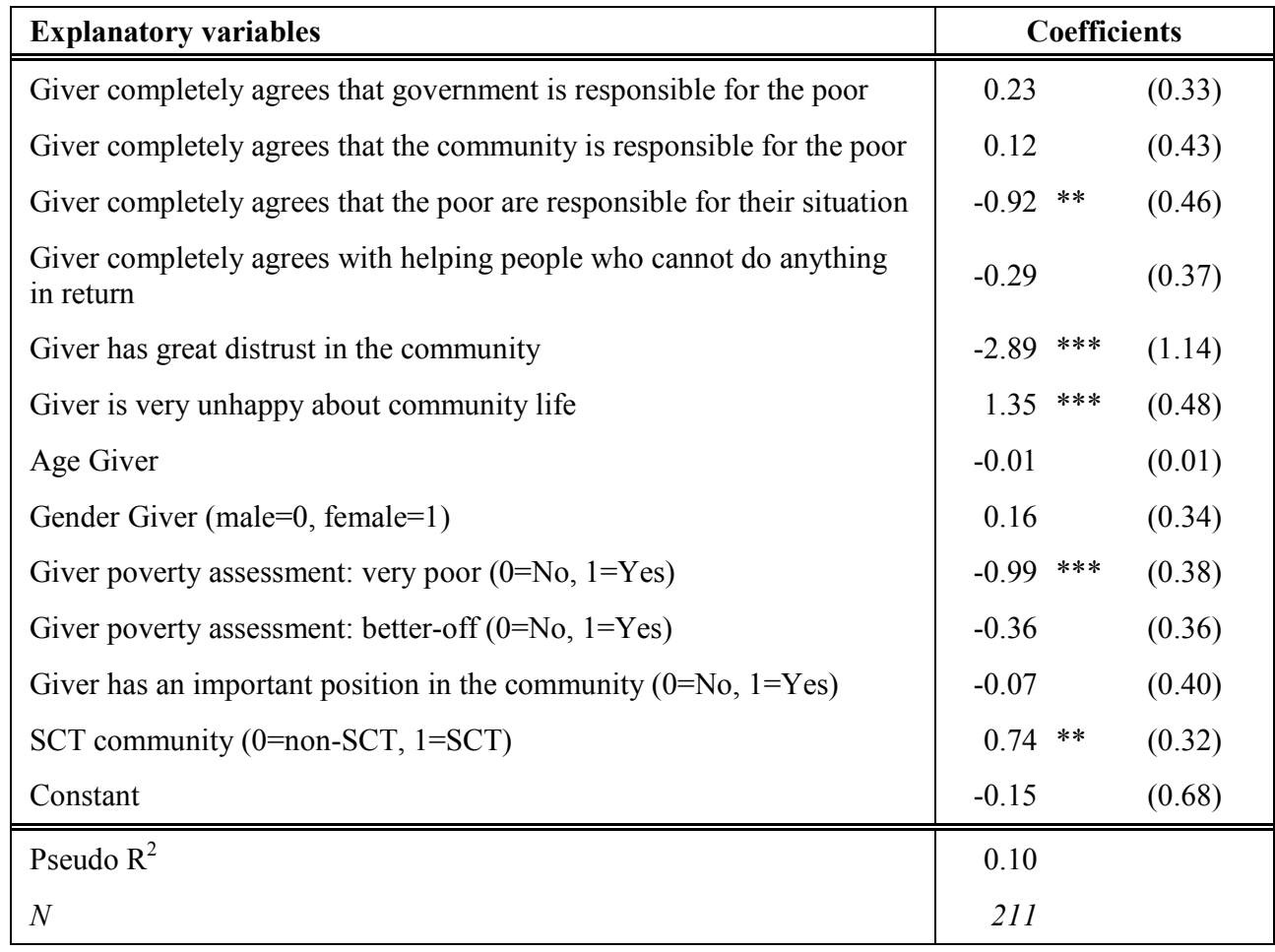

Logistic regression estimates. In parentheses, standard errors. * $10 \%$ significance level $* * 5 \%$ significance level $* * * 1 \%$ significance level. Reference group $=$ younger male poor givers from nonSCT communities with no important position in the community, who do not completely agree with the government or the community being responsible for the poor, do not completely agree that the poor are responsible for their situation, do not completely agree with helping people who cannot do anything in return, do not have great distrust in the community and who are not very unhappy about community life.

Source: Experiment - pre-survey, Experiment - individual allocation round \& Experiment survey II

Interestingly, distrust in the community resulted in lower self-allocations. Maybe those participants with lower trust levels were more afraid of potential consequences of their self-allocation behavior. Givers who are very unhappy about their life in the 
community have a higher probability (32 percentage points) of behaving selfishly, possibly motivated by the feeling that there is no need to share in a community where life has not proved beneficial for the individual. As we could have expected from the preceding discussion of selfishness across participants of different poverty status, very poor participants had a lower inclination to award tokens to themselves (23 percentage points).

\subsection{Group outcomes}

Hypothesis 4: CBT outcomes do not reflect majority positions

Individual allocation behavior differed from group choices in the second round with respect to egalitarianism (see table 5.9). The group decision process made targeting outcomes more egalitarian as 19 out of 46 groups (41\%) opted for a uniform distribution. In non-SCT with $\mathrm{TC} 1$, egalitarianism changes from a minority to a majority position. We can see that individuals in TC1 face greater difficulties in arguing out their preferences. This is an indication that group pressure, which is higher in instances where the group is directly concerned by the decisions it takes, might be an important determinant for egalitarian outcomes. Similar to the individual distribution, we also observe that greater experience in SCT communities leads to less egalitarian group outcomes.

Table 5.9: Percentage of individuals and groups opting for a uniform distribution, by community status and treatment condition

\begin{tabular}{|c|c|c|c|}
\hline \multicolumn{2}{|c|}{ SCT Communities } & \multicolumn{2}{|c|}{ Non-SCT Communities } \\
\hline $\begin{array}{c}\text { Treatment } \\
\text { condition } 1\end{array}$ & $\begin{array}{c}\text { Treatment } \\
\text { condition } 2\end{array}$ & $\begin{array}{c}\text { Treatment } \\
\text { condition } 1\end{array}$ & $\begin{array}{c}\text { Treatment } \\
\text { condition } 2\end{array}$ \\
\hline \multicolumn{4}{|c|}{ Individual } \\
\hline $23 \%$ & $25 \%$ & $34 \%$ & $41 \%$ \\
\hline$N 136$ & $N 152$ & $N 79$ & $N 80$ \\
\hline \multicolumn{4}{|c|}{ Group } \\
\hline $43 \%$ & $32 \%$ & $63 \%$ & $38 \%$ \\
\hline$N 14$ & $N 16$ & $N 8$ & $N 8$ \\
\hline
\end{tabular}

Source: Experiment - individual allocation round \& Experiment - group allocation round

For the very poor, fewer group distributions were regressive compared to the individual distributions (7\% vs. $17 \%)$ and more distributions were progressive $(48 \%$ vs. $35 \%)$, with the tendency for uniform distributions remaining at the same level ( $46 \%$ vs. $47 \%)$. This could have various explanations. First of all, individuals faced more constraints in benefiting themselves as all allocations had to be openly discussed and also negotiated 
with other group members. Secondly, information about different participants was probably more complete in a group of 10 people and there were more checks and balances in terms of preventing allocations to the non-poor.

The overall depth of progressiveness of group choices was however slightly lower with the very poor receiving $10 \%$ (vs. $12 \%$ in individual distributions) more than what they would have received through an equal distribution. We could hypothesize that group outcomes would be even more progressive in instances where a committee such as the CWAC is composed of people who have greater access to information than our participants. This is partly the reason why the CWACs are supposed to have representatives from every village and also literate members. In this way, it is easier for them to have and / or acquire information about community members.

As we are also interested in the relative effect size of poverty alongside motives such as favoritism, we replicate similar modeling for group choices on targeting, using OLS regressions:

$$
\mathrm{Y}_{\mathrm{ij}}=\alpha+\beta \mathbf{P}_{\mathrm{j}}+\gamma \mathbf{R}_{\mathrm{ij}}+\delta \mathbf{X}_{\mathrm{j}}+\mathrm{u}_{\mathrm{ij}}
$$

where

$\mathrm{Y}_{\mathrm{ij}}=$ number of tokens that individual $\mathrm{j}$ received from group $\mathrm{i}$

$\mathbf{P}_{\mathrm{j}}=$ vector of poverty status variables of recipient $\mathrm{j}$

$\mathbf{R}_{\mathrm{ij}}=$ vector of relationship variables between individual $\mathrm{j}$ and group $\mathrm{i}$

$\mathbf{X}_{\mathrm{j}}=$ vector of background characteristics of recipient $\mathrm{j}$

$\alpha=$ constant

$\beta, \gamma, \delta=$ vectors of coefficients to be estimated

$\mathrm{u}_{\mathrm{ij}}=$ error term.

When looking at the results of the group distribution in table 5.10, similar motives emerge compared to the individual distributions. Groups gave more to poorer and older recipients and to those households with a greater number of children under five. This shows that poverty and vulnerability concerns definitely influenced allocation decisions. Groups allocated a lot less to people with an important position in the community. The fact that people with a respectable position in the community did not receive more shows that the group distribution was not skewed to directly favor those in power. Similar to the individual distributions, favoritism to the inner circle also appears to have motivated group distributions as those recipients with a family member in the giver group benefited more. Looking at the effect size, favoritism again does not drive the allocation: $90 \%$ of committee members would have to be family for an individual to benefit from favoritism in the same way as from extreme poverty. Favoritism disappears as a motive in groups in $\mathrm{TC} 1$; the variable is not statistically significant and close to zero when we run separate regressions by TC. This could be 
due to the greater mutual control that is exerted in groups in TC1 where decisions are made transparent to all recipients.

Table 5.10: OLS regression on distribution motives of groups

Dependent variable: number of tokens given by the group in Round 2

\begin{tabular}{|l|rr|}
\hline Explanatory variables & \multicolumn{2}{|c|}{ Coefficients } \\
\hline \hline Recipient poverty assessment: very poor $(0=\mathrm{No}, 1=\mathrm{Yes})$ & $2.32 * * *$ & $(0.72)$ \\
Recipient poverty assessment: poor $(0=\mathrm{No}, 1=\mathrm{Yes})$ & $0.61 * *$ & $(0.28)$ \\
Too old / sick to work $(0=\mathrm{No}, 1=\mathrm{Yes})$ & 0.09 & $(1.27)$ \\
Important position in the community $(0=\mathrm{No}, 1=\mathrm{Yes})$ & $-1.68 * *$ & $(0.81)$ \\
Number of family members of individual j in the giver group & $0.27 * *$ & $(0.14)$ \\
Age Recipient & $0.04 *$ & $(0.02)$ \\
Gender Recipient (male=0, female=1) & 0.67 & $(0.56)$ \\
Number of children $0-4$ in the recipient's household & $0.25 * * *$ & $(0.10)$ \\
Number of children 5-18 in the recipient's household & -0.23 & $(0.17)$ \\
Constant & $16.78 * * *$ & $(1.05)$ \\
\hline \hline $\mathrm{R}^{2}$ & 0.13 & \\
$N$ & 442 & \\
\hline
\end{tabular}

OLS regression estimates. In parentheses, robust standard errors, adjusted for clustering on groups. * $10 \%$ significance level $* * 5 \%$ significance level $* * * 1 \%$ significance level. Reference group: male non-(very) poor recipients who are not too old/sick to work and do not have an important position in the community.

\section{Source: Experiment - pre-survey \& Experiment - group allocation round}

Even if motives were similar across individual and group distributions, the group round produced a different outcome for the individual when compared to the sum of all individual rounds. Differences ranged from 23 tokens less to 19 more through the group distribution with an absolute difference of 4.3 tokens on average. Absolute differences are higher for TC1 (4.8 vs. 3.8 for $\mathrm{TC} 2$ with the difference being statistically significant at the $1 \%$ level), probably because TC1 allowed individuals to distort results in their favor, leading to greater discrepancies with the group outcome. Differences could be due to better information ${ }^{112}$ and greater containment of selfinterests in the group round. The fact that the inconsistency between individual and

\footnotetext{
${ }^{112}$ We observe great variability in poverty assessments across different individuals. There is not a single recipient who received tokens out of the same poverty motive by all givers of his/her group. Only 5.3 givers on average acted out of the same poverty motive for the poorest recipients. There was also considerable variation in the number of tokens that individuals received from different members of the group: on average, each individual transfer deviated from the average group transfer by 0.7 tokens and the maximum difference of tokens came to an average of 2.4.
} 
group outcomes did not lead to greater dissatisfaction across group members points to the fact that the majority of community members appreciated the group exchange and regarded the group outcome as fair.

Participants were overall very satisfied with the group outcome and the group process (figure 5.2). They felt comfortable with the decision taken by the group (average of 6.3 on a satisfaction scale from 1-7 with $1=$ complete disagreement to $7=$ complete agreement); thought that the decision-making process was fair (average of 6.3), that everybody had an equal chance of influencing the outcome (average of 6.2) and that nobody dominated the decision-making process (average of 5.7). Satisfaction levels did not vary by poverty status, meaning that the poor or very poor did not feel more dominated or ignored than the better-off. People did not seem more content in communities with an egalitarian distribution. There was also no difference in the perception of whether anyone dominated the process depending on whether the community had a uniform distribution or not.

Figure 5.2: Satisfaction of individuals with group outcomes and the decision-making process, ranging from 1 (completely disagree) to 7 (completely agree)

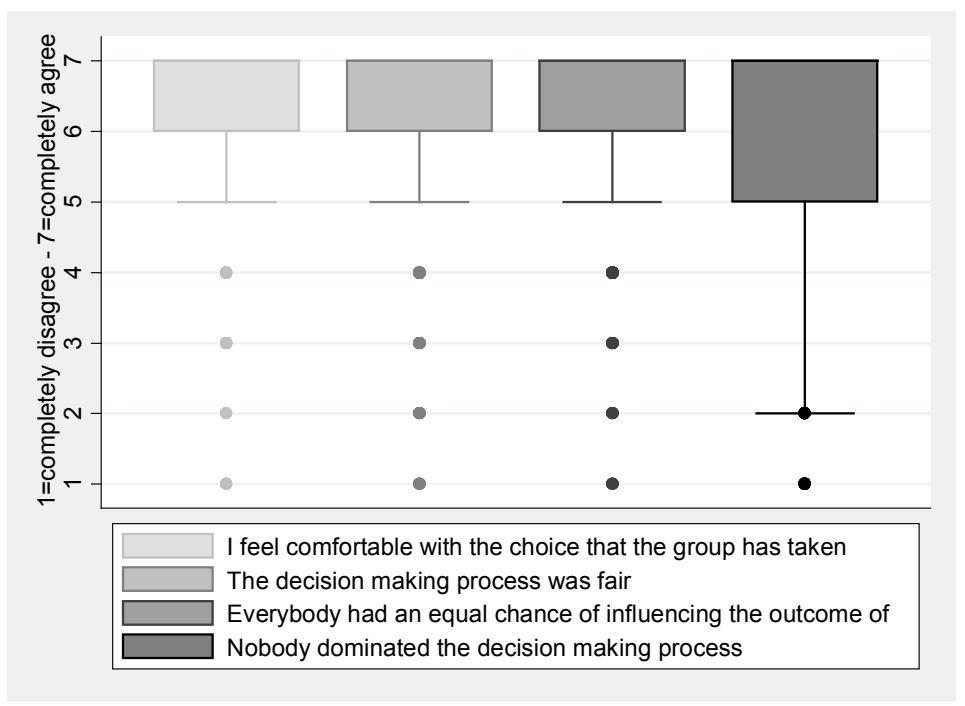

Source: Experiment - survey II

We can see a difference in satisfaction by treatment condition. Satisfaction levels for $\mathrm{TC} 1$, where everybody knew in the end whether the distribution was in his/her favor, were slightly but statistically significantly lower than for TC2. ${ }^{113}$ This might be due to

\footnotetext{
${ }^{113}$ Differences were statistically significant for the first three questions on comfort levels with the group decision, the fairness of the decision-making process and on everybody having an equal chance to influence the outcome. Satisfaction levels differed on average by .25 for these three questions.
} 
the fact that satisfaction for TC1 does not only capture satisfaction with the overall process but also (dis)satisfaction with the final outcome for oneself.

Despite the fact that group decisions do not reflect individual preferences in all instances, which confirms hypothesis 4 , they still follow similar patterns, satisfy individual group members and lead to superior results if we use the percentage of group distributions that were progressive to the very poor as a performance criterion.

\subsection{Determinants of progressiveness}

\subsubsection{The role of transparency}

Hypothesis 5: A more transparent CBT process leads to more progressive outcomes.

In both meta-reviews about CBT, transparency and accountability were cited as key factors that lead to more progressive targeting results in CBT. Involving the entire community and presenting the results to those who are concerned, is one way of rendering the process more transparent and more accountable. The two treatment conditions of the experiment and the two rounds of the experiment allow us to test the influence of making decisions in public (group vs. individual) as well as making decisions together with people concerned (group TC1 vs. group TC2).

Because of access to better information and more checks and balances, we would expect to see more progressive outcomes of decisions taken in public, in particular for the group process in TC1 where decisions are revealed to everyone. As we have observed in section 5.4, a higher percentage of groups distributed tokens more progressively and less regressively to the very poor than the individuals. This shows that greater transparency in terms of deciding jointly on a distribution can lead to more progressive outcomes.

When looking at the outcomes of the group distributions by treatment condition, we observe that the more transparent TC1 does not produce the most progressive outcomes (table 5.11). One possible explanation is that involving those concerned in the decision-making process led to more egalitarian results, an outcome which is confirmed by section 5.4. Greater peer pressure within the group might have dampened the depth of progressiveness.

Transparency influences targeting outcomes through different channels, which makes it difficult to draw a definite conclusion about its effects and hypothesis 5 . Transparency can lead to an informational advantage, producing more progressive results. It can also introduce better checks and balances which limit selfish behavior as well as more regressive choices. More transparency might, however, also translate into greater peer 
pressure, producing more egalitarian outcomes and therefore influencing progressiveness in a negative way.

Table 5.11: Depth and incidence of progressiveness of group distributions, by treatment condition

\begin{tabular}{|c|c|c|}
\hline & TC1 & TC2 \\
\hline \multicolumn{3}{|c|}{ Depth of progressiveness (average TPI across various poverty groups) } \\
\hline Very poor participants & 1.07 & 1.13 \\
\hline Poor participants & 1.02 & 0.98 \\
\hline Better-off participants & 0.91 & 0.91 \\
\hline \multicolumn{3}{|c|}{$\begin{array}{l}\text { Incidence of progressiveness to the very poor } \\
\text { (classification of group distributions to the very poor according to the TPI) }\end{array}$} \\
\hline Regressive & $5 \%$ & $8 \%$ \\
\hline Neutral & $55 \%$ & $38 \%$ \\
\hline Mildly Progressive & $41 \%$ & $54 \%$ \\
\hline Number of observations & 22 & 24 \\
\hline
\end{tabular}

Source: Experiment - group allocation round

\subsubsection{The role of experience}

Hypothesis 6: Experienced communities achieve better targeting outcomes.

As all communities on the SCT scheme in Monze had participated in training on targeting within the last two years, we can assume that members from these communities had more exposure and recent practice in selecting community members into an anti-poverty program. We have previously seen that non-SCT communities leaned more towards an egalitarian distribution, which could be an effect of not having had any (recent) experience with poverty targeting in the community. We will now assess whether previous exposure translated into more progressive poverty targeting.

Looking at the depth of progressiveness with regard to the very poor in table 5.12, groups in non-SCT communities appear slightly more progressive, even if the difference between SCT and non-SCT communities is rather small. The incidence of progressiveness of the different group distributions is higher in SCT communities than in non-SCT communities. In SCT communities, 53\% of all distributions were mildly progressive for the very poor, compared to $38 \%$ of all distributions to the very poor in non-SCT communities. Experience seems to have had a positive even if subtle effect on the incidence of progressiveness in group distributions. 
Table 5.12: Depth and incidence of progressiveness of group distributions, by community status

\begin{tabular}{|l|r|r|}
\cline { 2 - 3 } \multicolumn{1}{c|}{} & SCT communities & Non-SCT communities \\
\hline \hline Depth of progressiveness (average TPI across various poverty groups) & 1.12 \\
\hline \hline Very poor participants & 1.09 & 0.98 \\
\hline Poor participants & 1.01 & 0.92 \\
\hline Better-off participants & 0.90 & \\
\hline \hline $\begin{array}{l}\text { Incidence of progressiveness to the very poor } \\
\text { (classification of group distributions to the very poor according to the TPI) }\end{array}$ & $7 \%$ & $6 \%$ \\
\hline Regressive & $40 \%$ & $38 \%$ \\
\hline Neutral & $53 \%$ & $0 \%$ \\
\hline Mildly Progressive & $0 \%$ & 16 \\
\hline Progressive & 30 & \\
\hline \hline Number of observations & & \\
\hline
\end{tabular}

Source: Experiment - group allocation round

\subsubsection{Determinants of progressiveness}

The random sampling of participants, communities as well treatment conditions helps us to attribute any changes in targeting motives to the different experiment conditions. Nevertheless, we still want to conduct a multi-variate analysis to examine the relative effect size and the influence of other factors related to the giver. For this purpose, we use the following model, running separate logistic regressions ${ }^{114}$ for each treatment condition, starting with the individual round:

$$
\operatorname{Prob}\left(\mathrm{Y}_{\mathrm{i}}=1\right)=\alpha+\beta \mathbf{E}_{\mathrm{i}}+\gamma \mathbf{A}_{\mathrm{i}}+\delta \mathbf{X}_{\mathrm{i}}+\mathrm{u}_{\mathrm{i}}
$$

where

Prob $\left(\mathrm{Y}_{\mathrm{i}}=1\right)=$ probability of giver $\mathrm{i}$ of being progressive $(\mathrm{TPI}>1)$ vis-à-vis the very poor

$\mathbf{E}_{\mathrm{i}}=$ vector of experiment conditions for giver $\mathrm{i}$

$\mathbf{A}_{\mathrm{i}}=$ vector of attitude variables of giver $\mathrm{i}$

$\mathbf{X}_{\mathrm{i}}=$ vector of background characteristics of the giver $\mathrm{i}$

$\alpha=$ constant

$\beta, \gamma, \delta=$ vectors of coefficients to be estimated

$\mathrm{u}_{\mathrm{i}}=$ error term.

${ }^{114}$ OLS regression with TPI as the dependent variable produces similar results, in particular for TC2. All variables that are statistically significant in the logistic regression have the same sign in the OLS regression. The variable on the poverty status of the giver for TC1 and the variables on the responsibility of the government, the distrust and the poor being responsible for TC2 prove statistically significant in the OLS as well as the logistic regression. 
Table 5.13: Logistic regression on determinants of progressiveness of individual distributions, by treatment condition

Dependent variable: indicator variable that equals 1 when the giver is progressive (TPI>1) vis-à-vis the very poor

\begin{tabular}{|c|c|c|c|c|c|c|}
\hline \multirow{3}{*}{$\begin{array}{l}\text { Explanatory variables } \\
\text { SCT community }(0=\text { non-SCT, } 1=\mathrm{SCT})\end{array}$} & \multicolumn{3}{|c|}{$\mathrm{TC} 1$} & \multicolumn{3}{|c|}{ TC2 } \\
\hline & \multicolumn{6}{|c|}{ Coefficients } \\
\hline & 0.29 & & $(0.39)$ & -0.07 & & $(0.31)$ \\
\hline $\begin{array}{l}\text { Recipient group has an additional better-off person than prescribed } \\
(0=\text { No, } 1=\text { Yes })\end{array}$ & 0.53 & & $(0.83)$ & -0.03 & & $(0.44)$ \\
\hline $\begin{array}{l}\text { Giver agrees in general that government is responsible for the poor } \\
(0=\mathrm{No}, 1=\text { Yes })\end{array}$ & -0.05 & & $(0.69)$ & -1.77 & $* *$ & $(0.77)$ \\
\hline $\begin{array}{l}\text { Giver completely agrees that the community is responsible for the } \\
\text { poor }(0=\mathrm{No}, 1=\text { Yes })\end{array}$ & 0.25 & & $(0.43)$ & -0.62 & $*$ & $(0.33)$ \\
\hline $\begin{array}{l}\text { Giver agrees in general that the poor are responsible for their } \\
\text { situation }(0=\mathrm{No}, 1=\text { Yes })\end{array}$ & -0.53 & & $(0.38)$ & -0.79 & $* *$ & $(0.32)$ \\
\hline $\begin{array}{l}\text { Giver agrees in general with helping people who cannot do } \\
\text { anything in return }(0=\text { No, } 1=\text { Yes })\end{array}$ & 0.30 & & $(0.62)$ & 0.78 & & $(0.50)$ \\
\hline $\begin{array}{l}\text { Giver strongly agrees that overall, one cannot trust people }(0=\text { No, } \\
1=\text { Yes })\end{array}$ & -0.34 & & $(0.80)$ & -2.10 & $* * *$ & $(0.81)$ \\
\hline Giver is very unhappy about community life $(0=$ No, $1=$ Yes $)$ & -1.85 & & $(1.16)$ & -1.33 & * & $(0.81)$ \\
\hline Giver is old $(<65=0,65 \&$ above $=1)$ & -0.04 & & $(0.40)$ & -0.09 & & $(0.38)$ \\
\hline Gender Giver $($ male $=0$, female $=1)$ & -0.71 & $*$ & $(0.39)$ & 0.09 & & $(0.33)$ \\
\hline Giver poverty assessment: very poor $(0=\mathrm{No}, 1=\mathrm{Yes})$ & 1.92 & $* * *$ & $(0.46)$ & 0.39 & & $(0.45)$ \\
\hline Giver poverty assessment: poor $(0=\mathrm{No}, 1=\mathrm{Yes})$ & -0.73 & & $(0.46)$ & 0.57 & & $(0.38)$ \\
\hline Giver has an important position in the community $(0=\mathrm{No}, 1=\mathrm{Yes})$ & 1.13 & $* * *$ & $(0.45)$ & 0.86 & $* *$ & $(0.37)$ \\
\hline Constant & -1.25 & & $(0.95)$ & 0.58 & & $(0.90)$ \\
\hline Pseudo $\mathrm{R}^{2}$ & 0.24 & & & 0.11 & & \\
\hline $\mathrm{N}$ & 212 & & & 226 & & \\
\hline
\end{tabular}

Logistic regression estimates. In parentheses, standard errors. $* 10 \%$ significance level $* * 5 \%$ significance level $* * * 1 \%$ significance level. Reference group = younger male non-(very) poor givers from a non-SCT community with no important position in the community, who do not agree in general that government is responsible for the poor, do not completely agree that the community is responsible for the poor, do not agree in general that the poor are responsible for their situation, do not agree in general with helping people who cannot do anything in return, who do not strongly agree that overall one cannot trust people, who are not very unhappy about community life and who give to a group that does not have an additional better-off person. Source: Experiment - pre-survey, Experiment - individual allocation round \& Experiment -
survey II

Table 5.13 shows that the treatment condition, attitude as well as background characteristics of the giver prove decisive. If we restrict our sample to individuals in $\mathrm{TC} 1$, being very poor or having an important position in the community leads to more 
progressive results. The poverty status of the giver is only statistically significant for the sub-sample of individuals in TC1. Rather than pointing to a higher degree of progressiveness among the very poor, this effect might simply signal that the very poor in $\mathrm{TC} 1$ benefitted themselves. The very poor did not turn out as particularly progressive givers when this opportunity for self-allocations was denied to them (TC2). This is an effect which we can also observe in table 5.7 where after controlling for selfallocation, very poor givers actually gave less to very poor recipients. In order to factor out self-regarding interests from the determinants for progressiveness, we now focus on the regression output for individuals in TC2.

Givers with an important position in the community have a 20 percentage point higher probability of being progressive at the mean. This might be due to the fact that they have better access to information about recipients or are simply more sympathetic to the destiny of the very poor given their position in the community. Next to progressive community members with a status position, there were a number of other factors that influenced progressiveness among individuals in TC2. Givers who thought that the poor were responsible for their own situation as well as givers who were very unhappy about community life or very distrustful of people in general, were less progressive. ${ }^{115}$ The same holds for givers who thought in general that the government or the community should take responsibility for the poor. Those givers might have sensed less responsibility on their own part to redistribute in a progressive way.

When we use the same regression framework to identify determinants of progressiveness in the group round, using experiment conditions (experiment location and treatment condition) and the group characteristics (average age, share of very poor, share of women, share of CWAC members or the share of people with an important position in the community) as explanatory variables, only a few variables that are statistically significant at the $10 \%$ level emerge for groups in TC2. This is probably due to the fact that there is not a great deal of systematic variation across groups because of the random selection of group participants and the fact that we have a limited number of 46 observations. Groups in TC2 that were on average older and groups with a higher share of very poor members proved less progressive. These groups might have had fewer literate members and less information about other community members.

\subsubsection{Determinants of egalitarianism}

In order to understand why givers are not progressive in their choices, it is also important to consider factors that lead to a more egalitarian and hence potentially less progressive outcome. When regressing the choice for an egalitarian distribution on the

\footnotetext{
${ }^{115}$ The probability of them being progressive is 18,24 and 32 percentage points lower respectively at the mean, compared to givers who do not think that the poor are responsible, who are happy with the community life and trustful.
} 
same variables as mentioned in 5.5 .3 for individuals in $\mathrm{TC} 2^{116}$, using a logit regression model, we can see that prior exposure to targeting and possibly more information about community members reduce individuals' likelihood of opting for a uniform distribution (table 5.14).

Table 5.14: Logistic regression on determinants of egalitarianism of individual distributions for TC2

Dependent variable: indicator variable that equals 1 when the giver opts for a uniform distribution

\begin{tabular}{|c|c|c|c|}
\hline Explanatory variables & \multicolumn{3}{|c|}{ Coefficients } \\
\hline $\mathrm{SCT}$ community $(0=$ non-SCT, $1=\mathrm{SCT})$ & -0.92 & $* * *$ & $(0.32)$ \\
\hline $\begin{array}{l}\text { Recipient group has an additional better-off person than prescribed } \\
(0=\text { No, } 1=\text { Yes })\end{array}$ & -0.21 & & $(0.49)$ \\
\hline $\begin{array}{l}\text { Giver agrees in general that government is responsible for the poor } \\
(0=\text { No, } 1=\text { Yes })\end{array}$ & -0.01 & & $(0.64)$ \\
\hline $\begin{array}{l}\text { Giver completely agrees that the community is responsible for the poor } \\
(0=\mathrm{No}, 1=\mathrm{Yes})\end{array}$ & 0.30 & & $(0.33)$ \\
\hline $\begin{array}{l}\text { Giver agrees in general that the poor are responsible for their situation } \\
(0=\text { No, } 1=\text { Yes })\end{array}$ & 0.32 & & $(0.32)$ \\
\hline $\begin{array}{l}\text { Giver agrees in general with helping people who cannot do anything in } \\
\text { return }(0=\mathrm{No}, 1=\text { Yes })\end{array}$ & 0.40 & & $(0.50)$ \\
\hline Giver strongly agrees that overall, one cannot trust people $(0=\mathrm{No}, 1=$ Yes $)$ & 1.02 & $*$ & $(0.54)$ \\
\hline Giver is very unhappy about community life $(0=\mathrm{No}, 1=\mathrm{Yes})$ & 0.74 & & $(0.69)$ \\
\hline Giver is old $(<65=0,65 \&$ above $=1)$ & 0.13 & & $(0.39)$ \\
\hline Gender Giver $($ male $=0$, female $=1$ ) & -0.25 & & $(0.34)$ \\
\hline Giver poverty assessment: very poor $(0=\mathrm{No}, 1=\mathrm{Yes})$ & -0.19 & & $(0.44)$ \\
\hline Giver poverty assessment: poor $(0=\mathrm{No}, 1=$ Yes $)$ & -0.63 & & $(0.39)$ \\
\hline Giver has an important position in the community $(0=\mathrm{No}, 1=\mathrm{Yes})$ & -1.24 & $* * *$ & $(0.42)$ \\
\hline Constant & -0.21 & & $(0.82)$ \\
\hline Pseudo $\mathrm{R}^{2}$ & 0.09 & & \\
\hline $\mathrm{N}$ & 226 & & \\
\hline
\end{tabular}

Logistic regression estimates. In parentheses, standard errors. * $10 \%$ significance level $* * 5 \%$ significance level $* * * 1 \%$ significance level. Reference group = younger male non-(very) poor givers from a non-SCT community with no important position in the community, who do not agree in general that government is responsible for the poor, do not completely agree that the community is responsible for the poor, do not agree in general that the poor are responsible for their situation, do not agree in general with helping people who cannot do anything in return, who do not strongly agree

\footnotetext{
${ }^{116}$ We directly concentrate on TC2 to factor out the implications of self-regarding interests. When running the regression on the sub-sample on $\mathrm{TC} 1$, the only statistically significant variable at a $10 \%$ level is the giver agreeing with helping people who cannot do anything in return. The variable is negatively correlated with egalitarianism.
} 
that overall one cannot trust people, who are not very unhappy about community life and who give to a group that does not have an additional better-off person.

\section{Source: Experiment - pre-survey, Experiment - individual allocation round \& Experiment - survey II}

The results of the regression analysis confirm previous findings from section 5.3.2 that individuals from communities with less exposure to targeting distribute more equally. Individuals with greater distrust in society leaned towards an egalitarian distribution; this could mean that they were more concerned about making a possible mistake during the targeting exercise. People with a status position in the community, on the contrary, favored a less egalitarian distribution, which could be explained by the fact that they had better information about the individuals in the group and targeting in general and/or that they were not concerned about deviating from the default position.

When we run a logit regression to determine the factors of egalitarianism of group outcomes with TC2, using experiment conditions and group characteristics as explanatory variables, only the share of the very poor comes out as having a statistically significant positive effect on egalitarian outcomes. Once more, this could be a result of the very poor having restricted access to information and greater insecurity about deviating from the default position.

\subsection{Concluding remarks}

Using experimental research in rural Zambia, we have been able to enlarge the evidence base for CBT. The first interesting finding is that preferences for redistribution prevail over egalitarian motives of individuals, which is startling in a high-poverty context with relatively subtle differences across community members. Egalitarianism is much less a preference in rural community settings than a pragmatic choice, in reaction to pressure and practical constraints such as little exposure to targeting and subsequent uncertainty.

The second noteworthy finding is that, when individuals and groups make decisions for other community members, excluding themselves, neither favoritism to close relatives nor favoritism to those in the community with an important social position seems to drive the token allocation. Favoritism towards family members occurs but its effect is much smaller than we would have expected of a dominating motive. A stronger effect in terms of inter-personal relations is the inclination of givers to give preference to those who share similar characteristics. This confirms the theory that people are more willing to redistribute to those with whom they can identify. The motives behind the group distribution are similar, with outcomes not being tweaked in favor of those with a status position in the community and poverty prevailing over favoritism. On the basis of the experimental evidence, we therefore cannot conclude that CBT is mainly used as 
a vehicle for favoritism to family members or for the maintenance of one's social network.

A finding that critics of CBT might have expected is that poverty disappears as the main motive when the experiments allow participants to behave selfishly. This finding resonates with the criticism that $\mathrm{CBT}$ opens up the potential for self-enrichment. Selfishness is however constrained in the group decision-making process. The likelihood of being selfish is larger in SCT communities and among givers who are very dissatisfied with the community life. Selfishness does not seem to be more prevalent among givers who are better-off or who have an important position in the community, raising the question as to whether elite capture is not an over-emphasized problem of CBT.

Overall, there is very little consistency across individual and group allocations for the same recipient. This demonstrates that community members are either informed to varying degrees about the situation of the individual, that they do not share the same assessment or have different motives. Despite these discrepancies, participants were overall very satisfied with the group outcomes and process, implying that the majority did not feel that the group decision was imposed on them. Satisfaction levels were slightly lower in communities where participants decided for members of their own group and where consequently participants expressed their satisfaction after knowing the result of the group process for themselves.

Unlike the findings by the meta-study on CBT, we do not find any conclusive evidence that greater transparency produces more progressive outcomes. This could be mainly related to the fact that transparency influences targeting choices through different channels: it limits regressive choices through more checks and balances, facilitates progressive choices through better collective information but can also inhibit more progressive choices through greater peer pressure. Prior exposure to targeting seems to have an impact on the incidence but not on the depth of progressiveness of group distributions. There are also other determinants of progressiveness that surface at the individual level: givers who enjoy a particular social status in the community are more progressive, while unhappiness with the community life, distrust vis-à-vis other community members as well as a strong belief in individual responsibility for one's destiny, produce less progressive choices.

Whether Zambia is well-advised to continue with CBT cannot be a conclusion of this chapter as its main intention was not to do a comparative analysis of CBT vis-à-vis other targeting mechanisms. On the basis of this study, we can conclude that CBT leads to at least mildly progressive outcomes and does not produce any conflicts or greater dissatisfaction among participants of the experiment. If the government's intention is to decentralize the targeting mechanism, it seems sensible to have people with a certain authority in the community on the targeting committee as they are both more progressive and not particularly selfish in their choices. A decentralized 
mechanism also appears to have greater potential in communities where people are generally satisfied with community life, where they know each other better and where there is less distrust. It would therefore be advisable for government to either use CBT selectively in communities where there is already a high degree of cohesion and information or to ensure that more information about community members is made publicly available.

A committee with prior exposure to and training on targeting that will choose for the community (treatment condition 2 in the experiment), rather than the entire community deciding on targeting choices (treatment condition 1 in the experiment) leads to less egalitarian and more progressive results. Even if the group decision-making process limits the possibilities for self-enrichment, it might be advisable to have additional checks and balances in place. The present rule in Zambia's SCT program of not allowing committee members to register themselves as beneficiaries seems a wise precaution in that sense. The downside is that it might reinforce paternalistic patterns of the rich granting transfers to the poor.

The experiments have proven an insightful methodology to get a more detailed understanding of the mechanism at work behind CBT. The fact that we concentrated on a mechanism experiment as opposed to a policy evaluation, allowing us to vary different parameters of a policy and get a better understanding of the different transmission mechanism in place, makes our findings even relevant outside of Monze district. In order to strengthen the external validity of the results, it would still be recommendable to replicate the experiment at a broader scale. For studying in greater depth any dynamic effects that develop over time when people learn how to manipulate the system, when they see whether inappropriate behavior has social consequences and when there is more exchange between those selecting and those benefitting, researchers should consider designing multiple targeting rounds in future experiments. 


\section{CHAPTER 6: Whom to target - an obvious choice? ${ }^{117}$}

\subsection{Introduction}

There has been an ongoing debate among researchers, policy-makers and development partners in developing countries on whether and to what degree non-contributory social transfers should be targeted. Targeting concerns the allocation and distribution of resources and services to one particular (sub-) group. In the context of SCT, it refers to the process of granting transfers to recipients who are poor, particularly vulnerable or deprived, identified through means-testing, multiple-indicator-targeting or equivalent. The alternative to targeting would be to allocate transfers to everybody (universal approach), although this is usually restricted to certain categories such as the elderly or children. In a strict sense, universal transfers would refer to a basic income, which every citizen in society receives. This chapter does not adopt the strict notion of universal targeting but also classifies categorical targeting as universal.

Standard economic theory predicts that given a fixed budget for redistribution, targeting is the optimal solution as it renders the most effective and efficient outcome with the highest level of utility for the poor (see e.g. Besley 1990; Besley and Kanbur 1990; Atkinson 1995; Atkinson 1998; Coady, Grosh et al. 2004). Following this logic, the less resources leak to the non-poor and the higher the share received by the poor, the better the cost-effectiveness of an anti-poverty program. These models are criticized for ignoring the costs associated with targeting such as disincentive effects, informational constraints like the difficulty of correctly identifying the poor, social costs of asymmetric power and efficiency losses due to leakage and higher administrative costs (Atkinson 1995; Sen 1995; Atkinson 1998). Furthermore, they neglect any political economy considerations (De Donder and Hindriks 1998; Moene and Wallerstein 2001; Gelbach and Pritchett 2002; Pritchett 2005).

The political economy of targeting takes the problems of targeting beyond merely economic issues of selection, information and incentives. It is concerned with the political feasibility of targeting policies (Sen 1995) and stresses that only a naive policy maker would assume a fixed budget for redistribution (Gelbach and Pritchett 2002). Political economy models of targeting postulate that the level of targeting and the corresponding budget for social spending are interlinked. By taking into account that the budget is determined through majority voting and voters respond to targeting, the political economy models conclude that a universal transfer is the optimal solution. We

\footnotetext{
${ }^{117}$ This chapter is based on joint work with Franziska Gassmann and will be published in 2013 as a chapter in the book Social Protection in Developing Countries by Routledge:

http://www.routledge.com/books/details/9780415641012/.
} 
would therefore expect broad-based support for universal schemes, even more so in countries where poverty is widespread so that targeting is administratively challenging and leads to substantial costs.

A lot of research has been carried out on the effectiveness and efficiency of different targeting approaches. The existing evidence furthered our knowledge as to how targeting mechanisms of different complexities perform in different country contexts, what kind of costs they involve and which administrative capacity they require (Coady, Grosh et al. 2004; Samson, van Niekerk et al. 2006; Slater and Farrington 2009). Surprisingly little empirical research has however been conducted around the political economy of targeting in developing countries, despite the growing awareness that politics are not a subordinate but an integral element of any targeting decision. There are studies which show that universal social transfers, such as social pensions, are generally better protected against inflation and political pressure than targeted transfers. In Sri Lanka social benefit values eroded by 40 percent as a result of inflation after the introduction of targeting. In Colombia, food subsidies were eventually completely eliminated once universal access was replaced by narrow targeting and the program became politically unpopular (Pritchett, 2005). Such indirect evidence suggests that the political economy may indeed play a role in the targeting decision. This chapter attempts to enlarge the evidence base by analyzing actual targeting preferences of citizens in Zambia and revisiting the assumptions underlying the political economy model in the context of a low-income country.

The chapter starts by critically discussing the key assumptions behind the political economy models (Section 6.2) and hypothesizing on other factors which are currently not incorporated into the models but have been identified by the literature as important regarding targeting preferences (Section 6.3). Section 6.4 presents the data used to test whether the predictions of the models hold in the low-income country of Zambia with the main empirical findings being presented in section 6.5. We critically discuss in Section 6.6 to what extent the assumptions behind the universal political economy arguments apply in a low-income country like Zambia. Section 6.7 concludes and points towards further research needs.

\subsection{Revisiting the arguments for universal transfers}

Within the political economy models of targeting, the budget for transfers is determined through majority voting with voters responding to the degree of targeting. Assuming three distinct income groups (low, middle and high), the models postulate that the support of at least two income groups is necessary. Since the poor are always in favor of higher taxes ${ }^{118}$, and the rich in favor of lower taxes, the vote of the middle

\footnotetext{
${ }^{118}$ Low wage workers do not pay taxes in the model of Gelbach and Pritchett (2002), mirroring employment in the informal sector.
} 
income group is decisive in this model. Since the middle class has good and bad times, their support for redistributive transfers depends on their probability of being in need at some point in their life. A shift to a narrowly targeted program with little leakage to the non-poor can undermine the political support for the program if the middle-class is sufficiently unlikely to receive the transfer. As a result, the budget for transfers is adjusted downwards and the poor are worse off from better targeting. For the poor to benefit from a transfer program, a certain degree of leakage is therefore necessary. In their model, de Donder and Hindriks (1998) find that three-quarter of the population need to be covered for continuous support, which is close to universal. ${ }^{119}$

As with all theoretical models, the political economy models of targeting attempt to break down a rather complex reality into its key elements and draw conclusions on the basis of a set of assumptions. Not all political economy models of targeting depart from the same assumptions and scenarios, however: the model by de Donder and Hindriks (1998) experiments with simultaneous voting on tax rates and the budget share, while Gelbach and Pritchett (2002) let the voters decide on the tax rate after they have been presented with a targeting scenario. Within the models of Gelbach and Pritchett (2002) and Moene and Wallerstein (2001) transfers act as a kind of unemployment insurance ${ }^{120}$ as well as being a redistributive instrument. This aspect is not considered in de Donder and Hindrik's model. Moene and Wallerstein (2001) stress the centrality of self-interest of voters for a universal vote and show that altruism would produce different outcomes while altruism as a motive next to self-interest still leads to universalism in the models by de Donder and Hindriks (1998) and Gelbach and Pritchett (2002).

All authors agree that voters decide - even if not entirely - on the basis of self-interest with the expectation of deriving direct financial benefits from the program in the future. In all models either the median voter (Moene and Wallerstein 2001) or a coalition of the poor and middle class (De Donder and Hindriks 1998; Gelbach and Pritchett 2002) is decisive for policy making and realizes its interests through voting. Social budget endogeneity, meaning that the budget is not fixed but is responsive to majority-votes, is equally a strong assumption in all three models. In the following, we review the critical assumptions underlying these theoretical models within the context of low-income countries.

\footnotetext{
${ }^{119}$ In a slight variation, they let the targeting and tax rate be determined simultaneously. In that case, the poor are the decisive group as they can form coalitions with either the middle or high income group in order to raise taxation and targeting (De Donder \& Hindriks, 1998). The argument rests on the assumption that the poor can act as one group. Lower income groups are less inclined to unite and support redistributive policies as a result of last-place aversion which prevents political unity among the poor (Kuziemko, Buell et al. 2011).

${ }^{120}$ An unemployed middle income worker is automatically eligible for a transfer.
} 


\subsubsection{Self-interested voters}

Moene and Wallerstein (2001) demonstrate that as soon as some level of altruism is introduced, the political equilibrium moves towards targeting. If the median voter behaves altruistically and derives utility from a generous transfer to the poor, narrower targeting might not necessarily result in votes for minimal budgets. True altruism may actually lead to an outcome where more effective targeting leads to better results, and where reducing leakage makes the good (i.e. poverty reduction) cheaper. Hence, voters want more of this (Pritchett 2005). The influence of altruism on targeting outcomes should not be neglected as experimental evidence on collective action problems has shown that individuals act altruistically and not necessarily as the homo economicus in the standard microeconomic models (Bowles 2008).

But even if we assume that agents are mainly self-interested, the universal welfare state is not inevitably the only equilibrium of the voting game (Rothstein 2002; Tabor 2002). Whether the median voter opts for a universal or selective welfare state depends not only on monetary gains but also on more subtle benefits. Government support to the poor can have positive externalities. Those among the middle class who presently cater for the poor, those who are more risk-averse and value a more generous unemployment insurance, who sell goods and services to the poor and who appreciate that better support prevents a number of social problems such as high crime rates are all likely to benefit from support going directly to the poor (Tabor 2002). By supporting the poor, overall social welfare can increase and result in higher utility of the non-poor (Atkinson 1998).

In addition, if targeting leads to greater cost-effectiveness or if the non-poor benefit sufficiently from spending cuts (i.e. the gain from lower tax rates is larger than the gains from leakage), they may also favor a reallocation of spending to the poor (Atkinson 1998; De Donder and Hindriks 1998; Ravallion 1999). Moving from universal access to targeting is then a Pareto improvement (De Donder and Hindriks 1998). ${ }^{121}$ This effect would be even greater when the non-poor can rely on private markets rather than the state for unemployment insurance (Gelbach and Pritchett 2002). The question is however whether pro-poor spending would then be sufficiently protected (Ravallion 1999). Spending for the poor might be better protected in regions with a strong tradition of effective redistribution. ${ }^{122}$

\footnotetext{
${ }^{121}$ On the other hand, relaxing targeting from very high levels can also make everybody better-off (De Donder \& Hindriks, 1998).

${ }^{122}$ This is a rephrasing of the argument made by Graham (2002), where she links the strong faith in individual effort over state redistribution in Latin America to their weak tradition of effective redistribution. 


\subsubsection{A coalition of the poor and middle class is politically decisive}

The political feasibility of targeting social programs to a specific group depends on the preferences of politically more powerful groups (Sen 1995). Most theoretical models assume that the middle income group or the median voter is decisive in voting as the rich always favor lower taxes and the poor favor higher taxes. However, De Donder and Hindriks (1998) show that the poor voters actually become decisive when the level of taxation and the degree of targeting are simultaneously voted on and the poor form strategic, alternating coalitions with the middle class and the rich.

This assumption of the median voter being decisive presumes a democratic setting in which the government is accountable to its constituency and voting actually translates into policy-decisions. It might be questionable to what extent democratic structures of this nature have taken root in low-income countries. Citizens have often little means to influence policy-making, even through the election process. This proves particularly challenging for groups such as the poor who are often not sufficiently organized in large numbers to see their interests represented (Myles and Quadagno 2002). Even if elected representatives were interested in translating voters' interests into action, they would face difficulties in regimes where the role of the Parliament is curtailed to the benefit of the executive. This means that in low-income countries with a lower degree of democratization, the rich could be strong enough to force a decision in their own right.

\subsubsection{Budget endogeneity}

The political system also affects the assumption of budget endogeneity. In a dictatorial or patrimonial political system, the budget might be (near) fixed as the public has no influence on government decisions. Even if we assume that budgets are actually voted on, most low-income countries will face difficulties in sufficiently increasing the budget for a particular transfer program, either through additional revenue or shifting government spending from other sectors.

It is undoubtedly true that there is leeway in most low-income countries to improve tax-regimes and increase the government budget; whether feasible tax reforms would suffice to fund programs in the order of magnitude of $2-4 \%$ of $\mathrm{GDP}^{123}$ remains debatable. Broadening the tax base is particularly challenging in countries where the majority of the population works in the informal sector since this is hard to tax, the marginal costs of taxation are high and further taxation might also discourage much needed private investment. Hence, as long as the tax base cannot be expanded and the

\footnotetext{
${ }^{123}$ For cost calculations of a categorical child grant, see for example ILO (2008b).
} 
budget is fixed, narrow targeting may be the politically more sustainable policy option (Graham 2002; Pritchett 2005). ${ }^{124}$

The political dynamics become even more complex when we consider funding a more broadly targeted program through budget reallocations instead of a tax increase. This would mean that voters do not decide on particular interventions in isolation but decide jointly on whether they would like an increase in unemployment insurance for a decrease in funding for another program. The middle-class might be less supportive of a universal transfer if this results in budget cuts for other interventions such as fertilizer subsidies from which they largely benefit.

\subsection{Looking beyond the model assumptions}

The political economy models ignore a number of factors that other authors have raised in the debate on universal versus targeted transfers or in the literature on redistributive preferences.

\subsubsection{Attitudes towards the poor}

Electoral support for targeted programs depends on attitudes and perceptions about the targeting criteria (Van de Walle 1998; Gelbach and Pritchett 2002; Pritchett 2005). Attitudes towards the poor influence the voting behavior for redistributive policies, in particular when countries face great fiscal constraints (Graham 2002). Poverty seen as a result of bad luck and exogenous factors, rather than a lack of individual effort, garners more support for social spending and redistribution (Fong 2001; Alesina and La Ferrara 2005; Boarini and Le Clainche 2009). This means that a policy which favors the poor is politically more sustainable if they are perceived as deserving. According to Graham (2002: 10), "the distinction between deserving and non-deserving poor may be a more important determinant of public support for welfare in the United States than is that between targeted and universal programs." There is also evidence from experimental economics supporting the view that merit is a determining factor as to who receives support (Hoffman, McCabe et al. 1994; Cappelen, Hole et al. 2007; Cappelen, Moene et al. 2011).

\subsubsection{Social justice norms}

Ideological orientations or institutional structures can equally have a bearing on the acceptance of welfare programs (Graham 2002; Korpi and Palme 2004; Mkandawire

\footnotetext{
${ }^{124}$ This also applies in the case of donor funding. Here the argument is linked to altruistic preferences of donors which are in favor of sharp targeting (Pritchett, 2005). 
2005; Alesina and Fuchs-Schündeln 2007). While countries where the state has only played a residual role in welfare support might be more reluctant to accept broader and more expensive welfare programs, countries where the state has traditionally provided comprehensive welfare packages, tend to oppose closely targeted programs. People's understanding of social justice can prove influential in determining whether they are more inclined to targeting or universalism. Those societies who accord more importance to a justice of performance rather than needs-based justice and who believe in the equality of opportunity rather than in the equality of outcome might favor a more targeted approach. ${ }^{125}$ They would be more likely to subscribe to the subsidiarity principle with the welfare state only having a role when individuals face difficulties providing for themselves.

\subsubsection{The importance of cohesion}

The greater the similarity between the poor and middle class, the more likely is the support for poverty programs (Graham 2002). Stated differently, the higher the level of inequality in a given society, the stronger the arguments for universal transfers as the distance between the poor and non-poor may be too large. The distance may not only be defined in financial but also in geographic terms or with respect to individual characteristics. If the majority of the poor, for instance, lives in remote areas, i.e. they are not visible, support may dwindle. The impact of proximity to people in need on redistributive preferences is also confirmed by other authors. Luttmer (2001) distinguishes between the negative exposure effect and the racial group loyalty. An increasing share of benefit recipients within the local community decreases the support for welfare. On the other hand, support for welfare spending is higher if a larger share of beneficiaries belongs to one's own social group. ${ }^{126}$ Societies with high demographic heterogeneity are less supportive to redistributive policies as the share of beneficiaries in each group is relatively small (Luttmer 2001).

\subsubsection{Procedural justice $\&$ effectiveness}

Whether targeting can be implemented in a procedurally fair way without too many negative side effects and whether it actually produces an effective outcome are also important considerations. Targeting can lead to substantial costs at different levels, which the electorate might not be willing to accept such as a high level of stigmatization or fraud and favoritism on behalf of the administration or communities involved in the process (Rothstein 2002; Tabor 2002). At the same time, targeting might also contribute to greater fairness if it leads to actuarial soundness, reduces

\footnotetext{
${ }^{125}$ Here we do not refer to a single program but to the way the welfare state is structured and whether the focus is in general on universal provisions for citizens without a specific poverty-focus or whether interventions are mainly tailored to satisfy the needs of the poor.

${ }^{126}$ Pritchett (2005) calls this mechanism 'framing'.
} 
leakages and establishes a clear link between transfers and poverty reduction (Tabor 2002).

The effectiveness of a program or at least people's perception of it can also influence political support. Many targeted programs such as public work programs, in-kind transfers or CCTs are politically popular because they are perceived as effectively reducing poverty, changing recipients' behavior and promoting human development. The objective of a program might also determine whether targeted or universal transfers are considered more effective and enjoy greater political popularity: a different target group might be considered relevant for a safety net program with an equity perspective when compared to a safety ropes program with an insurance perspective (Pritchett 2005).

\subsubsection{Path dependency}

We can also expect a certain path dependency of targeting regimes, meaning that preferences are pre-determined by targeting choices made in the past (Mkandawire 2005) as well as regime types and their underlying understanding of social justice (Alesina and Fuchs-Schündeln 2007). Path dependency might be large for universal transfers such as subsidies, where reforms are difficult to launch (Grosh, del Ninno et al. 2008). Reforms prove challenging as a move from universalism to targeting is not likely to generate any tax reductions for the rich or the middle class, which means that everybody loses out unless there is compensation offered.

\subsection{Data}

In the remainder of this chapter, we empirically test whether the predictions of the political economy model hold in a low income country context, assessing the relevance of the assumptions underlying the political economy models as well as other contributing factors. Our analysis is based on descriptive statistics. We chose Zambia as a case study for the following reasons: first of all, the question is particularly policyrelevant as the country is currently debating on whether to introduce targeted or universal benefits and is piloting both approaches. It is also a country that shares a number of characteristics with other low-income countries such as a strongly prebendalist approach to policy-making, a limited resource base as well as a relatively high poverty incidence.

In a first step, we elicited targeting preferences through an attitudinal survey ${ }^{127}$, asking respondents which target group they would prioritize as a policy maker given the

\footnotetext{
${ }^{127}$ The structure of the questionnaire was partly inspired by the world values survey as well as the questions asked by Graham (2002).
}

152 
choice between children, the elderly, people with disability, the extremely poor or nobody. While this question only refers to the preferred target group without taking into account the financial implications, it allows people to make an unrestricted choice based on their preferences. The political economy models also presume that individuals from different strata consider all the possible trade-offs for themselves when voting on the budget. Using background information about the respondents, information about their perceptions and attitudes as well as further information about the Zambian context, we analyze in a second step which factors appear to have predominantly influenced their preferences.

The survey ${ }^{128}$ was administered among 435 urban respondents in Lusaka, 396 students of the University of Zambia (UNZA) and among 500 rural participants of Monze district in Southern province. While the 500 rural participants were randomly selected, ${ }^{129}$ urban respondents and students were purposefully sampled. Care was taken to guarantee sufficient variation among urban respondents and students by choosing different geographical locations in Lusaka ${ }^{130}$ as well as different years and faculties at the University ${ }^{131}$. This approach assured that the sample covered respondents of different locations, background and educational status, even though it is not representative for the entire population of Zambia.

Among the urban respondents to the attitudinal survey, we find slightly more men $(55 \%)$ than women (45\%). The group of respondents is 31.5 years on average, mirroring quite closely Zambia's demographics. The respondents to the urban attitudinal survey have relatively high educational levels (close to $40 \%$ have a tertiary education level completed). The majority are also in stable employment (government, self-employment, other wage-employment). ${ }^{132}$ In terms of poverty status, most of the respondents characterized themselves as belonging to the middle stratum (58\%), with $26 \%$ characterizing themselves as (very) poor and $16 \%$ as upper middle and rich. The composition of the urban sample confirms our expectation that the urban population is

\footnotetext{
${ }^{128}$ See Annex 6 and 9 for the questionnaires.

${ }^{129}$ Participants from rural communities of Monze district were randomly selected for participating in the allocation and conditionality experiment (see chapter $3 \& 5$ ) that also included an attitudinal survey. They were chosen from a pool of volunteers which was clustered into very poor, poor and better-off participants. The sample consisted of $30 \%$ very poor, $40 \%$ poor and $30 \%$ better-off.

${ }^{130}$ Markets, mini-bus and intercity-bus stops and shopping malls were selected as interview sites in order to maximize the likelihood of encountering people of different backgrounds. Enumerators were instructed to ensure some variation in respondents, approaching people of different gender, age and poverty status.

${ }^{131}$ Selected lecturers were asked by their faculty to administer the questionnaires to students in their respective classes. Students came from all across Zambia, with Lusaka, Copperbelt and Southern province being most represented. Students were enrolled in different study years and disciplines with predominantly $2^{\text {nd }}, 3^{\text {rd }}$ and $4^{\text {th }}$ year students from Humanities, Natural Sciences and Agriculture responding to the survey.

${ }_{132}$ As opposed to piecework, unpaid family worker and people who cannot participate in the labor market.
} 
likely to be better educated, wealthier and more in formal employment than the rural population, constituting a higher proportion of taxpayers rather than welfare recipients.

Students are expected to be the best-educated group, belong to the richer stratum of Zambia's society and become the future elite as well as future taxpayers of Zambia. They would be least concerned with acquiring insurance against poverty or any adverse events in life. Similar to the urban population, the majority of students characterized themselves as belonging to the middle class $(57 \%)$, with $12 \%$ characterizing themselves as (very) poor and one third characterizing themselves as upper middle class and rich. Students come from different backgrounds in terms of their parents' occupation even if the occupation does not appear to be correlated with students' perception about their poverty status. About the same percentage of female and male students participated.

The rural population is predominantly poor but also includes better-off individuals. The better-off would neither be entitled to welfare benefits nor constitute a large group of taxpayers as employment in rural areas is mostly informal. Among the rural participants, 59 percent of the respondents were female. With an average age of 51 years, the rural population is significantly older than the urban respondents. Most of the respondents are subsistence farmers who mainly live on their own produce. Despite the fact that 10 percent of all respondents are cash transfer beneficiaries, only two percent claim government assistance as their main source of income.

\subsection{Results}

\subsubsection{Targeting preferences}

When faced with the choice of giving social transfers either to all children, all elderly, all people with disabilities, to those in extreme poverty or nobody, only two percent of all respondents to the attitudinal survey opted against any type of transfer. As mentioned before, both the students as well as the urban population have the largest share of people who consider themselves as middle class with a certain probability from switching between the informal and formal sector. Following the logic of the political economy models, we would expect this middle class, in cooperation with the poorer group - the rural population - to prioritize more universal models such as the child grant or the social pension, where the middle class has a high likelihood of benefitting themselves and the poorer class has a higher probability of benefitting more generously. Even if we anticipate greater support for the extremely poor among the urban respondents and students, the majority among them should still vote in favor of a universal solution. 
Figure 6.1: Priority target group selected by urban, student and rural respondents

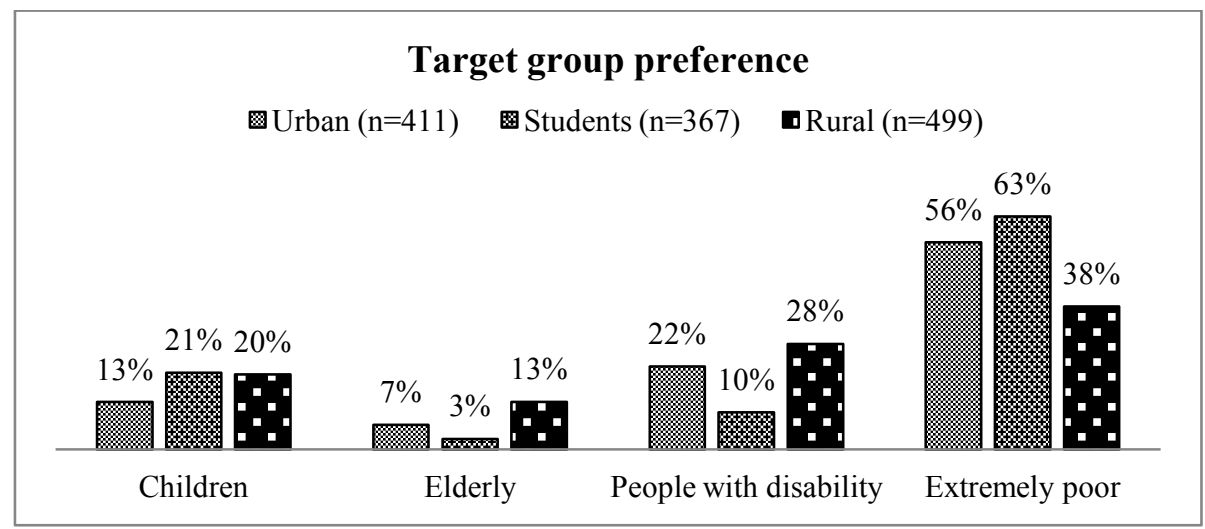

Source: Attitudinal surveys with the urban population, rural population \& students

The majority of respondents across all groups prioritized, however, the extremely poor (figure 6.1). Among the urban respondents and students, more than 56\% opted for the extremely poor, three times more than for any other target group. Although to a lesser extent, the very poor are also the preferred target group of the rural population. When we add up votes for a child grant and for a pension and compare those to the other target groups, the group of the extremely poor is still favored.

Figure 6.2: Priority target group selected by respondents, by self-assessed income

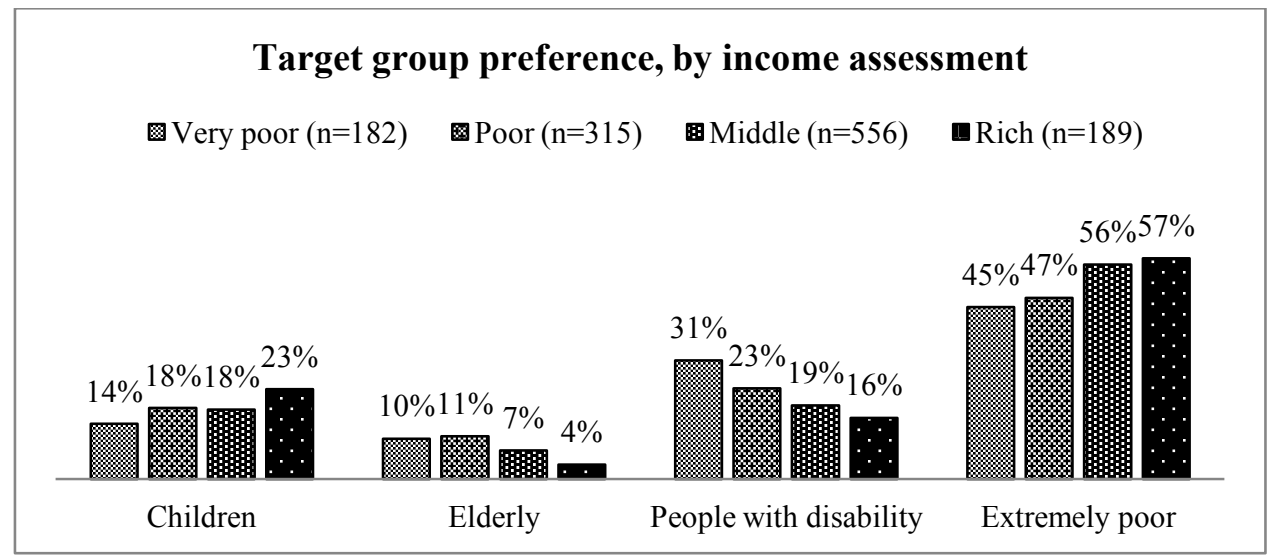

Source: Attitudinal surveys with the urban population, rural population \& students

Even if we disaggregate targeting preferences by the self-assessed income of respondents (figure 6.2), we cannot find support for the predictions of the political economy models. All groups, from very poor to rich prefer the group of the extremely poor and no coalition between any of the groups would subsequently change this result. 


\subsubsection{Corroborative evidence}

One reason why we obtain targeting preferences that are not in line with the predictions of the political targeting model is that surveys may not be the most appropriate tool to elicit targeting preferences. Köhler, Calì et al. (2009) find for instance that targeting preferences of people changed from targeting to universalism when they carried out focus group discussions (FGD) instead of a survey in the same districts in Nepal. We would, however, argue that FGDs introduce their own bias as peer pressure within the group might motivate participants to make choices that are in line with the expectations of other group members rather than their own preferences. Experimental data from the allocation and conditionality experiment with the rural sub-sample actually supports the assumption that decision-making at the group level tends to equalize outcomes (see section 5.4).

We can triangulate our findings with the data from the rural allocation experiment where participants had to make decisions regarding whom to target given real monetary pay-offs (see chapter 5). Strictly speaking, this data source does not allow us to test the validity of the political economy models as the experiments operate under a fixedbudget assumption. The triangulation is nevertheless useful as it helps us to see whether the outcome of the survey is just incidental or in line with preferences expressed through an experimental approach.

The data from the experiment corroborates the findings from the survey that targeting the extremely poor is a preferred choice. We first of all observe a greater preference for targeting rather than distributing universal benefits among the rural population, in particular in communities with prior targeting experience. Out of different recipient characteristics, the poverty status of the recipient has the greatest effect and also proves more statistically significant than characteristics such as age or the number of young children. We can thus conclude that across different methodologies used, targeting preferences seem to be consistent.

\subsection{Discussion of results}

In section 6.2 and 6.3 we discussed some of the potential shortcomings of the political economy models of targeting. These might also explain why the population in Zambia did not opt for a universal scheme. In order to have a better idea of potential factors that made people decide in favor of the extremely poor, we now revisit the assumptions of the political economy models as well as some of the other decisive factors identified in section 6.3 for which we have data. 


\subsubsection{Revisiting the assumptions of the political economy model}

In some political economy models of targeting, it matters whether the voter is purely self-interested or pursues altruistic motives. The rural allocation experiment in Zambia offered some participants the opportunity to allocate themselves money and allowed us to see to what extent selfishness or altruism prevailed as an allocation motive. Fortythree percent of participants were selfish in terms of allocating themselves a higher amount than they would have been entitled to according to their poverty status. Only $3 \%$ of participants, however, allocated all of the money to themselves. In addition, $89 \%$ of rural respondents agreed to the principle of giving without getting anything in return and $42 \%$ had actually given support during the last year to another person without getting anything in return. This demonstrates that people are not selfless but at the same time consider the welfare of others and might potentially be more altruistic than the models would suggest. Also the fact that we observe that respondents without any children were more in favor of a child grant than respondents with children (37\% vs. $20 \%$ respectively) shows that other forces than self-interest must play a role.

Moreover, countries like Zambia where the government is currently not the main actor in social protection provision and support is still predominantly provided by the family and communities probably set a different context for a potentially selfish voter. Even voters from the middle class who would not benefit directly from the transfer would gain from a shift in welfare provision from the family to the state level. This would free up their own financial resources and eliminate the need for ad-hoc support.

Even if the median voter was in favor of a universal scheme, it is questionable to what extent his/her preferences would realistically translate into policy changes. Political representatives in Zambia are not necessarily voted in and out of power based on past or expected performance; material benefits provided just before the election often have a greater impact than the political platform of the representative and his/her party. ${ }^{133}$ Although the Zambian Parliament has to officially approve the budget, it effectively still has limited power to change it according to their voters' preferences (Mudenda, Ndulo et al. 2005; Inter-Parliamentary Union 2009). Interest groups that might lobby politicians and in this way influence policy-making often neither have the mandate of the people themselves nor the power, in particular in the light of the NGO bill that the Government of Zambia passed in order to better control NGO activities ${ }^{134}$. All of these factors might explain why the voter turnout has been relatively low ( $45 \%$ in the last election in 2011) and why voters in Zambia might not act as strategically as portrayed in the political economy models.

\footnotetext{
${ }^{133}$ The comment by Former Minister of Finance, Mr. Magande, on the 2011 election is telling in this regard: "Most of the voters changed their minds one week before the elections, in the last five, six days, and what made them change it's just the money they were given, the chitenge they were given, the sugar, the cooking oil, that went round" (http://www.postzambia.com/postread article.php?articleId $=23319$ ).

${ }^{134} \mathrm{http}: / /$ www.ms.dk/sw139035.asp.
} 
It is also debatable whether people in Zambia assume budget endogeneity when they express their targeting preferences. While a recent study on tax reform highlights avenues for Zambia to improve the efficiency of its tax regime (Mwila, Manley et al. 2011), the potential for big leaps still appears limited. With tax revenues of around $15 \%$ of GDP (IMF 2010) Zambia has a narrow tax base that cannot easily be expanded to finance a program consuming an additional $2 \%$ of GDP. Two percent of GDP or roughly an additional $18 \%$ income tax on formal salaries would be required to fund a rather modest monthly transfer of 15 US\$ per month to every household in Zambia. ${ }^{135}$ Additional tax revenues are not easy to identify: the taxation of the informal sector is still in its infancy and the government's concern about further investments in the mining sector meant the windfall tax disappeared soon after its introduction in 2008.

\subsubsection{Revisiting other decisive factors}

Figure 6.3: Respondents' opinions on whether the poor take responsible decisions or whether they are irresponsible and should be told what to $\mathrm{do}^{136}$

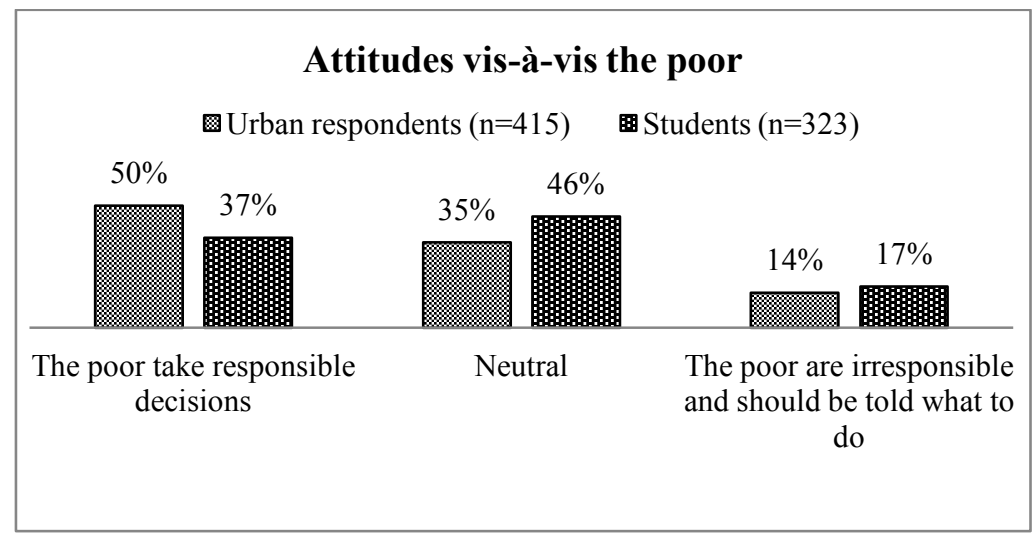

Source: Attitudinal survey for the urban and student sample

People's attitudes towards the poor may have an impact on targeting preferences. Respondents' attitudes towards the poor in Zambia are quite sympathetic. A lack of initiative or the attitude of the poor do not feature as prominently as other causes of poverty such as the lack of opportunities and wrong government policies (see chapter 7). The majority of urban respondents think that the poor take responsible decisions, while students are rather indifferent to the question. Only a minority thinks that the poor are irresponsible (figure 6.3). This indicates that the poor are not regarded as

\footnotetext{
${ }^{135}$ Based on the following assumptions: Total population of 13,046,508 (CSO 2011b), Average household size of 5.3 (CSO, LCMS 2008), a monthly transfer of 15 US\$ including admin costs of $15 \%, 511,338$ formal workers (CSO 2011a), average annual salary of 4908 US\$ (CSO 2011a).

${ }^{136}$ This question was not asked to the rural population for practical reasons. As the rural population participated in an allocation experiment and responded to several surveys, the attitude questionnaire had to be shortened and reduced in complexity.
} 
undeserving; the better-off understand that the poor have to deal with a number of adversities that are hard to control or influence and are in general considered trustworthy. These are all favorable preconditions for a social assistance program targeted to the poor.

Figure 6.4: Respondents' preferences for income (in)equality and perception on the merits of working hard
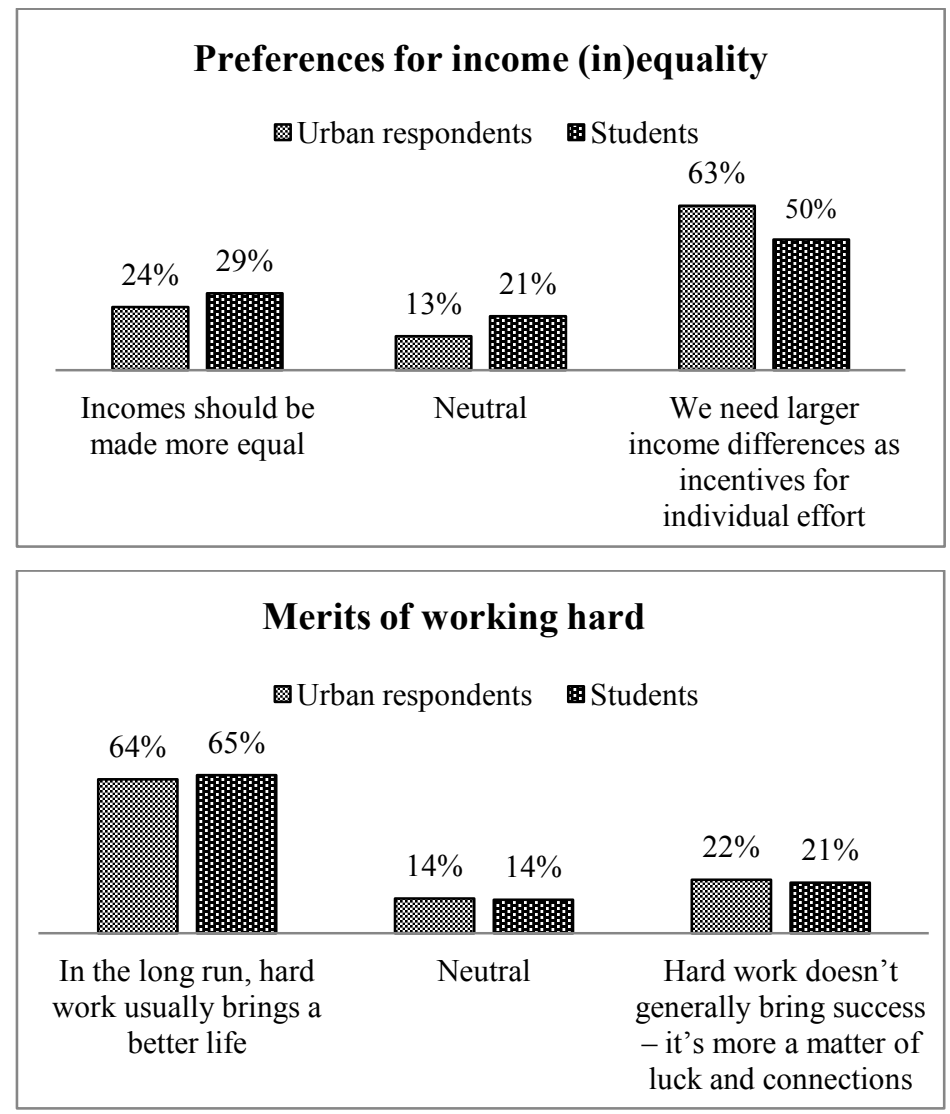

Source: Attitudinal survey for the urban and student sample

When it comes to ideology or institutional structures, the results of the attitudinal survey furthermore testify that most respondents believe in encouraging individual effort. When asked about preferences for income equality, the majority of respondents favored larger income differences as incentives for individual effort (Figure 6.4). There is also a belief in work effort paying off and not resulting in arbitrary outcomes. These beliefs might explain why there is less support for universal transfers: the individual is seen in charge of making provisions, in particular for phases of life that might be easier to anticipate such as old age and children, and is also expected to have a realistic chance of doing so. In line with this argument, those who opted for a universal transfer 
were less prepared to accept income inequalities than those who voted for a disability or poverty grant.

Figure 6.5: Respondents' opinions on whether the government or individual should take more responsibility

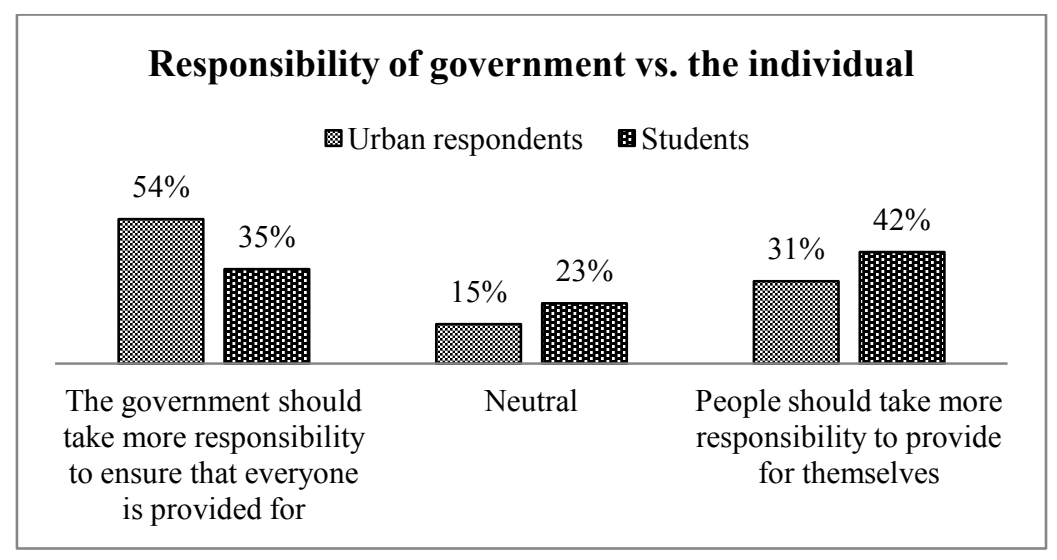

Source: Attitudinal survey for the urban and student sample

Encouraging individual effort does however not rule out a role for the state, even if this role might be more residual than encompassing. With the burden of social protection lying on the individual rather than the state in the Zambian society, the majority of urban respondents and one third of students expect government to increase its efforts (figure 6.5). The government is seen by far to have the largest responsibility to cater for the poor, even stronger than the family and the community (table 6.1). The combination of wanting to encourage individual effort while accepting that the state has a role to play in supporting the individual in adverse situations in life might explain why there is enthusiasm for a poverty grant. 
Table 6.1: Respondents' opinions on whether the following stakeholders have some form of responsibility to take care of the poor

\begin{tabular}{|l|r|r|r|r|r|r|r|r|r|}
\cline { 2 - 11 } \multicolumn{1}{c|}{} & \multicolumn{3}{c|}{ Urban } & \multicolumn{3}{c|}{ Students } & \multicolumn{3}{c|}{ Rural } \\
\cline { 2 - 12 } & Agree & Rank & $\begin{array}{c}\text { No of } \\
\text { obs. }\end{array}$ & Agree & Rank & $\begin{array}{c}\text { No of } \\
\text { obs. }\end{array}$ & Agree & Rank & $\begin{array}{c}\text { No of } \\
\text { obs. }\end{array}$ \\
\hline Family & $69 \%$ & 4 & 432 & $69 \%$ & $\mathbf{2}$ & 373 & $71 \%$ & 6 & 498 \\
\hline Community & $61 \%$ & 5 & 429 & $56 \%$ & 5 & 366 & $73 \%$ & 5 & 497 \\
\hline Entire society & $55 \%$ & 6 & 428 & $63 \%$ & 4 & 365 & $67 \%$ & 7 & 497 \\
\hline Government & $93 \%$ & $\mathbf{1}$ & 428 & $83 \%$ & $\mathbf{1}$ & 376 & $90 \%$ & $\mathbf{1}$ & 499 \\
\hline Church & $70 \%$ & $\mathbf{3}$ & 427 & $64 \%$ & $\mathbf{3}$ & 365 & $90 \%$ & $\mathbf{2}$ & 498 \\
\hline NGOs & $73 \%$ & $\mathbf{2}$ & 424 & $55 \%$ & 6 & 363 & $88 \%$ & $\mathbf{3}$ & 496 \\
\hline International CPs & $47 \%$ & 7 & 427 & $32 \%$ & 7 & 363 & $75 \%$ & 4 & 481 \\
\hline
\end{tabular}

Source: Attitudinal survey for the urban, student and rural sample

Most of the respondents had no prior exposure to universal or targeted transfer and their answers were therefore not influenced by any positive or negative experiences with the targeting process. This limits the extent to which we can analyze the role of path dependency or procedural justice and effectiveness. Only part of the rural population had prior exposure to targeted transfers which did not negatively impact people's preference for targeting. Comparing targeting preferences across communities with and without a targeted SCT scheme ${ }^{137}$, rural respondents from SCT communities have a six percentage points higher preference for the extremely poor as a target group. Even if the difference is not statistically significant, it means that the targeting experience in SCT communities must have at least been neutral, in the sense that it did not change people's targeting preferences towards universalism.

The data do not allow us to draw any conclusions with respect to the importance of cohesion regarding targeting decisions.

\subsection{Conclusion}

This study has shown that whom to target is not necessarily such an obvious choice for low-income countries. Even though the political economy models of targeting are right to suggest that political considerations are central and not subordinate to technical concerns, the relationship between political considerations and targeting may be less straightforward than thought. Drawing on attitudinal survey data from Zambia, we have highlighted that some of the central assumptions of the political economy models might well not hold in the context of a low-income country and other factors could

\footnotetext{
${ }^{137}$ About 60 percent of rural respondents are from pilot communities that are on the SCT scheme.
} 
have an equal bearing on voters' attitudes towards targeting. These other factors comprise voters' attitudes towards the poor, their understanding of social justice, the level of cohesion in society, the degree to which a program is perceived as procedurally fair and effective as well as the fact whether a program is designed from scratch or has already been in existence.

The extent to which these different factors matter in different country contexts and whether we can establish any trends would be subject to further research. On the basis of the existing literature and the case study of Zambia, we hypothesize that countries with a stronger preference for targeting would be countries with a rather homogeneous society with relatively low economic inequality. Voters in these countries would believe in the collective responsibility of protecting the poor and they exhibit a certain level of altruism, while still believing in the principles of subsidiarity. These countries might be characterized by limited democratic accountability and a nearly fixed budget, potentially supported by donor financing. Universal preferences might resonate more with countries with high levels of economic inequality, a heterogeneous society with a strong belief in comprehensive state provision, populated by self-interested voters and a democratic government accountable to its constituency.

In order to get a better understanding of these political determinants and their relative importance, it would be recommendable to carry out a cross-national study, using representative data and shedding more light on all factors that were identified as potentially decisive. This would help to strengthen the political economy models of targeting and ensure that policies around targeting are based on the right set of assumptions. 


\section{CHAPTER 7: Social protection in Zambia - whose politics? ${ }^{138}$}

\subsection{Introduction}

Consideration of the socio-economic ripple effects of the HIV and AIDS pandemic, the impact of the triple F crisis, the failure of economic growth to impact broadly on poverty reduction and the increasing pressure to show progress towards the Millennium Development Goals, would seem to make social protection the policy instrument of choice in low income countries. Yet, in some of the countries with the worst chronic poverty, skepticism regarding social protection appears to prevail despite exposure visits to Latin America, tailor-made training courses, much generation and communication of evidence regarding the positive impacts of social protection initiatives and increasing donor commitments.

Zambia - in particular - has been critiqued for a lack of government commitment to social protection in general and to SCT in particular. The Ministry responsible, that of Community Development and Social Services (MCDSS), was given the task of replacing a set of fragmented, erratic and grossly underfunded services with a holistic social protection strategy and ensuring that programs and new initiatives such as the SCT scheme were well implemented and funded. SCT started in Zambia in Kalomo district in 2003 as a donor-funded initiative and was later extended to five districts. The pilot aimed to generate evidence and offer government and the MCDSS, the necessary information and skills to demonstrate the value of social protection for citizens with limited or no productive capacity. The SCT was proposed alongside other social protection interventions in the first national Social Protection Strategy of 2005 (Government of the Republic of Zambia 2005).

While small victories such as the creation of a budget line for SCT, maintaining a degree of funding for the other interventions, deploying more staff and winning over allies (some Members of Parliaments and a few previously opposed Ministers) have been won, progress overall has been slow. For example, it has taken the Ministry almost three years to scale-up SCT beyond the initial five pilot districts and development partners (DPs) still foot most of the bill. Piloting and experimentation continue (SCT are now targeted to the incapacitated in some districts, to the elderly in others and to children in the most recent districts) with, however, little political commitment to take SCT forward - in whatever form. Increased funding for other important social protection interventions has been equally elusive.

\footnotetext{
${ }^{138}$ A shorter version of this chapter, developed in collaboration with Julie Lawson-McDowall (Regional Social Protection Specialist, UNICEF-ESARO), has been published in the IDS Bulletin 42(6): 21-27, 2011.
} 
Academics and development practitioners have sought answers as to why pro-poor social protection has not taken stronger root in Zambia, starting as early as 2005 with a 'drivers of change' study (Barrientos, Hickey et al. 2005), studies featuring Zambia in 2008 (Lindström 2008), in 2009 (Habasonda 2009; McCord 2009) as well as 2010 (Devereux, Davies et al. 2010; Devereux and White 2010; Niño-Zarazúa, Barrientos et al. 2010). The key question on which debate has focused is whether the relative stagnation is currently observed because stakeholders in Zambia resisted policy recommendations and if so, why. Is it because recommendations were wrong-headed or inadequate or is it a mistake to conclude that we see no progress in Zambia? To capture the complexity of political will in Zambia, this study aims to take a first pass at dissecting the notion into its different components, starting from the framework developed by Hickey (2007). This is briefly introduced in Section 7.2. This framework is then applied to assess in what way these different components can explain the political will behind social protection in Zambia (Section 7.3), critically reflecting on the criticisms voiced by different authors. The chapter then draws some lessons from this analysis (Section 7.4).

\subsection{Politics and social protection}

Figure 7.1: Framework for links between politics and social protection

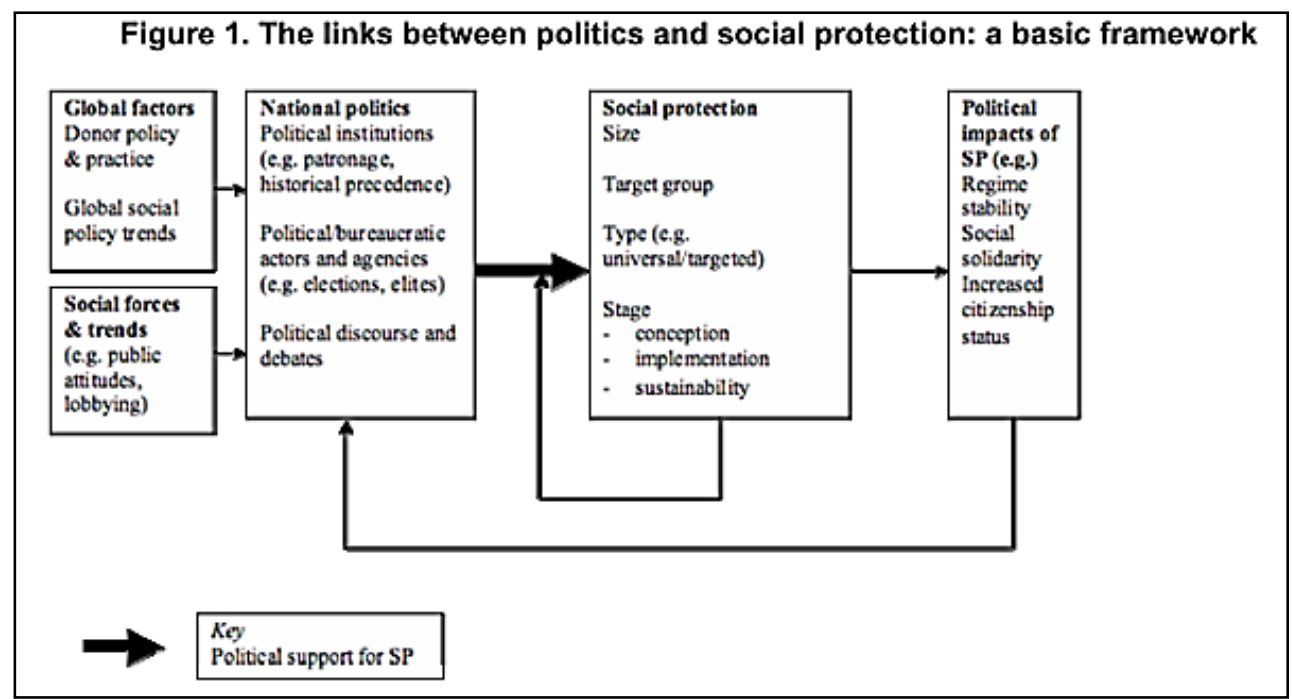

Source: Hickey (2007)

Commentators have been comfortable in using lack of political will to explain the absence of national funding and advocacy for social protection in sub-Saharan Africa. Yet the term has different connotations for different stakeholders and provokes diverse 
policy recommendations. Hickey's basic framework for understanding politics in the context of social protection distinguishes between political institutions, political actors and agencies, socio-economic forces and the global dimension (see figure 7.1). Political institutions refer to the rules of the political game, including election rules, the nature of the political regime and the various ways in which citizens may influence the decision-making process. Political actors are members of the overall political regime who operationalize and contest its (formal and informal) rules and include political elites, the executive, legislators, political parties, etc. Socio-economic forces encompass public attitudes as well as aspects of socio-economic development (degree of urbanization, inequality, social fragmentation) of a country, and global actors and discourses refer to donor practices and policy trends in the international arena.

The model is interactive: political will (whatever its source) is necessary to get social protection off the ground but the design and impact of social protection interventions then have repercussions for the political processes and actors and may themselves contribute towards strengthening or weakening subsequent political will for social protection. The design and impact of social protection programs also influence socio economic forces, leading, for instance, to a change in public attitudes towards the poor; they may also impact on donor perceptions and shape the latter's engagement with social protection programming.

For our analysis, we will prioritize those areas of the framework most subject to criticism in previously cited studies on Zambia:

- Institutional factors, examining the extent to which political will and the potential lack of it are really endemic to social protection and which systemic factors render the strengthening of political will extremely difficult

- Discourse \& thinking on poverty, assessing whether political elites prioritize the productive poor ('the vulnerable but viable') in pro-poor policy making and whether the general public consents

- Knowledge base, analyzing whether the pilots have lived up to their promise of informing evidence-based policy making

- Drivers of change, seeing in what way agents have done justice to their role and whether there are any new levers of support that have not yet been identified

- Design \& implementation, scrutinizing in what way these may have stalled political progress by letting the best be the enemy of the good

\subsection{The politics behind social protection in Zambia}

Critiques of the processes and actors promoting social protection interventions in SubSaharan Africa have suggested that, "the extension of social protection can be thwarted 
by the lack of attention to domestic political and policy processes" (Niño-Zarazúa, Barrientos et al. 2010:16). This is an important argument but seems to apply less in the Zambian context. Donors supporting social protection in Zambia endeavored to analyze political processes to see how social protection might better fit the local political agenda. A key document was the Drivers of Change for Social Protection analysis in 2005 (Barrientos, Hickey et al. 2005). This married the more familiar Drivers of Change approach ${ }^{139}$ with Hickey's conceptualization of the politics of social protection in Africa. The document still impresses today in its systematic review of possible actors, discourses, institutions and processes that might support or oppose systematic pro-poor interventions in the form of social protection. Its recommendations were sensible, if not always realizable by effort or strategy alone, depending as they did - ultimately - on convincing powerful gatekeepers who could choose (and often chose not) to listen nor engage.

The report identified several barriers to social protection interventions: a tendency towards a 'massification of poverty,' the complex and impenetrable language employed and a MCDSS with low human, organizational and financial capacity. Together with other major analyses of poverty at this time, from the Drivers of Change of Pro-Poor Growth (Duncan, Macmillan et al. 2003) to the Poverty and Vulnerability Report (World Bank 2007), it argued that donors must push for a stronger focus on the poor and vulnerable and encouraged them to make use of existing institutions, engage with powerful social and economic sector ministries and the Minister and Ministry of Finance, to ally with civil society and research institutions and to prioritize monitoring and evaluation. The Constitutional Review Committee as well as the new SCT pilots were seen as possible entry points for generating more political will.

\subsubsection{Institutional features}

It is important to understand the institutional forces at play at the time in Zambia since these set the stage for policy-making. The interaction of formal and informal policy making dynamics makes analysis of institutional incentives much harder. It can be argued that this interaction causes a degree of built-in resistance to institutional change. We now analyze to what extent Zambia's political regime might be generally characterized as pro-poor, which political spaces offer entry, whether citizens have an opportunity to hold decision-makers accountable and whether the concept of social contract is of analytical assistance in the Zambian context.

\subsubsection{Putting social protection into the broader context}

Recent analyses in Zambia of social protection and SCT in particular have taken insufficient account of the broader policy and programming environment of the country

\footnotetext{
${ }^{139}$ For more information about DfID's Drivers of Change approach, see Warrener (2004). 166
} 
but have shone a spotlight on social protection. In the context of Zambia's long term economic decline from middle-income to low-income status, and the resulting (and concomitant) structural adjustment processes, a policy and funding void emerged around responses to poverty which persists today. Poverty alleviation was subsumed under growth while government investment across the board has been limited by the dynamics of the shadow political economy, dominated by a patronclient/patrimonial/prebendalist rationale, regulating the status quo by generating rents to be allocated within various political ethnic elites ${ }^{140}$. Despite the fact that Zambia subscribed to a National Poverty Reduction Action Plan as early as 1997 and appointed one Ministry, MCDSS, as the focal point for poverty reduction interventions, poverty and vulnerability responses by government have, consequently, been piecemeal, underfunded and projectized, and often delivered through non-government channels.

The magnitude of challenges ahead for a national SCT program is revealed by the budget allocation for poverty alleviation and other social protection measures. In 2010, the MCDSS budget ceiling was fixed at $0.5 \%$ of total government revenue (about US $\$ 15.5$ million). The allocation for the food security packs, a national program to support poor small-scale farmers, represented just $13 \%$ of this small budget, while that for the in-kind transfer provided by the Public Welfare Assistance Scheme (PWAS) also supposed to be a national program - amounted to 7\% of the entire MCDSS budget (Ministry of Finance and National Planning 2010). To fund a national SCT scheme targeting $10 \%$ of households (for calculations, see: International Labour Office 2008a), the present MCDSS budget would have to be doubled. These insights show that Zambia has been a difficult terrain for launching large-scale pro-poor interventions and it puts the government allocations of about $5 \%$ of the overall MCDSS budget for a SCT pilot into perspective.

\subsubsection{Personalized decision-making}

Where there have been significant shifts in social protection policy, a careful examination reveals their highly personal and opportunistic nature. For example, until October 2005, rural health user fees, introduced in the 1990s, seemed a fixture and the Ministry of Health was firmly pro-user fees. The reform trigger was an idiosyncratic combination of factors and events: the Minister, a visionary champion able to manipulate free political space due to her non-membership of the ruling party, motivated by a personal encounter with poverty, teamed up with a donor that was able

\footnotetext{
${ }^{140}$ For a thorough discussion of how these terms have been used and might meaningfully apply in the context of different sub-Saharan African regimes, see Erdmann \& Engels (2006). For our purpose, the argument is that in the Zambian context, and varying in extent and recipient group/individuals according to particular political eras, there has always been a degree of illicit and semi-illicit distribution of state resources - from jobs, to loans to land or contracts - along lines that have ultimately served the personal and political ends of powerful political and business interests. Above all, this distribution does not take place transparently and is pro-elite and pro-elite maintenance. It may serve both highly negative and also more positive ends (Zambia has avoided internal ethnic conflict to date) but in many of its aspects is commonly considered corruption.
} 
to organize support quickly. Similarly, the former Minister of the MCDSS managed in 2007 to mobilize rapidly a significant budget for street children, partly to the detriment of the national in-kind transfer program. A personal interest became a political priority for these particular actors, enabling them to change the political course of action in no time.

\subsubsection{Political spaces}

Unfortunately, then and now, unofficial policy space is often more important and more difficult to influence. Political economy analyses suggest that,

"Zambia has long been characterized by a disconnect between its formal institutional structure, and the informal 'rules of the game'. The country has a full array of formal institutions characteristic of a liberal democracy, and all of them function to some degree, but the actors within them do not necessarily operate within a norm of rule-boundedness." (Levy and Palale 2007: 10$)^{141}$

Since independence, important constituencies in Zambia, either ethnic, linguistic, regional or political elites or a mixture, have been balanced through access to patronage rents of one form or another ${ }^{142}$. This has maintained the unity of the state but also served to concentrate and consolidate political power. These "mutual guarantees of economic and political support within social networks" inhibit the functioning of the "mechanisms of performance-based accountability" (Posner and Simon 2002: 332) and do not provide easy entry-points for outsiders to influence policy. The seismic political and economic shifts from the 1990s onwards did little to reduce the informal policy space. The move to multi-party democracy, continuing economic decline, high indebtedness and the introduction of the 1990s Washington Consensus package of reforms were accompanied by splits in the governing MMD (Movement for Multiparty Democracy) and the almost total disintegration of the opposition party UNIP (United National Independence Party).

Rents had to be generated and the "economic dimensions of development policy making became increasingly subordinated to the imperatives of creating and allocating the rents necessary for political management" (Levy and Palale 2007: 8). This meant that unofficial political-economic imperatives were as important as official ones but even less likely to be pro-poor. According to availability, these rents shifted from

\footnotetext{
${ }^{141}$ The following discussion draws on a widely shared report authored by Levy and Palale (2007), with contributions from Taylor and Simutanyi which built on a series of workshops on governance and development strategy with the World Bank Zambia Country Team in 2007.

${ }^{142}$ Rents are defined as a "premium above opportunity costs for a given set of resources" (Lewis 1994: 440), which is when market's price setting mechanisms are distorted by non-market forces. Rentier activities are "politically mediated opportunities for obtaining wealth through non-productive economic activity" (Boone 1990: 427). Rentiers, belonging to the "political class", gain wealth through the privatization of state resources (loans, property, subsidies, cash transfers etc.), and the appropriation of rents generated by state intervention in markets (government contracts, trading in state controlled markets etc.). (Erdmann \& Engel: 2006: 27)
} 
employment in or diversion of resources from parastatals, the bureaucracy or ministerial posts to access to resources in land, the spoils of privatization and procurement during the different decades. Thus, both official pro-growth and unofficial pro-rent generation dynamics limit the space and the paths along which the poor might be able to make themselves heard and in this way complicate the inception of national social protection interventions.

\subsubsection{Accountability}

In Zambia today political accountability remains limited. Policy makers do not face the consequences of bad or inconsistent policy-making to its full extent except at key moments (such as former President Chiluba's bid for a 3rd term) which call for a major civil mobilization. It is not clear to what extent politicians who fail to deliver are voted out of power. Dependence on relations with the leaders of the party for the resources and opportunity to be elected means that constituents have much less influence than the formal structure suggests. A study examining factors of support for the incumbent in Zambia in the 1991 and 1996 elections at subnational level found that "non-economic factors such as urban-rural location and ethnic background to have been at least as important as economic factors in shaping voters behaviour." (Posner and Simon 2002: 319) They also found evidence that along the familiar exit/voice/loyalty spectrum (Hirschmann 1970), exit - in terms of not voting/abstaining - was still, as under the single party system, regarded as a valid strategy. Evidence of a small shift away from prebendalist voting patterns by Posner and Simon (2002) is a sign that incumbents will increasingly be judged on their performance in office. This accountability bodes well for the future of social protection.

\subsubsection{Towards a social contract?}

The issue of a social contract has been posed as a useful framework in the politics of social protection in Africa. However, here its greatest contribution to the debate is in showing the degree to which such a contract is absent. The description above of the coexistence of official and unofficial policy spaces illustrates that the majority of the population is excluded from influencing both spaces. A social contract has to be recognized by both sides and, to some extent, be enforceable.

Despite the fact that social protection is gradually being institutionalized and integrated into the Social Security Policy, the draft Social Welfare Policy, the National Development Plan and so on, Zambia, like other Sub-Saharan African countries, is known to be good at agreeing and developing policies but poor at implementation (Ablo, Vantzos et al. 2004; Levy and Palale 2007). The Zambian government has also been particularly careful about the commitments it makes to its citizens. A key issue in Zambia's recent Constitution debates concerned whether it could risk promising education for all, let alone the progressive realization of social and economic rights. 
The fact that the draft Constitutional Bill has included a 'right to social protection' is, however, a promising sign with respect to the longer term future of social protection. ${ }^{143}$

\subsubsection{Discourse \& thinking on poverty}

How is poverty understood by Zambians? A mixed picture emerges from political elites as well as the broader public.

\subsubsection{Elites}

Earlier studies suggested that fears of welfare traps and irreversible political commitments dominated the views of the elite (the wealthiest $3-5 \%$ of the population) on poverty. Commentators have argued that elites prefer tools directed at the productive poor (Barrientos, Hickey et al. 2005; Hickey 2007). However, there is evidence that this view has shifted. We now find a more nuanced view within the Ministry of Finance (Lindström 2008; RuralNet Associates Limited 2008), a richer debate on social protection in Parliament ${ }^{144}$ and, in policy terms, social protection, once a side chapter in the 5th National Development Plan, is being considered as a right in the new Constitution. Furthermore, targeting in Zambia falls short of any international measure, whether for the productive or unproductive poor, as the previous budget figures in section 7.3.1.1 have shown. This challenges the social protection regime typology by Niño-Zarazúa, Barrientos et al. (2010), which concludes that governments in the Middle African countries such as Zambia favor policies for the productive poor while a greater concern for the 'unproductive/deserving' poor is discernible in the Southern African model.

\subsubsection{Public opinion}

What do 'ordinary Zambians' think about the incapacitated poor? Ordinary Zambians care about the incapacitated poor, as much as they can afford to, which is evidenced by them taking in orphans, sending remittances to poor family members or participation in faith based care organizations. This is also confirmed by an attitudinal survey administered among the urban population in Lusaka, students at the University of Zambia and the rural population of the district Monze, that explored how Zambians understand the poor and which response to poverty they find acceptable. Further details about the methodology can be found in chapter 6 .

\footnotetext{
${ }^{143}$ The previous constitution did not grant full socio-economic rights. They even restricted basic rights such as the right to education, claiming financial and administrative incapacity to do full justice to it.

${ }^{144} \mathrm{http} / / / \mathrm{www}$. parliament.gov.zm/index.php?option=com_content\&task=view\&id=1142\&Itemid=86, $\mathrm{http}: / /$ www.parliament.gov.zm/index.php?option=com_content\&task=view\&id=1336\&Itemid=86. 170
} 
Table 7.1: Respondents' opinions about the importance and feasibility of labor

Percentage of respondents who (dis) agree or are neutral on the following statements:

\begin{tabular}{|l|r|r|r|r|r|r|}
\cline { 2 - 7 } \multicolumn{1}{c|}{} & \multicolumn{2}{|c|}{$\begin{array}{c}\text { It is humiliating to receive } \\
\text { money without working } \\
\text { for it }\end{array}$} & \multicolumn{3}{|c|}{$\begin{array}{c}\text { People who don't work } \\
\text { become lazy }\end{array}$} \\
\cline { 2 - 7 } & Urban & Students & Rural & Urban & Students & Rural \\
\hline Disagree & $41 \%$ & $34 \%$ & $66 \%$ & $34 \%$ & $21 \%$ & $24 \%$ \\
\hline Neutral & $13 \%$ & $23 \%$ & $5 \%$ & $13 \%$ & $13 \%$ & $15 \%$ \\
\hline Agree & $46 \%$ & $43 \%$ & $29 \%$ & $54 \%$ & $66 \%$ & $61 \%$ \\
\hline No of obs. & 425 & 380 & 498 & 425 & 378 & 499 \\
\hline
\end{tabular}

\begin{tabular}{|c|c|c|c|c|c|c|}
\hline & \multicolumn{3}{|c|}{$\begin{array}{l}\text { Everybody in society can } \\
\text { and should work }\end{array}$} & \multicolumn{3}{|c|}{$\begin{array}{c}\text { Work is difficult to } \\
\text { combine with caring } \\
\text { obligations }\end{array}$} \\
\hline & Urban & Students & Rural & Urban & Students & Rural \\
\hline Disagree & $23 \%$ & $13 \%$ & $11 \%$ & $53 \%$ & $58 \%$ & $36 \%$ \\
\hline Neutral & $18 \%$ & $12 \%$ & $28 \%$ & $19 \%$ & $14 \%$ & $24 \%$ \\
\hline Agree & $59 \%$ & $75 \%$ & $60 \%$ & $28 \%$ & $27 \%$ & $40 \%$ \\
\hline No of obs. & 421 & 377 & 499 & 422 & 380 & 499 \\
\hline
\end{tabular}

Source: Attitudinal survey with urban and rural sample \& students

When asked about the individual's duty and capability to work, the majority thought that supporting oneself through work was extremely important, and that the majority of people were in a position to work, as demonstrated by table 7.1. Opinions were more divided on the question of the acceptability of receiving money without working for it. The median respondent is neutral for the urban and student sample and agrees that it is not humiliating for the rural sample. This suggests that while there is limited belief in the ability of some not to work due to age, sickness or other caring obligations, these answers also show that a cash transfer without a work obligation, would be far from completely unacceptable.

When attitudes towards the degree of deservingness of the poor were investigated, a majority of urban and student respondents were clear that wrong government policies and an absence of opportunities for the poor were important causes of poverty (table 7.2). Rural populations focused on the impact of HIV/AIDS and a lack of opportunities. Only among students were the mindset or lack of initiative of the poor considered as main drivers of poverty. For the urban as well as rural sample, more structural factors dominated as the potential causes of poverty, which should translate into lower resistance towards state-funded social assistance programs. 
Table 7.2: Respondents' opinions about the causes of poverty

Percentage of respondents who agree with the following causes of poverty / Ranking of poverty causes according to the percentage of respondents who is in agreement

\begin{tabular}{|l|c|c|c|c|c|c|c|c|c|}
\cline { 2 - 11 } \multicolumn{1}{c|}{} & \multicolumn{3}{c|}{ Urban } & \multicolumn{3}{c|}{ Students } & \multicolumn{3}{c|}{ Rural } \\
\cline { 2 - 11 } & Agree & Rank & $\begin{array}{c}\text { No of } \\
\text { obs. }\end{array}$ & Agree & Rank & $\begin{array}{c}\text { No of } \\
\text { obs. }\end{array}$ & Agree & Rank & $\begin{array}{l}\text { No of } \\
\text { obs. }\end{array}$ \\
\hline $\begin{array}{l}\text { Lack of opportunities } \\
\text { for the poor }\end{array}$ & $80 \%$ & $\mathbf{2}$ & 431 & $66 \%$ & $\mathbf{3}$ & 374 & $65 \%$ & $\mathbf{2}$ & 499 \\
\hline $\begin{array}{l}\text { Lack of initiative of } \\
\text { the poor }\end{array}$ & $42 \%$ & 6 & 429 & $56 \%$ & 4 & 367 & $42 \%$ & 5 & 499 \\
\hline Mindset of the poor & $47 \%$ & 5 & 426 & $68 \%$ & $\mathbf{2}$ & 373 & $39 \%$ & 6 & 497 \\
\hline $\begin{array}{l}\text { Wrong government } \\
\text { policies }\end{array}$ & $81 \%$ & $\mathbf{1}$ & 426 & $80 \%$ & $\mathbf{1}$ & 373 & $45 \%$ & 4 & 493 \\
\hline Wrong donor policies & $52 \%$ & $\mathbf{3}$ & 424 & $43 \%$ & 6 & 362 & $22 \%$ & 7 & 495 \\
\hline $\begin{array}{l}\text { External } \\
\text { circumstances }\end{array}$ & $39 \%$ & 7 & 425 & $28 \%$ & 7 & 363 & $63 \%$ & $\mathbf{3}$ & 486 \\
\hline HIV AIDS & $51 \%$ & 4 & 424 & $44 \%$ & 5 & 361 & $80 \%$ & $\mathbf{1}$ & 496 \\
\hline
\end{tabular}

Source: Attitudinal survey with urban and rural sample \& students

Another positive precondition for a social assistance program to those that are not economically active is that the majority of rural respondents ${ }^{145}(89 \%)$ would be willing to support even those who cannot give anything in return, at least in the short term. Respondents of all samples also felt strongly that the government had primary responsibility for care of the poor. No other stakeholder, ranging from the family to the community to the church and NGOs received such a high agreement rate (see section 6.6.2). In addition, the percentage of participants in the attitudinal surveys who, when asked to imagine themselves in the position of a policy maker, denied any form of support to the poor, was negligible.

Despite the fact that these attitudinal surveys are not nationally representative, they suggest that there might be more support for a program directed at the incapacitated than previously believed. More problematic here is the limited degree to which citizens can voice their interests and place active demands on government.

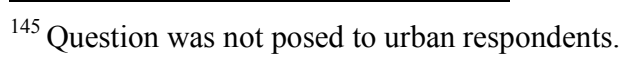




\subsubsection{Knowledge base - getting the right message out to the right people?}

\subsubsection{Merging science with reality}

It is clear that methodologically robust and independent impact evaluations of SCT programs in the Latin American context contributed an important body of knowledge in support of policy and allocation decisions. This finding calls the European Development Report to issue a fresh demand for robust evaluations in Sub-Saharan Africa (ERD, 2011: 5, 8, 119). While evaluations are informative for design purposes, help counter critical arguments, can and do inspire other countries in the region and are of importance to sustain a program once political will has built up, it is unlikely that an impact evaluation alone can change the political dynamics in Zambia.

In Zambia, numerous studies have been commissioned on the impact of SCT (Ministry of Community Development and Social Services and GTZ 2007; Wietler 2008; Tembo and Freeland 2008a; Tembo and Freeland 2008b; Hichaambwa 2009), its operational efficiency with regard to targeting (Watkins 2008a; Watkins 2008b), payments (Langhan, Mackay et al. 2008), incentives (Mbandama and Musonda 2007), conditionality (Schüring 2010a), institutional arrangements (RuralNet Associates Limited 2008) or the scheme as a whole (Devereux and Wood 2008). Much effort was given to ensuring that the process was transparent and credible, data and studies were shared with a wider audience and areas for improvement were highlighted as much as achievements. Additional internal audits as well as a fiduciary risk assessment (Hawkins and Mugala 2008) were conducted to react to concerns expressed by Ministry of Finance. The pilots have consequently been used to build an evidence base for Zambia as recommended in the "Drivers of Change Study" (Barrientos, Hickey et al. 2005). Findings attested that the SCT scheme had positive effects on beneficiaries and their communities. The studies on the operational effectiveness confirmed that transfers were neither used for the wrong purpose, nor were they going predominantly to the wrong people.

The challenge is that policy makers may not base decisions on evidence; in particular, the true believers as Prichett (2002) calls them, may deny. The former Minister of Finance in Zambia, a true believer that cash transfers would either be captured or misspent, based his view about the SCT on his personal experience as an agricultural credit officer and interactions with a few cash transfer recipients in his home district, rather than examining the broader and more positive evidence. It is therefore unlikely that a randomized broad-scale experiment would have provided a tipping-point. Evidence is a necessary but not sufficient condition for social protection in any country where personalities and other policy considerations dominate. 


\subsubsection{Market social protection better?}

A key question in Zambia is whether stakeholders found the right channels of communication for social protection and whether, in particular, they failed to emphasize its potential to stimulate local economic growth. Habasonda (2009) hints at a lack of understanding about the program from the side of government and also notes that there was little public debate due to the relatively low transfer amounts. Looking at the parliamentary debates in 2010 on SCT, we note that despite the many communication events noted above, certain misconceptions persist, mainly about dependency and affordability. ${ }^{146}$ This clarifies that continuous workshops, trainings and regular information flows about the goals and methods of social protection are indispensable. This is normal in most sectors in Zambia as capacity building, technical training and government reforms continue.

Table 7.3: Respondents' prioritization of economic growth, redistribution or both as a policymaker

\begin{tabular}{|l|l|l|}
\cline { 2 - 3 } \multicolumn{1}{c|}{} & Urban & Students \\
\hline \hline Economic growth & $49 \%$ & $29 \%$ \\
\hline Redistribution & $15 \%$ & $10 \%$ \\
\hline Both & $36 \%$ & $60 \%$ \\
\hline No of observations & 420 & 391 \\
\hline
\end{tabular}

Source: Attitudinal survey with urban sample \& students

Other authors such as Niño-Zarazúa, Barrientos et al. (2010) criticize donors for not emphasizing the growth potential behind social protection, selling it as a poverty reduction intervention and thereby putting off African elites. In Zambia, an active dialogue with Ministry of Finance about the economic effects of social protection was sought at an early stage and the economic spin-off effects were highlighted and supported with national and international evidence as far as available. Table 7.3, showing the opinions of the wider public, also demonstrates that growth is not people's exclusive concern with about one third of urban respondents and two thirds of students voting for a policy mix of economic growth and redistribution.

Finding the right language and evidence is crucial in addressing the concerns and fears of the Ministry of Finance and also in correcting misperceptions that SCT are counterproductive. However, there is a real risk of claiming social protection as a silver bullet and/or not recognizing the budgetary implications and difficult allocation decisions that governments face. Although we can identify an economic impact from SCT aimed at the incapacitated, the lack of capacity of the recipient households and the low sums

\footnotetext{
${ }^{146} \mathrm{http} / / / \mathrm{www}$. parliament.gov.zm/index.php?option=com_content\&task=view\&id=1142\&Itemid=86, $\mathrm{http}: / /$ www.parliament.gov.zm/index.php?option=com_content\&task=view\&id=1336\&Itemid=86. 174
} 
transferred necessarily limit the economic impact. If SCT programs are promoted primarily on their propensity to promote growth, they will be assessed against other productive programs and probably fail the test. This would take us back to growth with no protection for those least able to participate.

Secondly, funding for social protection needs to be brought into context. While the ILO (2008a) has advocated that a minimum package of universally acceptable benefits would be affordable - social assistance to the $10 \%$ poorest households plus a universal pension would cost less than $1 \%$ of GDP - we still need to realize that even a budget representing close to $1 \%$ of GDP effectively means a significant budget increase for countries like Zambia that have mobilized about $25 \%$ of GDP or less as government revenues and grants over the course of the past 10 years (IMF 2010).

\subsubsection{Drivers of change - going the right way?}

When it comes to drivers of change in the area of social protection, papers have recommended civil society step up their efforts, donors tone down their interventions and Ministries of Social Affairs leave the field to the more powerful players. How might these recommendations play out in the Zambian context?

\subsubsection{Civil society needs to step up}

Civil society in Zambia is a diverse group of organizations, active in lobbying for the poor and vulnerable, for sufferers of HIV and AIDS, for improved democratic processes, for women's rights and delivering many vital services on the ground. At community level, particularly through volunteers from faith based organizations, their members offer many of the social services for the incapacitated and vulnerable that the state does not provide. The larger, better funded and network organizations also play a role at national level but this is neither constant nor always well-received. Mass movement has arisen only at crucial moments in the democratic evolution. In social protection, sporadic pressure has been exerted on the government by some organizations such as the Jesuit Centre for Theological Reflection or the Civil Society for Poverty Reduction for a greater focus on poverty reduction (Petrauskis 2007). Civil society has mainly played a consultative role, although the initiative of a civil society platform for social protection has gained some momentum of late.

Is it fair to suggest that civil society has failed to provide national leadership on social protection? A more sophisticated and dynamic understanding of the limitations of civil society in a country such as Zambia would suggest not. The shrinking of the middle class and absence of a pro-poor activist elite has meant that Zambian NGOs are almost entirely dependent on funding from external sources. Over the last few years, there have been significant declines in funding as bilateral and multilateral donors switched their attention and resources away from civil society and parallel systems and towards 
trying to strengthen government. Thus, civil society engagement is curtailed by lack of funds and funds are curtailed by donor strategies. Many excellent NGOs are struggling to survive and must follow donor enthusiasms rather than expect to find funding for their own agendas. The NGO Bill in 2009 further limited room for maneuver through introducing a government dominated NGO registration board which approves or denies establishment or mandatory re-registration of NGOs. ${ }^{147}$

What the funding gap and government's assault on NGO independence meant in practice for social protection is that the influence civil society could and can bring to bear in Zambia is highly constrained.

\subsubsection{Donors taking too much of the initiative}

Have donors taken too much of the initiative in social protection? Let us reverse the question to establish what role we expect donors to play to ensure that the interests of those without a voice are taken on board. Looking at donors' engagement in other sectors, it could be argued that donors, overall, did not take sufficient initiative given the presence of a policy void that was damaging to the poor and vulnerable. This contrasts with a more robust approach in other similar policy and programming voids, for example, in promoting a response to HIV and AIDS. Zambia has also found that greater donor engagement can have many positive spin-off effects. Donors have for instance achieved solid results in partnership with ministries in other sectors, delivering funds needed for capacity building, internal reconstruction, infrastructural development and material resources. Long-standing donor involvement in the Ministries of Health and Education show these ministries in Zambia today are in a better shape than they were twenty years ago. ${ }^{148}$

This does not imply that donors should attempt to impose their preoccupations on the policy-making process but they should certainly act to support local actors, institutions and processes that benefit the poor and vulnerable. Donor initiatives in social protection in Zambia have followed more than one agenda, which might not have fostered consistency in policy-making and ministerial ownership. ${ }^{149}$ In their defense, however, it must be stated that DPs made extensive use of the official policy space, particularly through the Technical Working Groups (TWG) that fed into the Sector Advisory Group (SAG). Despite at times erratic meetings and low-level representation from other key Ministries, the SAG, the TWG and the DP meetings were slowly

\footnotetext{
${ }^{147} \mathrm{http}: / / \mathrm{www} . \mathrm{ms} . \mathrm{dk} / \mathrm{sw} 139035 . \mathrm{asp}$.

${ }^{148}$ Even and especially if this means that grand corruption can be identified and is dealt with more swiftly than in earlier years - http://www.bbc.co.uk/news/10331717.

${ }^{149}$ GTZ, DfID and Irish Aid supported a cash transfer project aimed at helping elderly carers and AIDS orphans through targeting the incapacitated. UNICEF with DfID and Irish Aid funding has pushed for a set of emergency five year universal child grant programs in the districts with the worst outcomes for child survival. HelpAge and the ILO seemed at times to regard social pensions as the only true way to establish a framework for social assistance and are now working primarily with the Ministry of Labour that has this mandate.
} 
institutionalized within the MCDSS and became useful arenas for widespread discussions on responses to the different forms and levels of vulnerability and poverty with different departments of the ministry and with civil society.

Without the support of donors, poverty and social protection would not have risen on the agenda of those who make decisions and MCDSS would not have the same capacity and clout as today. Although the shift has not been dramatic, the role of MCDSS has been strengthened and its mandate has gained greater recognition. The support was even more welcome given the unintended consequences of donor harmonization, which favored the already better resourced social sector ministries to the detriment of Ministries such as MCDSS, which were already underfunded and not at the focus of political attention.

\subsubsection{Appropriate institutions}

Choosing the appropriate institutions for a particular intervention is key to ensure capacity, the right skill-set and sustainability. Academics and practitioners in social protection debate at length whether to work with existing or new institutions. Many advocate that a more powerful ministerial home would further the agenda and that working with weak Social Affairs ministries is self-defeating as they might have the mandate but not necessarily the political clout.

There are some serious difficulties with this suggestion though. To shift a social transfer program from the ministry which holds a mandate presupposes an interest in the recipient for such an inter-sectoral adoption. In the Zambian context, this was a non-starter. The Minister of Finance was one of very few Ministers of Finance absent from the regional Livingstone conference on social protection in 2006, hosted in Zambia, and was reluctant in 2007 to sign a SCT grant agreement with donors for a SCT scheme for which the MCDSS lobbied strongly.

Furthermore, social protection interventions at a time when donors are preoccupied with alignment, harmonization, division of labor and delivering results need to promote government systems and to support a broader Ministry of Social Affairs' mandate, rather than elevate a single intervention. Micro-credit, public works, community projects as well as the food security packs are all housed by MCDSS and would be further weakened if social grants were managed by a different Ministry. This suggests that a move to a more powerful Ministry for SCT might not be the most sustainable strategy.

\subsubsection{The government?}

Most critics of the failure of social protection bemoan a lack of political will and this is also true for Zambia. But the concept of political will embodies an assumption that government is a) a homogeneous and static body and b) to a large extent, represents the 
will of most of the people. A useful contribution to the debate on political will would be to deconstruct the government into its different actors and to undertake a more dynamic analysis of stakeholders.

Social protection in Zambia does have its supporters. MCDSS, once viewed as a passive actor in social protection (Barrientos, Hickey et al. 2005) has evolved into an active driver of change (Devereux and White 2010). The Ministry has made numerous attempts to engage actively with critics such as its colleagues at the Ministry of Finance. Looking at the nature of the Parliamentary Debates led by the Minister of MCDSS in 2010 on the SCT scheme ${ }^{150}$, MCDSS increasingly comes across as an informed and determined Ministry rather than just a strong ally to the DPs as characterized by Devereux and White (2010). Similarly, the once baffling language of social protection is now handled with relative ease.

The debate also overlooks that several MPs have recognized the political potential behind the SCT scheme and demonstrated keen interest in the scheme being extended to their constituency. To this, one can add the evidence presented above on public opinion regarding government's responsibility for poverty reduction and (some) social assistance. Strategically, strengthening rather than criticizing these stakeholders in the Zambian regime that promote social protection would be more constructive.

Furthermore, neither the MCDSS nor donors have been as inactive as some of the studies have suggested in finding new levers of support (Devereux, Davies et al. 2010; Niño-Zarazúa, Barrientos et al. 2010). MCDSS together with DPs actually started searching for new allies as early as 2006. Several workshops with the Ministry of Finance were held, social protection trainings and sensitization tours were organized inviting stakeholders from different Ministries, Members of Parliament and media representatives, and the Livingstone conference was hosted with the President making opening remarks in 2006. There were strategy meetings with civil society, radio and television were used to share information about the pilot, a website was set up to document everything and donors with stronger relationships with the Ministry of Finance such as World Bank and ADB were identified as strategic allies. A Civil Society Thematic group set itself up and the Constitutional Review Commission was approached. The UNICEF steering committee for the situation analysis of women and children was housed in and chaired by the Ministry of Finance to try and bring home to the financial technocrats the extent and depth of poverty and the urgent need for more adequate responses.

So how can these new levers of support be more effectively mobilized in Zambia? Can we expect to find the new levers in the formal political arena, when informal political processes have a great impact on political processes around social protection, as several

\footnotetext{
${ }^{150} \mathrm{http} / / / \mathrm{www}$. parliament.gov.zm/index.php?option=com_content\&task=view\&id=1142\&Itemid=86, http://www.parliament.gov.zm/index.php?option=com_content\&task=view\&id=1336\&Itemid=86
} 
authors have highlighted (Grindle and Thomas 1991; Hickey 2006; RHVP 2008; Devereux and White 2010)? What is to be done if no visionary Prime Minister stands up and commits himself to a pension as in Lesotho? The continuous pressure for new levers of support will most likely have to be maintained in Zambia.

\subsubsection{Design \& implementation - the devil is in the detail?}

A further explanation offered for the failure (or slow momentum) of social protection interventions has been that the interventions are inappropriate. Did the MCDSS and DPs opt for the wrong interventions, place too much stress on a single program, give preference to the wrong target group or fail to acknowledge a public demand for assistance to be conditional?

\subsubsection{Best as enemy of the good?}

Devereux and White (2010) suggest that donors support technically superior but politically unpopular social protection interventions rather than supporting those programs to which government is fully committed. They cite, for example, the potential to engage with government supported fertilizer support programs in Malawi as well as Zambia. While strengthening politically popular programs seems a sensible avenue to take, we also have to critically ask ourselves why certain interventions such as the Fertilizer Support Program in Zambia enjoy greater priority and support from the Ministry of Finance and to what extent they can be labeled as social protection.

A recent World Bank evaluation in Zambia highlights problems with the Fertiliser Support Programme ranging from leakage to incomplete, late and inefficient delivery, to badly managed and non pro-poor targeting (World Bank 2010). ${ }^{151}$ The political attractiveness of the program therefore appears not to result from the impact of the program per-se but from the political buy-in of better-off farmer recipients. How far such a program can be fine-tuned to make it more pro-poor is hard to say if its unspoken aim is to reward those who can rally party support.

Another critical question is whether existing social protection schemes can be expanded and improved. This requires a critical assessment of the extent to which existing interventions such as the in-kind support delivered through the Public Welfare Assistance Scheme (PWAS) of the MCDSS offer social protection, or employ mechanisms able to sustain a higher caseload or enjoy political support. Given the challenges that PWAS faced in the past (Johnson and Do Rosario Advirta 2002), it was probably a reasonable choice to root the SCT pilots in the old structure but to also test more efficient new modalities such as switching from in-kind to cash transfers. This made social assistance operationally easier, reduced leakage and ensured that a greater

\footnotetext{
${ }^{151}$ For a collection of paper clippings on the Fertilizer Support Programme, see: http://www.aec.msu.edu/fs2/zambia/tour/FSP_Difficulties_Press_Clipping_Nov_Dec_2008.pdf.
} 
proportion of the budget was spent on benefits rather than administration. The issues of monitoring and evaluation, probity, planning and training were also carefully addressed to build on, re-activate and improve the 'new' PWAS. Consequently, while it is important to build on existing structures, it should not limit the room for innovation or necessary modifications.

\subsubsection{Over-emphasis on just a single intervention}

Devereux, Davies et al. (2010) rightly criticize the over-emphasis on social transfers in social protection strategies. There has been a great flurry of excitement over the flexibility, the effectiveness, the range of impacts and the 'respectful' dimensions of regular cash transfers to the poor that have sometimes made these look like the only social protection tool in the bag. While it is true that social protection is more than just cash transfers, countries like Zambia need to start somewhere and prioritize interventions, given budget as well as capacity constraints. MCDSS was actually complimented at the World Bank conference on mainstreaming social protection in 2005 (Ministry of Community Development and Social Services 2005) for keeping its social protection strategy focused and for prioritizing interventions. Being visionary is important but being too ambitious also comes at a price. Whereas a broader strategy allows for broader coalition-building in society to lobby the government for social protection, it might also lead to a situation where the interventions for the better-off are eventually prioritized or scarce resources are spread too thinly.

\subsubsection{Wrong choice of target group}

Would categorically targeted SCT rather than the poverty focus of the initial pilots have solicited more political support? A number of authors discussing the political economy of targeting (Sen 1995; DeDonder and Hindriks 1998; Gelbach and Pritchett 2002; Hickey 2006) conclude that a categorical transfer as opposed to a povertytargeted transfer would not only be politically more popular but also result in greater benefits for the poor. We could thus question whether the poverty focus of the initial pilot projects (excluding the old age pension in Katete as well as the child grants which have recently been launched) could have been a cause of reduced support and interest from the population as well as the political elites.

This suggestion is not supported by the evidence from the public attitudinal surveys (see section 6.5), where we see the greatest support across all samples for targeting the extremely poor, followed by people with disability for the urban and rural sample as well as children among the students. The elderly seem to enjoy the lowest priority, in particular in urban areas. When answering this question, few respondents probably reflected on the difficulty of selecting the extremely poor. These results show, however, that there should at least neither be great opposition to the target group selected for the SCT scheme nor would the political dynamics change greatly if Zambia opted for a categorical scheme (all elderly or all children for instance). 
The political elites do not seem to be opposed to the target group of the poor and incapacitated either. The previous Minister of Finance (who was otherwise very skeptical of SCT) welcomed the idea of targeting (Habasonda 2009) in order to ration resources. The MCDSS itself has a long tradition of poverty targeting and is wary of disregarding the poverty dimension.

\subsubsection{Going conditional?}

The form of the transfer may also influence political acceptability. The attitudinal survey demonstrated that the majority among the urban respondents $(73 \%)$ and students (74\%) opted for in-kind support, that is, support which is indirectly conditioned. When respondents only had the choice of cash as a medium, $35 \%$ of the urban public and $20 \%$ of students actually decided to give no support at all (see table 7.4). Only about $1 / 6$ of respondents would vote for unconditional cash. The same preference is reflected by the qualitative interviews with different stakeholders where two thirds out of 73 interview partners who took a stance, decided in favor of conditionality. MCDSS, facing implementation difficulties regarding conditionality, and DPs familiar with the mixed international evidence, were more skeptical.

Table 7.4: Respondents' preference for unconditional, conditional or no cash transfers as a policy-maker

\begin{tabular}{|l|l|l|}
\cline { 2 - 3 } \multicolumn{1}{c|}{} & Urban & Students \\
\hline Unconditional & $19 \%$ & $12 \%$ \\
\hline Conditional & $46 \%$ & $69 \%$ \\
\hline No cash transfer & $35 \%$ & $20 \%$ \\
\hline No of observations & 392 & 244 \\
\hline
\end{tabular}

Source: Attitudinal survey with urban sample \& students

From a purely political and short-term perspective of getting initial buy-in, a CCT might increase political will. At the same time, we cannot ignore the evidence that programs such as the food security pack, school feeding or the in-kind PWAS support, all programs that should, according to this argument, resonate more with public and elite opinion, have not received high levels of domestic financial allocations.

\subsubsection{Wrong process - never-ending piloting}

The recommendation by Devereux, Davies et al. (2010) that pilots be abandoned in favor of going national is hard to judge without a counterfactual. Although the criticism that in a pilot anything can be made to work is true to an extent, not testing a new idea is highly risky in terms of potential problems and wasted resources in countries with financial and human constraints. In the public and private sectors and in every practical discipline, trying out an idea or hypothesis in a small way is regarded as 
the sensible/cautious method to find out if it works, what might be improved, where there are problems, what resources are needed or which of a set of approaches works best. The experience of Lesotho suggests that going national fast can embed problems that are avoidable by testing and proceeding more gradually (Pelham 2007). Pelham comments,

\footnotetext{
'The haste with which the Pension Bill was put together obstructed the transparency of the process and the quality of the design. The programme fails to address security issues of pension delivery, justice and potential fraudulent claims or corruption on the part of administrators; there is no clearly defined structure of administration; an inappropriate and unclear complaints process; and, as yet, no supervision or evaluation procedure to monitor the pension over time. In contrast to the extensive research that has backed the reforms for the South African pension over the years, in Lesotho, there was no assessment into the demand, use or feasibility of a pension.' (2007: 25)
}

For Kenya, piloting and a more gradual upscaling process has proven the right strategy. The Cash Transfers Programme for Orphans and Vulnerable Children began as a pilot of 500 households in 2004, and has slowly grown to approximately 86,000 by 2010 . While the objectives and program design are somewhat different, the Kenyan experience is argued to provide invaluable lessons for how to scale up in terms of capacity building for targeting, management information systems, and impact evaluation. The Mchinji Project in Malawi is similarly being gradually scaled up.

Not going national can also be a precautionary measure: although it has been argued that it is hard to identify anything that counts as fully government owned in terms of genuine responses to poverty in Zambia, it is surely more ethical to resist scaling up until there is some engagement from government. In what way would donor funding to a social protection system, virtually disowned by power brokers in government, be more promising - let alone possible - than the conservative approach of slowly increasing government's financial contributions?

It is also worth reconsidering what is an acceptable and realistic timeframe for a program to go national. When to call it a day is a difficult decision to make in a country where policy-making is highly personalized, volatile and little influenced by the public vote. Sometimes having patience and perseverance are necessary to producing policy changes.

\subsection{Conclusion}

Given the technical potential of social protection to address chronic poverty and vulnerability, observing slow progress in low-income countries as Zambia is frustrating. While also frustrating for Ministries of Social Affairs, cooperating donors and analysts, it is most serious for the poor and vulnerable themselves. Locating and strengthening the political support for issues low on the list of priorities for influential 
political players is complex, often gradual, and requires a readiness to seize the moment. This is particularly true in countries where only some policy-making or political incentives exist in official policy spaces. Here, citizens are still waiting to be able to hold their leaders accountable and conditions are absent for government to be viewed as entering into a social contract with its citizens.

Despite the seeming stagnation of Zambia in social protection, some progress has been made. Zambia's discourse and thinking on poverty have a wider remit than the productive poor. We find that over time, a greater recognition for the incapacitated poor can be noted in the discourse of political elites. There is also evidence that the greater public opinion is not necessarily opposed to a social assistance program. Zambia has now gained a much broader and deeper knowledge base as to how to refine interventions to meet the needs of the poor. Different avenues have been explored regarding how to communicate findings to policy-makers and the wider public. During the lifetime of the Fifth National Development Plan, the MCDSS has turned into a more active agent for change and has made considerable effort to garner support from influential Ministries, members of Parliament, civil society as well as the media. Even if progress is slow and strategies are not always successful, more acknowledgment should be given to the efforts of the actors who drive the process despite institutional adversities.

Donors have been influential in terms of agenda-setting in social protection in Zambia and it is important that not only government, but also the citizens it represents gain more space to further shape the social protection agenda in the future. At the same time, we need to recognize donors' crucial contributions to keeping poverty and social protection on the agenda and supporting the gradual integration of social protection into various policy documents and formal policy channels. Donors' concern for the poor also allows governments preoccupied with generating growth, to focus what are often limited resources on this important task.

In terms of politically desirable design and implementation features, we have noted the importance of building on existing structures while not ignoring innovations. This requires balancing vision with realism when it comes to the number and choice of social protection interventions. While the target group seems to be politically acceptable, conditionality could make the SCT program more attractive. It is however unlikely that it would greatly change the political dynamics behind SCT and social protection in Zambia. With respect to piloting, we suggest that given the choice between a slow and gradual process through pilots or waiting - possibly in vain - for a visionary leader who launches a national program, the pilot might be the lesser evil and can represent a first step towards a national program.

Coming back to our initial questions, this investigation has highlighted that although many recommendations from previous studies were adopted and there was a strong commitment to engage in an evidence-based policy process, progress has been 
painfully slow. Simultaneously, this chapter has demonstrated the complexities of the political maneuvering around social protection. Recommendations for strengthening political support for social protection are badly needed but must be attuned to the systemic features and political realities in Zambia, and must also prioritize the majority who are still trapped below the poverty line. Last but not least, more realistic timeframes and measurements should be employed to gauge success for complex political processes in low-income countries, while unfavorable comparisons with rapid advances in countries like South Africa or Ethiopia should be avoided. 


\section{CHAPTER 8: Conclusion}

Many academics and policy-makers in low-income countries have controversially debated the appropriateness of poverty-targeting (ex-ante conditionality) as well as behavioral requirements (ex-post conditionality) in SCT programs. Rather than finding a straight answer to the question of whether conditionality works, this dissertation has studied the mechanisms at play and identified factors that determine in what way conditionality influences the effectiveness of SCT programs. It therefore follows the spirit of the second generation of evaluations in social protection that has moved from demonstrating a discernible impact of cash towards studying more intensively the determinants of positive and negative change. The dissertation not only makes a timely and relevant contribution to an ongoing policy-debate and helps to advance the academic agenda in this area, but it has also made some methodological advances. Inspired by experimental economics, it draws on economic experiments to unpack the phenomena of targeting and conditionality. The uniquely designed experiments have brought new insights into the debate and proven useful in triangulating additional information collected through surveys, secondary data and stakeholder interviews.

\subsection{Main findings}

Chapter 2 demonstrates that conditionality cannot only take on different forms but that it also influences the effectiveness of SCT programs through various channels. It has therefore laid a conceptual foundation for future debates and research on the effectiveness of conditionality. While conditionality can be justified on the grounds that it optimizes household behavior, empowers households, raises political acceptance levels as well as ensures better targeting outcomes, the chapter has also demonstrated that there are many hurdles to realizing these gains and that there a number of inefficiencies that can undo any of those effects. Not only can conditionality lead to adverse effects in unconditioned areas and prove demotivating but the way conditionality is designed and implemented can prove costly for beneficiaries, the administration and politicians. By providing a recap of the evidence available, the chapter contributes to fostering an evidence rather than an ideology-based debate around conditionality. The evidence gaps highlighted then serve to motivate the subsequent empirical chapters.

The finding in chapter 3 that beneficiaries, voters and policy-makers alike are all very supportive of the idea of conditionality challenges common assumptions held by social protection experts, many of whom have argued that conditions are irksome and patronizing. Conditionality proves not only to be a politically powerful tool but also to empower beneficiaries by offering them the necessary guidance and even a nascent sense of a contract or entitlement. The empowerment effects have been confirmed by 
survey as well as experimental evidence and we can therefore be sure that this effect is not just coincidental. This contradicts earlier studies that have stressed the patronizing effect of conditionality and highlights the importance of eliciting views on new programmatic features of those who are directly concerned. As conditionality preferences and choices are not static but change for instance in response to community dynamics, exposure to SCT and greater information about beneficiary households and their behavior, it remains important to observe conditionality preferences over time.

The important lesson from chapter $\mathbf{4}$ is that the design and implementation of conditionality can have a substantive effect on the effectiveness of SCT programs. While inefficiencies might be less of a concern in middle-income countries where costs can be kept at manageable levels and the standard package of human development conditions in the area of health and education prove meaningful, the stakes look different in a low-income country context. The inefficiencies at design and implementation level that this chapter identifies within the Zambia context reveal that conditionality particularly risks excluding households from the program, foregoing poverty reduction effects, and overburdening the administration, leading in turn to significant costs, incredibility and mismanagement of conditionality and other activities. Consequently, even if conditionality has the potential to change households' behavior to their own and society's advantage and if conditionality can attract additional political support, the inefficiencies can easily turn conditionality into a suboptimal choice.

Chapter 5 holds some thought-provoking findings for those who have mainly characterized CBT as a vehicle for favoritism, elite-capture and community divisions in societies which prefer to share benefits equally. This chapter has illustrated that decentralized targeting mechanisms are not inherently flawed and can contribute to better equity outcomes of SCT programs. In our case study of Zambia, community members definitely pursued poverty motives when allocating limited funds; neither favoritism to family members, members' concerns about social capital nor preferences for egalitarianism prevailed to the extent suggested by the literature. Egalitarianism surfaced primarily as a pragmatic choice rather than an innate preference, either caused by peer pressure, lack of information and exposure to targeting, and possibly by community members' aversion to making mistakes. CBT has the greatest chances of success in communities where cohesion, trust and information levels are high, where knowledgeable community members are involved, where peer pressure is dampened and where targeting rules curb individuals' self-interests.

Chapter 6 demonstrates that targeting is a viable alternative also from a political economy perspective. Studying targeting preferences of different socio-economic groups in Zambia, chapter 6 illustrates that going universal with SCT does not automatically translate into higher political acceptance and future effectiveness of SCT programs. The chapter raises doubts as to whether the traditional assumptions behind the political economy models of targeting - a decisive middle class, budget endogeneity 
and self-interested voters - apply in a low-income context where the median voter does not necessarily drive policy outcomes, where budgets might be exogenously given and where voters are often more altruistic than portrayed. Even if these assumptions were to hold, there would be a range of other crucial factors to consider when deciding on redistributive schemes. Along with reviewing attitudes towards the poor and existing norms regarding social justice, the role of cohesion, procedural justice and effectiveness as well as path dependency should also be studied more closely when deciding which redistributive scheme enjoys the greatest political potential.

Chapter 7 cautions the reader to avoid making quick inferences about the political sustainability of a program on the basis of conditionality and targeting choices in a particular country. While there is definitely a link between conditionality and targeting and the political economy of a SCT program, the magnitude of this effect partly depends on other factors. Conditionality is not always sufficient as a trigger to change the political dynamics behind a SCT program. Institutional factors, attitudes towards the poor, the existing knowledge base, the engagement of different stakeholders and other design features might prove even more decisive in garnering political support. The case study of Zambia has illustrated the complexities of political maneuvering around social protection and has called for more realistic timeframes and measurements when gauging success for complex political processes in low-income countries.

\subsection{Policy recommendations}

Given the negative implications of a wrongly conceptualized and badly designed and implemented conditionality on beneficiaries, the population, the administration and politicians, this dissertation intended to better equip policy-makers with conceptual clarity and more evidence allowing them to take better-informed decisions in the area of ex-ante and ex-post conditionality.

The first important insight for policy-makers is that, even without any prior impact evaluation that studies how households respond to conditionality, they can already gauge the potential of conditionality for their particular country context. They can assess the need and scope for improvement in conditioned areas as well as potential negative implications of conditionality by carefully studying the constraints to education, health and any other conditioned service. Conditionality should only be imposed once it is clear that children's access to education and health is mainly constrained by their own or their parents' attitude and behavior and that alternative means would neither be more cost-effective nor politically acceptable. If conditionality is administratively unfeasible or produces too many other unintended consequences, policy-makers would be advised to go for unconditional transfers. If this proves politically challenging, they can try to influence those factors that obviate the need for 
conditionality such as better information campaigns and transparent processes at community level or more sensitization on the evidence about the use and impact of cash transfers.

Another crucial insight is that, once conditionality has been agreed, policy-makers should ensure that it is designed in a way that still incentivizes rather than discourages households and that it does not exclude too many households from participating in the program by either raising unrealistic expectations or ignoring the supply-side constraints. Time should be taken to prepare the administration, reach inter-ministerial agreements on the management of conditionality and introduce any technological tools that facilitate the management and sharing of data. In particular when conditionality is motivated by political economy considerations, it would be advisable for policymakers in low-income countries to design conditionality in a way that it remains an official requirement but is not strictly enforced right from the beginning. If households are properly oriented on the program objectives and expectations of the program, if they display the desired behavior and policy-makers and the broader public are satisfied, there might not even be a need for rigorous enforcement mechanisms over time.

A further key insight is that even though conditionality appears to be a powerful design-tool to convince social-cash-transfer-skeptics, policy-makers also need to factor in the possible negative consequences of conditionality when considering the political economy. Exclusion effects, corruption, implementation constraints and no change in the desired behavior might backfire and even reduce further interest in SCT programs. This reminds us of the importance of a holistic pre-assessment of the role of conditionality and a careful design before conditionality is introduced. It is therefore important to better sensitize policy-makers on the possible inefficiencies of conditionality and the measures that need to be put in place to minimize them.

Regarding targeting, the dissertation similarly provides some useful insights for policymakers on the decentralization of targeting as well as on whether to target cash transfers to the poor in the first place. While there are still many other reasons why decentralized targeting might not be the best choice out of a broader menu of targeting alternatives, policy-makers should not be discouraged from decentralizing targeting on the grounds that it automatically fosters nepotism, contradicts an innate culture of egalitarianism and is flawed by elite-capture. If they decide to decentralize targeting, they should ensure that community committees, also comprising those who command respect in their communities, are in place and well trained, that opportunities for individuals to benefit themselves are limited and that information about potential beneficiaries is available. It would also be advisable to invest time and resources in explaining in detail the targeting mechanism and program objectives to the community. This could prevent any distrust in the mechanism, the system or in potential beneficiaries, and in this way promote the progressiveness of (future) targeting outcomes. 
An additional important insight is that the choice between universal or targeted transfers is certainly politically motivated. Policy-makers would, however, be illadvised to automatically opt for a universal scheme for political reasons without studying in more depth the political and tax regime, social norms and attitudes towards the poor, social cohesion as well as distributional justice perceptions. Targeting might in fact be the optimal choice for policy-makers in low-income countries that are characterized by limited democratic accountability, a nearly fixed government budget and a rather homogeneous society, where voters are altruistically motivated and believe in the collective responsibility of protecting the poor while still believing in the principles of subsidiarity.

Last but not least, it is also vital for policy-makers to see that conditionality and targeting are not the only levers for increasing political acceptance behind SCT. There are many more factors that determine the likelihood of a SCT taking root. More contextualized institutional as well as stakeholder analysis is required that assesses the institutional constraints and identifies drivers of change as well as drivers of stagnation in this area. This will also help to set more realistic benchmarks for evaluating when a SCT scheme or social protection in general can be considered a success.

The dissertation has thus shown that while policy-makers have to eventually find an answer to the question of whether they should condition or not, academics would best support this decision-making process in continuing their research on distilling conditions under which social cash transfer programs should be conditioned ex-ante as well as ex-post. 


\section{Bibliography}

3ie (2010). Impact Evaluation 01. Conditional cash transfer programmes: A magic bullet to improve people's health and education? New Delhi.

Abdul Latif Jameel Poverty Action Lab. (2010). "Policy Lessons with respect to Student Attendance." Retrieved 14.07.2010, from http://www.povertyactionlab.org/policy-lessons/education/student-attendance.

Aber, L. and L. Rawlings (2011). North-South Knowledge Sharing on Incentive-based Conditional Cash Transfer Programs. Social Protection Discussion Paper No. 1101. Washington, DC, World Bank.

Ablo, E. Y., Z. Vantzos, et al. (2004). Republic of Zambia. 1999 CAS Completion Report, The World Bank.

Acemoglu, D. and J. Angrist (1999). How Large are the Social Returns to Education? Evidence from Compulsory Schooling Laws, National Bureau of Economic Research, Inc, NBER Working Papers: 7444.

Adato, M., B. de la Brière, et al. (2002). The impact of Progresa on women's status and intrahousehold relations. Washington, USA, International Food Policy Research Institute.

Adato, M. and L. Haddad (2002). "Targeting Poverty through Community-Based public Works Programmes: Experience from South Africa." Journal of Development Studies 38(3): 1.

Adato, M. and J. Hoddinott (2007). Conditional cash transfer programs: A "magic bullet" for reducing poverty? 2020 vision briefs, International Food Policy Research Institute

Adato, M. and T. Roopnaraine (2004). A Social Analysis of the Red de Protección Social (RPS) in Nicaragua, International Food Policy Research Institute.

Akresh, R., D. De Walque, et al. (2012). Alternative Cash Transfer Delivery Mechanisms. Impacts on Routine Preventative Health Clinic Visits in Burkina Faso. Policy Research Working Paper 5958. Washington D.C., World Bank.

Alatas, V., A. Banerjee, et al. (2010). Targeting the Poor: Evidence from a Field Experiment in Indonesia. NBER Working Paper No. 15980. NBER.

Alderman, H. (2001). "Multi-Tier Targeting of Social Assistance: The Role of Intergovernmental Transfers." The World Bank Economic Review 15(1): 33 53. 
Alesina, A. and N. Fuchs-Schündeln (2007). "Good-Bye Lenin (or Not?): The Effect of Communism on People's Preferences." The American Economic Review 97(4): 1507-1528.

Alesina, A. and E. La Ferrara (2005). "Preferences for redistribution in the land of opportunities." Journal of Public Economics 89(5-6): 897-931.

Alkire, S., J. M. Roche, et al. (2011). "Zambia Country Briefing. Oxford Poverty \& Human Development Initiative (OPHI) Multidimensional Poverty Index Country Briefing Series."

Alvarez, C., F. Devoto, et al. (2008). "Why Do Beneficiaries Leave the Safety Net in Mexico? A Study of the Effects of Conditionality on Dropouts." World Development 36(4): 641-658.

Arnold, C., T. Conway, et al. (2011). Cash Transfers Evidence Paper. Policy Division 2011, Department for International Development.

Atkinson, A. B. (1995). On Targeting Social Security: Theory and Western Experience with Family Benefits. Public Spending and the Poor. D. Van de Walle and K. Nead. Baltimore, John Hopkins University Press.

Atkinson, A. B. (1998). Poverty in Europe. Oxford, Blackwell Publishers.

Attanasio, O. and K. Kaufmann (2009). Educational Choices, Subjective Expectations, and Credit Constraints. NBER Working Paper No. 15087.

Baird, S., J. de Hoop, et al. (2011). Income shocks and adolescent mental health, The World Bank, Policy Research Working Paper Series: 5644.

Baird, S., C. McIntosh, et al. (2011). "Cash or Condition? Evidence from a Cash Transfer Experiment. ." Forthcoming in: The Quarterly Journal of Economics.

Barrientos, A. (2011). "Conditions in antipoverty programmes." Journal of Poverty and Social Justice 19(1): 15-26.

Barrientos, A. and J. de Jong (2004). Child Poverty and Cash Transfers CHIP Report No. 4. Childhood Poverty Research and Policy Centre.

Barrientos, A. and J. de Jong (2006). "Reducing Child Poverty with Cash Transfers: A Sure Thing?" Development Policy Review 24(5): 537-552.

Barrientos, A., S. Hickey, et al. (2005). Report of Study on Drivers of Change for a National Social Protection Scheme in Zambia, DfID. 
Barrientos, A. and D. Neff (2011). "Attitudes to Chronic Poverty in the 'Global Village'." Social Indicators Research 100(1): 101-114.

Bastagli, F. (2008). "Conditionality in Public Policy Targeted to the Poor: Promoting Resilience?" Social Policy \& Society 8(1): 127-140.

Behrman, J. R. and J. C. Knowles (1999). "Household Income and Child Schooling in Vietnam." World Bank Economic Review 13(2): 211-256.

Belzil, C. and M. Leonardi (2007). "Can risk aversion explain schooling attainments? Evidence from Italy." Labour Economics 14: 957-970.

Benabou, R. and J. Tirole (2003). "Intrinsic and Extrinsic Motivation." Review of Economic Studies 70(3): 489-520.

Bergeron, G., S. S. Morris, et al. (1998). "How Reliable are Group Informant Ratings? A Test of Food Security Ratings in Honduras." World Development 26(10): 1893-1902.

Besley, T. (1990). "Means Testing Versus Universal Provision in Poverty Alleviation Programmes." Economica 57(225): 119-129.

Besley, T. and R. Kanbur (1990). The Principles of Targeting', Poverty, Research and External Affairs Working Paper. WPS 385. Washington DC, The World Bank.

Bils, M., P. J. Klenow, et al. (2004). Does Schooling Cause Growth? Recent developments in growth theory. Volume 1. Empirical patterns, Elgar Reference Collection. International Library of Critical Writings in Economics, vol. 179. Cheltenham, U.K. and Northampton, Mass.: Elgar: 363-386.

Binswanger, H. P. (1980). "Attitudes toward Risk: Experimental Measurement In Rural India." American Journal of Agricultural Economics 62(3): 395.

Blackorby, C. and D. Donaldson (1988). "Cash versus Kind, Self-Selection, and Efficient Transfers." The American Economic Review 78(4): 691-700.

Boarini, R. and C. Le Clainche (2009). "Social preferences for public intervention: An empirical investigation based on French data." Journal of Socio-Economics 38(1): 115-128.

Bobonis, G. and F. Finan (2009). "Neighborhood Peer Effects in Secondary School Enrollment Decisions." Review of Economics and Statistics 91(4): 697-716.

Boone, C. (1990). "The Making of a Rentier Class: Wealth Accumulation and Political Control in Senegal." Journal of Development Studies 26: 425-449. 
Bougheas, S., I. Dasgupta, et al. (2007). "Tough love or unconditional charity?" Oxford Economic Papers(59): 561-582.

Bourguignon, F., F. H. G. Ferreira, et al. (2002). Ex-Ante Evaluation of Conditional Cash Transfer Programs: The Case of Bolsa Escola. Policy Research Working Paper Series: 2916, The World Bank.

Bowles, S. (2008). "Policies Designed for Self-Interested Citizens May Undermine "The Moral Sentiments": Evidence from Economic Experiments." Science 320(5883): 1605-1609.

Bradshaw, S. (2008). "From Structural Adjustment to Social Adjustment. A Gendered Analysis of Conditional Cash Transfer Programmes in Mexico and Nicaragua." Global Social Policy 8(2): 188-207.

Caeyers, B. and S. Dercon (2008). Political Connections and Social Networks in Targeted Transfer Programmes: Evidence from Rural Ethiopia. CSAE Working Paper Series No. 313. Oxford, Centre for the Study of African Economies.

Caldes, N., D. Coady, et al. (2006). "The Cost of Poverty Alleviation Transfer Programs: A Comparative Analysis of Three Programs in Latin America." World Development 34(5): 818-837.

Cameron, J., K. M. Banko, et al. (2001). "Pervasive negative effects of rewards on intrinsic motivation: The myth continues." The Behavior Analyst 24(1): 1-44.

Cappelen, A. W., A. D. Hole, et al. (2007). "The Pluralism of Fairness Ideals: An Experimental Approach." American Economic Review 97(3): 818-827.

Cappelen, A. W., K. O. Moene, et al. (2011). "Needs vs entitlements - an international fairness experiment. Updated version of Tinbergen Institute Discussion Paper, TI 2008-098/3." Forthcoming in: Journal of the European Economic Association.

Cardenas, J. C. and J. Carpenter (2008). "Behavioural Development Economics: Lessons from Field Labs in the Developing World." Journal of Development Studies 44(3): 311-338.

Carletto, C. (2001). "Using Group Ratings to Assess Household Food Security: Empirical Evidence from Southern Africa." Development Southern Africa 18(5): 541-552.

Case, A. (2004). Does Money Protect Health Status? Evidence from South African Pensions. Perspectives on the Economics of Aging. D. A. Wise, University of Chicago Press. 
Castelán, C. R. (2010). Participation of the Poorest and Distributional Effects of Conditional Cash Transfer Programs. Job Market Paper, Cornell University.

Center for Health Research University of Indonesia (2010). PKH Spot Check. Quantitative and Qualitative Assessments to Monitor Household Conditional Cash Transfers Operations. Jakarta, World Bank.

Central Intelligence Agency (2011). The World Factbook. Zambia. USA.

Chininga, B. (2005). "Targeting Safety Net Interventions in Developing Countries: Some Insights from a Qualitative Simulation Study from Malawi." European Journal of Development Research 17(4): 706-734.

Coady, D., M. Grosh, et al. (2004). Targeting of Transfers in Developing Countries. Review of Lessons and Experience. Washington, The World Bank.

Coady, D., R. Perez, et al. (2005). Evaluating the Cost of Poverty Alleviation Transfer Programs. FCND Discussion Paper 199. Washington, International Food Policy Research Institute.

Coate, S. and S. Morris (1995). "On the Form of Transfers to Special Interests." The Journal of Political Economy 103(6): 1210-1235.

Cohen, E. and R. Franco (2006). Los Programas de Transferencias con Corresponsabilidad en América Latina: Similitudes y Diferencias. Transferencias con Corresponsabilidad: Una Mirada Latinoamericana. E. Cohen and R. Franco. Mexico City, SEDESOL: 85-136.

Conning, J. and M. Kevane (2002). "Community-Based Targeting Mechanisms for Social Safety Nets: A Critical Review." World Development 30(3): 375-394.

Corrigan, P. W. (1997). "Behavior Therapy Empowers Persons with Severe Mental Illness." Behavior Modification 21(1): 45-61.

CSO (2008). Living Conditions Monitoring Survey Report 2006. Lusaka, Government of Zambia.

CSO (2011a). Labour Force Survey 2008. Lusaka, Government of Zambia.

CSO (2011b). Population Projections Report. Lusaka, Government of Zambia.

CSO, MOH, et al. (2009). Zambia Demographic and Health Survey 2007. CSO and M. I. Inc. Calverton, Maryland, USA.

Das, J., Q.-T. Do, et al. (2005). "Reassessing Conditional Cash Transfer Programs." World Bank Research Observer 20(1): 57-80. 
Davis, B., S. Handa, et al. (2002). Conditionality and the impact of program design on household welfare: Comparing two diverse cash transfer programs in rural Mexico. ESA Working Paper No. 02-10, Agricultural and Development Economics Division. The Food and Agriculture Organization of the United Nations.

de Brauw, A. and J. Hoddinott (2011). "Must Conditional Cash Transfer Programs Be Conditioned to Be Effective? The Impact of Conditioning Transfers on School Enrollment in Mexico." Journal of Development Economics 96(2): 359-370.

de Britto Feitosa, T. (2004). Conditional Cash Transfers: Why have they become so prominent in recent poverty reduction strategies in Latin America. Working Paper Series No. 390, Institute of Social Studies.

de Carvalho Filho, I. E. (2008). Household Income as a Determinant of Child Labor and School Enrollment in Brazil: Evidence from a Social Security Reform. IMF Working Paper WP/08/241. Paris, IMF.

De Donder, P. and J. Hindriks (1998). "The political economy of targeting." Public Choice 95: 177-200.

de Janvry, A., F. Finan, et al. (2009). Local Electoral Incentives and Decentralized Program Performance, University of California at Berkeley.

de Janvry, A. and E. Sadoulet (2005). Conditional cash transfer programs for child human capital development: Lessons derived from experience in Mexico and Brazil. GRADE 25th anniversary Conference, "Investigación, Politicas y Desarrollo". Lima, Peru.

de Janvry, A. and E. Sadoulet (2006a). "Making Conditional Cash Transfer Programs More Efficient: Designing for Maximum Effect of the Conditionality." World Bank Economic Review 20(1): 1-29.

de Janvry, A. and E. Sadoulet (2006b). When to use a CCT versus a CT approach? Third International Conference on Conditional Cash Transfers. Istanbul, Turkey, The World Bank.

de Janvry, A., E. Sadoulet, et al. (2006c). Uninsured risk and asset protection: Can conditional cash transfer programs serve as safety nets? Social Protection Discussion Paper No. 0604. Washington, USA, The World Bank.

de la Brière, B. and L. B. Rawlings (2006). Examining Conditional Cash Transfer Programs: A Role for Increased Social Inclusion? Social Protection Discussion Paper No. 0603, The World Bank. 
Deci, E. L., R. Koestner, et al. (1999). "A meta-analytic review of experiments examining the effects of extrinsic rewards on intrinsic motivation." Psychological Bulletin 125(6): 627-668.

DeDonder, P. and J. Hindriks (1998). "The political economy of targeting." Public Choice 95(1-2): 177-200.

Devereux, S. (2001). Social pensions in Namibia and South Africa. Brighton, Institute of Development Studies.

Devereux, S., M. Davies, et al. (2010). Social Protection in Africa: Where Next?, IDS, ODI, UEA-DEV, RHVP.

Devereux, S. and R. Sabates-Wheeler (2004). Transformative social protection. IDS Working Paper 232. Brighton, Institute of Development Studies.

Devereux, S. and P. White (2010). "Social Protection in Africa: Evidence, Politics, and Rights." Poverty \& Public Policy 2(3).

Devereux, S. and D. Wood (2008). Zambia's social cash transfer pilot schemes: A review report for the Technical Working Group on Social Assistance.

Dohmen, T., A. Falk, et al. (2010). "Are Risk Aversion and Impatience Related to Cognitive Ability?" American Economic Review 100(3): 1238-1260.

Duncan, A., H. Macmillan, et al. (2003). Zambia Drivers of pro-poor change: an overview. Oxford Policy Management. Oxford.

Ellis, F. (2008). We Are All Poor Here: Economic Difference, Social Divisiveness, and Targeting Cash Transfer in Sub-Saharan Africa. Social Protection for the Poorest in Africa: Learning from Experience. C. P. R. Center. Uganda.

EPRI (2008). Quantitative Analysis of the Impact of the Child Support Grant, UNICEF.

Erdmann, G. and U. Engel (2006). Neopatrimonialism Revisited - Beyond a Catch-All Concept. GIGA Working Papers No. 16. German Institute of Global and Area Studies.

European Union (2010). Social Protection for Inclusive Development. A new perspective in EU co-operation with Africa. Overview. European Report on Development.

Ezemenari, K., N. Chaudhury, et al. (2002). Gender and Risk in the Design of Social Protection Interventions. Social Protection Discussion Paper Series. Washington, The World Bank. 
Falk, A. and M. Kosfeld (2006). "The Hidden Costs of Control." The American Economic Review 96(5): 1611-1630.

Fehr, E. and S. Gächter (2001). "Do Incentive Contracts Crowd Out Voluntary Cooperation?" SSRN eLibrary.

Fiszbein, A. and N. Schady (2009). Conditional Cash Transfers. Reducing Present and Future Poverty. A World Bank Policy Research Report. Washington, The World Bank.

Fong, C. (2001). "Social preferences, self-interest, and the demand for redistribution." Journal of Public Economics 82(2): 225-246.

Frederick, S., G. Loewenstein, et al. (2002). "Time Discounting and Time Preference: A Critical Review." Journal of Economic Literature 40(2): 351-401.

Freeland, N. (2007). "Superfluous, Pernicious, Atrocious and Abominable? The Case Against Conditional Cash Transfers " IDS Bulletin 38(3): 75-78.

Frey, B. S. (2008). Motivation Crowding Theory--A New Approach to Behaviour. Behavioural Economics and Public Policy: Roundtable Proceedings: Melbourne, 8-9 August 2007, Melbourne: Australian Productivity Commission: 37-54.

Fryer, R. G. (2011). "Financial Incentives and Student Achievement: Evidence from Randomized Trials." The Quarterly Journal of Economics 126(4): 1755-1798.

Galasso, E. and M. Ravallion (1999). Distributional Outcomes of a Decentralized Welfare Program. Policy Research Working Paper Series: 2316. Washington DC, The World Bank

Garcia, M. and C. Moore (2010). Cash Transfer Programs: The Emerging Safety Net in Sub-Saharan Africa. Washington, Africa Human Development, The World Bank.

Gelbach, J. B. and L. Pritchett (2002). "Is more for the poor less for the poor? The politics of means-tested targeting." Topics in Economic Analysis \& Policy 2(1).

Gentilini, U. and S. W. Omamo (2011). "Social protection 2.0: Exploring issues, evidence and debates in a globalizing world." Food Policy 36(3): 329-340.

Gilligan, D. O., A. R. Hoddinott, et al. (2005). Assessing the Effectiveness of Community-Based Targeting of Emergency Food Aid in Bangladesh, Ethiopia, and Malawi. Linking Research and Action. Strengthening Food Assistance and Food Policy Research. IPFRI \& WFP. 
Gitter, S. R. and B. L. Barham (2008). "Women's Power, Conditional Cash Transfers, and Schooling in Nicaragua." World Bank Economic Review 22(2): 271-290.

Glaeser, E. L. (2005). Paternalism and Psychology. Working Paper 11789. NBER Working Papers Series. Cambridge, National Bureau of Economic Research.

Gómez, C. (2011). Scoping Report for the Design of 3ie's Social Protection Window, International Initiative for Impact Evaluation, Department for International Development.

Government of the Republic of Zambia (2005). Social Protection Strategy for Zambia (draft). Lusaka.

Graham, C. (2002). Public Attitudes Matter: A Conceptual Frame for Accounting for Political Economy in Safety Nets and Social Assistance Policies. Social Protection Discussion Paper, The World Bank.

Green, L., J. Myerson, et al. (1996). "Temporal discounting in choice between delayed rewards: The role of age and income." Psychology and Aging 11(1): 79-84.

Grindle, M. S. and J. W. Thomas (1991). Public Choices and Policy Change. The Political Economy of Reform in Developing Countries. London, The John Hopkins University Press.

Grosh, M., C. del Ninno, et al. (2008). For Protection \& Promotion. The Design and Implementation of Effective Safety Nets. Washington, The World Bank.

Gugerty, M. K. and M. Kremer (2000). Does Development Assistance Help Build Social Capital? . Social Capital Initiative Working Paper No. 20. The World Bank. Washington DC.

Habasonda, L. M. (2009). Political Economy of Cash Transfers in Zambia. A report prepared for ODI. ODI. London.

Haddad, L., J. Hoddinott, et al. (1997). Intrahousehold resource allocation in developing countries: Models, methods, and policy, Baltimore and London: Johns Hopkins University Press for the International Food Policy Research Institute.

Haenn, N. (1999). "Community formation in frontier Mexico: accepting and rejecting new migrants." Human Organization 58(1): 36-43.

Hammitt, J. and K. Haninger (2010). "Valuing fatal risks to children and adults: Effects of disease, latency, and risk aversion." Journal of Risk and Uncertainty 40(1): 57-83. 
Handa, S. (2000). Poverty, Inequality and "Spill-Over" in Mexico's Education, Health, and Nutrition Program. Washington, DC, International Food Policy Research Institute.

Handa, S. and B. Davis (2006). The Experience of Conditional Cash Transfers in Latin America and the Caribbean. ESA Working Paper No. 06-07, Agricultural and Development Economics Division. The Food and Agriculture Organization of the United Nations.

Handa, S., C. Huang, et al. (2010). Targeting effectiveness of Social Cash Transfer Programs in Three Africa Countries. The Transfer Project Working Paper 1.

Handa, S., A. Peterman, et al. (2009). "Opening Up Pandora's Box: The Effect of Gender Targeting and Conditionality on Household Spending Behavior in Mexico's Progresa Program." World Development 37(6): 1129 - 1142.

Harrison, G. W. and J. A. List (2004). "Field Experiments." Journal of Economic Literature 42(4): 1009-1055.

Hawkins, R. and C. Mugala (2008). Fiduciary Assessment of Social Cash Transfers in Zambia. C. I. Development.

Heckman, J. (2000). "Policies to Foster Human Capital." Research in Economics 54: 356.

Heinrich, C. J. (2007). "Demand and Supply-Side Determinants of Conditional Cash Transfer Program Effectiveness." World Development 35(1): 121-143.

Hichaambwa, M. (2009). Analysis of the Social Cash Transfer Expenditure and Market PANEL Survey Data in Zambia. Lusaka.

Hickey, S. (2006). The Politics of What Works in Reducing Chronic Poverty. A synthesis report for the Ministry of Foreign Affairs, The Netherlands. $\underline{\text { CPRC }}$ Working Paper 91, Chronic Poverty Research Centre.

Hickey, S. (2007). Conceptualising the Politics of Social Protection in Africa. Brooks World Poverty Institute Working Paper.

Hirschmann, A. O. (1970). Exit, Voice and Loyalty: Responses to Decline in Firms, Organisations and States, Harvard University Press.

Hobley, M. and B. R. Paudyal (2008). Study of Income Generating Activities in Kapilvastu and Ramechhap Districts, Nepal.

Hoddinott, J. and E. Skoufias (2004). "The Impact of PROGRESA on Food Consumption." Economic Development and Cultural Change(53): 37-61. 
Hoffman, E., K. McCabe, et al. (1994). "Preferences, Property Rights and Anonymity in Bargaining Games." Games and Economic Behavior 7(3): 346-380.

IMF (2010). Zambia: 2009 Article IV consultation. Washington DC, International Monetary Fund.

Inter-Parliamentary Union (2009). Parliament's Role in the Develoment Agenda: Two Case Studies, Inter-Parliamentary Union.

International Labour Office (2008a). Zambia: Social Protection Expenditure and Performance Review and Social Budget. ILO. Geneva.

International Labour Office (2008b). Can low-income countries afford basic social security? Social security policy briefings, Paper 3. Geneva, ILO.

Jensen, R. (2010). "The (Perceived) Returns to Education and the Demand for Schooling*." Quarterly Journal of Economics 125(2): 515-548.

Johnson, D. and M. Do Rosario Advirta (2002). Mid-term review of the Project "Public Welfare Assistance Scheme". Lusaka.

Kagel, J. H. and Alvin E. Roth eds (1995). The handbook of experimental economics, Princeton: Princeton University Press.

Kakwani, N., F. V. Soares, et al. (2005). Conditional Cash Transfers in African Countries. Working Paper Brasilia, Brazil, International Poverty Centre, UNDP.

Kane, R. L., P. E. Johnson, et al. (2004). "A structured review of the effect of economic incentives on consumers' preventive behavior." American Journal of Preventive Medicine 27(4): 327-352.

Kidd, S. and R. Calder (2011). Conditional cash transfer programmes: their relevance for Nepal, DFID.

Kimetrica (2010). Spot Check Report for February - April 2010. External Process Monitoring System for the CT OVC Programme in Kenya. Nairobi.

Köhler, G., M. Calì, et al. (2009). "Rethinking Poverty and Social Exclusion Responses in Post-Conflict Nepal: Child-Sensitive Social Protection." Children, Youth and Environments 19(2): 229-249.

Korpi, W. and J. Palme (2004). Robin Hood, St Matthew, or simple egalitarianism? Strategies of equality in welfare states. A Handbook of Comparative Social Policy. P. Kennett. Cheltenham, UK and Northampton, MA, Edward Elgar. 
Kremer, M., E. Miguel, et al. (2009). "Incentives to learn." The Review of Economics and Statistics 91(3): 437-456.

Künnemann, R. and R. Leonhard (2008). A human rights view of social cash transfers for achieving the millennium development goals. Stuttgart, Brot für die Welt, Evangelischer Entwicklungsdienst.

Kuziemko, I., R. W. Buell, et al. (2011). "Last-Place Aversion": Evidence and Redistributive Implications. NBER Working Paper 17234. Cambridge, National Bureau of Economic Research.

Laibson, D. (1998). "Life-Cycle Consumption and Hyperbolic Discount Functions." European Economic Review 42(3-5): 861-871.

Lalive, R. and M. A. Cattaneo (2009). "Social Interactions and Schooling Decisions." Review of Economics and Statistics 91(3): 457-477.

Langhan, S., G. Mackay, et al. (2008). Distribution mechanism scoping study. Qindiem and exactconsult.

Levy, S. and P. Palale (2007). Zambia: Governance, Political Economy and Development Strategy. The World Bank. Washington DC.

Lewis, P. M. (1994). "Economic statism, private capital, and the dilemmas of accumulation in Nigeria." World Development 22: 437-451.

Lindert, K. and V. Vincensini (2009). Bolsa Família in the Spotlight of Public Opinion: Some Observations and Theories on the Political Economy of CCTs. Presentation at the Safety Nets Core Course. The World Bank. Washington.

Lindström, C. (2008). The Politics of Institutionalising Social Protection in Zambia, University of Sussex.

Lipton, M. (1968). "The theory of the optimising peasant." Journal of Development Studies 4: 327-351.

Loewenstein, G., C. F. Camerer, et al. (2004). Out of Control: Visceral Influences on Behavior. Advances in behavioral economics, Roundtable Series in Behavioral Economics. New York: Russell Sage Foundation; Princeton and Oxford: Princeton University Press: 689-723.

Ludwig, J., J. R. Kling, et al. (2011). "Mechanism Experiments and Policy Evaluations." Journal of Economic Perspectives 25(3): 17-38. 
Lund, F., M. Noble, et al. (2008). Is there a rationale for conditional cash transfers for children in South Africa. Working Paper No 53. Durban, South Africa, School of Development Studies, University of Kwazulu-Natal.

Luttmer, E. F. P. (2001). "Group Loyalty and the Taste for Redistribution." Journal of Political Economy 109(3): 500-528.

Luttrell, C. and C. Moser (2004). Gender and Social Protection. DfID. London.

Martinelli, C. and S. W. Parker (2003). "Should Transfers To Poor Families Be Conditional On School Attendance? A Household Bargaining Perspective." International Economic Review 44(2): 523-544.

Mbandama, N. and M. Musonda (2007). Evaluation Report of the Kalomo Pilot Incentive Scheme. MCDSS and GTZ. Kalomo.

McCord, A. (2009). Cash transfers and political economy in sub-Saharan Africa. Project Briefing No 31. ODI. London.

Medlin, C. and D. de Walque (2008). Potential applications of conditional cash transfers for prevention of sexually transmitted infections and HIV in SubSaharan Africa. Policy Research Working Paper Series: 4673. Washington DC, The World Bank.

Micklewright, J. and S. Marnie (2005). "Targeting Social Assistance in a Transition Economy: The Mahallas in Uzbekistan." Social Policy \& Administration 39(4): 431-447.

Miguel, E. and M. Kremer (2004). "Worms: Identifying Impacts on Education and Health in the Presence of Treatment Externalities." Econometrica 72(1).

Miller, C., M. Tsoka, et al. (2008a). Impact Evaluation Report. External Evaluation of the Mchinji Social Cash Transfer Pilot. Boston, Center for International Health and Development, Boston University School of Public Health.

Miller, C., M. Tsoka, et al. (2008b). Targeting Report. External Evaluation of the Mchinji Social Cash Transfer Pilot. Boston University School of Public Health $\&$ University of Malawi.

Ministry of Community Development and Social Services (2005). Social Protection Strategy for Zambia (draft). Mainstreaming Social Protection. Tunis.

Ministry of Community Development and Social Services and GTZ (2007). Final evaluation report. Kalomo Social Cash Transfer Scheme. Lusaka. 
Ministry of Finance and National Planning (2010). Yellow Book. Lusaka, Government of Zambia.

Mkandawire, T. (2005). Targeting and Universalism in Poverty Reduction. Social Policy and Development Programme Paper Number 23. Geneva, United Nations Research Institute for Social Development.

Moene, K. O. and M. Wallerstein (2001). "Targeting and political support for welfare spending." Economics of Governance 2(1): 3.

Molyneux, M. (2006). "Mothers at the Service of the New Poverty Agenda: Progresa/Oportunidades, Mexico's Conditional Transfer Programme." Social Policy \& Administration 40(4): 425-449.

Moore, C. (2009). Nicaragua's Red de Protección Social: An Exemplary but ShortLived Conditional Cash Transfer Programme. Country Study No. 17, International Policy Centre for Inclusive Growth.

Mosley, P. and A. Verschoor (2005). "Risk Attitudes and the 'Vicious Circle of Poverty'." The European Journal of Development Research 17(1): 59-88.

Mudenda, D., M. Ndulo, et al. (2005). The Budgetary Processes and Economic Governance in Zambia: A Literature Review. Seapren Working Paper No. 3. Windhoek, Southern and Eastern African Policy Research Network.

Mwila, M. A., D. Manley, et al. (2011). The taxation system in Zambia. Lusaka, Jesuit Centre for Theological Reflection.

Myles, J. and J. Quadagno (2002). "Political Theories of the Welfare State." Social Service Review 76(1): 34.

Nguyen, T. (2008). Information, Role Models and Perceived Returns to Education: Experimental Evidence from Madagascar. MIT working Paper, MIT.

Niño-Zarazúa, M., A. Barrientos, et al. (2010). Social protection in sub-Saharan Africa: Will the green shoots blossom? Manchester, Brooks World Poverty Institute, The University of Manchester.

O'Donoghue, T., M. Rabin, et al. (2003). Self-awareness and self-control. Time and decision: Economic and psychological perspectives on intertemporal choice. New York, NY US, Russell Sage Foundation: 217-243.

Pan, L. and L. Christiaensen (2011). Who is vouching for the input voucher? Decentralized targeting and elite capture in Tanzania. Policy research working paper 5651, The World Bank. 
Park, A. and S. Wang (2010). "Community-based Development and Poverty Alleviation: An Evaluation of China's Poor Village Investment Program." Journal of Public Economics 94: 790-799.

Pelham, L. (2007). The politics behind the non-contributory old age social pensions in Lesotho, Namibia and South Africa. CPRC Working Paper 83, Chronic Poverty Research Centre.

Petrauskis, C. (2007). Investing Directly in the Poor: A Demand for Social Protection in Zambia. Lusaka, Jesuit Centre For Theological Reflection.

Petry, N. M., I. Petrakis, et al. (2001). "Contingency management interventions: From research to practice." The American Journal of Psychiatry 158(5): 694-702.

Platteau, J. (2004). "Monitoring Elite Capture in Community-driven Development." Development and Change 35: 223-246.

Posner, N. and J. Simon (2002). "Economic Conditions and Incumbent Support in Africa's New Democracies: Evidence from Zambia." Comparative Political Studies 35(3).

Pritchett, L. (2005). A lecture on the political economy of targeted safety nets. Social protection discussion paper series No. 0501. Washington, The World Bank.

Pritchett, L. H. (2002). It Pays to be Ignorant: A Simple Political Economy of Rigorous Program Evaluations. K. S. o. Government.

Ravallion, M. (1999). "Is More Targeting Consistent with Less Spending?" International Tax and Public Finance 6: 411-419.

Regalia, F. (2006). Some thoughts about "conditionalities" in cash transfer programs. Lessons from Latin America and the Caribbean. Learning Workshop on Orphans and Vulnerable Children and Conditional Cash Transfers. Nairobi, Kenya, The World Bank.

RHVP (2008). Institutional \& Policy Context for Social Protection: Regional Synthesis. REBA IPC brief Number 1. Johannesburg.

Ribas, R. P., F. V. Soares, et al. (2010). Beyond cash: assessing externality and behavior effects of non-experimental cash transfers. Working Paper number 65. Brasilia, International Policy Center for Inclusive Growth.

Ridde, V., S. Haddad, et al. (2010). "Low coverage but few inclusion errors in Burkina Faso: a community-based targeting approach to exempt the indigent from user fees." BMC Public Health 10(631). 
Ridde, V., M. Yaogo, et al. (2010). "A community-based targeting approach to exempt the worst-off from user fees in Burkina Faso." J Epidemiol Community Health 64: $10-15$.

Robinson, V. C. (2006). Strategic Impact Inquiry on Women's Empowerment: Care Bangladesh's Rural Maintenance Program. CARE Bangladesh.

Rothstein, B. (2002). "Cooperation for Social Protection: Explaining variation in Welfare Programs." American Behavioural Scientist 45: 901-918.

Rubalcava, L., G. Teruel, et al. (2004). Spending, Saving and Public Transfers Paid to Women. On-Line Working Paper Series. Los Angeles, California Center for Population Research.

RuralNet Associates Limited (2008). Assessing Administrative Capacity and Costs of Cash Transfer Schemes in Zambia. Implications for Rollout. International Poverty Centre and United Nations Children Fund.

Samson, M., I. van Niekerk, et al. (2006). Designing and Implementing Social Transfer Programmes. Cape Town, Economic Policy Research Institute.

Schady, N. (2011). Some comments on new research on CCTs, and remaining challenges. CCT's: the Second Generation Evaluations Workshop, Washington DC, World Bank.

Schady, N. and M. C. Araujo (2008). "Cash Transfers, Conditions, and School Enrollment in Ecuador." Economia: Journal of the Latin American and Caribbean Economic Association 8(2): 43.

Schubert, B. and R. Slater (2006). "Social Cash Transfers in Low-Income African Countries: Conditional or Unconditional?" Development Policy Review 24(5): 571-578.

Schüring, E. (2009). Cashing in - How cash transfers shore up Zambian households affected by HIV. GTZ. Eschborn.

Schüring, E. (2010a). Strings attached or loose ends? The role of conditionality in Zambia's social cash transfer scheme. Kiel, PEGNET.

Schüring, E. (2010b). Conditions, Conditionality, Conditionalities, Responsibilities Finding Common Ground. Working Paper 2010/014. MGSoG University of Maastricht. Maastricht.

Schüring, E. and J. Lawson-McDowall (2011). "Social Protection in Zambia - Whose Politics?" IDS Bulletin 42(6): 21-27. 
Sen, A. (1995). The Political Economy of Targeting. Public Spending and the Poor. D. Van de Walle and K. Nead. Baltimore and London, John Hopkins University Press: 11-24.

Sharp, K., T. Brown, et al. (2006). Targeting Ethiopia's Productive Safety Net Programme (PSNP). ODI.

Shaw, K. L. (1996). "An Empirical Analysis of Risk Aversion and Income Growth." Journal of Labor Economics 14(4): 626-653.

Slater, R. and J. Farrington (2009). Targeting of Social Transfers: A review for DfID. ODI. London.

Sliwka, D. (2007). "Trust as a Signal of a Social Norm and the Hidden Costs of Incentive Schemes." American Economic Review 97(3): 999-1012.

Standing, G. (2007). Conditional Cash Transfers: Why Targeting and Conditionalities Could Fail. One Pager No. 47. Brasilia, Brazil, International Poverty Centre. United Nations Development Programme.

Stiglitz (2000). Economics of the Public Sector. New York / London, W.W. Norton \& Company.

Subbarao, K., A. Bonnerjee, et al. (1997). Safety Net Programs and Poverty Reduction. Lessons from Cross-Country Experience. Washington DC.

Tabor, S. R. (2002). Assisting the Poor with Cash: Design and Implementation of Social Transfer Programs. Social Protection Discussion Paper Series No. 0223, The World Bank.

Tanaka, T., C. F. Camerer, et al. (2010). "Risk and Time Preferences: Linking Experimental and Household Survey Data from Vietnam." Economic Review 100(1): 557-571.

Taylor-Gooby, P. (2001). "Sustaining state welfare in hard times: who will foot the bill?" Journal of European Social Policy 11(2): 133-147.

Teixeira, C., F. V. Soares, et al. (2011). Externality and Behavioural Change Effects of a non-randomised CCT Programme. Heterogeneous Impact on the Demand for Health and Education. Working Paper number 82. Brasilia, International Policy Centre for Inclusive Growth.

Tembo, G. and N. Freeland (2008a). Impact of Social Cash Transfers on Welfare, Investment, and Education in Zambia. Lusaka, Ministry of Community Development and Social Services. 
Tembo, G. and N. Freeland (2008b). Baseline survey report for the Monze Social Cash Transfer Programme. Ministry of Community Development and Social Services. Lusaka, Zambia.

Thaler, R. H. and C. R. Sunstein (2003). "Libertarian Paternalism." The American Economic Review 93(2): 175-179.

Todd, P. E. and K. I. Wolpin (2006). "Assessing the Impact of a School Subsidy Program in Mexico: Using a Social Experiment to Validate a Dynamic Behavioral Model of Child Schooling and Fertility." American Economic Review 96(5): 1384-1417.

UNDP (2011). Zambia. Country Profile: Human Development Indicators, UNDP.

Van de Walle, D. (1998). "Targeting Revisited." The World Bank Research Observer 13(2): 231-248.

Veit-Wilson, J. (2009). "Who Sets the Conditions? Conditionality, Reciprocity, Human Rights and Inclusion in Society." Global Social Policy 9(2): 171-174.

Ward, P., A. Hurrell, et al. (2010). Cash Transfer Programme for Orphans and Vulnerable Children (CT-OVC), Kenya. Operational and Impact Evaluation, 2007-2009, Oxford Policy Management.

Warrener, D. (2004). The Driver of Change Approach. Synthesis Paper 3. ODI. London.

Watkins, B. (2008a). Alternative Methods for Targeting Social Assistance to Highly Vulnerable Groups. Washington D.C., Kimetrica.

Watkins, B. (2008b). Addendum to the Report "Alternative Methods for Targeting Social Assistance to Highly Vulnerable Groups". Kimetrica. Washington.

Wietler, K. (2008). The Impact of Social Cash Transfers on Informal Safety Nets in Kalomo District, Zambia. MCDSS and GTZ. Lusaka.

Wik, M., T. A. Kebede, et al. (2004). "On the measurement of risk aversion from experimental data." Applied Economics 36(21): 2443-2451.

World Bank (2001). World development report 2000/2001: Attacking poverty, Oxford and New York: Oxford University Press.

World Bank (2007). Zambia: Poverty and Vulnerability Assessment. Report No. 32573-ZM, The World Bank. 
World Bank (2010). Zambia: Impact Assessment of the Fertilizer Support Program. Analysis of Effectiveness and Efficiency. Report No. 54864-ZM, The World Bank.

World Bank (2011). CCT's: The Second Generation of Evaluations Workshop, Washington DC.

Yamauchi, C. (2008). Community-based Targeting and Initial Local Conditions: Evidence from Indonesia's IDT Program, Centre for Economic Policy Research, Research School of Social Sciences, Australian National University, CEPR Discussion Papers: 584.

Yesuf, M. (2004). Risk, Time and Land Management under Market Imperfections: Applications to Ethiopia. PhD dissertation, Göteborg University.

Yusuf, M. (2010). Community Targeting for Poverty Reduction: Lessons from Developing Countries. The Pardee Papers No. 8. University of Boston. Boston. 


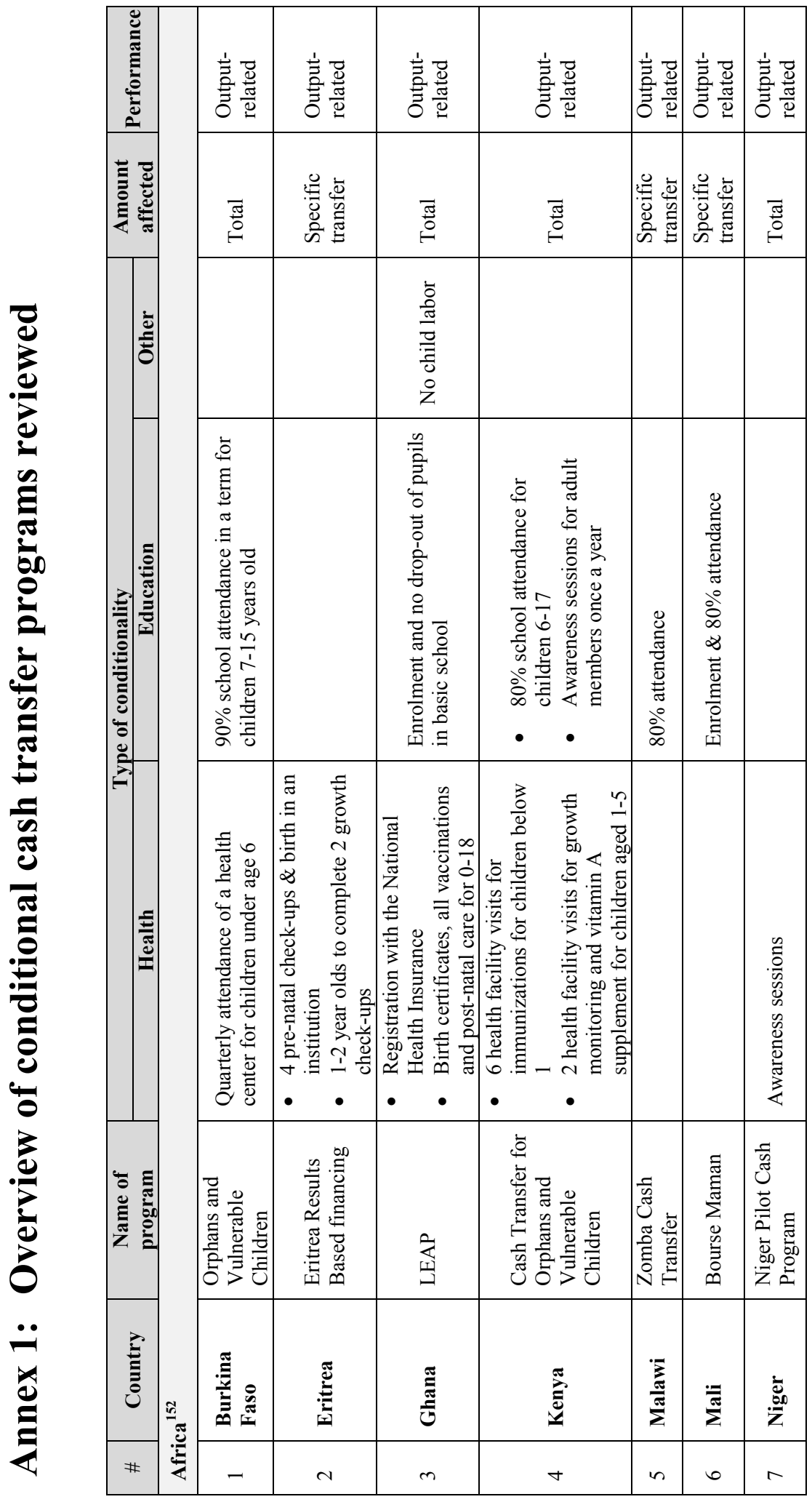

으

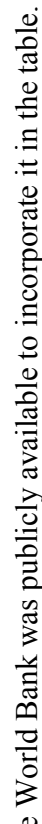

듬

ลิ

븡

灵

정

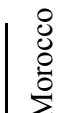

I

ธี

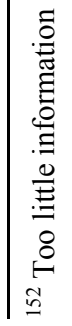




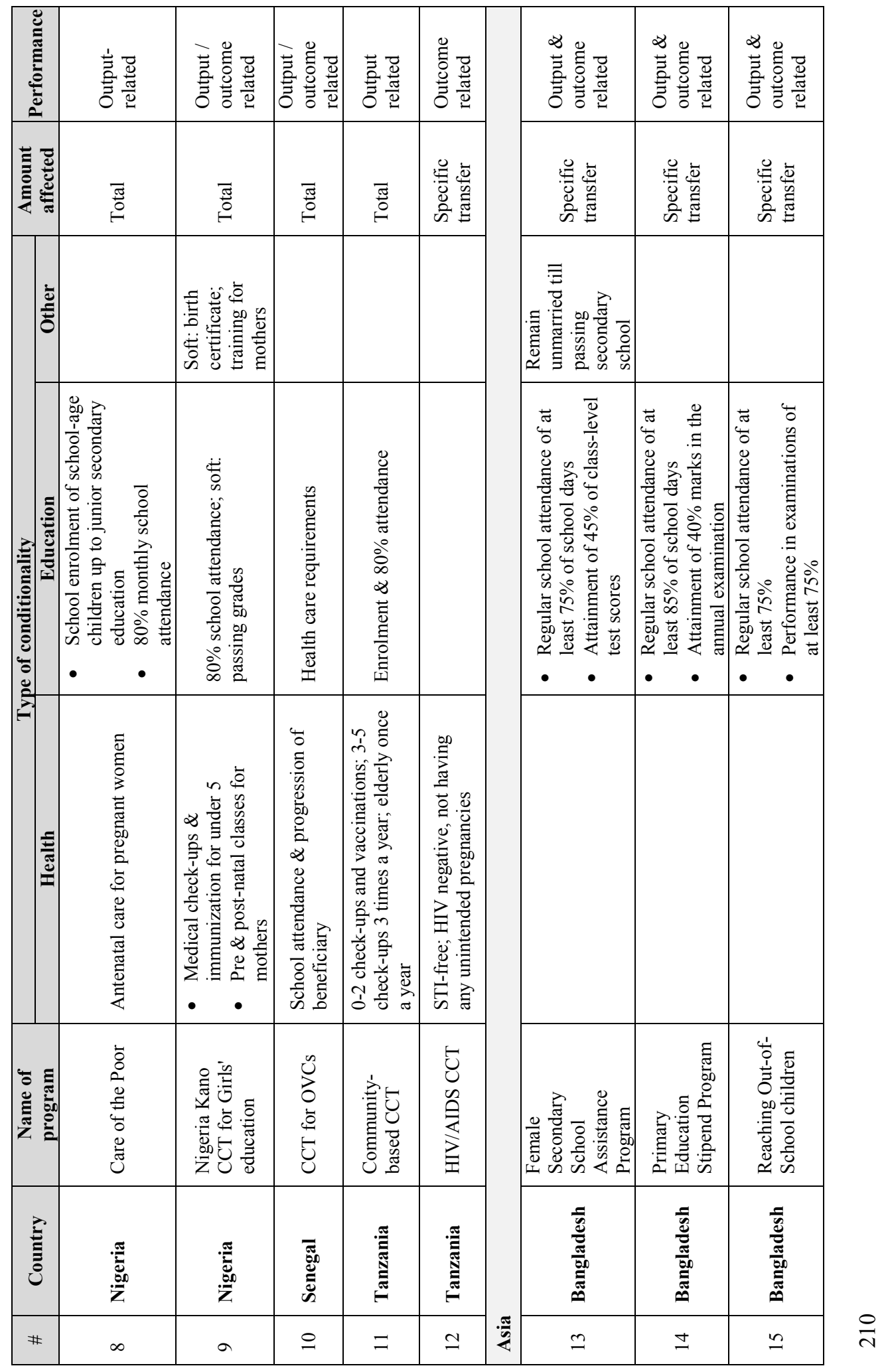




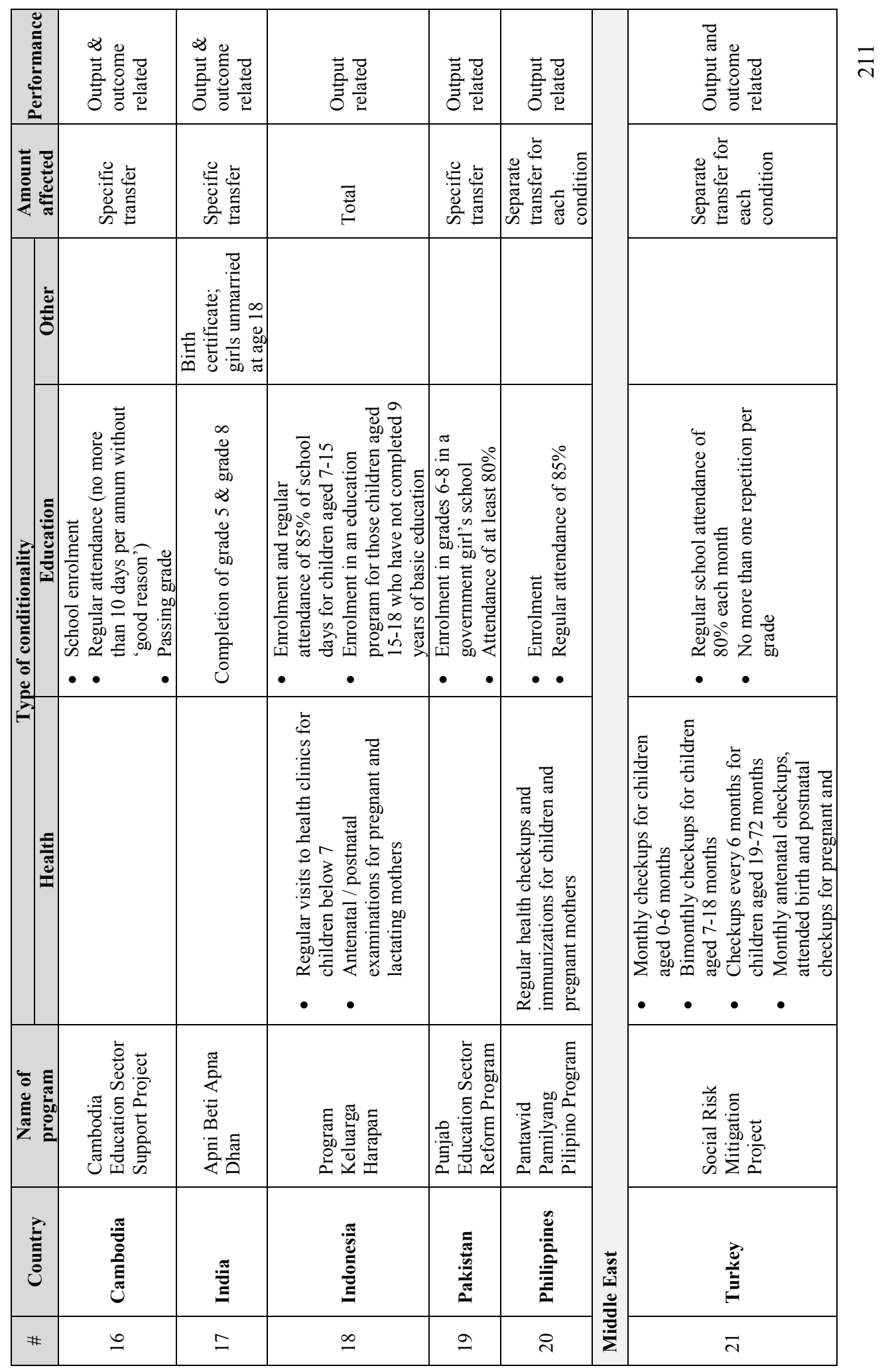




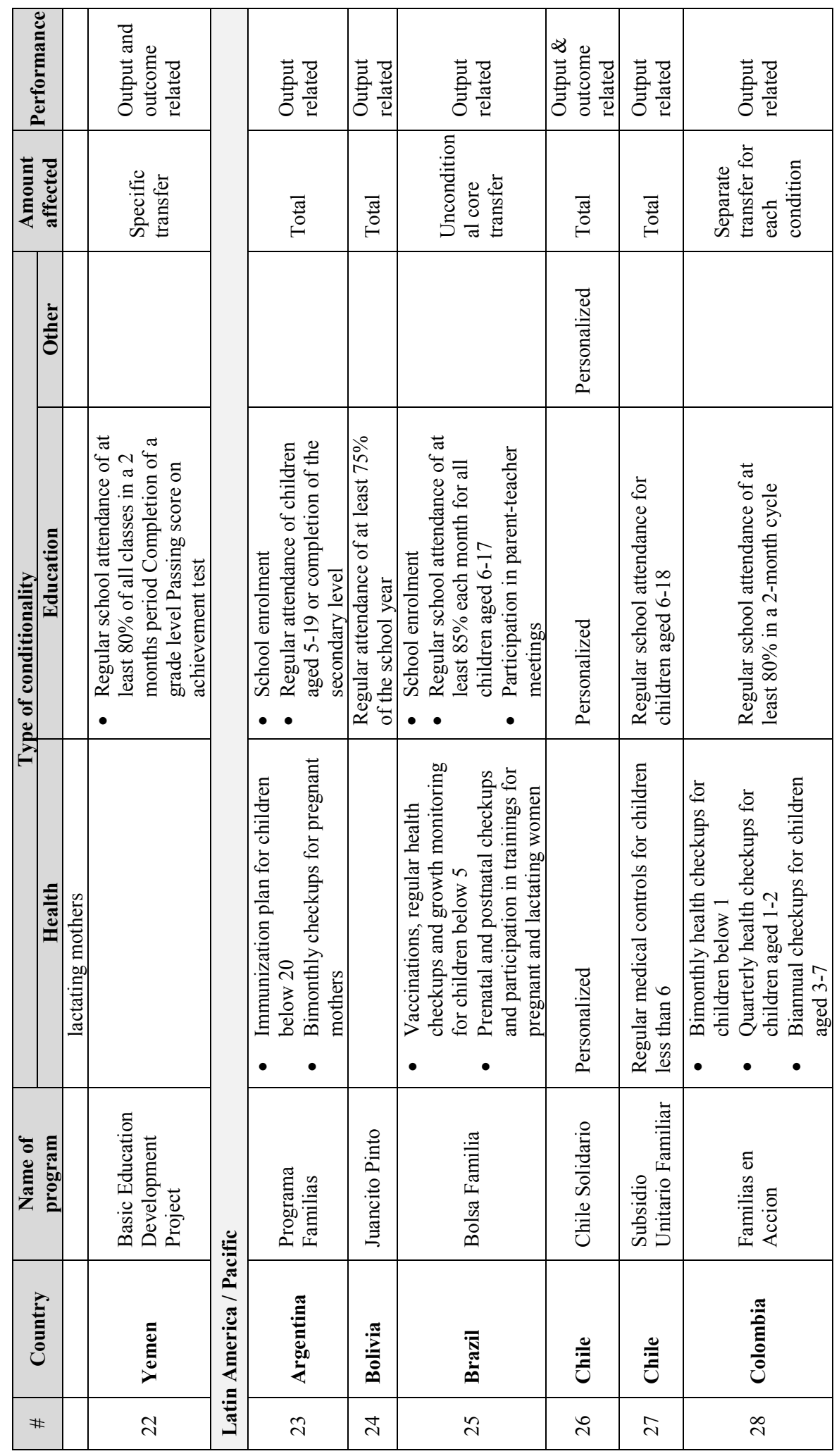




\begin{tabular}{|c|c|c|c|c|c|c|c|}
\hline 这 & 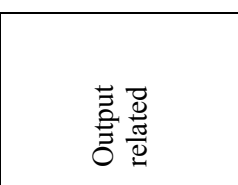 & 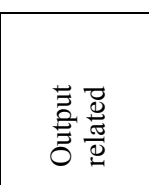 & 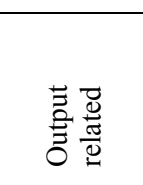 & 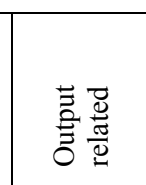 & & 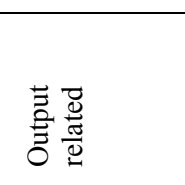 & 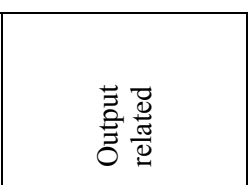 \\
\hline 总 & 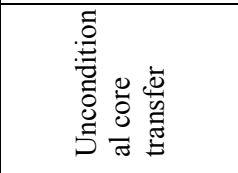 & $\stackrel{\sqrt[\pi]{0}}{\circ}$ & 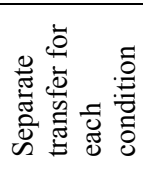 & 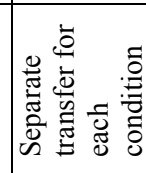 & & 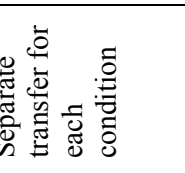 & 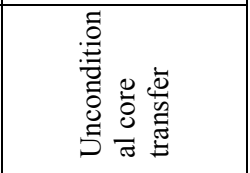 \\
\hline పे & 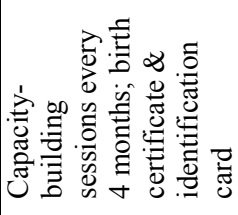 & & & & & 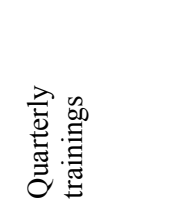 & \\
\hline 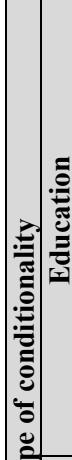 & 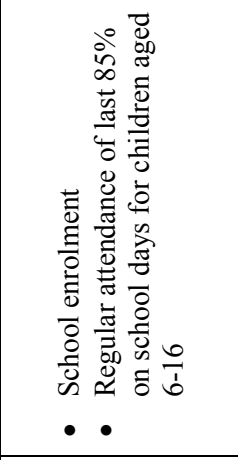 & 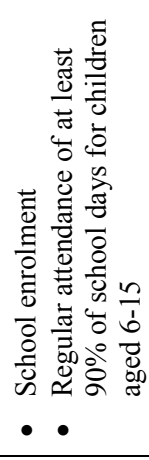 & 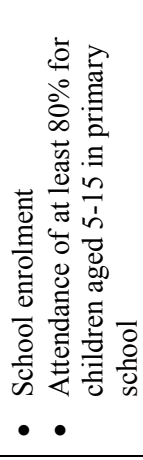 & 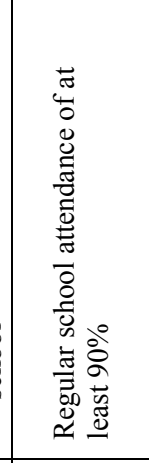 & & 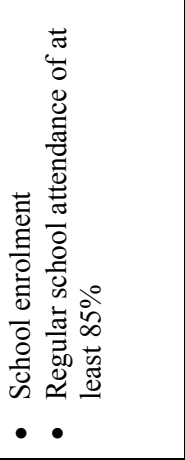 & 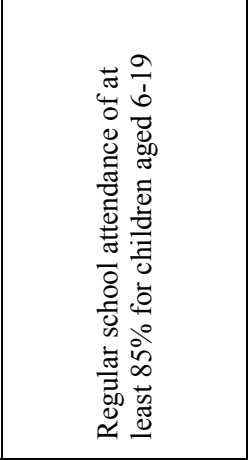 \\
\hline 2 & 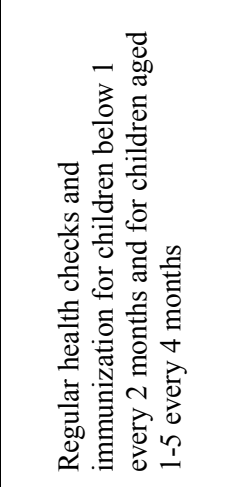 & 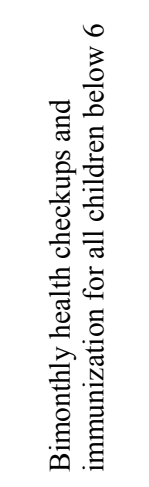 & 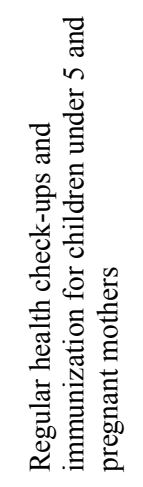 & 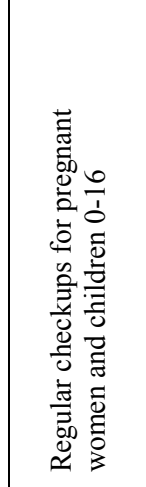 & 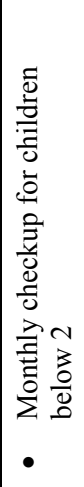 & 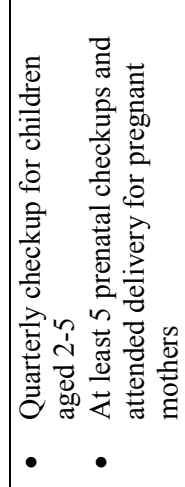 & 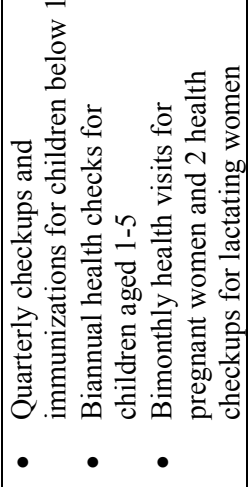 \\
\hline 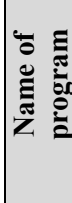 & 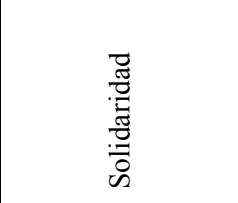 & 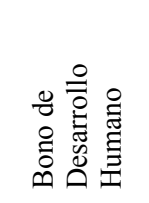 & 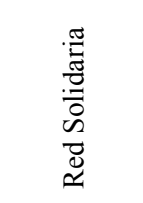 & 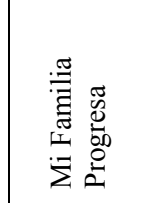 & \multicolumn{2}{|r|}{ 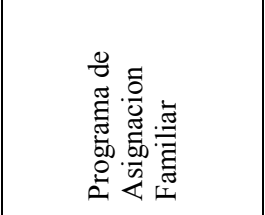 } & 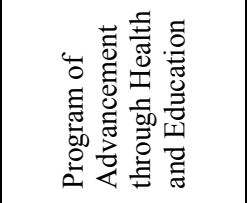 \\
\hline$\stackrel{\vec{E}}{E}$ & 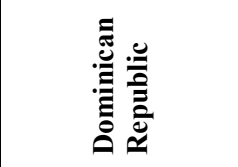 & 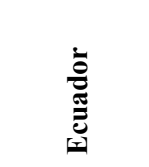 & 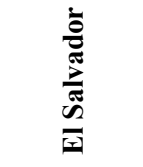 & 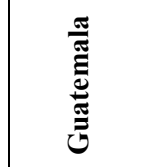 & \multicolumn{2}{|r|}{ 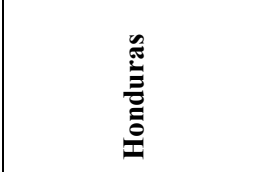 } & \\
\hline \# & సे & in & $\vec{m}$ & तె & \multicolumn{2}{|r|}{$m$} & 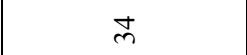 \\
\hline
\end{tabular}



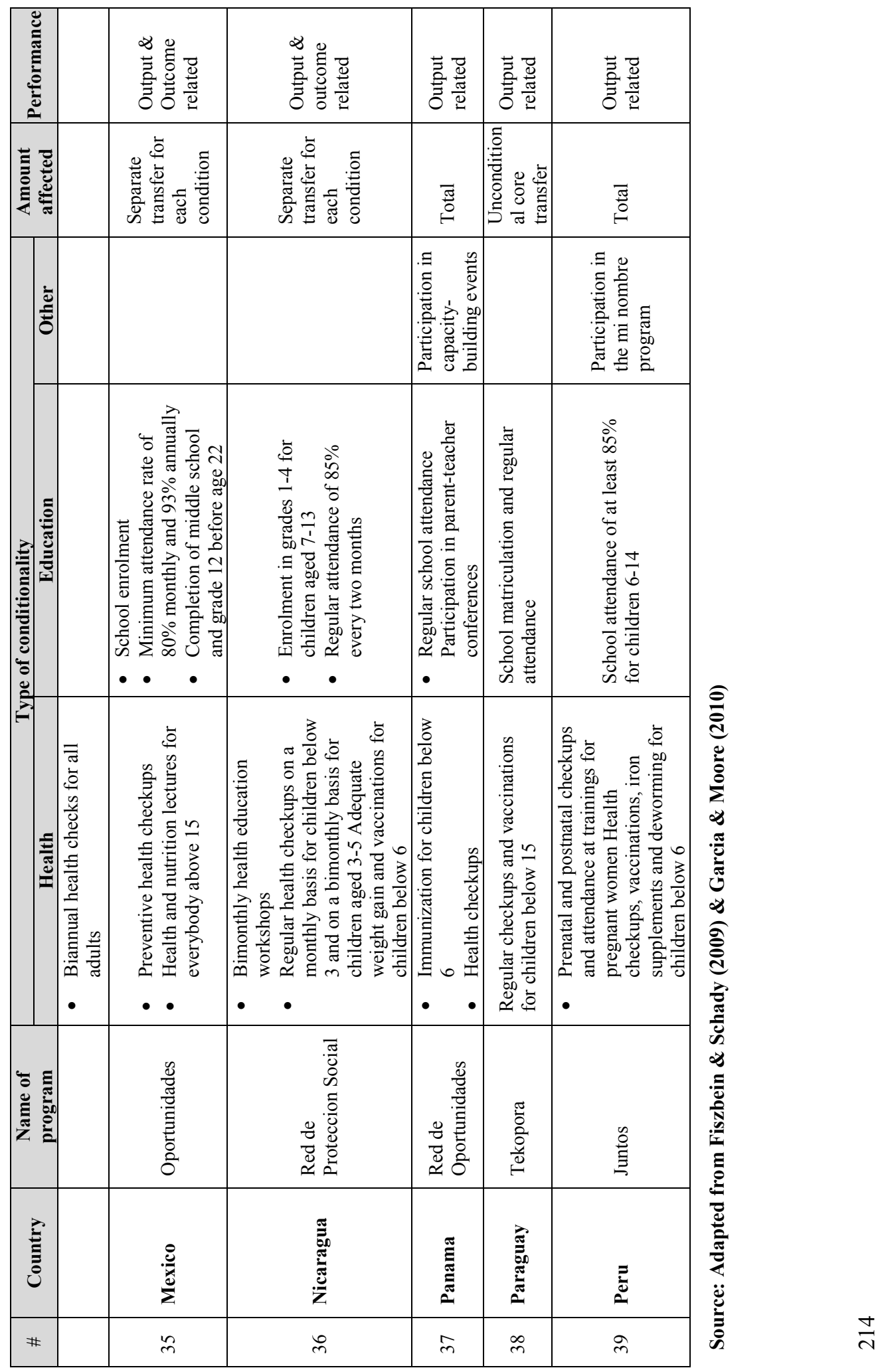


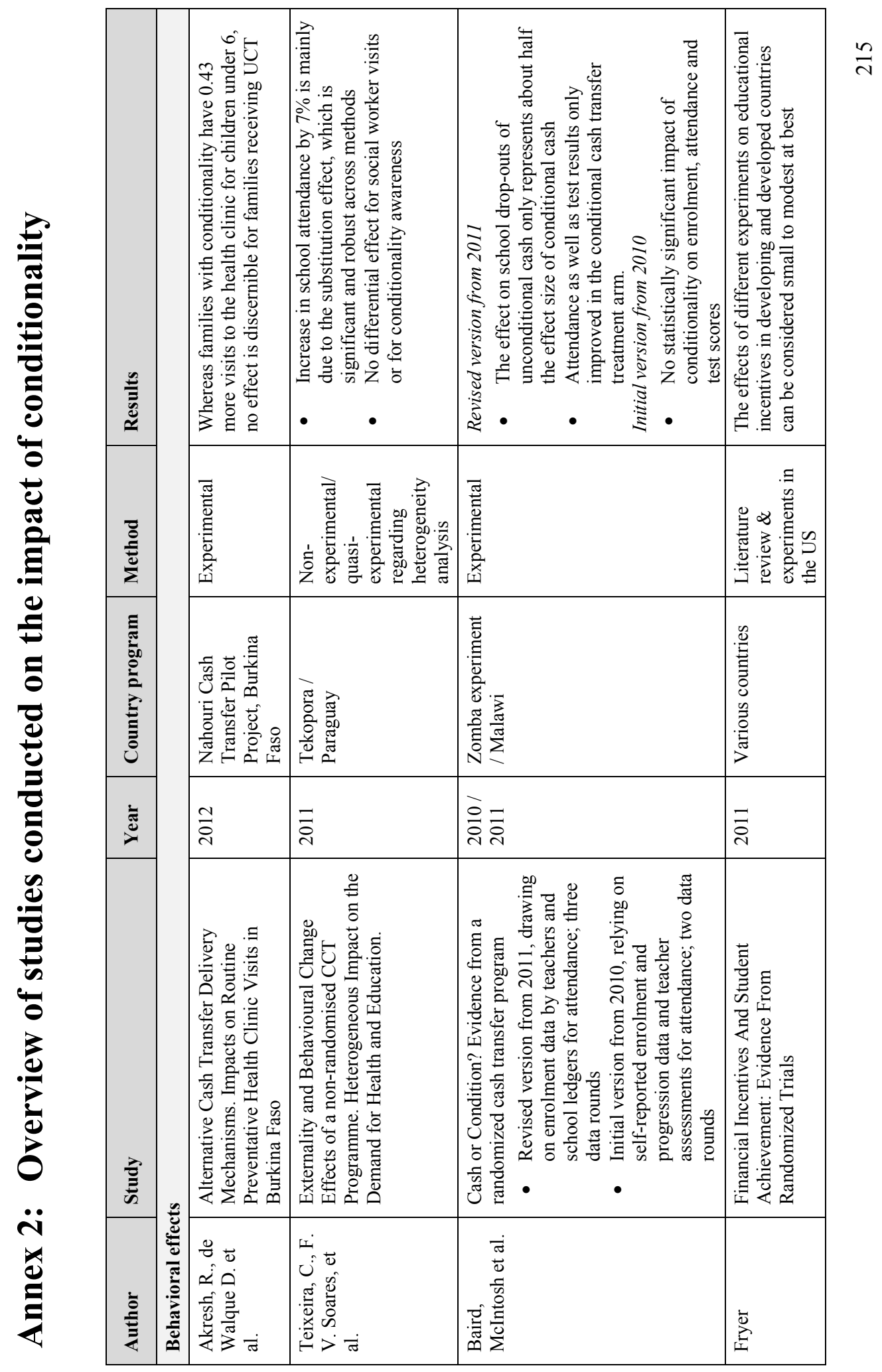




\begin{tabular}{|c|c|c|c|c|c|c|c|}
\hline 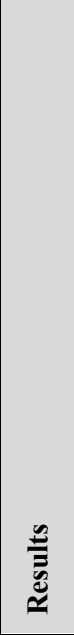 & 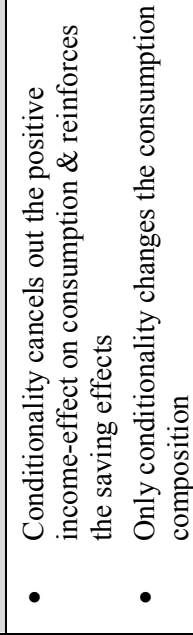 & 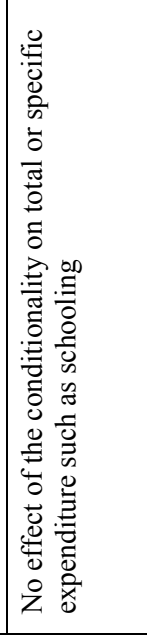 & 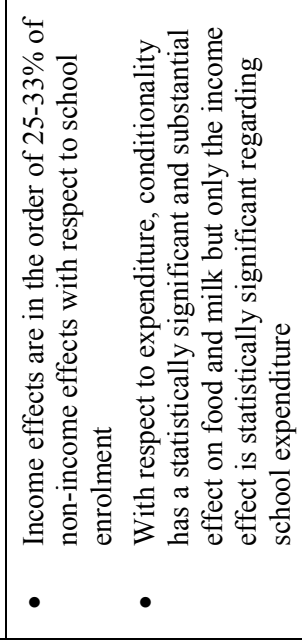 & 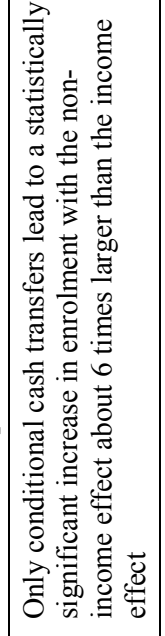 & 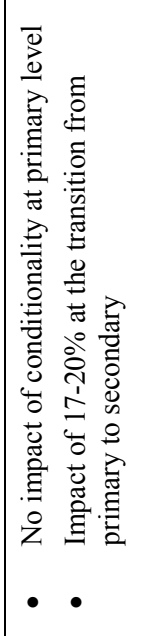 & 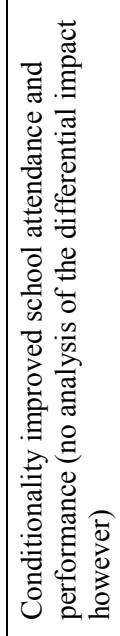 & 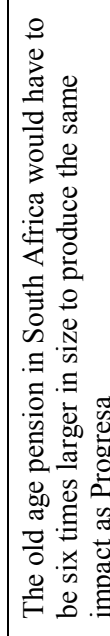 \\
\hline 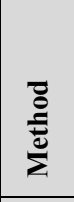 & 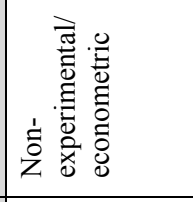 & 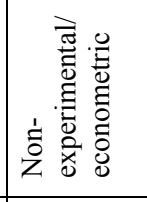 & 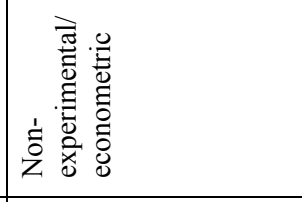 & 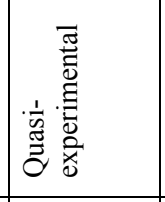 & 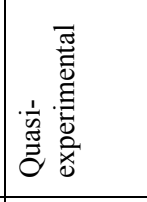 & 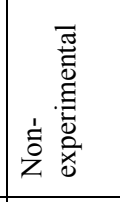 & 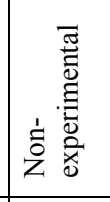 \\
\hline 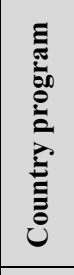 & 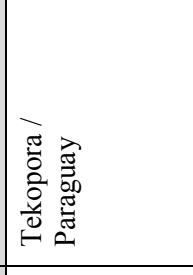 & 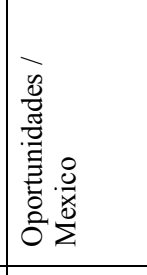 & 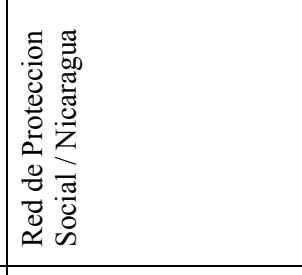 & 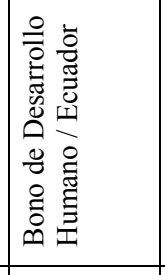 & 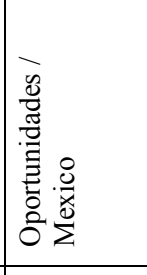 & 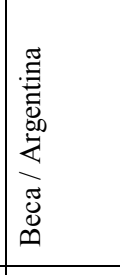 & 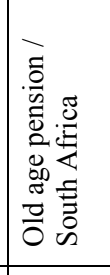 \\
\hline$\stackrel{\bar{\Xi}}{\bar{J}}$ & 啇 & ఫ్సి & 甯 & ఫ్ & ) & ఫ్ & ठ্ণ \\
\hline 竞 & 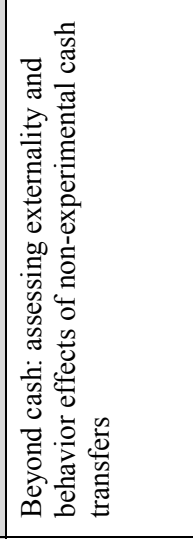 & 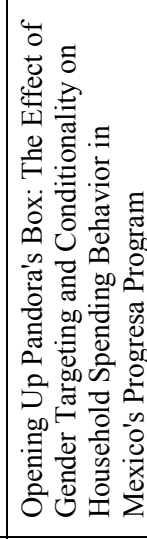 & 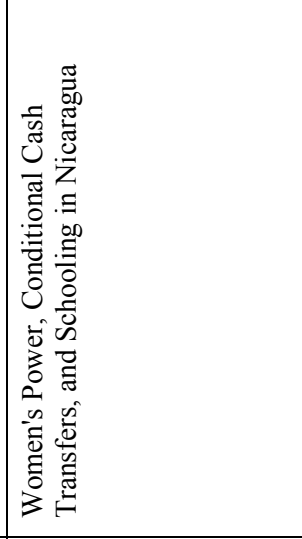 & 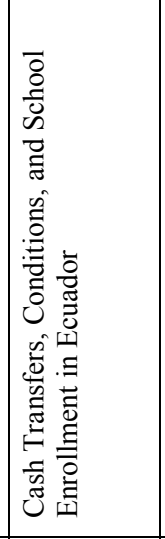 & 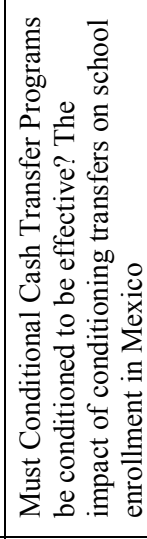 & 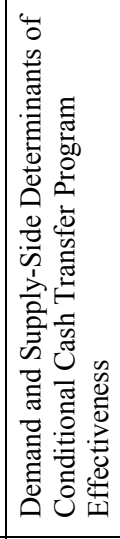 & 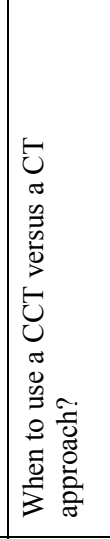 \\
\hline 童 & 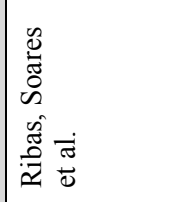 & 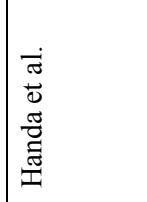 & 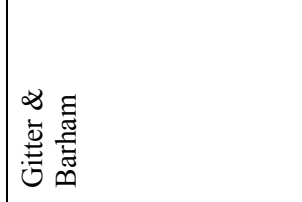 & 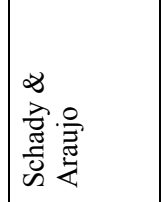 & 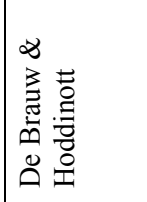 & 量 & 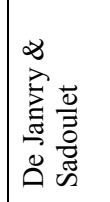 \\
\hline
\end{tabular}




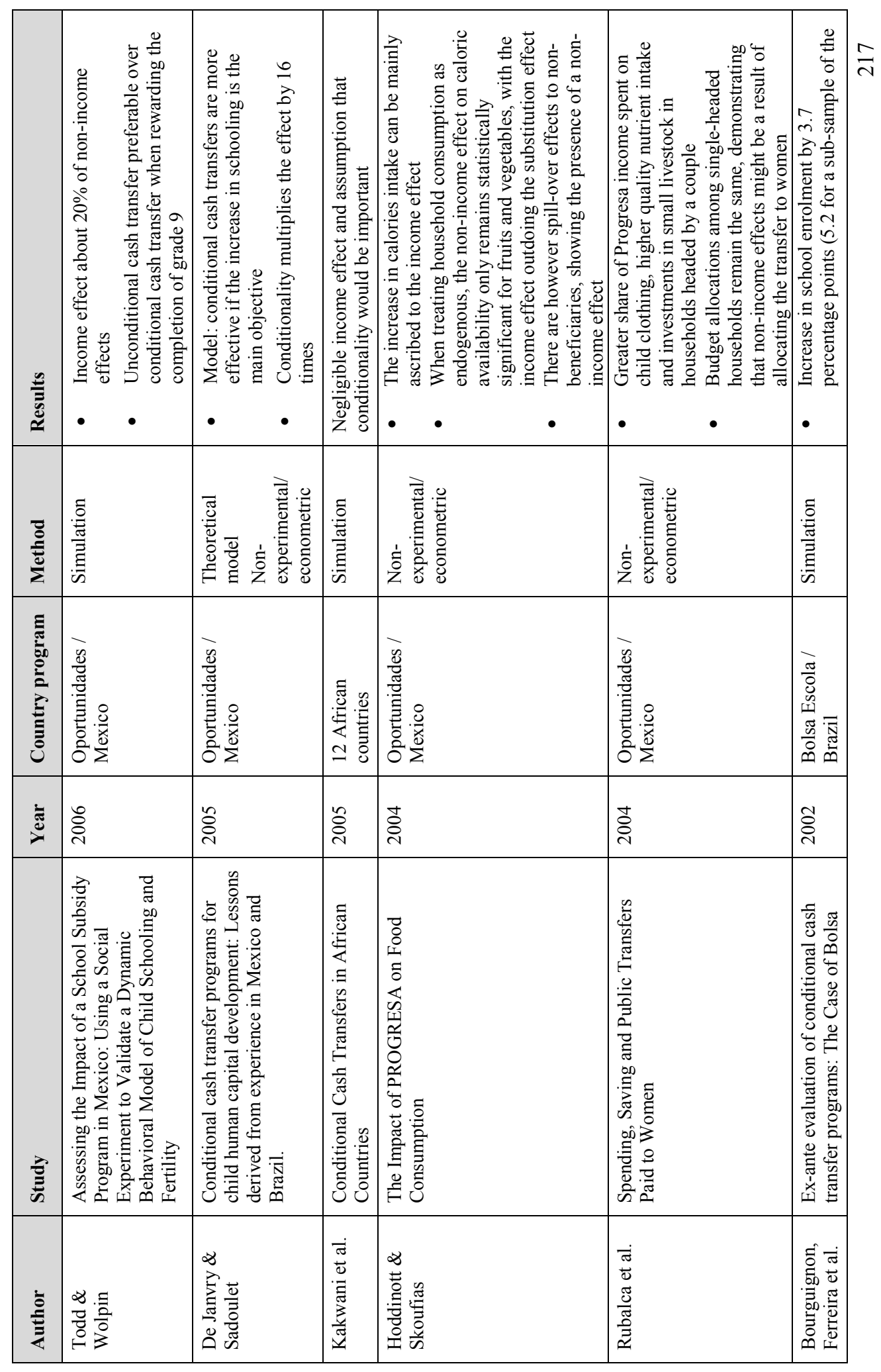




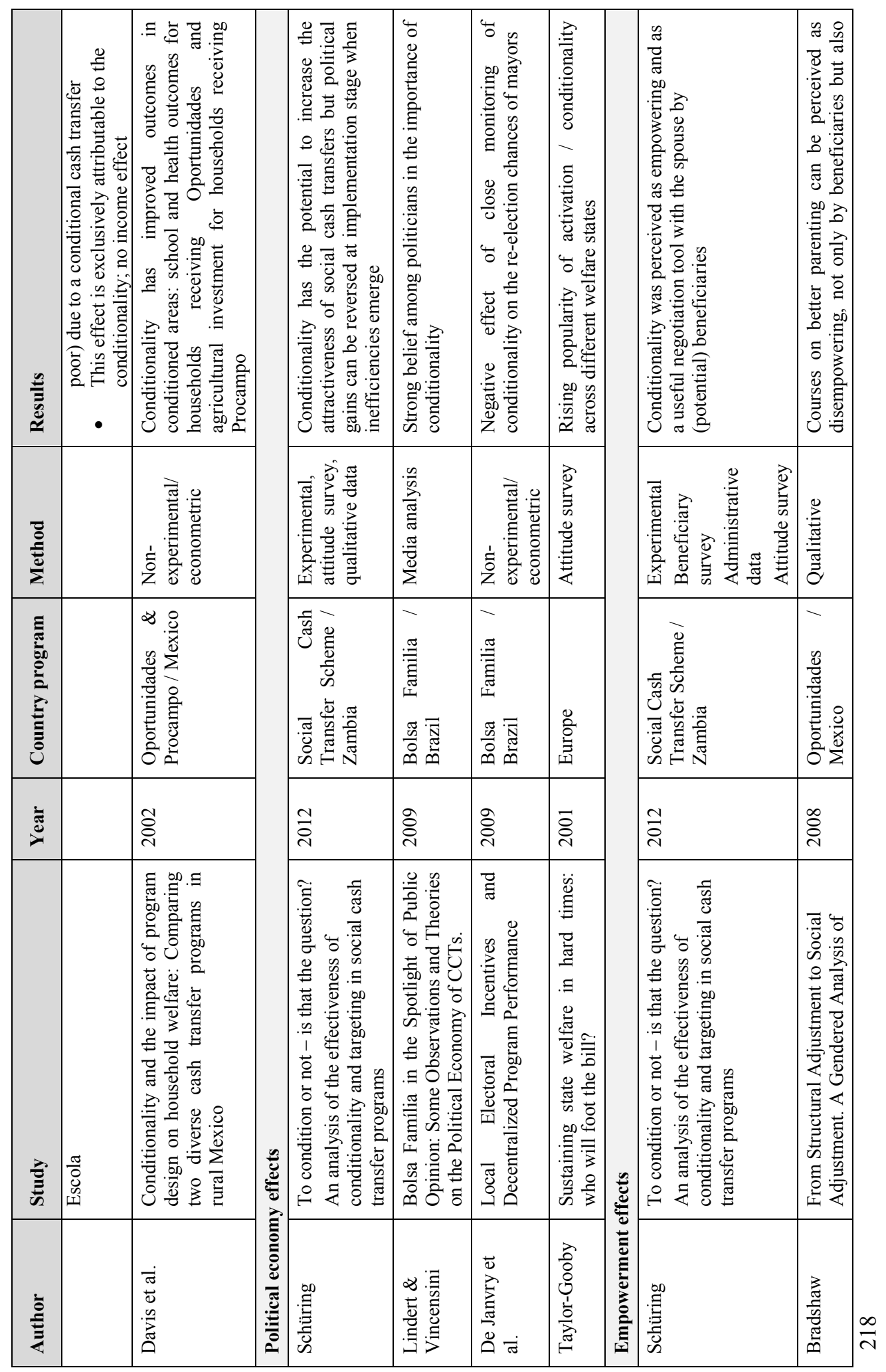




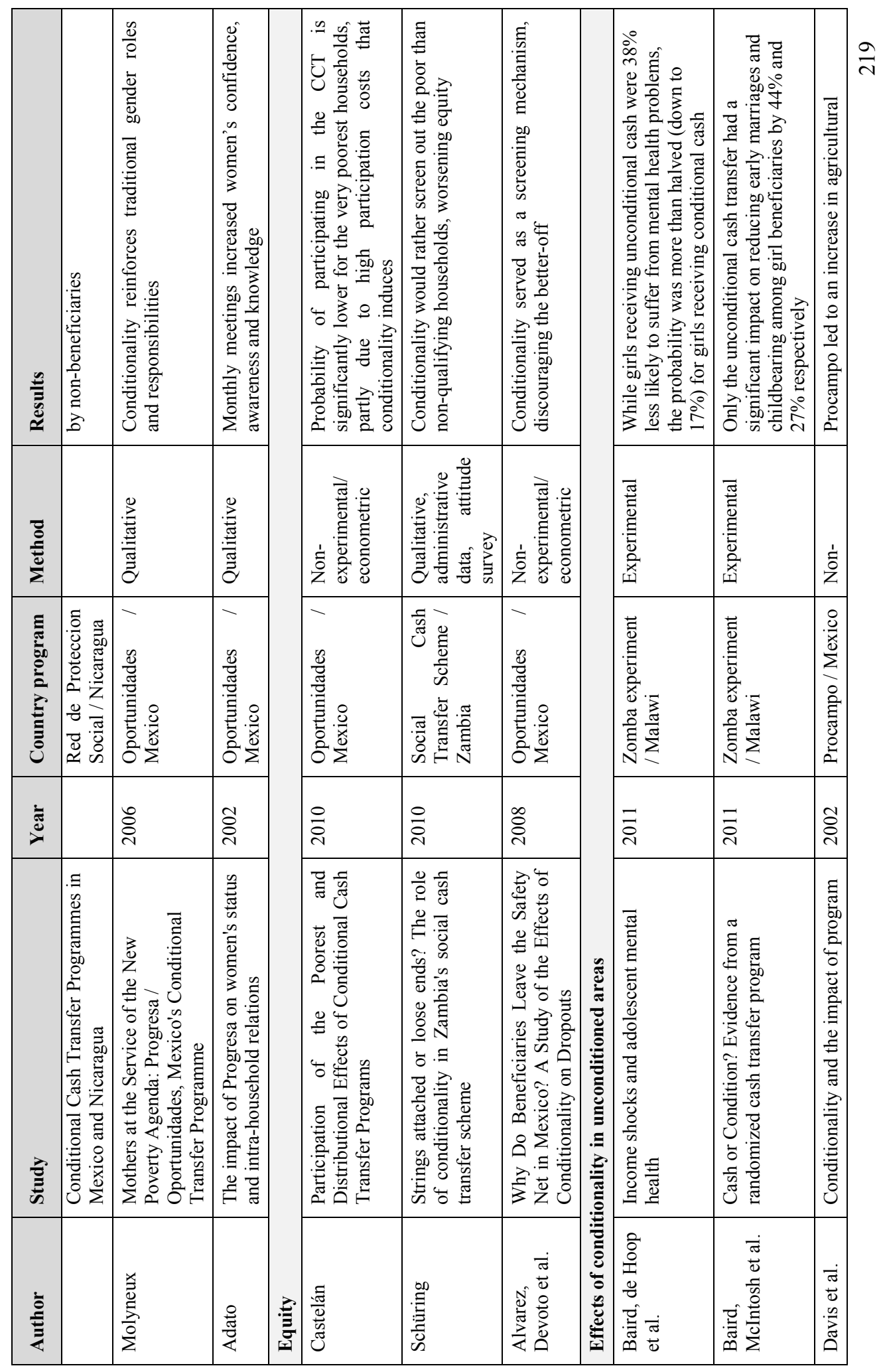




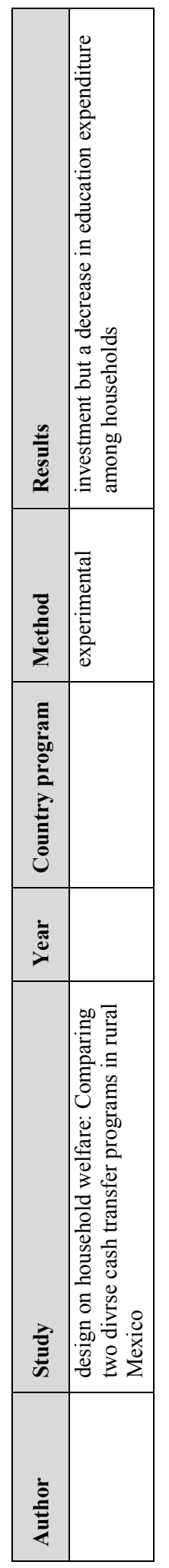




\section{Annex 3: Pre-survey form for community members interested in participating in the experiment}

\begin{tabular}{|l|l|l|l|l|l|l|l|}
\hline Date & .09 .2009 & CWAC & & $\begin{array}{l}\text { \# of } \\
\text { interview }\end{array}$ & & $\begin{array}{l}\text { Interview } \\
\text { started at: }\end{array}$ & $\begin{array}{l}\text { Interview } \\
\text { ended at: }\end{array}$ \\
\hline $\begin{array}{l}\text { Any particular } \\
\text { observations: }\end{array}$ & \multicolumn{1}{|l|}{} \\
\hline Name of interviewer: & & Signature: & \\
\hline Interview checked by: & Signature: & \\
\hline
\end{tabular}

Pre-survey for interested community members

\begin{tabular}{|l|l|l|}
\hline 1. First name & 2. Family name \\
\hline 3. Gender $\square$ Female $\square$ Male & 4. Age in years $\square$ \\
\hline 5. Tribe & 6. Place of birth \\
\hline 7. Village & $\begin{array}{l}\text { 8. Special role in the } \\
\text { village? }\end{array}$ \\
\hline $\begin{array}{l}\text { 9. Are you a beneficiary of the } \\
\text { SCTS? - only for treatment cWACs! }\end{array}$ Yes \\
\hline
\end{tabular}

\begin{tabular}{|l|l|l|}
\hline $\begin{array}{l}\text { 11. Number of household } \\
\text { members - members who stay } \\
\text { and eat together }\end{array}$ & $\begin{array}{l}\text { 12. Number of } \\
\text { children 0-4 }\end{array}$ & $\begin{array}{c}\text { 13. Number of } \\
\text { children 5- } \\
18\end{array}$ \\
\hline $\begin{array}{l}\text { 14. Number of fit members - } \\
\text { members who have the strength } \\
\text { and capacity to contribute to the } \\
\text { family income on a regular basis }\end{array}$ & $\begin{array}{l}\text { 15. Main } \\
\text { occupation }\end{array}$ \\
\hline
\end{tabular}

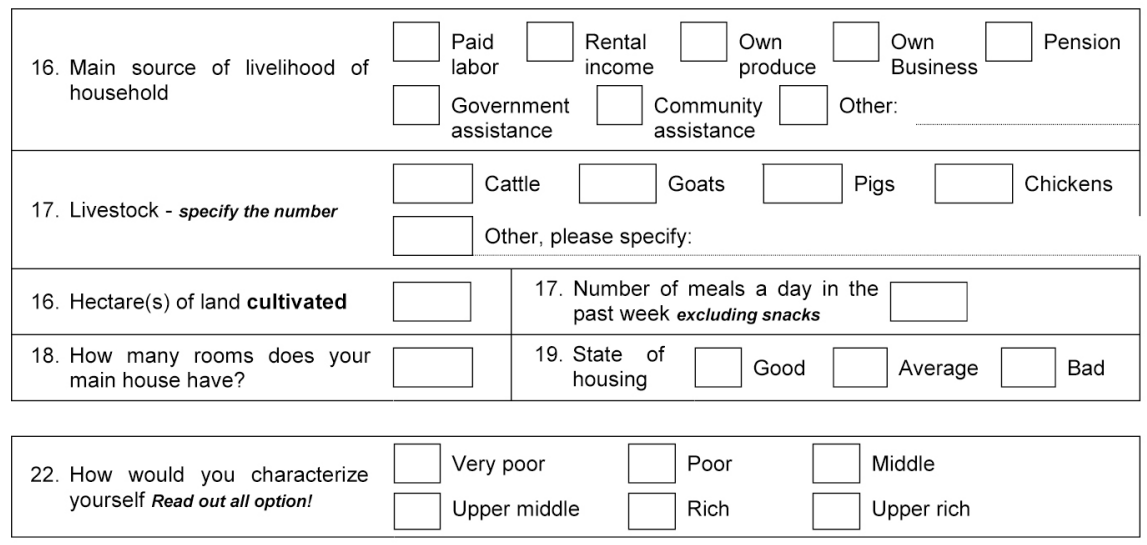

Assessment by the interviewer $\square$ Very poor $\square$ Poor $\square$ Better off

\begin{tabular}{|l|l|}
\hline Group: & Number: \\
\hline
\end{tabular}




\title{
Annex 4: Instructions for the introduction of the experiment
}

\author{
Introduction to the group game
}

Research assistant 1: Welcome to everybody and thank you once again for participating in the experiment. We are organizing these small games with the community in order to see how decisions are taken in communities on how to redistribute money. During this game each of you gets to redistribute money that you are given with the objective to alleviate poverty in your group. Everybody will have a budget of ZMK 1,000,000, 20 tokens that are worth 50,000 ZMK each. In the first round of the game, every group member gets to decide for himself/herself how to distribute the money. Nobody else in the group will know about the decision made. In the second round, the entire group takes a joint decision. At the end of both rounds, for every token received, the person will be paid $500 \mathrm{ZMK}$. This means that if the group members have all distributed $Z M K 1,000,000$ to member $A$, member $A$ will get ZMK 10,000. If the group decided to distribute ZMK 5,000,000 to member B, member $B$ will get ZMK 50,000. If the group decided to distribute ZMK 100,000 to member C, member C will get ZMK 1,000.

After each round of the game, we will ask you a number of questions about your decision as well as about you as a person. Please be assured that all information that you provide will remain completely confidential. Nobody will be able to know which answers you gave. At the end of the community game, everybody gets to roll a dice - it is a game that purely depends on luck. You will be paid according to the number on the dice. For every dot on the dice you receive ZMK 5000 except for when you get a six, which means that you won't get anything. Nobody verifies the number on the dice - it will be up to you to tell us the number that the dice shows.

If you feel uncomfortable with any of the games or with answering a particular question during the interview, please say so and we will interrupt the game or skip to the next question. Do you have any questions with respect to the entire procedure?

We will start now with the first experiment. All of you have received a name tag with a number on it. This number does not mean anything. It should just help you to easily recognize the other persons when you distribute the money. We will now first start with a round of introduction. Please say briefly your name, how many children you have and what your favorite color is. My name is .......................... I have ...... children and my favorite color is .............. Research assistant 2, 3, 4 \& 5 to follow. Now we continue with candidate No. 1: ........ Make sure that you keep the order or numbers and clearly mention the number for each and every group member.

Now each person gets a budget of ZMK $1,000,000$ that is meant to alleviate poverty. All of you will get 20 tokens that are worth 50,000 ZMK each. Research assistants 2 \& 3 distribute the tokens. We will now ask you individually how you would like to distribute the tokens to the members of this group. This money is meant to alleviate extreme poverty in your group. In a second step, we will ask you whether in exchange for the money, you expect the different members of the group to do something. There are different options you can choose from (show cards when explaining):

$>$ The first option is a school condition, meaning that the beneficiary is expected to send the children in his/her household to school on a regular basis ( $80 \%$ of the time). This conditionality will cost the beneficiary ZMK 20,000 per child for paying money to the building fund and to the Teacher Parent Association and will be deducted from the amount that you give this person. 
The second option is a growth monitoring condition, meaning that the beneficiary is expected to take all the under $5 \mathrm{~s}$ in his/her household to regular growth checkups. This conditionality will cost the beneficiary ZMK 10,000 per child for traveling to the nearest health post and will be deducted from the amount that you give this person.

$>$ The third option is a vaccination condition, meaning that the beneficiary is expected to complete the vaccinations for all under $5 \mathrm{~s}$ in his/her household. This conditionality will cost the beneficiary ZMK 10,000 per under 5 for traveling to the nearest health post and will be deducted from the amount that you give this person.

$>$ The fourth option is a work condition, meaning that the beneficiary is expected to do community work for a day such as working in the fields of others, fetching water etc. This conditionality will not have any financial costs but means that the beneficiary will use all his time and strength.

$>$ The fifth option is a training condition, meaning that the beneficiary is expected to participate in trainings on important matters such as hygiene, health, how to start an income generating activity etc. This conditionality will cost the beneficiary ZMK 20,000 for the training costs.

The information you give us will be confidential and none of the other members of this group will find out what decision you took. At the end of this experiment we will count the number of tokens that each candidate received. At the end of all the experiments you will be paid an amount of money that depends on the number of tokens you received. For each token you will receive ZMK 500 minus ZMK 200 for an education per child of school-going age, ZMK 200 for a training conditionality and/or minus ZMK 100 for the growth monitoring / vaccination conditionality per child under 5 .

We ask two members of the group to follow each research assistant. He/she will explain again what you have to do and then ask you individually how you have decided. After all of you have told us their decision, we will gather again here and continue with the second experiment. 


\section{Annex 5: Instructions and questionnaire for Round 1 of the experiment}

Additional codes: 77 - respondent refused to answer / 88 - respondent does not know / 99 - question does not apply

\begin{tabular}{|l|l|l|l|l|l|l|l|}
\hline Date & .09 .2009 & CWAC & & $\begin{array}{l}\text { \# of } \\
\text { interview }\end{array}$ & $\begin{array}{l}\text { Interview } \\
\text { started at: }\end{array}$ & $\begin{array}{l}\text { Interview } \\
\text { ended at: }\end{array}$ & \\
\hline $\begin{array}{l}\text { Any particular } \\
\text { observations: }\end{array}$ & & & Signature: & \\
\hline Name of interviewer: & & Signature: & \\
\hline Interview checked by: & &
\end{tabular}

Information about the respondent

\begin{tabular}{|l|l|}
\hline 1. First name & 2. Surname \\
\hline 3. NRC & \\
\hline
\end{tabular}

\section{Explanation to the respondent}

Now I want to ask you to distribute the tokens of money that you received. I want to remind you that this money is supposed to alleviate poverty in your community. In addition, you can be assured that none of the other group members will find out how you distributed the money. For each candidate there is a little pot where you can place your tokens. Now you can decide. How many tokens do you want to give to candidate 1 , mention name? How many tokens do you want to give to candidate 2? Do you want him/her to be subject to any of the conditions? Continue

When the person has finished: Now I would like to learn a bit more on what basis you decided to distribute the money to particular members of the group, why you chose to condition or not to condition the transfer and what motivated your choice of conditionalities. Let me start with the person you gave the highest amount to: 


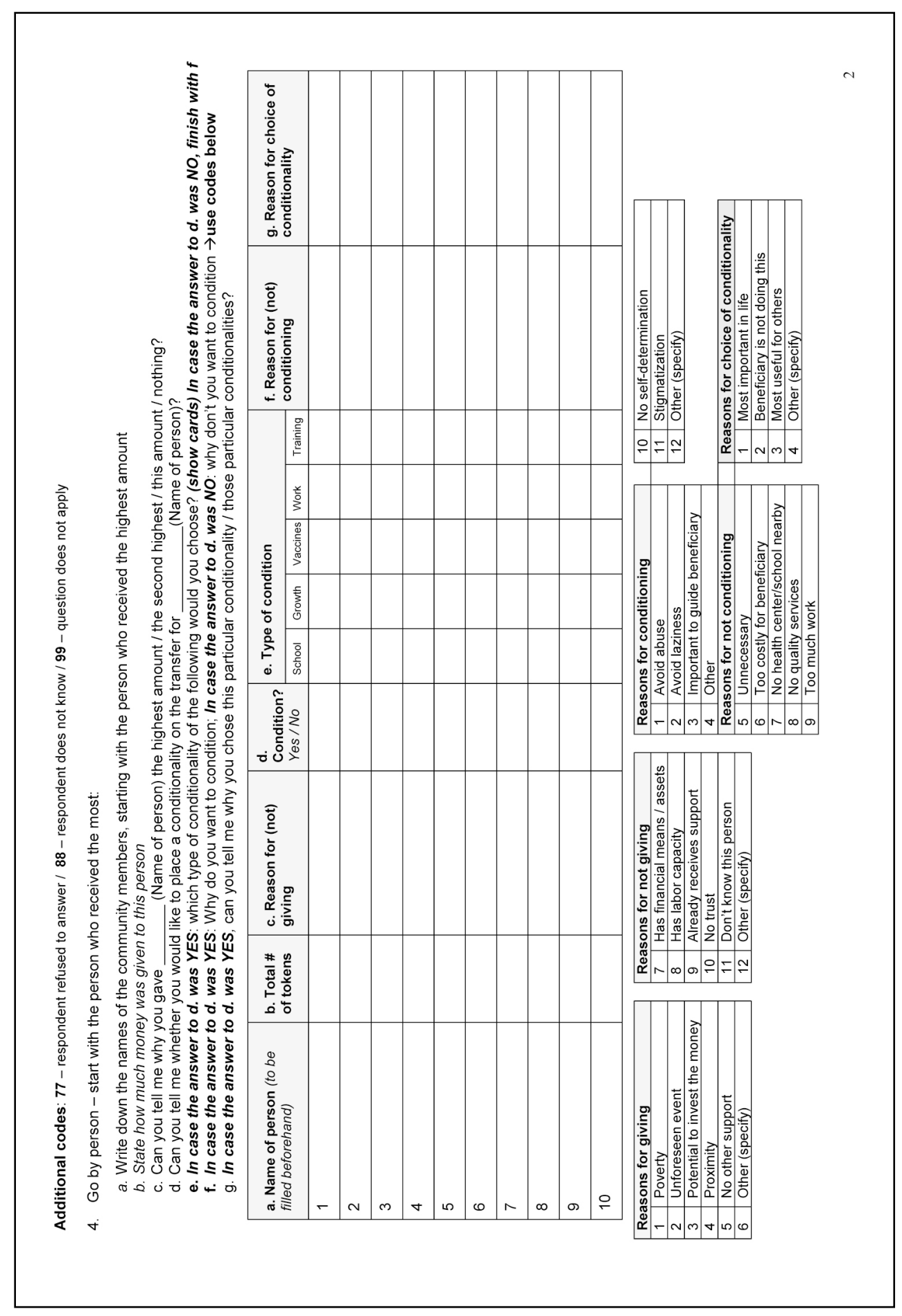


Additional codes: 77 - respondent refused to answer / 88 - respondent does not know / 99 - question does not apply

5. Now let me ask you a few more questions about how you feel about the different conditionalities if they were imposed on you:

a. How comfortable would you feel with the following conditions on a scale from 1 (very uncomfortable) to 7 (very comfortable)?

\begin{tabular}{|l|c|c|c|c|c|c|c|}
\hline Conditionality & \multicolumn{3}{|c}{ Very uncomfortable } & \multicolumn{3}{c|}{ Very comfortable } \\
\hline School & 1 & 2 & 3 & 4 & 5 & 6 & 7 \\
\hline Growth monitoring & 1 & 2 & 3 & 4 & 5 & 6 & 7 \\
\hline Vaccinations & 1 & 2 & 3 & 4 & 5 & 6 & 7 \\
\hline Work & 1 & 2 & 3 & 4 & 5 & 6 & 7 \\
\hline Training & 1 & 2 & 3 & 4 & 5 & 6 & 7 \\
\hline
\end{tabular}

b. If uncomfortable (1-3), can you tell us the principle reason why you would feel uncomfortable? (please use the same codes from above for reasons for not conditioning; if 'other', please specify)

c. Would you perceive the conditionalities as (please read out all the options)

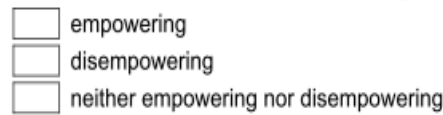

d. Would you decide against a transfer of ZMK 50,000 if you had to comply with all of these conditionalities?

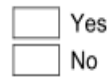

e. If YES, can you tell us the principle reason why you would not take the money? (please use the same codes from above for reasons for not conditioning; if 'other', please specify) 


\section{Annex 6: Instructions and questionnaire for Round 2 of the experiment}

Additional codes: $\mathbf{7 7}$ - respondent refused to answer / 88 - respondent does not know / 99 - question does not apply

\section{Round 2 - group distribution}

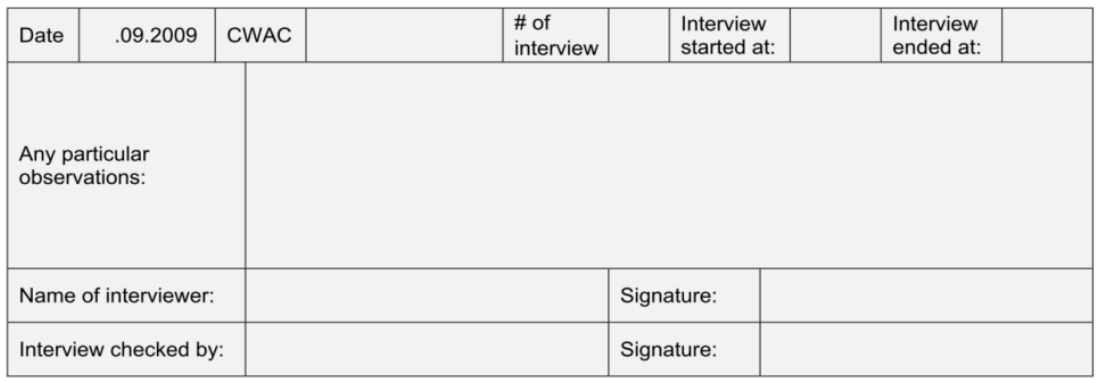

Information about the respondent

\begin{tabular}{|l|l|}
\hline 1. First name & 2. Surname \\
\hline 3. NRC & \\
\hline
\end{tabular}

\section{Group decision}

Now let me ask you a few questions about the group discussion. I would first like to know how satisfied you are with the outcome of the group discussion with respect to the distribution of money and the choice of conditions. I will first start with the targeting outcome.

4. How strongly do you agree / disagree with the following statements concerning the targeting outcome for the FIRST group decision on a scale of 1 (strongly disagree) to 7 (strongly agree)

\begin{tabular}{|c|c|c|c|c|c|c|c|}
\hline Statement & \multicolumn{3}{|c|}{ Strongly disagree } \\
\hline $\begin{array}{l}\text { a. feel comfortable with the choice that the } \\
\text { group has taken }\end{array}$ & 1 & 2 & 3 & 4 & 5 & 6 & 7 \\
\hline b. The decision making process was fair & 1 & 2 & 3 & 4 & 5 & 6 & 7 \\
\hline $\begin{array}{l}\text { Everybody had an equal chance of influencing } \\
\text { the outcome of the group decision }\end{array}$ & 1 & 2 & 3 & 4 & 5 & 6 & 7 \\
\hline d. Nobody dominated the decision making \\
process
\end{tabular}

5. How strongly do you agree / disagree with the following statements concerning the conditionality outcome of the FIRST group decision on a scale of 1 (strongly disagree) to 7 (strongly agree)

\begin{tabular}{|c|c|c|c|c|c|c|c|}
\hline Statement & \multicolumn{5}{|l|}{ Strongly disagree } \\
\hline $\begin{array}{l}\text { a. feel comfortable with the choice that the } \\
\text { group has taken }\end{array}$ & 1 & 2 & 3 & 4 & 5 & 6 & 7 \\
\hline b. The decision making process was fair & 1 & 2 & 3 & 4 & 5 & 6 & 7 \\
\hline $\begin{array}{l}\text { Everybody had an equal chance of influencing } \\
\text { the outcome of the group decision }\end{array}$ & 1 & 2 & 3 & 4 & 5 & 6 & 7 \\
\hline $\begin{array}{l}\text { Nobody dominated the decision making } \\
\text { process }\end{array}$ & 1 & 2 & 3 & 4 & 5 & 6 & 7 \\
\hline
\end{tabular}


Additional codes: 77 - respondent refused to answer / 88 - respondent does not know / 99 - question does not apply

\section{Preferences for education / health}

Now I would like to ask you a few questions with respect to your general preferences in life.

6. How important on a scale from 1 (not important) to 7 (very important) is it for you to plan ahead in the following areas:

\begin{tabular}{|l|c|c|c|c|c|c|c|}
\hline Area & \multicolumn{9}{|c|}{ Not important } \\
\hline a. Health & 1 & 2 & 3 & 4 & 5 & 6 & 7 \\
\hline b. Education & 1 & 2 & 3 & 4 & 5 & 6 & 7 \\
\hline c. Family planning & 1 & 2 & 3 & 4 & 5 & 6 & 7 \\
\hline
\end{tabular}

7.

a. If you had access to the ZMK $1,000,000$ yourself, what would you do with the money?

\begin{tabular}{ll}
\hline Agriculture & $\square$ Sanitary items \\
\hline$\square$ Income generating activity, such as & Home \\
\hline$\square$ Assets & Education \\
\hline$\square$ Food & Health \\
\hline$\square$ Other, please specify: & Clothes
\end{tabular}

b. Would you spend all the money right now?

$\square$ Yes
$\square$ No

c. If NO, how much would you keep?

d. For what purpose?

$\square$ Investment
$\square$ Education
$\square$ Other, please specify:

8.

a. How important is it for you that your (grand) children are in school on a scale from 1 (not important) to 7 (very important)? In case the person does not have any (grand)children, just ask the person to imagine they had

\begin{tabular}{|c|c|c|c|c|c|c|}
\hline $\begin{array}{l}\text { Not } \\
\text { important }\end{array}$ & $\begin{array}{r}\text { Very } \\
\text { important }\end{array}$ \\
\hline 1 & 2 & 3 & 4 & 5 & 6 & 7 \\
\hline
\end{tabular}

b. Why do you think that education is important?

\begin{tabular}{l}
$\square$ Easier to find a job \\
$\square$ Facilitates day to day activities $\quad \square$ Respect \\
\hline$\square$ Other, please specify:
\end{tabular}

c. Why do you think that education is not important?

$\square$ No monetary pay-off
Low quality
There is a better use of time
Other, please specify:


Additional codes: 77 - respondent refused to answer / 88 - respondent does not know / 99 - question does not apply

9.

a. How important is it for you that your (grand) children under $\mathbf{5}$ regularly go for check-ups and are vaccinated on a scale from 1 (not important) to 7 (very important)? In case the person does not have any (grand)children, just ask the person to imagine they had

\begin{tabular}{|c|c|c|c|c|c|c|}
\hline $\begin{array}{l}\text { Not } \\
\text { important }\end{array}$ & \multicolumn{1}{|r}{$\begin{array}{r}\text { Very } \\
\text { important }\end{array}$} \\
\hline 1 & 2 & 3 & 4 & 5 & 6 & 7 \\
\hline
\end{tabular}

b. Why is this important for you?

\begin{tabular}{l}
$\square$ Better health in the future \\
Take action in due time / prevention is better than cure \\
$\square$ Duty \\
\hline Other, please specify:
\end{tabular}

c. Why is this not so important for you?
Low quality
Does not make any change
There is a better use of time
Other, please specify:

Time preferences

10.

a. Now let me present two different scenarios to you. If you were given $\mathbf{5 0 , 0 0 0 ~ Z M K ~ t o d a y ~ o r ~} \mathbf{7 0 , 0 0 0}$ ZMK in a month's time, which option would you choose? Every time that the interviewee takes the 50,000 today, offer the next highest amount and circle the respective answers

\begin{tabular}{|l|l|l|l|l|l|}
\hline Options & Option 1 & Option 2 & Option 3 & Option 4 & Option 5 \\
\hline Today & 50,000 & 50,000 & 50,000 & 50,000 & 50,000 \\
\hline In a month's time & 70,000 & 80,000 & 90,000 & 100,000 & 110,000 \\
\hline
\end{tabular}

b. If you were given $\mathbf{5 0 , 0 0 0 ~ Z M K ~ i n ~ s i x ~ m o n t h s ~ o r ~} \mathbf{7 0 , 0 0 0 ~ Z M K ~ i n ~ s e v e n ~ m o n t h s , ~ w h i c h ~ o p t i o n ~ w o u l d ~}$ you choose? Every time that the interviewee takes the 50,000 today, offer the next highest amount and circle the respective answers

\begin{tabular}{|l|l|l|l|l|l|}
\hline Options & Option 1 & Option 2 & Option 3 & Option 4 & Option 5 \\
\hline In 6 months & 50,000 & 50,000 & 50,000 & 50,000 & 50,000 \\
\hline In 7 months & 70,000 & 80,000 & 90,000 & 100,000 & 110,000 \\
\hline
\end{tabular}

\section{Risk behavior}

With respect to risks in life...

11. Are you generally a person who is fully prepared to take risks or do you try to avoid taking risks? Where do you see yourself on a scale from 0 "not prepared to take any risks in life" to 10 "fully prepared to take risks in life"

\begin{tabular}{|c|c|c|c|c|c|c|c|c|c|c|}
\hline \multicolumn{2}{|c|}{ Not prepared to take any risks } & \multicolumn{1}{c|}{ Fully prepared to take risks } \\
\hline 0 & 1 & 2 & 3 & 4 & 5 & 6 & 7 & 8 & 9 & 10 \\
\hline
\end{tabular}


Additional codes: 77 - respondent refused to answer / 88 - respondent does not know / 99 - question does not apply

\section{Reciprocal behavior}

In a next step, I would like to ask you a few questions on your interaction with other people.

To what degree do the following statements apply to you personally on a scale from 1 (does not apply to me at all) to 7 (applies to me perfectly)?

\begin{tabular}{|c|c|c|c|c|c|c|c|}
\hline \multirow{2}{*}{$\begin{array}{l}\text { Statement } \\
\text { 12. If someone does me a favor, I am prepared to } \\
\text { return it }\end{array}$} & \multicolumn{7}{|c|}{ Does not apply } \\
\hline & 1 & 2 & 3 & 4 & 5 & 6 & 7 \\
\hline $\begin{array}{l}\text { 13. If I suffer a serious wrong, I will take revenge as } \\
\text { soon as possible, no matter what the cost }\end{array}$ & 1 & 2 & 3 & 4 & 5 & 6 & 7 \\
\hline $\begin{array}{l}\text { 14. If somebody puts me in a difficult position, I will do } \\
\text { the same to him/her }\end{array}$ & 1 & 2 & 3 & 4 & 5 & 6 & 7 \\
\hline $\begin{array}{l}\text { 15. I go out of my way to help somebody who has been } \\
\text { kind to me before }\end{array}$ & 1 & 2 & 3 & 4 & 5 & 6 & 7 \\
\hline 16. If somebody offends me, I will offend him/her back & 1 & 2 & 3 & 4 & 5 & 6 & 7 \\
\hline $\begin{array}{l}\text { 17. I am ready to undergo personal costs to help } \\
\text { somebody who helped me before }\end{array}$ & 1 & 2 & 3 & 4 & 5 & 6 & 7 \\
\hline $\begin{array}{l}\text { 18. I help people who cannot do anything for me in } \\
\text { return }\end{array}$ & 1 & 2 & 3 & 4 & 5 & 6 & 7 \\
\hline
\end{tabular}

19. Have you personally given payments or in-kind support during the last year to the following people? Please tick the respective boxes for yes or no

\begin{tabular}{|l|l|l|l|l|l|l|l|}
\hline & Parents & Spouse & Children & $\begin{array}{l}\text { Other } \\
\text { relatives }\end{array}$ & Neighbors & Friends & Any other person: \\
\hline Yes & & & & & & & \\
\hline No & & & & & & & \\
\hline
\end{tabular}

20. Have you personally received payments or in-kind support during the last year from the following people? Please tick the respective boxes for yes or no

\begin{tabular}{|l|l|l|l|l|l|l|l|}
\hline & Parents & Spouse & Children & $\begin{array}{l}\text { Other } \\
\text { relatives }\end{array}$ & Neighbors & Friends & Any other person: \\
\hline Yes & & & & & & & \\
\hline No & & & & & & & \\
\hline
\end{tabular}

\section{Attitudes on poverty and government assistance}

21. We would like to find out whose responsibility is it to take care of the poor in Zambia. Please tell us what kind of responsibility the following stakeholders have on a scale from 1 (no responsibility) to 7 (full responsibility). If your views fall somewhere in between, you can choose any number in between. Please circle the corresponding answer

\begin{tabular}{|lllllllll|}
\hline & & No responsibility & & & & Full responsibility \\
\hline a. & Family & 1 & 2 & 3 & 4 & 5 & 6 & 7 \\
\hline b. Community & 1 & 2 & 3 & 4 & 5 & 6 & 7 \\
\hline c. Entire society & 1 & 2 & 3 & 4 & 5 & 6 & 7 \\
\hline d. Government & 1 & 2 & 3 & 4 & 5 & 6 & 7 \\
\hline e. Church & 1 & 2 & 3 & 4 & 5 & 6 & 7 \\
\hline f. $\quad$ NGOs & 1 & 2 & 3 & 4 & 5 & 6 & 7 \\
\hline g. International cooperating partners & 1 & 2 & 3 & 4 & 5 & 6 & 7 \\
\hline h. Other: & 1 & 2 & 3 & 4 & 5 & 6 & 7 \\
\hline
\end{tabular}


Additional codes: 77 - respondent refused to answer / 88 - respondent does not know / 99 - question does not apply

22. Next, we like to find out your opinion on why poverty is so high in Zambia. Please indicate for each of the following causes to what extent they apply on a scale from 1 (does not apply) to 7 (fully applies). If your views fall somewhere in between, you can choose any number in between Please circle the corresponding answer

\begin{tabular}{|c|c|c|c|c|c|c|c|}
\hline \multirow[b]{2}{*}{ a. Lack of opportunities for the poor } & \multicolumn{5}{|c|}{ Does not apply $\leftarrow$} & \multicolumn{2}{|c|}{ Fully applies } \\
\hline & 1 & 2 & 3 & 4 & 5 & 6 & 7 \\
\hline b. Lack of initiative of the poor & 1 & 2 & 3 & 4 & 5 & 6 & 7 \\
\hline c. Mindset of the poor & 1 & 2 & 3 & 4 & 5 & 6 & 7 \\
\hline d. Wrong government policies & 1 & 2 & 3 & 4 & 5 & 6 & 7 \\
\hline e. Wrong donor policies & 1 & 2 & 3 & 4 & 5 & 6 & 7 \\
\hline $\begin{array}{l}\text { f. External circumstances (climate, natural } \\
\text { resources, characteristics \& history of the country) }\end{array}$ & 1 & 2 & 3 & 4 & 5 & 6 & 7 \\
\hline g. HIV / AIDS & 1 & 2 & 3 & 4 & 5 & 6 & 7 \\
\hline $\begin{array}{l}\text { h. Other: } \\
\quad \ldots \ldots \ldots . . .\end{array}$ & 1 & 2 & 3 & 4 & 5 & 6 & 7 \\
\hline
\end{tabular}

23. Please specify for each of the following statements how strongly you agree or disagree on a scale from 1 (strongly disagree) to 7 (strongly agree). If your views fall somewhere in between, you can choose any number in between. Please circle the corresponding answer

\begin{tabular}{|c|c|c|c|c|c|c|c|}
\hline \multirow[b]{2}{*}{$\begin{array}{l}\text { a. It is humiliating to receive money without } \\
\text { working for it }\end{array}$} & \multicolumn{2}{|c|}{ Strongly disagree } & \multirow{2}{*}{3} & \multirow[b]{2}{*}{4} & \multirow[b]{2}{*}{5} & \multicolumn{2}{|c|}{ Strongly agree } \\
\hline & 1 & 2 & & & & 6 & 7 \\
\hline b. People who don't work become lazy & 1 & 2 & 3 & 4 & 5 & 6 & 7 \\
\hline c. Work is a duty toward society & 1 & 2 & 3 & 4 & 5 & 6 & 7 \\
\hline $\begin{array}{l}\text { d. Work is difficult to combine with caring } \\
\text { obligations for other household members }\end{array}$ & 1 & 2 & 3 & 4 & 5 & 6 & 7 \\
\hline $\begin{array}{l}\text { e. Everybody in society can and should } \\
\text { work }\end{array}$ & 1 & 2 & 3 & 4 & 5 & 6 & 7 \\
\hline
\end{tabular}

24. If you were a policymaker in Zambia, would you: Please choose only ONE answer that is the most relevant to you

$\begin{array}{ll} & \\ \begin{array}{ll}\text { a. Give social } \begin{array}{c}\text { all children } \\ \text { (government assistance) }\end{array} \\ \text { first to }\end{array} \\ & \text { all elderly } \\ & \text { all people with disabilities } \\ & \text { all those in extreme poverty } \\ & \text { nobody (skip the next question) } \\ \text { b. Give assistance in } & \text { cash }\end{array}$


Additional codes: 77 - respondent refused to answer / 88 - respondent does not know / 99 - question does not apply

25. Imagine you are a Social Welfare Officer and the following people ask you for assistance. Please read out the information for all three people. Who would you give the money to first? After the person has decided: Who would you give to second? Please give the person who is chosen first the rank 1, the second person chosen the rank 2 and the remaining person the rank 3.

\begin{tabular}{|c|c|}
\hline Person & Ranking \\
\hline 1) $\begin{array}{l}\text { Mr. Benson Mainza, } 45 \text { years old, is married to Gladys. They have } 8 \text { children together of } \\
\text { which half of them are not in school. He seeks money for fertilizer to grow vegetables in } \\
\text { order to generate some more income for his family. }\end{array}$ & $\begin{array}{l}\text { Ms. Elizabeth Cholwe is } 80 \text { years old. She takes care of her } 4 \text { grandchildren as two of her } 5 \\
\text { children recently died. They all share one room and Elizabeth does not manage anymore to } \\
\text { do any farming activities to nourish the children properly. }\end{array}$ \\
\hline 3) $\begin{array}{l}\text { Mr. Milton Luyando is in a wheelchair after he had a serious car accident. He can no longer } \\
\text { work as a truck driver and stays in the village with his wife Agnes and } 4 \text { children. His wife is } \\
\text { expecting soon the } 5^{\text {th }} \text { child and needs to get medical support. }\end{array}$ & \\
\hline
\end{tabular}

\section{Trust}

The next set of questions is centered on trust.

26. What is your opinion on the following six statements from 1 (strongly disagree) to 7 (strongly agree)?

\begin{tabular}{|lllllllc|}
\hline & & \multicolumn{1}{c}{ Strongly disagree } & \multicolumn{3}{c|}{ Strongly agree } \\
\hline a. Overall one can trust people & 1 & 2 & 3 & 4 & 5 & 6 & 7 \\
\hline b. Nowadays one can't rely on anyone & 1 & 2 & 3 & 4 & 5 & 6 & 7 \\
\hline c. $\begin{array}{l}\text { If one is dealing with strangers, it is better to be } \\
\text { careful before one can trust them }\end{array}$ & 1 & 2 & 3 & 4 & 5 & 6 & 7 \\
\hline d. Overall one can trust family members & 1 & 2 & 3 & 4 & 5 & 6 & 7 \\
\hline e. Overall one can trust community members & 1 & 2 & 3 & 4 & 5 & 6 \\
\hline f. Overall one can trust government & 1 & 2 & 3 & 4 & 5 & 6 & 7 \\
\hline
\end{tabular}

27. Do you believe that most people would (please read out both options)

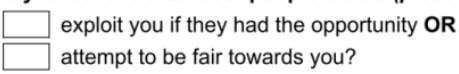

28. Would you say that for most of the time, people attempt

to be helpful OR
only act in their own interests?

\section{Happiness}

29. How satisfied are you today with the following areas of your life? Please answer by using the following scale: 1 means "very unhappy", 7 means "very happy".

\begin{tabular}{|l|c|c|c|c|c|c|c|}
\hline Statement & \multicolumn{3}{|c|}{ Very unhappy } \\
\hline a. Your health & 1 & 2 & 3 & 4 & 5 & 6 & 7 \\
\hline b. Your household income & 1 & 2 & 3 & 4 & 5 & 6 & 7 \\
\hline c. Your place of dwelling & 1 & 2 & 3 & 4 & 5 & 6 & 7 \\
\hline $\begin{array}{l}\text { d. The supply of goods and services } \\
\text { in your area }\end{array}$ & 1 & 2 & 3 & 4 & 5 & 6 & 7 \\
\hline e. The community life & 1 & 2 & 3 & 4 & 5 & 6 & 7 \\
\hline f. Your overall standard of living & 1 & 2 & 3 & 4 & 5 & 6 & 7 \\
\hline
\end{tabular}


Additional codes: 77 - respondent refused to answer / 88 - respondent does not know / 99 - question does not apply

\section{Relationship with other group members}

Last but not least, I would like to ask you about your relationship with other group members

30. Can you tell us for each of the group members

a. How well you know each other? (Please read out all the options from 'very well to' to 'not really')

b. What kind of relationship you have (Use the relationship codes)

\begin{tabular}{|l|l|l|l|l|l|l|}
\hline \multirow{2}{*}{ Group member } & \multicolumn{3}{|l|}{ Level of knowing each other } & \multicolumn{2}{l|}{$\begin{array}{l}\text { Relationship } \\
\text { see codes }\end{array}$} \\
\hline & Very well & Well & A bit & Hardly & Not really & \\
\hline 1 & & & & & & \\
\hline 2 & & & & & & \\
\hline 3 & & & & & & \\
\hline 4 & & & & & & \\
\hline 5 & & & & & & \\
\hline 6 & & & & & & \\
\hline 7 & & & & & & \\
\hline 8 & & & & & & \\
\hline 9 & & & & & & \\
\hline 10 & & & & & & \\
\hline
\end{tabular}

Thank you very much for your time and all the information you provided us with! We now proceed to the last round. 


\section{Annex 7: Conditionality monitoring cards}

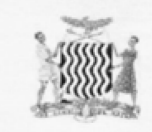

Ministry of Community Development and Social Services

Cash Transfer Scheme

P.O. BOX 31999 LUSAKA

\section{Conditionality Education - 2007}

District Monze

ACC: Chikuni CWAC: SINTEMBA

School: Sintemba Basic School.

Date Started Scheme: $\quad$ 07-Sep-07

Information about child:

Name of Head of Household:

NRC of Head of Household:

Name of a Child:

Relationship to Head of HH: $\quad$ Grandson

Gender: Male Age: 10 Grade: 2 

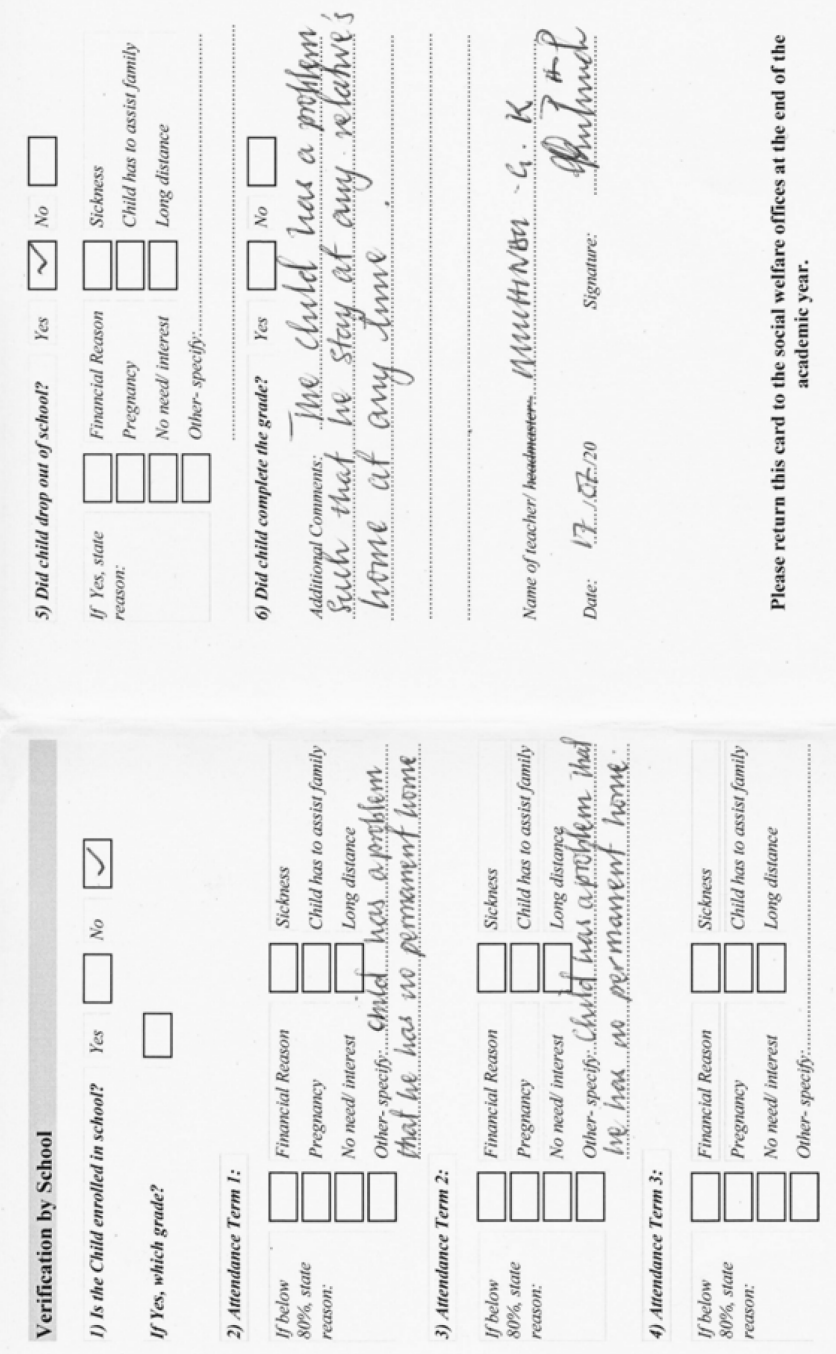
Ministry of Community Development and Social Services

Cash Transfer Scheme

P.O. BOX 31999 LUSAKA

\section{Conditionality Health}

District Monze

ACC: Keemba CWAC: Monzwe 2

Date Started Scheme : 07-Oct-07

\section{Information about child:}

Name of Head of Household:

NRC of Head of Household:

Name of a Child

Relationship to Head of HH: Grandson

Gender: Male Age: 1

Possession of U5 card? Yes 

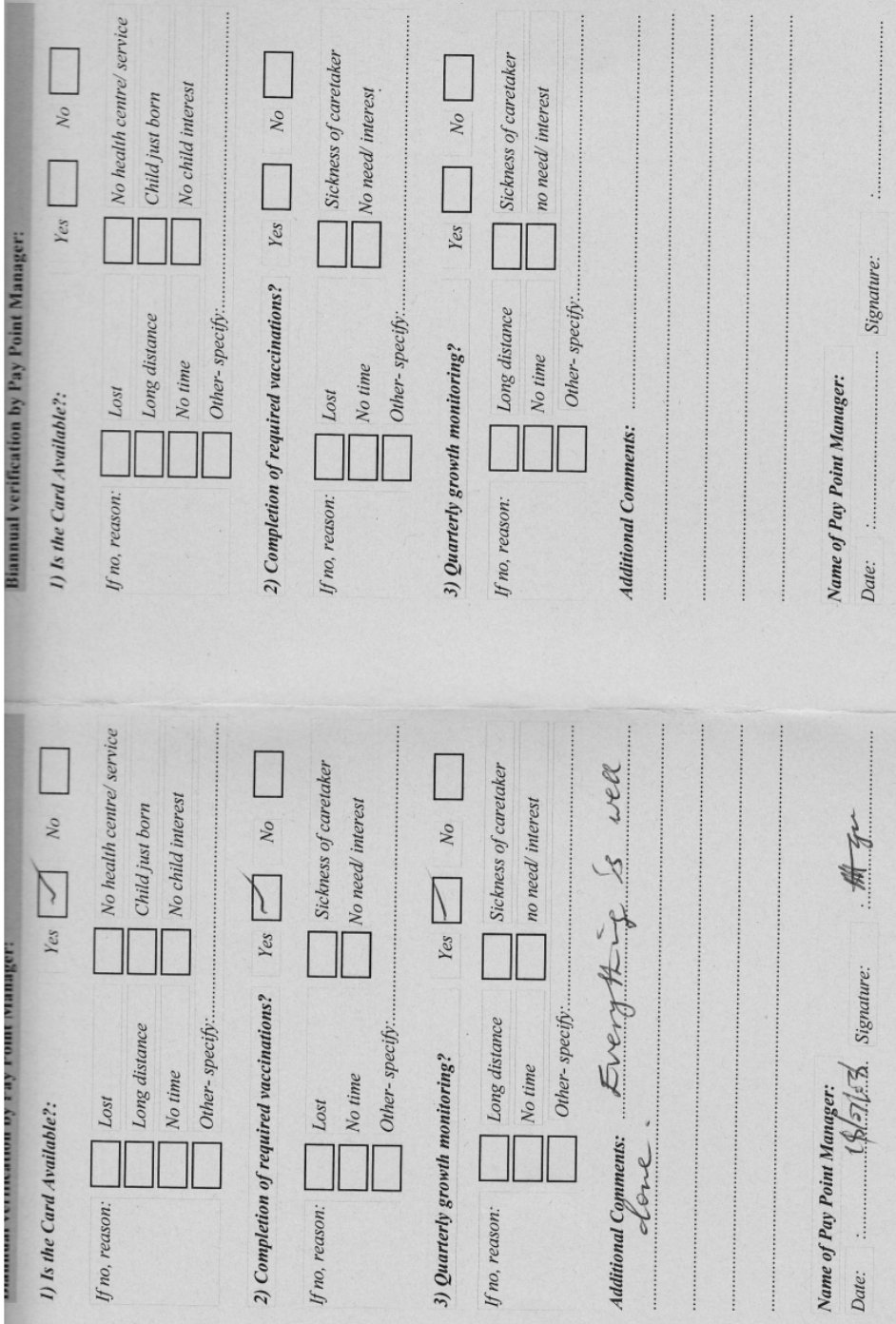


\section{Annex 8: Questionnaire for beneficiary survey}

Additional codes: 77 - respondent refused to answer / 88 - respondent does not know / 99 - question does not apply

\section{Questionnaire for beneficiary households}

\begin{tabular}{|c|c|c|c|c|c|}
\hline Date & .09 .2009 & CWAC & $\begin{array}{l}\text { \# of } \\
\text { interview }\end{array}$ & $\begin{array}{l}\text { Interview } \\
\text { started at: }\end{array}$ & $\begin{array}{l}\text { Interview } \\
\text { ended at: }\end{array}$ \\
\hline \multicolumn{6}{|c|}{$\begin{array}{l}\text { Any particular } \\
\text { observations: }\end{array}$} \\
\hline \multicolumn{2}{|c|}{ Name of interviewer: } & & & Signature: & \\
\hline \multicolumn{2}{|c|}{ Interview checked by: } & & & Signature: & \\
\hline
\end{tabular}

Thank you for your time and willingness to participate in this research activity that is jointly carried out by the University of Zambia and the University of Maastricht, a University from the Netherlands. We are studying how the social cash transfer scheme can be optimized to make suggestions to the Ministry of Community Development and Social Services. All the information you provide will be confidential and will have no implications on your status as a beneficiary of the social cash transfer scheme. We would like to ask you a few questions about the impact of the social cash transfer scheme as well as about your preferences, future vision and happiness. If you feel uncomfortable answering a particular questions, please tell us and we will skip to the next question. Do you have any questions with respect to the procedure? The interview will take approximately 45 minutes of your time.

\section{Personal information}

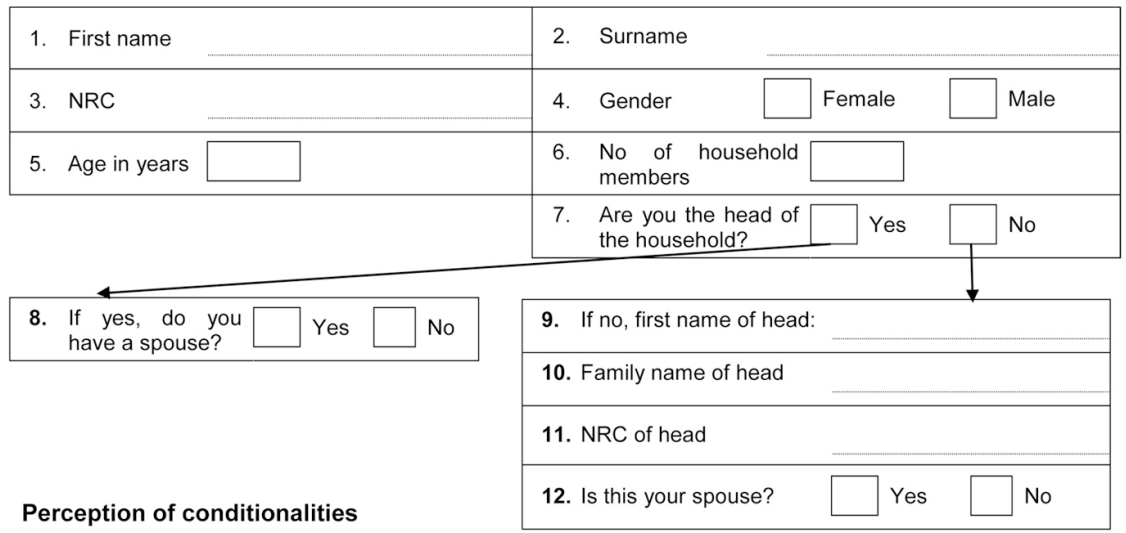

13. We know you are a beneficiary of the Social Cash Transfer Scheme. Do you have to do anything in exchange for the money? Please probe by asking: So, there were no conditions attached to the transfer OR so you did not have to comply with any conditions?

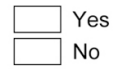

If YES, proceed to question 14; if NO proceed to question 15 on page 3

14. If YES to Question 13 
Additional codes: 77 - respondent refused to answer / 88 - respondent does not know / 99 - question does not apply

a. What were your obligations? Please tick the conditionalities that the beneficiary mentioned

\begin{tabular}{|l|l|l|l|l|l|l|}
\hline $\begin{array}{l}\text { Enrolment of all } \\
\text { children } \\
\text { primary school in }\end{array}$ & $\begin{array}{l}\text { Attendance } \\
\text { of } 80 \%\end{array}$ & U5 card & $\begin{array}{l}\text { All } \\
\text { vaccinations } \\
\text { for U5 }\end{array}$ & $\begin{array}{l}\text { Quarterly growth } \\
\text { monitoring for } \\
\text { U5 }\end{array}$ & $\begin{array}{l}\text { Not to } \\
\text { misuse } \\
\text { money }\end{array}$ & $\begin{array}{r}\text { Other, please state: } \\
\text { the }\end{array}$ \\
\hline
\end{tabular}

b1. Did anyone follow up on these obligations?

$\square$ Yes
No (skip to question c1)

b2. Who followed up?

\begin{tabular}{l}
$\square$ Teacher / headmaster \\
\hline Pay point manager \\
\hline Social welfare officer \\
\hline Community Welfare Assistance Committee \\
Other, please specify:
\end{tabular}

b3. How often did this person follow up with respect to [mention those conditionalities stated in 14a]

\begin{tabular}{|c|c|c|c|c|c|c|c|}
\hline Conditionality & $\begin{array}{l}\text { Every } \\
\text { month }\end{array}$ & $\begin{array}{l}\text { Every } 2 \\
\text { month }\end{array}$ & $\begin{array}{l}\text { Every } 3 \\
\text { months }\end{array}$ & $\begin{array}{l}\text { Every } 6 \\
\text { months }\end{array}$ & $\begin{array}{l}\text { Not on a } \\
\text { regular } \\
\text { basis }\end{array}$ & Never & $\begin{array}{l}\text { Other (please } \\
\text { specify) }\end{array}$ \\
\hline \multicolumn{8}{|l|}{ Enrolment } \\
\hline \multicolumn{8}{|l|}{ Attendance } \\
\hline \multicolumn{8}{|l|}{ U5card } \\
\hline \multicolumn{8}{|l|}{ Vaccinations } \\
\hline \multicolumn{8}{|l|}{ Growth monitoring } \\
\hline \multicolumn{8}{|l|}{ No misuse } \\
\hline Other & & & & & & & \\
\hline
\end{tabular}

b4 Did the person following up ever ask for any money to fill in the monitoring card?<smiles>[Y6]C1C2=C3CC2C([N+](=O)[O-])C1C3</smiles>

b5 If YES, how much money did he / she ask you to pay?

b6 How much did you pay?

c1. Do you think that these obligations were fair?

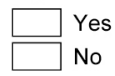

c2. If NO, why not?

\begin{tabular}{l}
$\square$ Too little money \\
\hline$\quad$ No quality service \\
\hline$\quad$ No self-determination \\
\hline Other, please specify:
\end{tabular}

No supply-side structure

Too much work

Stigmatization

d. Did the conditionalities produce additional work?

$\square$ Yes
$\square$ No

e1 Did the conditionalities lead to any additional costs?

$\square$ Yes
$\square$ No

e2 If YES, how much money out of the transfer did you spend on conditionalities? 
Additional codes: 77 - respondent refused to answer / 88 - respondent does not know / 99 - question does not apply

f1. Did you comply with the obligations? [mention those conditionalities stated in 14a]

\begin{tabular}{|l|l|l|l|l|l|l|l|}
\hline & Enrolment & Attendance & U5 card & Vaccinations & Growth monitoring & No misuse & Other \\
\hline Yes & & & & & & & \\
\hline No & & & & & & & \\
\hline
\end{tabular}

f2. If NO, why not?

\begin{tabular}{l}
$\square$ No supply-side structure \\
\hline
\end{tabular}

Too much work

Other, please specify:

g. Would you say that the conditionalities have (please read out all the options)
$\square$ Empowered you
Disempowered you
Neither empowered nor disempowered you

h. Do you think community members who are not benefitting would prefer to have conditionalities attached?

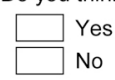

i. Do you think that policy-makers would prefer to have conditionalities attached?

$$
\begin{aligned}
& \square \text { Yes } \\
& \square \text { No }
\end{aligned}
$$

\section{Go directly to question 16}

\section{If NO to question 13}

a. If NO, how would you feel about the following conditions on a scale from 1 (very uncomfortable) to 7 (very comfortable):

\begin{tabular}{|l|c|c|c|c|c|c|c|}
\hline Conditionality & \multicolumn{1}{|c}{ Very uncomfortable } & \multicolumn{3}{c}{$\boldsymbol{4}$ Very comfortable } \\
\hline Enrolment & 1 & 2 & 3 & 4 & 5 & 6 & 7 \\
\hline Attendance 80\% & 1 & 2 & 3 & 4 & 5 & 6 & 7 \\
\hline U5card & 1 & 2 & 3 & 4 & 5 & 6 & 7 \\
\hline Vaccinations & 1 & 2 & 3 & 4 & 5 & 6 & 7 \\
\hline Growth monitoring & 1 & 2 & 3 & 4 & 5 & 6 & 7 \\
\hline
\end{tabular}

b. If uncomfortable, can you tell us the principal reason why you feel uncomfortable?

$\square$ Too little money
$\square$ No quality service
$\square$ No self-determination
$\square$ Other, please specify:

c. If you were asked to comply with the following conditions, how feasible do you think the following conditions would for you on a scale from 1 (not feasible) to 7 (very feasible)?

\begin{tabular}{|l|c|c|c|c|c|c|c|}
\hline Conditionality & \multicolumn{2}{|c|}{ Not feasible } \\
\hline Enrolment & 1 & 2 & 3 & 4 & 5 & 6 & 7 \\
\hline Attendance 80\% & 1 & 2 & 3 & 4 & 5 & 6 & 7 \\
\hline U5card & 1 & 2 & 3 & 4 & 5 & 6 & 7 \\
\hline Vaccinations & 1 & 2 & 3 & 4 & 5 & 6 & 7 \\
\hline Growth monitoring & 1 & 2 & 3 & 4 & 5 & 6 & 7 \\
\hline
\end{tabular}


Additional codes: 77 - respondent refused to answer / 88 - respondent does not know / 99 - question does not apply

d. If unfeasible, can you tell use the principal reason why they would not be feasible?

\begin{tabular}{ll}
$\square$ No supply-side structure & $\square$ No quality service \\
\hline$\square$ Too much work & Too little money \\
\hline$\square$ Other, please specify: &
\end{tabular}

e. Would you perceive the conditionalities as (please read out all the options)
$\square$ Empowering
Disempowering
neither empowering nor disempowering

f. Would you decide against the transfer if you had to comply with all of these conditionalities?

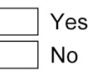

g. Do you think other community members who are not benefitting prefer to have conditionalities attached?

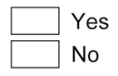

h. Do you think that policy-makers prefer to have conditionalities attached?

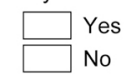

\section{Preferences for education / health}

Now I would like to ask you a few questions with respect to your general preferences in life.

16. How important on a scale from 1 (not important) to 7 (very important) is it for you to plan ahead in the following areas:

\begin{tabular}{|l|c|c|c|c|c|c|c|}
\hline Area & \multicolumn{3}{|c|}{ Not important } & \multicolumn{3}{c|}{ Very important } \\
\hline a. Health & 1 & 2 & 3 & 4 & 5 & 6 & 7 \\
\hline b. Education & 1 & 2 & 3 & 4 & 5 & 6 & 7 \\
\hline c. Family planning & 1 & 2 & 3 & 4 & 5 & 6 & 7 \\
\hline
\end{tabular}

17.

a. If you had access to ZMK $1,000,000$, what would you do with the money?
$\square$ Agriculture
Other income generating activity:
Assets
Food
Other, please specify:

\begin{tabular}{|c|}
\hline Sanitary items \\
\hline Home \\
\hline Education \\
\hline Health \\
\hline Clothes \\
\hline
\end{tabular}

b. Would you spend all the money right now?

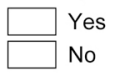

18. If NO, how much would you keep?

\section{For what purpose?}

\begin{tabular}{l}
$\square$ Investment \\
\hline Education \\
\hline Other, please specify:
\end{tabular}




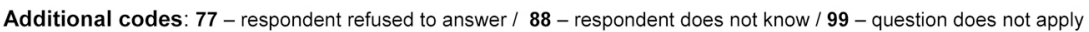

20.

a. How important is it for you that your (grand) children are in school on a scale from 1 (not important) to 7 (very important)?

\begin{tabular}{|c|c|c|c|c|c|c|}
\hline $\begin{array}{l}\text { Not } \\
\text { important }\end{array}$ & \multicolumn{1}{|c}{$\begin{array}{r}\text { Very } \\
\text { important }\end{array}$} \\
\hline 1 & 2 & 3 & 4 & 5 & 6 & 7 \\
\hline
\end{tabular}

b. Why do you think that education is important?

$\begin{array}{ll}\square \text { Easier to find a job } & \square \text { More money } \\ \square \text { Facilitates day to day activities } \\ \square \text { Respect }\end{array}$

c. Why do you think that education is not important?

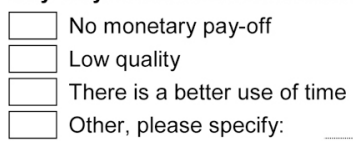

21. How important is it for you that your children under 5 regularly go for check-ups and are vaccinated on a scale from 1 (not important) to 7 (very important)?

\begin{tabular}{|c|c|c|c|c|c|c|}
\hline \multicolumn{2}{|c|}{$\begin{array}{l}\text { Not } \\
\text { important }\end{array}$} & & & & \multicolumn{2}{|c|}{$\begin{array}{r}\text { Very } \\
\text { important }\end{array}$} \\
\hline 1 & 2 & 3 & 4 & 5 & 6 & 7 \\
\hline
\end{tabular}

a. Why is this important for you?

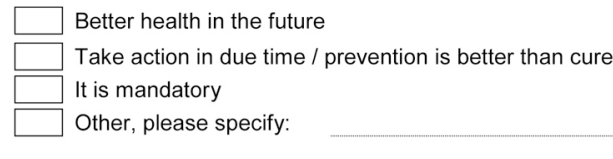

b. Why is this not so important for you?

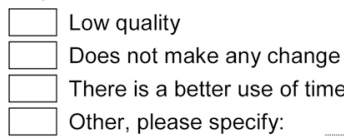

Time preferences

22.

a. Now let me present two different scenarios to you. If you were given 50,000 ZMK today or 70,000 ZMK in a month's time, which option would you choose? Every time that the interviewee takes the 50,000 today, offer the next highest amount and circle the respective answers

\begin{tabular}{|l|c|c|c|c|c|}
\hline Options & Option 1 & Option 2 & Option 3 & Option 4 & Option 5 \\
\hline Today & 50,000 & 50,000 & 50,000 & 50,000 & 50,000 \\
\hline In a month's time & 70,000 & 80,000 & 90,000 & 100,000 & 110,000 \\
\hline
\end{tabular}

b. If you were given $50,000 \mathrm{ZMK}$ in six months or 70,000 ZMK in seven months, which option would you choose? Every time that the interviewee takes the 50,000 today, offer the next highest amount and circle the respective answers

\begin{tabular}{|l|c|c|c|c|c|}
\hline Options & Option 1 & Option 2 & Option 3 & Option 4 & Option 5 \\
\hline In 6 months & 50,000 & 50,000 & 50,000 & 50,000 & 50,000 \\
\hline In 7 months & 70,000 & 80,000 & 90,000 & 100,000 & 110,000 \\
\hline
\end{tabular}


Additional codes: 77 - respondent refused to answer / 88 - respondent does not know / 99 - question does not apply

Risk behavior

23. Are you generally a person who is fully prepared to take risks or do you try to avoid taking risks? Where do you see yourself on a scale from 0 "not prepared to take any risks in life" to 10 "fully prepared to take risks in life"

\begin{tabular}{|c|c|c|c|c|c|c|c|c|c|c|} 
Not prepared to take any risks & \multicolumn{4}{c}{ Fully prepared to take risks } \\
\hline 0 & 1 & 2 & 3 & 4 & 5 & 6 & 7 & 8 & 9 & 10
\end{tabular}

\section{Happiness}

24. I will now read to you a number of feelings. Please indicate for each feeling how often or rarely you experienced this feeling in the last four weeks. How often have you felt on a scale of 1 (very rarely) to 5 (very often)

\begin{tabular}{|l|c|c|c|c|c|}
\hline Statement & \multicolumn{2}{|c|}{ Very rarely } \\
\hline a. Angry & 1 & 2 & 3 & 4 & 5 \\
\hline b. Worried & 1 & 2 & 3 & 4 & 5 \\
\hline c. Happy & 1 & 2 & 3 & 4 & 5 \\
\hline d. Sad & 1 & 2 & 3 & 4 & 5 \\
\hline
\end{tabular}

25. How satisfied are you today with the following areas of your life? Please answer by using the following scale: 1 means "very unhappy", 7 means "very happy".

\begin{tabular}{|l|r|r|r|r|r|r|r|}
\hline Statement & \multicolumn{1}{|c|}{ Very unhappy } \\
\hline a. Your health & 1 & 2 & 3 & 4 & 5 & 6 & 7 \\
\hline b. Your household income & 1 & 2 & 3 & 4 & 5 & 6 & 7 \\
\hline c. Your place of dwelling & 1 & 2 & 3 & 4 & 5 & 6 & 7 \\
\hline $\begin{array}{l}\text { d. The supply of goods and services } \\
\text { in your area }\end{array}$ & 1 & 2 & 3 & 4 & 5 & 6 & 7 \\
\hline e. The community life & 1 & 2 & 3 & 4 & 5 & 6 & 7 \\
\hline f. Your overall standard of living & 1 & 2 & 3 & 4 & 5 & 6 & 7 \\
\hline
\end{tabular}

\section{Future}

Let's now talk about how you view the future

26. When you think about the future, are you (please read out all options)

\begin{tabular}{|c|c|}
\hline Optimistic & More optimistic than pessimistic \\
\hline More pessimistic than optimistic & \\
\hline
\end{tabular}

27.

a. Do you have any future plans?

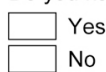

b. If YES, what are those?

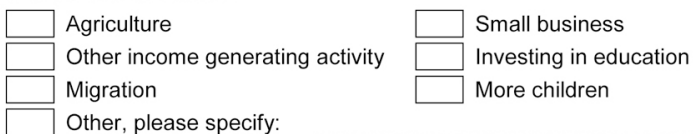

Decision making within the household

Only ask the following questions if interviewee said YES to either question 8 or 12 
Additional codes: 77 - respondent refused to answer / 88 - respondent does not know / 99 - question does not apply

Now let me ask I few questions about how decisions are made in your household

28. Who decides within the household on how to spend the cash transfer?

\begin{tabular}{l}
$\square$ Head of household \\
Spouse \\
\hline$\quad$ Joint decision \\
\hline$\quad$ Other, please specify:
\end{tabular}

29.

a. Does ........... (answer from question 28) also decide on how to spend other money that comes into the household?

Nos

b. If NO, why not?
$\square$ Depends on the source of revenue
Depends on who made the money
Other, please specify:

30. Only ask if beneficiary is aware of conditionalities: Did the conditionalities put you in a better position to negotiate the expenses with your spouse?

$\square$ Yes

\section{Interaction}

We are almost through. Let me ask you a few more questions on how your interacted with different stakeholders of the Social Cash Transfer Scheme

31. Did you launch any complaints with respect to the social cash transfer scheme to the following people since the start of the programme: (please read out all options)

\begin{tabular}{|l|l|l|l|l|l|l|l|}
\hline & CWAC & ACC & DSWO & School & $\begin{array}{l}\text { Health } \\
\text { center }\end{array}$ & $\begin{array}{l}\text { Pay point } \\
\text { manager }\end{array}$ & $\begin{array}{l}\text { Other person } \\
\ldots \ldots \ldots \ldots \ldots \ldots \ldots \ldots \ldots . . . \ldots \ldots\end{array}$ \\
\hline Yes & & & & & & & \\
\hline No & & & & & & & \\
\hline
\end{tabular}

32. If the person is aware of conditionalities (see question 14): Did the conditionalities make you contact the following people more often? (please read out all options)

\begin{tabular}{|c|c|c|c|c|c|c|c|}
\hline & CWAC & $A C C$ & DSWO & School & $\begin{array}{l}\text { Health } \\
\text { center }\end{array}$ & $\begin{array}{l}\text { Pay point } \\
\text { manager }\end{array}$ & $\begin{array}{l}\text { Other person } \\
\ldots \ldots \ldots \ldots \ldots \ldots \ldots \ldots \ldots\end{array}$ \\
\hline Yes & & & & & & & \\
\hline No & & & & & & & \\
\hline
\end{tabular}

\section{Initiative}

Has the social cash transfer scheme changed: (read out options! If person responds "a bit" or "a lot", proceed to ask "in what way")

\begin{tabular}{|l|l|l|l|l|l|}
\hline \multicolumn{2}{|l|}{} & Not at all & A bit & A lot & \multicolumn{2}{l|}{ If yes, in what way? } \\
\hline & & & & Positive & Negative \\
\hline 33. Your self confidence & & & & & \\
\hline 34. Your status in the community? & & & & & \\
\hline 35. Your participation in community activities? & & & & & \\
\hline 36. Your participation in political events? & & & & & \\
\hline 37. Your participation in official committees? & & & & & \\
\hline
\end{tabular}

Thank you very much for your time and all the information you provided us with. We will do our best to ensure that it informs policy-makers in Lusaka and that the programme will be adjusted in the best way to cater for your needs. Do you have any further questions for us? 
$\begin{array}{ll} & \square \text { cash } \\ \text { c. Give assistance in } & \text { In-kind } \\ & \square \text { nothing }\end{array}$

Making school enrolment a condition for those who receive government assistance

d. Raise school enrolment by $\square$ Raising more awareness on the value of education

Building more schools

No need for any intervention

Making school attendance a condition for those who receive government assistance

e. Raise school attendance by

Raising more awareness on the value of education

Improving the quality of schooling

No need for any intervention

Making health checks a condition for those who receive government assistance

f. Get more women to take their babies to health checks by

Improving the availability of services

Raising more awareness on the value of health checks

No need for any intervention

g. Offer social cash transfers Without any conditions that households have to fulfill

$\square$ With conditions attached that households have to fulfill

Not at all (ptease skip question 6 \& 7)

6. In case person DOES NOT prefer attaching conditions: Can you briefly tell us why you prefer to make the cash unconditional?
7. In case person DOES prefer attaching conditions:

a. Can you briefly tell us why?

b. What kind of condition(s) would you attach? 
8. Imagine you would receive a monthly grant of ZMK 50,000 from government and for this money you are asked to do something in exchange.

a. How comfortable would you feel with the following conditions on a scale from 1 (very uncomfortable) to 7 (very comfortable): Please circle the corresponding answer

\begin{tabular}{|l|c|c|c|c|c|c|c|}
\hline Conditionality & \multicolumn{2}{|l|}{ Very uncomfortable } & \multicolumn{2}{|c|}{ Very comfortable } \\
\hline $\begin{array}{l}\text { Enrolment of all children of school going age in } \\
\text { primary school }\end{array}$ & 1 & 2 & 3 & 4 & 5 & 6 & 7 \\
\hline $\begin{array}{l}\text { Enrolment of all children of school going age in } \\
\text { secondary school }\end{array}$ & 1 & 2 & 3 & 4 & 5 & 6 & 7 \\
\hline School attendance of at least 80\% for all children & 1 & 2 & 3 & 4 & 5 & 6 & 7 \\
\hline U5 cards for all children under 5 & 1 & 2 & 3 & 4 & 5 & 6 & 7 \\
\hline All vaccinations completed for all children under 5 & 1 & 2 & 3 & 4 & 5 & 6 & 7 \\
\hline Quarterly growth monitoring for all children under 5 & 1 & 2 & 3 & 4 & 5 & 6 & 7 \\
\hline
\end{tabular}

b. Would you decide against a monthly transfer of ZMK 50,000 if you had to comply with all of the conditionalities stated above?

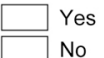

c. What do you think would be a fair transfer level if you had to comply with all the conditionalities stated above?

9. Please give us some more information about yourself

\begin{tabular}{|c|c|c|c|c|c|c|}
\hline a. Gender & \multicolumn{2}{|c|}{ Female } & \multicolumn{4}{|l|}{ Male } \\
\hline b. Age & \multicolumn{3}{|c|}{ c. Place of birth } & & & \\
\hline \multicolumn{7}{|l|}{ d. Tribe } \\
\hline \multicolumn{7}{|l|}{ e. Place of residence } \\
\hline f. Education level completed & \multicolumn{6}{|c|}{ See education codes } \\
\hline \multicolumn{7}{|l|}{ g. No. of household members } \\
\hline h. Occupation & \multicolumn{4}{|c|}{ See occupation codes } & & \\
\hline \multirow{3}{*}{$\begin{array}{l}\text { Main source of income of } \\
\text { household }\end{array}$} & \multicolumn{2}{|c|}{ Paid labor } & \multicolumn{2}{|c|}{ Rental income } & \multirow{3}{*}{$\begin{array}{l}\text { Sale of } \\
\text { produce } \\
\text { Other: }\end{array}$} & Pension \\
\hline & \multirow{2}{*}{\multicolumn{2}{|c|}{$\begin{array}{l}\text { Government } \\
\text { assistance }\end{array}$}} & \multirow{2}{*}{\multicolumn{2}{|c|}{$\begin{array}{l}\text { Community } \\
\text { assistance }\end{array}$}} & & \\
\hline & & & & & & \\
\hline \multirow{2}{*}{$\begin{array}{l}\text { How would you characterize } \\
\text { yourself? }\end{array}$} & \multirow{2}{*}{\multicolumn{2}{|c|}{$\begin{array}{l}\text { Very poor } \\
\text { Upper middle }\end{array}$}} & \multicolumn{2}{|l|}{ Poor } & \multicolumn{2}{|l|}{ Middle } \\
\hline & & & Rich & & Upper rich & \\
\hline $\begin{array}{l}\text { k. Did you vote in the last } \\
\text { election? }\end{array}$ & \multicolumn{2}{|l|}{ Yes } & \multicolumn{4}{|l|}{ No } \\
\hline
\end{tabular}




\section{Annex 9: Questionnaires for the attitudinal survey}

\begin{tabular}{|c|c|c|c|c|c|}
\hline Date & .09 .2009 & Location & $\begin{array}{l}\text { \# of } \\
\text { interview }\end{array}$ & $\begin{array}{l}\text { Interview } \\
\text { started at: }\end{array}$ & $\begin{array}{l}\text { Interview } \\
\text { ended at: }\end{array}$ \\
\hline \multicolumn{6}{|c|}{$\begin{array}{l}\text { Any particular } \\
\text { observations: }\end{array}$} \\
\hline \multicolumn{3}{|c|}{ Name of interviewer: } & & \multicolumn{2}{|l|}{ Signature: } \\
\hline \multicolumn{3}{|c|}{ Interview checked by: } & & Signature: & \\
\hline
\end{tabular}

Attitude survey for the General Public

Thanks very much for your willingness to participate in the survey. This survey is meant to gather information on opinions of the general public in Zambia on poverty and government assistance. You can be assured of strict confidentiality of any information you provide. The information will be used for a research project jointly carried out by the University of Maastricht and the University of Zambia. The research project looks more closely at values and attitudes of different groups in society and analyses how these values and attitudes influence or might potentially influence future policy-making. The findings are intended to inform decisionmakers in the area of social protection in Zambia. If you do not feel comfortable answering a particular question, please let us know and we will proceed to the next question.

1. We would like to find out whose responsibility is it to take care of the poor in Zambia. Please tell us what kind of responsibility the following stakeholders have on a scale from 1 (no responsibility) to 7 (full responsibility). If your views fall somewhere in between, you can choose any number in between. Please circle the corresponding answer

\begin{tabular}{|c|c|c|c|c|c|c|c|c|}
\hline \multirow{2}{*}{\multicolumn{2}{|c|}{ a. Family }} & \multicolumn{4}{|c|}{ No responsibility } & \multicolumn{3}{|c|}{ Full responsibility } \\
\hline & & 1 & 2 & 3 & 4 & 5 & 6 & 7 \\
\hline & Community & 1 & 2 & 3 & 4 & 5 & 6 & 7 \\
\hline & Entire society & 1 & 2 & 3 & 4 & 5 & 6 & 7 \\
\hline & Government & 1 & 2 & 3 & 4 & 5 & 6 & 7 \\
\hline & Church & 1 & 2 & 3 & 4 & 5 & 6 & 7 \\
\hline & NGOs & 1 & 2 & 3 & 4 & 5 & 6 & 7 \\
\hline & International cooperating partners & 1 & 2 & 3 & 4 & 5 & 6 & 7 \\
\hline & $\begin{array}{l}\text { Other: } \\
\ldots \ldots \ldots . .\end{array}$ & 1 & 2 & 3 & 4 & 5 & 6 & 7 \\
\hline
\end{tabular}

2. Next, we like to find out your opinion on why poverty is so high in Zambia. Please indicate for each of the following causes to what extent they apply on a scale from 1 (does not apply) to 7 (fully applies). If your views fall somewhere in between, you can choose any number in between Please circle the corresponding answer

\begin{tabular}{|c|c|c|c|c|c|c|c|}
\hline \multirow[b]{2}{*}{ a. Lack of opportunities for the poor } & \multicolumn{5}{|c|}{ Does not apply $\longleftrightarrow$} & \multicolumn{2}{|c|}{ Fully applies } \\
\hline & 1 & 2 & 3 & 4 & 5 & 6 & 7 \\
\hline b. Lack of initiative of the poor & 1 & 2 & 3 & 4 & 5 & 6 & 7 \\
\hline c. Mindset of the poor & 1 & 2 & 3 & 4 & 5 & 6 & 7 \\
\hline d. Wrong government policies & 1 & 2 & 3 & 4 & 5 & 6 & 7 \\
\hline e. Wrong donor policies & 1 & 2 & 3 & 4 & 5 & 6 & 7 \\
\hline $\begin{array}{l}\text { f. External circumstances (climate, natural } \\
\text { resources, characteristics \& history of the country) }\end{array}$ & 1 & 2 & 3 & 4 & 5 & 6 & 7 \\
\hline g. HIV / AIDS & 1 & 2 & 3 & 4 & 5 & 6 & 7 \\
\hline h. Other: & 1 & 2 & 3 & 4 & 5 & 6 & 7 \\
\hline
\end{tabular}


3. Please specify for each of the following statements how strongly you agree or disagree on a scale from 1 (strongly disagree) to 7 (strongly agree). If your views fall somewhere in between, you can choose any number in between. Please circle the corresponding answer

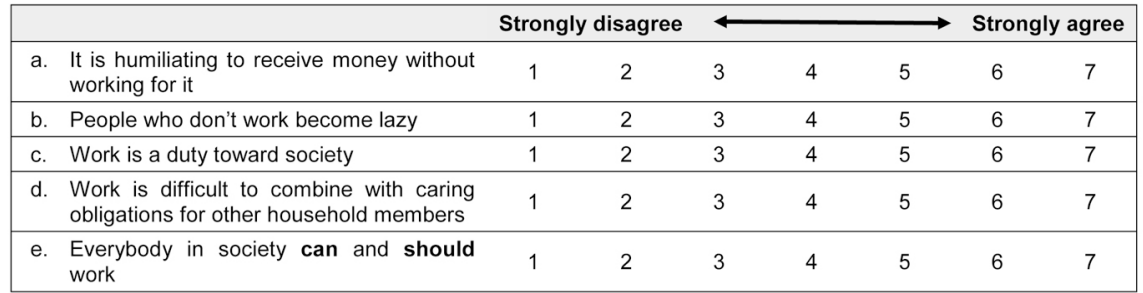

4. Please tell us your views on the following issues. 1 on the scale from 1-7 means that you agree completely with the first statement; 7 means you agree completely with the second statement; if your views fall somewhere in between, you can choose any number in between. 4 means that you are neutral Please circle the corresponding answer

\begin{tabular}{|c|c|c|c|c|c|c|}
\hline \multicolumn{2}{|c|}{$\begin{array}{l}\text { We need larger income differences as } \\
\text { incentives for individual effort }\end{array}$} \\
\hline 1 & 2 & 3 & 4 & 5 & 6 & 7 \\
\hline
\end{tabular}

\begin{tabular}{l}
$\begin{array}{l}\text { b. The government should take more } \\
\text { responsibility to ensure that everyone is } \\
\text { provided for }\end{array}$ \\
\hline 1
\end{tabular}

\begin{tabular}{|c|c|c|c|c|c|}
\hline c. In the long run, hard work usually brings \\
a better life
\end{tabular}

\begin{tabular}{|c|c|c|c|c|c|c|}
\hline \multicolumn{4}{|c|}{$\begin{array}{l}\text { d. People can only get rich at the expense } \\
\text { of others }\end{array}$} & \multicolumn{3}{|c|}{$\begin{array}{l}\text { Wealth can grow so there's enough for } \\
\text { everyone }\end{array}$} \\
\hline 1 & 2 & 3 & 4 & 5 & 6 & 7 \\
\hline
\end{tabular}

\begin{tabular}{|c|r|r|c|c|c|c|}
\hline e. Quality education is accessible to & \multicolumn{5}{c|}{ Quality education is a luxury good for the rich } \\
everyone in society
\end{tabular}

\begin{tabular}{|c|c|c|c|c|c|c|}
\hline f. The poor take responsible decisions & $\begin{array}{l}\text { The poor are irresponsible and should be } \\
\text { told what to do }\end{array}$ \\
\hline 1 & 2 & 3 & 4 & 5 & 6 & 7 \\
\hline
\end{tabular}

5. If you were a policymaker in Zambia, would you: Please only choose ONE answer that you consider most relevant.
a. Prioritize
economic growth
$\square$ redistribution of resources to the poorest
$\square$ both
none of them

$\begin{array}{ll}\text { b. Give social } & \text { transfers } \\ \text { (government } & \\ \text { assistance) } & \text { all elderly } \\ \text { first to } & \text { all people with disabilities } \\ & \\ & \\ & \text { all those in extreme poverty } \\ & \text { nobody }\end{array}$


$\begin{array}{ll} & \\ \text { c. Give assistance in } & \text { cash } \\ \square & \text { In-kind } \\ \square \text { nothing }\end{array}$

Making school enrolment a condition for those who receive government assistance

d. Raise school enrolment by

Raising more awareness on the value of education

Building more schools

No need for any intervention

Making school attendance a condition for those who receive government assistance

e. Raise school attendance by

Raising more awareness on the value of education

Improving the quality of schooling

No need for any intervention

Making health checks a condition for those who receive government assistance

f. Get more women to take their babies to health checks by

Improving the availability of services

Raising more awareness on the value of health checks

No need for any intervention

g. Offer social cash transfers Without any conditions that households have to fulfill With conditions attached that households have to fulfill Not at all (prease skip question 6 \& 7)

6. In case person DOES NOT prefer attaching conditions: Can you briefly tell us why you prefer to make the cash unconditional?
7. In case person DOES prefer attaching conditions:

a. Can you briefly tell us why?

b. What kind of condition(s) would you attach? 
8. Imagine you would receive a monthly grant of ZMK 50,000 from government and for this money you are asked to do something in exchange.

a. How comfortable would you feel with the following conditions on a scale from 1 (very uncomfortable) to 7 (very comfortable): Please circle the corresponding answer

\begin{tabular}{|l|c|c|c|c|c|c|c|}
\hline Conditionality & \multicolumn{2}{|l|}{ Very uncomfortable } & \multicolumn{2}{|c|}{ Very comfortable } \\
\hline $\begin{array}{l}\text { Enrolment of all children of school going age in } \\
\text { primary school }\end{array}$ & 1 & 2 & 3 & 4 & 5 & 6 & 7 \\
\hline $\begin{array}{l}\text { Enrolment of all children of school going age in } \\
\text { secondary school }\end{array}$ & 1 & 2 & 3 & 4 & 5 & 6 & 7 \\
\hline School attendance of at least 80\% for all children & 1 & 2 & 3 & 4 & 5 & 6 & 7 \\
\hline U5 cards for all children under 5 & 1 & 2 & 3 & 4 & 5 & 6 & 7 \\
\hline All vaccinations completed for all children under 5 & 1 & 2 & 3 & 4 & 5 & 6 & 7 \\
\hline Quarterly growth monitoring for all children under 5 & 1 & 2 & 3 & 4 & 5 & 6 & 7 \\
\hline
\end{tabular}

b. Would you decide against a monthly transfer of ZMK 50,000 if you had to comply with all of the conditionalities stated above?

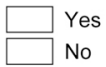

c. What do you think would be a fair transfer level if you had to comply with all the conditionalities stated above?

9. Please give us some more information about yourself

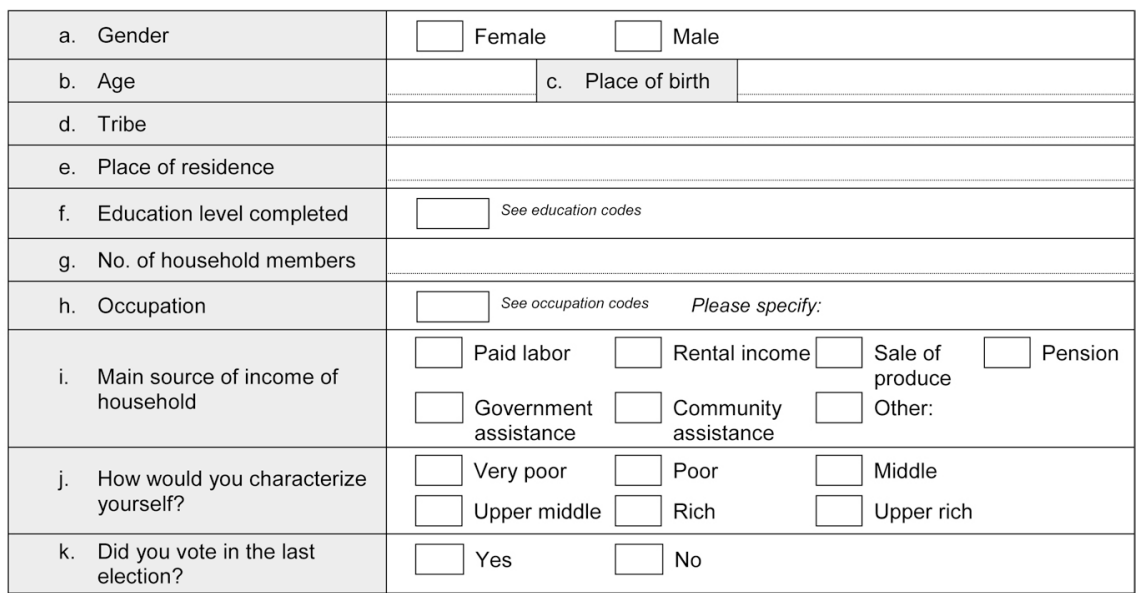




\section{Attitude Survey for University Students}

Thanks very much for your willingness to participate in the survey. This survey is meant to gather information on opinions of young people who will shape the future of the Zambia. You can be assured of strict confidentiality of any information you provide. The information will be used for a research project jointly carried out by the University of Maastricht and the University of Zambia. The research project looks more closely at values and attitudes of different groups in society and analyses how these values and attitudes influence or might potentially influence future policy-making. The findings will be made available to you if you wish and are intended to inform decision-makers in the area of social protection in Zambia

1. Whose responsibility is it to take care of the poor? Please indicate what kind of responsibility the following stakeholders have on a scale from 1 (no responsibility) to 7 (full responsibility). If your views fall somewhere in between, you can choose any number in between. Please circle the corresponding answer

\begin{tabular}{|lllllllll|}
\hline & No responsibility & & & \multicolumn{3}{c|}{ Full responsibility } \\
\cline { 2 - 7 } a. & Family & 1 & 2 & 3 & 4 & 5 & 6 & 7 \\
\hline b. & Community & 1 & 2 & 3 & 4 & 5 & 6 & 7 \\
\hline c. & Entire society & 1 & 2 & 3 & 4 & 5 & 6 & 7 \\
\hline d. & Government & 1 & 2 & 3 & 4 & 5 & 6 & 7 \\
\hline e. & Church & 1 & 2 & 3 & 4 & 5 & 6 & 7 \\
\hline f. & NGOs & 1 & 2 & 3 & 4 & 5 & 6 & 7 \\
\hline g. & International cooperating partners & 1 & 2 & 3 & 4 & 5 & 6 & 7 \\
\hline h. & Other: & 1 & 2 & 3 & 4 & 5 & 6 & 7 \\
\hline
\end{tabular}

2. Why do you think poverty is so high in Zambia? Please indicate for each of the following causes to what extent they apply on a scale from 1 (does not apply) to 7 (fully applies). If your views fall somewhere in between, you can choose any number in between Please circle the corresponding answer

\begin{tabular}{|c|c|c|c|c|c|c|c|}
\hline \multirow[b]{2}{*}{ a. Lack of opportunities for the poor } & \multicolumn{5}{|c|}{ Does not apply $\leftarrow$} & \multicolumn{2}{|c|}{ Fully applies } \\
\hline & 1 & 2 & 3 & 4 & 5 & 6 & 7 \\
\hline b. Lack of initiative of the poor & 1 & 2 & 3 & 4 & 5 & 6 & 7 \\
\hline c. Mindset of the poor & 1 & 2 & 3 & 4 & 5 & 6 & 7 \\
\hline d. Wrong government policies & 1 & 2 & 3 & 4 & 5 & 6 & 7 \\
\hline e. Wrong donor policies & 1 & 2 & 3 & 4 & 5 & 6 & 7 \\
\hline $\begin{array}{l}\text { f. External circumstances (climate, natural } \\
\text { resources, characteristics \& history of the country) }\end{array}$ & 1 & 2 & 3 & 4 & 5 & 6 & 7 \\
\hline g. HIV / AIDS & 1 & 2 & 3 & 4 & 5 & 6 & 7 \\
\hline h. Other: & 1 & 2 & 3 & 4 & 5 & 6 & 7 \\
\hline
\end{tabular}

3. Please specify for each of the following statements how strongly you agree or disagree on a scale from 1 (strongly disagree) to 7 (strongly agree). If your views fall somewhere in between, you can choose any number in between. Please circle the corresponding answer

\begin{tabular}{|c|c|c|c|c|c|c|c|}
\hline \multirow[b]{2}{*}{$\begin{array}{l}\text { a. It is humiliating to receive money without } \\
\text { working for it }\end{array}$} & \multicolumn{5}{|c|}{ Strongly disagree } & \multicolumn{2}{|c|}{ Strongly agree } \\
\hline & 1 & 2 & 3 & 4 & 5 & 6 & 7 \\
\hline b. People who don't work become lazy & 1 & 2 & 3 & 4 & 5 & 6 & 7 \\
\hline c. Work is a duty toward society & 1 & 2 & 3 & 4 & 5 & 6 & 7 \\
\hline d. Work is difficult to combine with caring & 1 & 2 & 3 & 4 & 5 & 6 & 7 \\
\hline
\end{tabular}




\begin{tabular}{|c|c|c|c|c|c|c|c|}
\hline \multicolumn{8}{|c|}{ obligations for other household members } \\
\hline & & \multicolumn{5}{|c|}{ Strongly disagree } & Strongly agree \\
\hline e. & $\begin{array}{l}\text { Everybody in society can and should } \\
\text { work }\end{array}$ & 1 & 2 & 3 & 4 & 5 & 7 \\
\hline
\end{tabular}

4. Please tell us your views on the following issues. 1 on the scale from 1-7 means that you agree completely with the statement on the left; 7 means you agree completely with the statement on the right; if your views fall somewhere in between, you can choose any number in between. 4 means that you are neutral. Please circle the corresponding answer

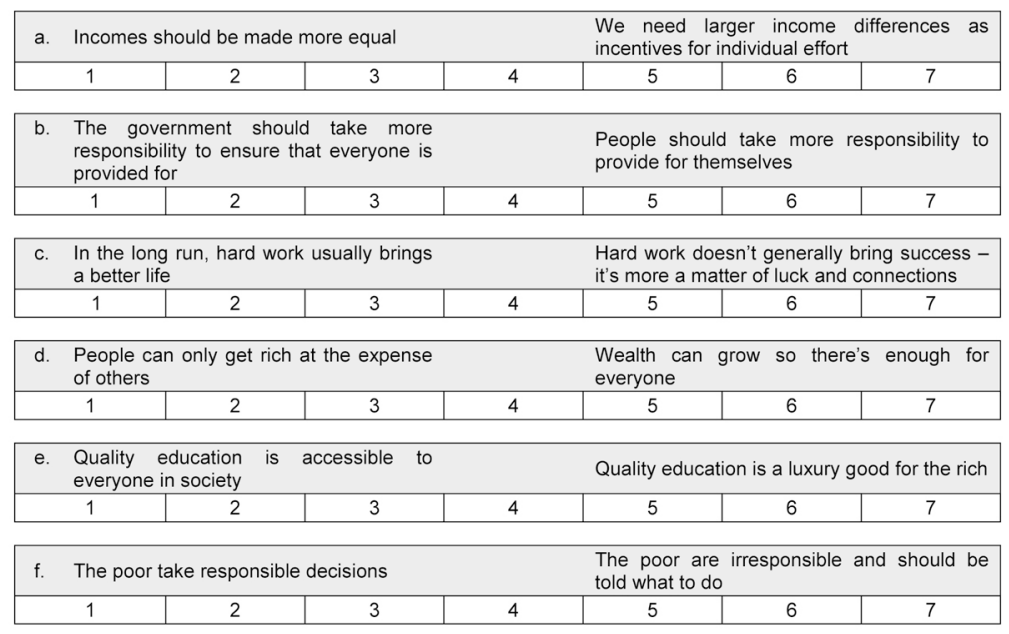

5. If you were a policymaker in Zambia, would you: Please tick ONLY ONE answer that you consider most relevant.

a. Prioritize economic growth

$\square$ redistribution of resources to the poorest
$\square$ both

\begin{tabular}{|c|c|}
\hline \multirow{5}{*}{$\begin{array}{l}\text { b. Give social } \\
\text { (government } \\
\text { first to }\end{array}$} & all children \\
\hline & all elderly \\
\hline & all people with disabilities \\
\hline & all those in extreme poverty \\
\hline & nobody \\
\hline \multirow{3}{*}{ c. Give assistance in } & cash \\
\hline & In-kind \\
\hline & nothing \\
\hline \multirow{3}{*}{ d. Raise school enrolment by } & Making school enrolment a condition for government assistance \\
\hline & Raising more awareness on the value of education \\
\hline & Building more schools \\
\hline
\end{tabular}



No need for any intervention
Making school attendance a condition for government assistance
e. Raise school attendance by
Raising more awareness on the value of education
Improving the quality of schooling
No need for any intervention

f. Get more women to take their babies to health checks by

Making health checks a condition for government assistance Improving the availability of services

No need for any intervention

g. Offer social cash transfers Without any conditions that households have to fulfill

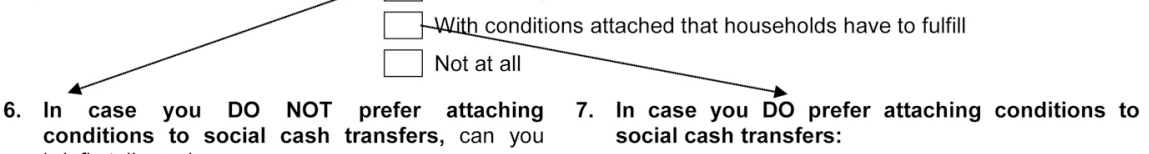
conditions to social cash transfers, can you briefly tell us why:

a. Can you briefly tell us why?

b. What kind of condition(s) would you attach?

\section{Please give us some more information about yourself}

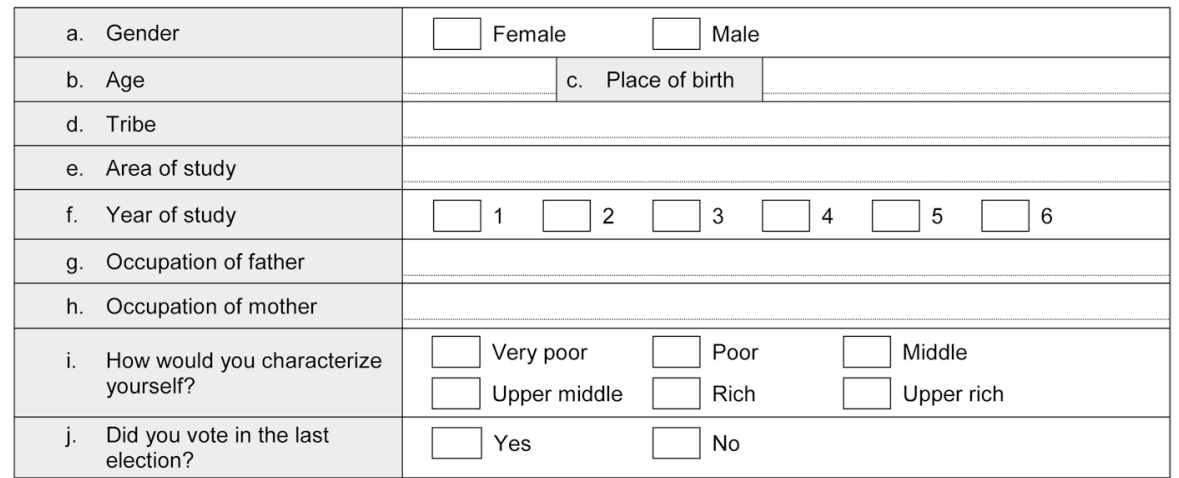

I would like to receive a summary of the findings of the research and can be contacted via the following email address: 


\title{
Annex 10: Interview outline for semi-structured interviews
}

\author{
Questionnaire guidelines for interviews
}

\section{Reasons behind deprivation and extreme poverty}

Research question: Political acceptability - attitude on poverty

Interviewees:

Method:

$$
\begin{aligned}
& \text { Zambian stakeholders (politicians, government officials, NGOs) } \\
& \text { Semi-structured interview / potentially a small survey in the } \\
& \text { Ministry of Finance and Ministry of Community Development } \\
& \text { and Social Services }
\end{aligned}
$$

\section{Questions:}

1. What characterizes extremely poor households?

2. What prevents households from exiting extreme poverty?

3. To what extent are households responsible for their poverty status?

\section{Opinion on conditionalities}

Research question:

Interviewees:

Method:

\begin{abstract}
Political acceptability - attitude on government assistance Zambian stakeholders (politicians, government officials, NGOs) Semi-structured interview / potentially a small survey in the Ministry of Finance and Ministry of Community Development and Social Services
\end{abstract}

\section{Questions:}

1. Do you think that poor households should be obliged to do something in exchange for state assistance? Why? What?

2. What do you think would be the (dis)advantages of conditionalities (ask opposite of their preference)?

3. Do you think that the Zambian society would feel more comfortable if social cash transfers were conditioned? Why?

4. Who in society do you think would support conditionalities? Why?

5. Who in society would oppose them?

6. If you were offered a cash transfer of 5 US\$, would you be willing to first of all comply with all the conditionalities?

7. Secondly, would you provide all the documentation each and every month that you complied with a set of conditionalities? If no, why not?

8. Would your attitude change if the transfer amount was increased? By how much?

9. Do you think that cooperating partners would support or oppose conditionalities? How does this influence your decision-making? 
Research question: $\quad$ Political acceptability - donor influence

Interviewees:

Method:

Zambian stakeholders (politicians, government officials, NGOs)

Questions:

Semi-structured interview

1. What is your general take on conditionalities?

2. Do you think that they would make sense in the Zambian context? Why?

3 . Is there an official policy by your organization on conditionalities?

4. Do you think that conditionalities would make social cash transfers politically more attractive? Why?

5. What kind of role do donors play in Zambian policy-making according to your opinion?

\section{Feasibility of conditionalities in the Zambian context}

Research question:

Interviewees:

Method:

Questions:

1. What do you think are the challenges with administering conditionalities in Zambia?

2. Do you think that conditionalities could increase the potential for corruption? In what way? Any evidence?

\section{Research question:}

Interviewees:

Method:

Questions:

\section{Administrative feasibility - implementation}

Stakeholders not involved in the experiment (government officials, international donors, NGOs)

Semi-structured interview

1. What was overall your experience of the conditionality experiment?

2. What were some of the challenges you encountered?

3. Did you feel like you were well prepared for the conditionality experiment?

4. Did you get any assistance from other stakeholders in the scheme? What kind?

5. What are your tasks in managing conditionalities?

6. How much time do you spend on managing conditionalities in a month?

7. How does the time you spend compare to other tasks?

8. Were there any activities you could not do because of the monitoring obligations? What kind of activities and how did you feel about it?

9. Were there any people who exited the program after they heard about the conditionalities or after they noticed they were being monitored? Who were those people? Why did they exit?

10. Did any of the beneficiaries ever offer money for a more positive monitoring result? 
Research question:

Interviewees:

\section{Administrative feasibility - monitoring}

Government officials from MCDSS, representatives from education \& health

Semi-structured interview

\section{Questions:}

Method:

1. Do you currently have a monitoring system in place? Could you describe it?

2. How does it work, in particular at district level? Where do you see strong / weak points?

3. What kind of improvements would you suggest?

4. Who analyzes the data and how is the data used? Could you tell us whether the data has been actively used in the last year? What were some of the concrete actions taken?

5. Could we take a look at the data that came out of the monitoring system?

\section{Cooperation spin-off effects}

\section{Research question:}

Interviewees:

Method:

Questions:

1. How do you cooperate with other social ministries? How has this cooperation changed over time [the past six months] and why? Give me a concrete example.

2. How many joint meetings did you have in the past 6 months? Did you take any joint decisions? Do you use the data that other Ministries provide? Did the data, the joint meetings or the collaboration in general change your programming?

3 . Where do you see strong points in the cooperation?

4. Where do you see weak points?

5. What kind of improvements would you suggest?

\section{Reason for under-utilization of social services}

\section{Research question: Households - Efficiency / Equity}

Interviewees:

Method: Government officials from MCDSS and Ministry of Education, teachers

Questions:

1. Why do you think that some children are not enrolled in school?

2. Why do children who are enrolled not attend school on a regular basis?

3. Which priority measures would you suggest to correct the problem?

4. Can conditionalities play a role in correcting the problem? If yes, what kind of role can conditionalities play in correcting the problem? 
Research question: Households - Efficiency / Equity

Interviewees:

Government officials from MCDSS and Ministry of Health

Method:

Semi-structured interview

\section{Questions:}

1. Some mothers do not take their babies to u5 checks and complete vaccinations. Why do you think that is?

2. Which priority measures would you suggest to correct the problem?

3. Can conditionalities play a role in correcting the problem? If yes, what kind of role can conditionalities play in correcting the problem?

\section{Relationship between the state and its citizens}

$\begin{array}{ll}\text { Research question: } & \begin{array}{l}\text { Households - Empowerment } \\ \text { Administrative impact - consumer sovereignty }\end{array} \\ & \text { Political acceptability - attitude on government assistance } \\ \text { Interviewees: } & \text { NGOs } \\ \text { Method: } & \text { Semi-structured interviews } \\ \text { Questions: } & \end{array}$

1. How would you characterize the relationship between the state and its citizens in Zambia? Which factors might explain the development of this relationship?

2. Would you say that Zambians have trust in the government? Why not?

3. In what way can citizens influence the state?

4. In what way can the state influence its citizens?

5. How would you describe the political participation of Zambians? Which factors might explain a lack of interest / participation?

\section{Legal obligations of the country}

\section{Research question: $\quad$ Political acceptability - legal obligations}

Interviewees:

Method:

NGOs, Ministry of Justice, cooperating partners

Questions:

Semi-structured interviews

1. Zambia subscribed to a number of international legal covenants (universal declaration of human rights, ILO convention) that call for the obligation of the government to provide social protection. What kind of role do these legal covenants play in the Zambian government - commitment or lip service?

2. Are there intentions or mechanisms in place to enforce these human rights? What kind of role do local NGOs play in this area?

3. Do you personally feel that conditionalities would violate the right to social protection? 


\section{Annex 11: Motivation for using OLS}

We assume that OLS produces estimators that are unbiased and consistent. This is the case if outliers are rare (implying finite fourth moments in a technical sense), observations are independent and identically distributed and the conditional distribution of $\mathrm{u}$ given $\mathrm{X}$ has mean zero. First of all, large outliers are absent in our case as both the dependent and explanatory variables have limited ranges. Secondly, despite random sampling, we can see that observations are not independent as every giver makes ten decisions in the experiment and each allocation decision influences the next. We allow for this dependence by clustering the data by giver, using robust standard errors. In order to test whether the order of the numbering of potential recipients made a difference, we assessed to what extent the first recipient in each poverty category received more. We did not find any consistent ranking so there does not seem to be a systematic bias.

Thirdly, with respect to any possible endogeneity bias, we can say the following: the experiments were specifically designed in a way to test the hypotheses around targeting. This limits the chances that any important variables were omitted. There might be different individual effects across givers and across recipients but we do not see any reason for assuming that they systematically bias the other variables included in the model. In addition, it makes sense to opt for a random-effects rather than a fixedeffects model in our case as we are not specifically interested in the individual as such but in the effect of particular characteristics of individuals. We can assume that there are some measurement errors with respect to the poverty classifications but those are not likely to be huge, as discrepancies between the external and self-assessment are moderate and poverty characteristics such as number of livestock, state of housing, number of meals consumed etc. of the experiment participants do vary according to their poverty status.

As discussed in the methodology section, volunteers participating in the experiment can be expected to share similar characteristics to community members who volunteer to target beneficiaries for a social transfer program, reducing the likelihood of selection bias. Given that participants made their choices in private and opportunities for information exchange among participants were limited, there is little risk for simultaneous causality bias, in the sense that givers made choices with a particular expectation of reciprocity. In conclusion, it is not unreasonable to assume that the least squares assumptions hold. 


\section{Samenvatting}

Onder mensen actief in de ontwikkelingshulp heerst veel onenigheid over de controversiële vraag of we sociale cash transfer-programma's (SCT's) al dan niet aan voorwaarden moeten verbinden. Dit debat wordt vaak gevoerd zonder een duidelijk concept van wat die conditionaliteit precies zou moeten zijn en wat de realistische prestaties en de beperkingen ervan zijn. Daarom begint deze scriptie met een conceptueel hoofdstuk. In hoofdstuk 2 wordt naar een algemeen begrip van het concept en de theorie achter conditionaliteit gestreefd. Het hoofdstuk heeft als doel de verschillende factoren te benadrukken die essentieel blijken om te bepalen of conditionaliteit een SCT-programma meer efficiënter maakt. Verder wordt geprobeerd bestaand bewijsmateriaal te verzamelen. Hoofdstuk 2 borduurt voort op talrijke contributies van andere auteurs, maar krijgt tegelijkertijd een meerwaarde omdat het een duidelijk verschil aangeeft tussen de verschillende dimensies van conditionaliteit en het een theoretisch economisch perspectief biedt met inzichten vanuit de psychologie en de politieke wetenschappen. Bovendien presenteert het alle factoren die de impact bepalen die conditionaliteit kan hebben op de doeltreffendheid van SCTprogramma's. Tenslotte legt het bewijsmateriaal voor, dat verder gaat dan de invloed van conditionaliteit op huishoudelijk gedrag. Het hoofdstuk moet beleidsmakers voorzien van een beslissing-makend raamwerk om te beslissen al dan niet te gaan voor conditionaliteit en geeft aan waar verder onderzoek nodig is.

De empirische hoofdstukken 3 en 4 zijn geïnspireerd door de lacunes in het onderzoek zoals uitgewerkt in hoofdstuk 2 . Terwijl de voorkeuren voor conditionaliteit vaak als model dienen voor economen en politieke wetenschappers zijn ze niet nauwkeurig getest op empirisch vlak. Daarom worden in hoofdstuk 3 de lokale voorkeuren van potentiele ontvangers voor conditionaliteit onder de loep genomen en wordt besproken in welke mate ze compatibel zijn met conditionaliteitsvoorkeuren van besluitvormers op verschillende niveaus. Door gebruik te maken van het bewijs van een experiment uitgevoerd op het platteland van Zambia worden in dit hoofdstuk conditionaliteitsvoorkeuren toegelicht van diegenen die het meest getroffen worden door een beleidsbeslissing om transfers aan voorwaarden te binden. In de studie wordt ook bestudeerd hoe individuele voorkeuren zich vertalen in beleidsvorming op een gecentraliseerd niveau en hoe deze zich verhouden tot de voorkeuren van de begunstigden van het SCT-programma, de stedelijke bevolking van Lusaka en beleidsmakers in verschillende ministeries en op verschillende niveaus. We stellen vast dat conditionaliteit voldoet aan de interesses van de beleidsmakers, van zowel het algemene publiek als ook van de begunstigden en dat ze de nodige controle biedt voor de gevers van de transfers en begeleiding voor de ontvangers ervan. Daarentegen toont het experiment ook aan dat conditionaliteitsvoorkeuren noch homogeen noch statisch zijn en dat deze voorkeuren onderhevig zijn aan veranderingen naar gelang SCT en conditionaliteit vaker voorkomen, betere informatie over de ontvangers 
beschikbaar is en er meer vertrouwen en zekerheid is omtrent het gedrag van de begunstigden.

In hoofdstuk 4 worden de verschillende tekortkomingen van conditionaliteit benadrukt die zich in de omgeving van een land met lage inkomens plegen voor te doen en die een negatieve invloed hebben op de doeltreffendheid van een SCT-programma. In recent onderzoek wordt de nadruk gelegd op het vergroten van de kennis over en het verzamelen van bewijs van de gedragseffecten van conditionaliteit. Hoewel deze zoektocht naar overtuigender bewijsmateriaal lovenswaardig is, negeert men vaak de kostenkant van conditionaliteit en legt men als gevolg slechts de halve waarheid voor. Op basis van gegevens van een enquête bij de begunstigden, overheidsgegevens en gegevens uit andere bronnen wordt in dit hoofdstuk aangetoond dat opgedrongen conditionaliteit in het geval van Zambia geleid zou hebben tot aanzienlijke ondoelmatigheden. Ondanks het feit dat conditionaliteit een enigszins positieve invloed zou kunnen hebben op het huishoudelijk gedrag, zou ze ook het risico dragen begunstigden uit te sluiten van het programma en directe of indirecte administratieve kosten te creëren. Naar aanleiding van de bevindingen wordt daarom de vraag opgeworpen of conditionaliteit de beste keuze is voor een land als Zambia waar het afstemmen van gedrag niet beschouwd zou kunnen worden als een prioritaire maatregelwanneer het bedrag van de transfer heel beperkt is en het algemene budget en de administratieve capaciteit beperkt zijn .

In hoofdstuk 5 gaan we verder naar het tweede deel van dit proefschrift, wat het thema van het targeten omvat. In dit hoofdstuk worden een aantal kritische veronderstellingen van het CBT (gemeenschaps gericht targeting) bekeken, waardoor we een beter begrip krijgen van de progressieve aard van het targeting mechanisme en onder welke voorwaarden dit het beste functioneert. Althoewel het inschakelen van plaatselijke structuren in de besluitvorming over het algemeen als positief wordt beschouwd, heerst er een levendig debat over hoe ver die betrokkenheid dient te gaan en welke mate van invloed er lokaal op de targeting-beslissingen moet zijn. Middels een economisch experiment in ruraal Zambia belichten we het relatieve belang van verschillende targetingmotieven bij CBT en de compatibiliteit van individuele targetingbeslissingen en gemeenschappelijke targetbeslissingen. Tenslotte behandelen we de determinanten van de progressiviteit. De bevindingen van de studie onderbouwen het bewijs van eerdere studies dat CBT op zijn minst licht progressief is. Terwijl er egalitaire tendensen waargenomen kunnen worden bij individuen en groepen variëren ze sterk, afhankelijk van de de mate van gemeenschapsdruk en eerdere blootstelling aan het targeten. Armoede is één van de belangrijkste targetingmotieven en armoede is van groter belang dan bijvoorbeeld favoritisme tegenover gezinsleden of favoritisme tegenover belangrijke mensen in iemands sociaal netwerk. Leden van een gemeenschap gedragen zich egoïstisch als ze zichzelf kunnen voortrekken, ondanks de beperkingen die het groepbesluitvormingsproces oplegt. Egoïsme is niet positief gecorrelateerd aan het beter af zijn of het hebben van een statuspositie in de gemeenschap. Daarom kunnen we ons afvragen of de zogenaamde inpalming door de elite ('elite capture') 
geen probleem is waarop te veel nadruk wordt gelegd. Gemeenschapsleden zijn niet consistent in hun targetingkeuzes, hoewel dat niet leidt tot ontevredenheid over de in de gemeenschap genomen beslissingen. CBT lijkt meer potentieel te hebben in gemeenschappen met meer cohesie, minder wantrouwen en waar mensen elkaar beter kennen. Het inzetten van mensen met een belangrijke sociale positie in de gemeenschap en de betrokkenheid van een comité van experts in plaats van de hele gemeenschap hebben een positieve invloed op de progressiviteit van de resultaten.

$\mathrm{Er}$ is een aanhoudende discussie onder onderzoekers, beleidsmakers en ontwikkelingspartners in landen met lage inkomsten over de mate waarin nietcontributieve sociale transfers gericht zou moeten zijn op de armen of universeel uitbetaald zou moeten worden aan elke burger of aan alle burgers in een bepaalde categorie. In hoofdstuk 6 wordt een kritische discussie gevoerd over de veronderstellingen achter de politieke economische argumenten van het targeten. Er wordt getest of een universeel mechanisme een automatische politieke resonantie zou hebben in de context van een land met lage inkomens. Een aantal auteurs beargumenteren dat een universele methode een situatie oplevert waarbij iedereen wint, zowel de armen, de middenklasse als de gevestigde macht. Daarom zouden we een brede steun verwachten voor een universeel programma, in het bijzonder in landen waar armoede wijd verspreid is en waar targeting ook op administratief vlak moeilijk is. Op basis van opiniepeilingen onder de stedelijke, landelijke en studerende bevolking in Zambia stellen we echter vast dat er in feite meer steun is voor beleid om de armen te targeten dan de politieke, economische modellen doen vermoeden. Die bevindingen worden bevestigd door experimenteel bewijsmateriaal van het Zambiaanse platteland. We bespreken de veronderstellingen van de politieke, economische modellen in het licht van die bevindingen en nemen potentieel beslissende parameters in beschouwing die de modellen momenteel niet incorporeren.

In hoofdstuk 7 wordt geillustreerd dat conditionaliteit en targeting allebei stukjes zijn van een grotere puzzel en dat ze slechts gedeeltelijk kunnen uitleggen waarom SCT's aan populariteit winnen of verliezen. Er zijn pogingen ondernomen om uit te leggen waarom sociale zekerheidssystemen kennelijk niet worden opgezet daar waar ze het meest nodig zijn, zoals in landen die sterk getroffen zijn door de HIV- en AIDSepidemie, die te maken hebben met een groeiend aantal wezen en kwetsbare kinderen, of met overweldigende armoede op het platteland en hoge mate van ongelijkheid. Bij die pogingen is vaak geen rekening gehouden met de eerdere complexe politieke situaties in de landen in kwestie. Analyses dwingen de Minister van Financiën in de rol van enige vertegenwoordiger van politieke wil. Dezelfde analyses geven lage budgettaire toewijzingen aan sociale zekerheid, en daarmee brengen ze een onaantrekkelijke programma-ontwerp en negeren de ze een lange, onregelmatige geschiedenis van sociale zekerheid in de Westerse wereld. Daarnaast blijven ook de rollen voor donoren en het maatschappelijke middenklasse in zulke politieke economieën vaag. Deze studie is gebaseerd op andere studies over factoren die een verandering in gang zetten, maar biedt een diepere kijk op de politieke dynamiek achter 
sociale bescherming in Zambia. Ze onderzoekt of de waargenomen of gesignaleerde stagnatie in de sociale zekerheid te wijten is aan het feit dat de belanghebbenden in Zambia de beleidsaanbevelingen verwerpen of dat er andere oorzaken zijn, namelijk het feit dat de aanbevelingen ondergeschikt zijn aan andere zaken, of dat de geboekte vooruitgang te vroeg wordt geevalueerd. 


\section{Biography}

Esther Schüring was born in 1979 in Wesel, Germany. Esther soon discovered her passion for traveling, discovering new territories as well as studying and working abroad. In 2004, she received her Masters of Arts in Law and Diplomacy from the Fletcher School of Law and Diplomacy, specializing in development economics as well as comparative and developmental political analysis. She obtained her second Masters from the University of Passau in 2004 where she pursued languages, economics and cultural studies. During her studies, she participated in exchange programs at Sciences-Po Paris and the Université de Laval in Canada.

After her studies, Esther started working for GTZ (Gesellschaft für technische Zusammenarbeit - now: GIZ) and was posted in Zambia as a social protection adviser to the Ministry of Community Development and Social Services for three years. This experience not only deeply rooted her interest in social protection, established strong ties with Zambia but also taught her valuable lessons in how to confront challenges in social protection in a low-income country context. Her work in Zambia and the region inspired Esther to take up a $\mathrm{PhD}$ in social protection policy in 2008 at the Maastricht Graduate School of Governance, tackling policy-relevant questions in the area of social cash transfers.

Next to conducting research on the effectiveness of conditionality and targeting in social cash transfer programs, Esther has engaged in different social protection projects with the School and has also worked as an independent social protection analyst and adviser. Over the past years, on behalf of various agencies (e.g. GFA, GIZ, HelpAge, Maxwell Stamp, UNCDF, UNICEF), she has advised governments in Sub-Saharan Africa and Asia on the design, implementation and evaluation of social protection programs. In addition to this, Esther has trained policymakers, conceptualized and carried out research projects and has also worked as a lecturer. Seeing the great merits of evidence-based policy-making, she intends to stay committed to the academic and policy world. 


\section{MGSoG Dissertation Series}

Joe Abah

Strong Organisations in Weak States.Atypical Public Sector Performance in Dysfunctional Environments

MGSoG Dissertation Series, nr. 28 (2012)

Zina Samih Nimeh

Social Citizenship Rights: Inequality and Exclusion

MGSoG Dissertation Series, nr. 27 (2012)

Lenka Eisenhamerová

Legitimacy of 'Humanitarian Military Intervention'

MGSoG Dissertation Series, nr. 26 (2011)

Sonila Tomini

Informal Payments for Health Care Services in Albania

MGSoG Dissertation Series, nr. 25 (2011)

Jinjing Li

Dynamic Microsimulation in Public Policy Evaluation

MGSoG Dissertation Series, nr. 24 (2011)

Aziz Atamanov

Rural Nonfarm Employment and International Migration as Alternatives to Agricultural Employment: The Case of Kyrgyztan

MGSoG Dissertation Series, nr. 23 (2011)

Frieda Vandeninden

Poverty Alleviation: Aid and Social Pensions

MGSoG Dissertation Series, nr. 22 (2011)

Juliana Nyasha Tirivayi

The Welfare Effects of Integrating AIDS Treatment with Food Transfers:

Evidence from Zambia

MGSoG Dissertation Series, nr. 21 (2011)

Agnieska Ewa Sowa

Who's Left Behind? Social Dimensions of Health Transition and Utilization of Medical Care in Poland

MGSoG Dissertation Series, nr. 20 (2011) 
Emmanaouil Sfakianakis

The Role of Private Actors in the Provision of Public Goods with Applications to Infrastructure and Financial Stability

MGSoG Dissertation Series, nr. 19 (2011)

Siu Hing Lo

White Collars Green Sleeves. An Interonganizational Compariso of Deteminants of Energie-Related Behaviors among Office Workers

MGSoG Dissertation Series, nr. 18 (2011)

Treena $\mathrm{Wu}$

Constraints to Human Capital Investment in Developing Countries:

Using the Asian Financial Crisis in Indonesia as a Natural Experiment

MGSoG Dissertation Series, nr. 17 (2011)

Henry Espinoza Peña

Impact Evaluation of a Job-Training Programme for Disadvantaged Youths:

The Case of Projoven

MGSoG Dissertation Series, nr. 16 (2011)

Florian Tomini

Between Family and Friends

Understanding the Interdependency of Private Transfers

MGSoG Dissertation Series, nr. 15 (2010)

Michał Polalowski

The Institutional Transformation of Social Policy in East Central Europe:

Poland and Hungary in comparative and historical perspective

MGSoG Dissertation Series, nr. 14 (2010)

Maha Ahmed

Defining, Measuring and Adressing Vulnerability:

The Case of Post Conflict Environments

MGSoG Dissertation Series, nr. 13 (2010)

Pascal Beckers

Local Space and Economic Success

The role of spatial segregation of migrants in the Netherlands

MGSoG Dissertation Series, nr. 12 (2011)

Victor Cebotari

Complicting Demands in Ethnically Diverse Societies

Ethnopolitical Contention and Identity Values in Europe

MGSoG Dissertation Series, nr. 11 (2010) 
Dennis Gyllensporre

Competing and Complementary Perspectives on the EU as a Crisis Management Actor: An Examination of the Common Security and Defence Policy through the Lenses of Idealism and Realism

MGSoG Dissertation Series, nr. 10 (2010)

Judit Vall Castello

Business Cycle and Policy Effects on Labour Market Transitions of Older and Disabled Workers in Spain

MGSoG Dissertation Series, nr. 9 (2010)

Keetie Roelen

False Positives or Hidden Dimentions: the definition and measurement of child poverty MGSoG Dissertation Series, nr. 8 (2010)

Denisa Maria Sologon

Earning Dynamics in Europe

MGSoG Dissertation Series, nr. 7 (2010)

Melissa Siegel

Money and Mobility: Migration and Remittances

MGSoG Dissertation Series, nr. 6 (2010)

Jessica S. Hagen-Zanker

Modest Expectations: Causes and effects of migration on migrant households in source countries

MGSoG Dissertation Series, nr. 5 (2010)

Mirtha R. Muniz Castillo

Human Development and Autonomy in Project Aid: Experiences from four bilateral projects in Nigaragua and El Salvador

MGSoG Dissertation Series, nr. 4 (2009)

Christiane Arndt

Governance Indicators

MGSoG Dissertation Series, nr. 3 (2009)

Britta Augsburg

Microfinance - Greater Good or Lesser Evil?

MGSoG Dissertation Series, nr. 2 (2009)

Geranda Notten

Measuring and Managing Poverty Risks

MGSoG Dissertation Series, nr. 1 (2008) 